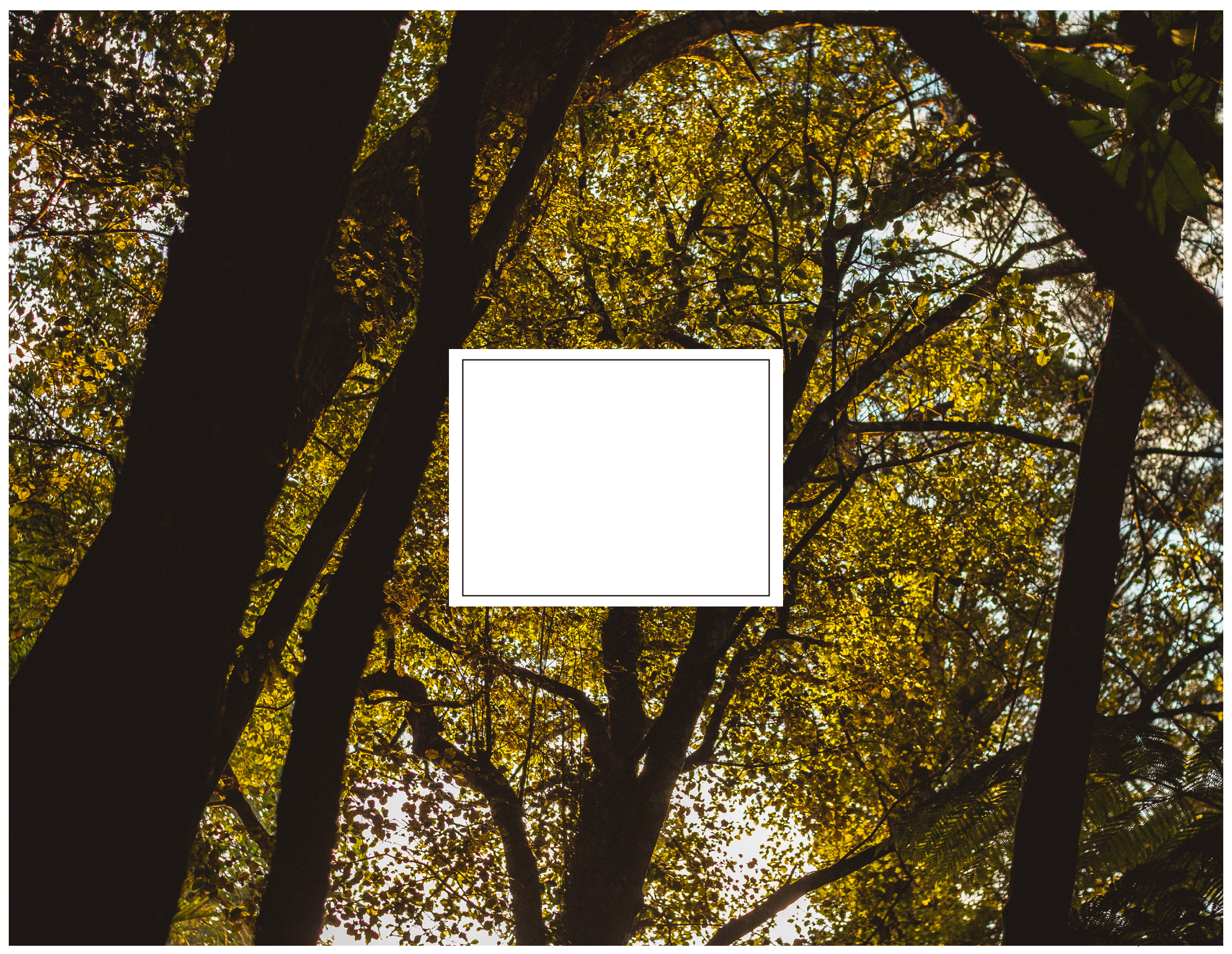




\section{Rethinking the Suburban Shopping Centre}

By

Anthony Green

Submitted to the School of Architecture and Design, Victoria University of Wellington, in partial fulfillment of the requirements for the degree of Master of Architecture (Professional)

Victoria University of Wellington School of Architecture

2016 


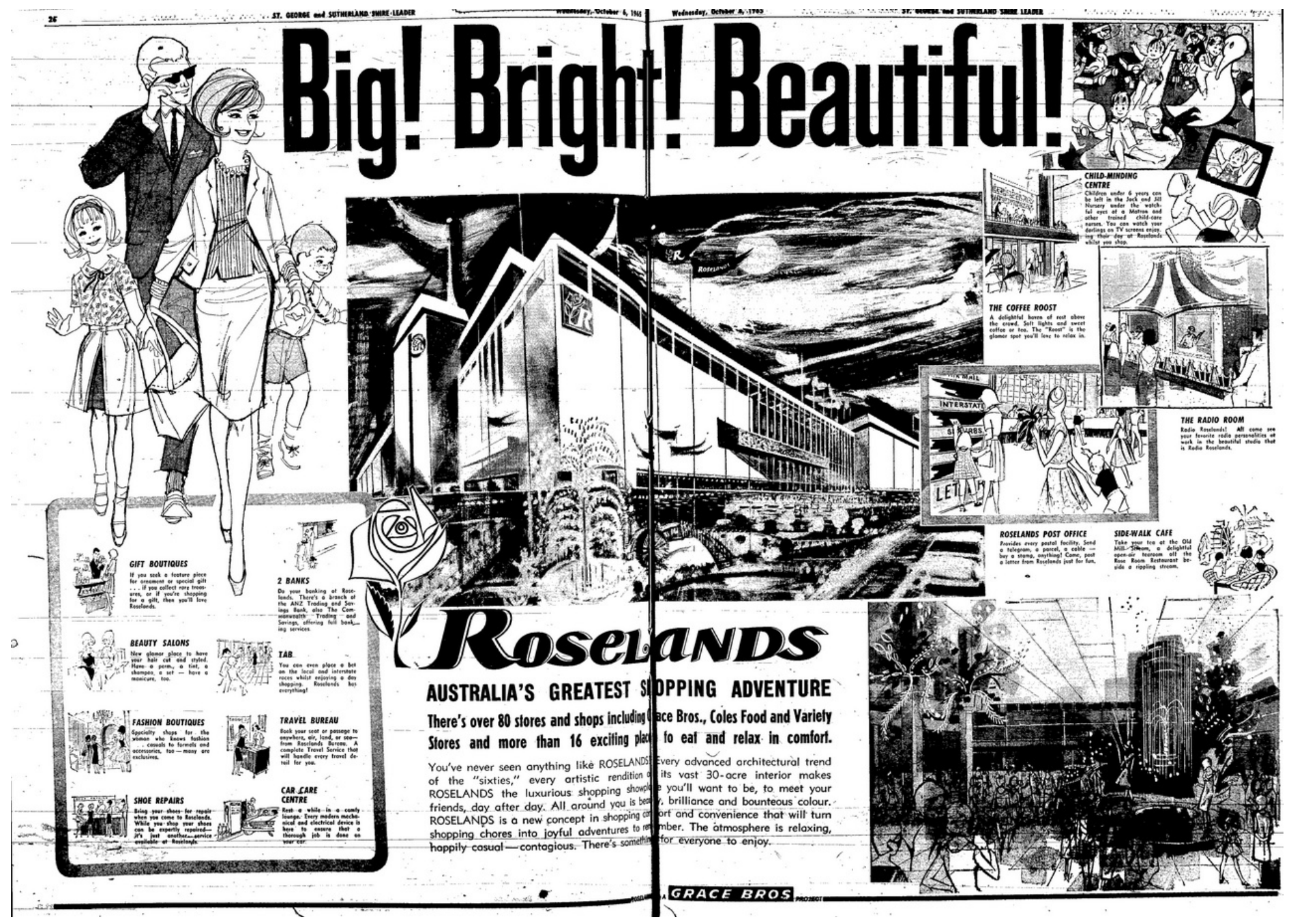




\section{A B STRACT}

Auckland city is New Zealand's fastest growing city which continues to sprawl outwards degrading the biodiversity of the natural systems. The population's culture of the 'quarter-acre dream' opposes intensification in low rise suburbia. While suburban shopping centres are the product of urban sprawl they are now situated in central areas relative to the growing city. Their land is now more valuable than the surface car parking that occupies the majority of the site and has the opportunity to foster intensification. In addition, these centres no longer provide a new exciting retail experience and the retail environments lack any point of difference between suburb to suburb, city to city and country to country.

The research explores three bodies of work; new urbanists Jan Gehl and Peter Calthorpe; retail theory on theatrical experience from the architect Jon Jerde, and eco-master-planning of Ken Yeang. Forming the hypothesis that ecology has the ability to facilitate the hybridisation of new urbanism and retail environments creating identity and sense of place for an intensified suburban-centre. Ecology has the capacity to create a theatrical experience to re-image the retail environments towards environmental conscious consumption. The inquiry contends that urban planning and development has fragmented the regions natural systems degrading the biodiversity of species that once occupied the built area. As we continue to consume more land and more commodities, we become removed from the environment, the thing that gives us life.

The outcome of this investigation is an urban masterplan and framework for Highland Park Shopping Centre, accommodating commercial, retail, recreational and residential activities in the form of a new suburban centre that reconnects and enhances the region's natural systems. The centre becomes a catalyst for further intensification in its surrounding context. The strategies employed for the design case study can be replicated at other suburban centres allowing intensification to be enriched from the sites ecology. 
" the reason why we wont face up to Our problems With THE ENVIRONMENT IS THAT WE ARE THE PROBLEM. IT'S NOT THE CORPORATIONS OUT THERE, IT'S NOT THE GOVERNMENTS, IT'S US. WE'RE THE ONES TELLING THE CORPORATIONS TO MAKE THE STUFF, AND MAKE IT AS CHEAP AND AS DISPOSABLE AS POSSIBLE. WE'RE NOT CITIZENS ANYMORE. WE'RE CONSUMERS. THAT'S WHAT WE'RE CALLED. IT'S JUST LIKE BEING AN ALCOHOLIC AND BEING IN DENIAL THAT YOU'RE AN ALCOHOLIC. WE'RE IN DENIAL THAT EACH AND EVERY ONE OF US IS THE PROBLEM. AND UNTIL WE FACE UP TO THAT, NOTHING'S GOING TO HAPPEN. SO, THERE'S A MOVEMENT TO SIMPLIFYING YOUR LIFE: PURCHASE LESS STUFF, OWN A FEW THINGS THAT ARE VERY HIGH QUALITY THAT LAST A LONG TIME, AND THAT ARE MULTIFUNCTIONAL

| YVON CHOUINARD | 


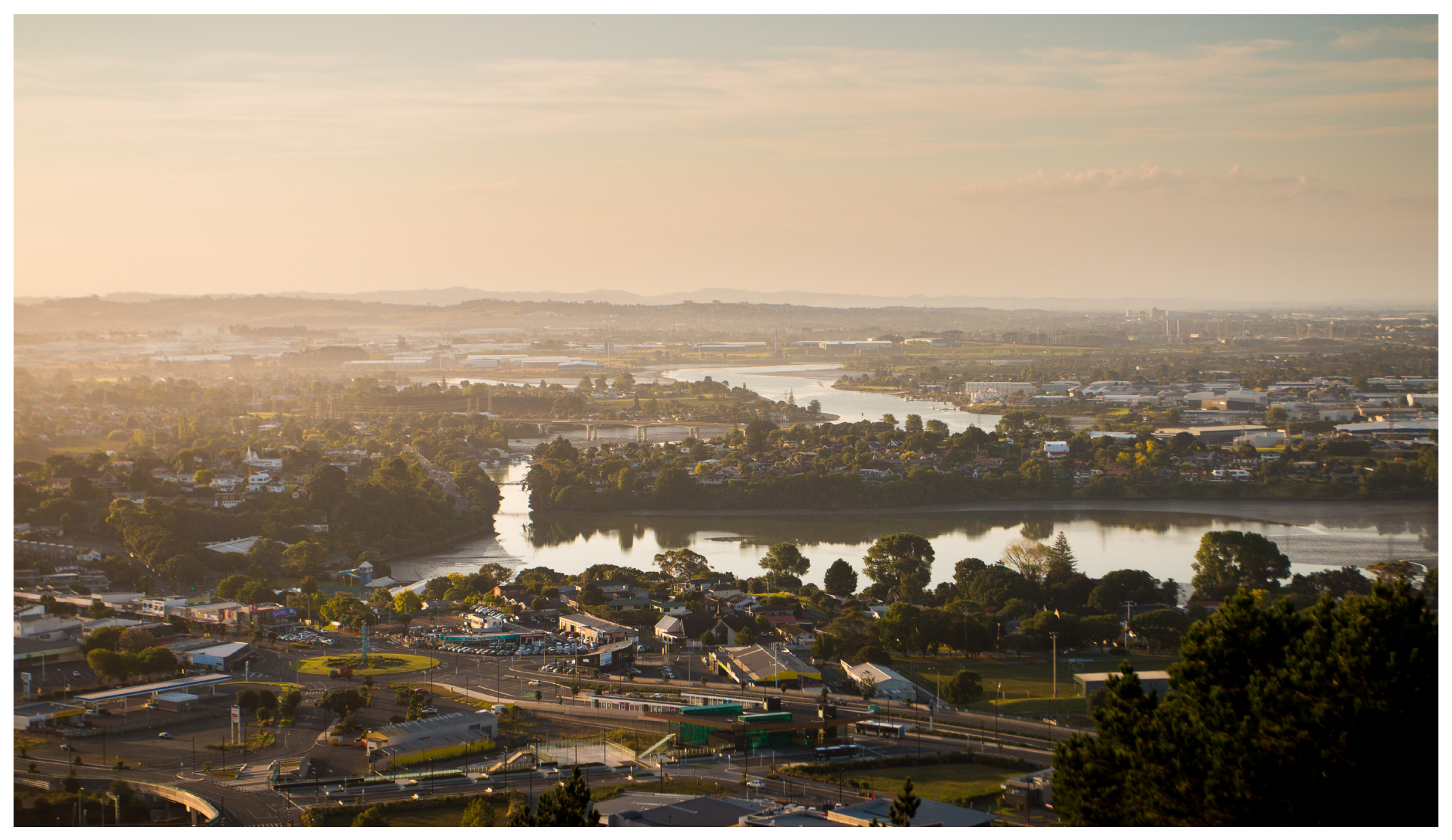

| Panmure Basin \& Tamaki River | 


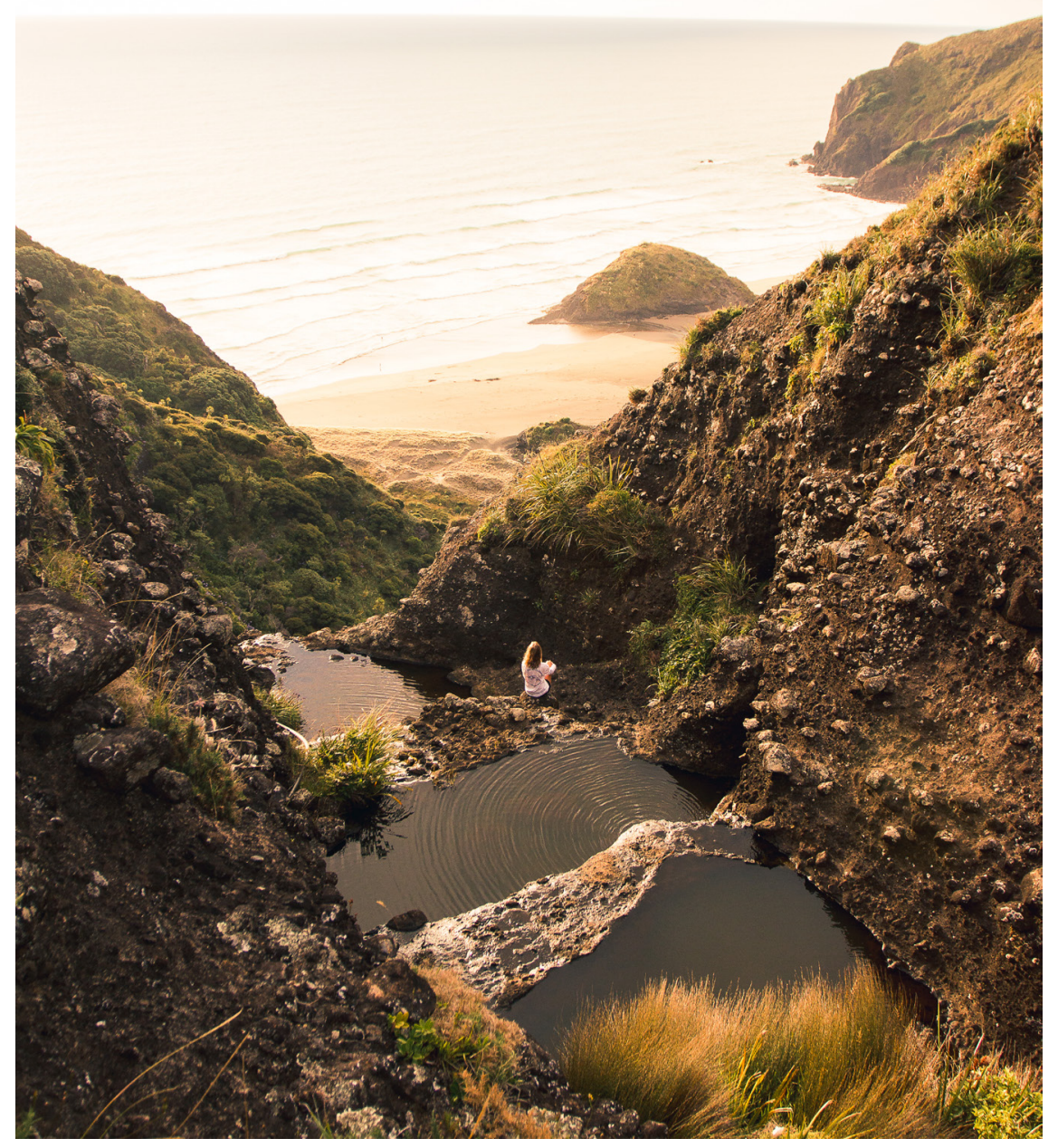

| Auckland West Coast Beach | 


\section{ACKNOWLEDGMENTS}

I would like to thank everyone who has had an influence on me during my years at architecture school.

Firstly to my Parents Viv \& Donna, I would like to thank you for your continued support towards everything I do and your words of encouragement during my Thesis, especially towards in the last month. To my siblings Matthew \& Nicole cheers for all the fun times and banter when we hang out. I always look forward to going home because I can spend time with you all.

To Chris my Supervisor your experience and knowledge has impacted my thesis in ways that I would have never imagined from the start. Thank you for your words of advice and keeping me on track, without them I probably would have never finished. Thank You.

To my buddies, I have enjoyed all the moments together over the years; Studio \& architecture banter, coffee meetings, banter in the line-up, surf \& skiing talk and everything else in-between, you guys have always been there through the thick and thin. Cheers for all the good times. Shaka! 
Auckland Urban Sprawl |

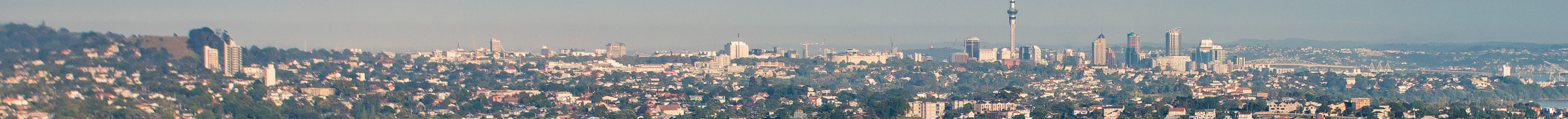

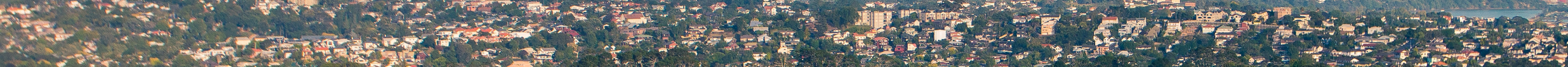

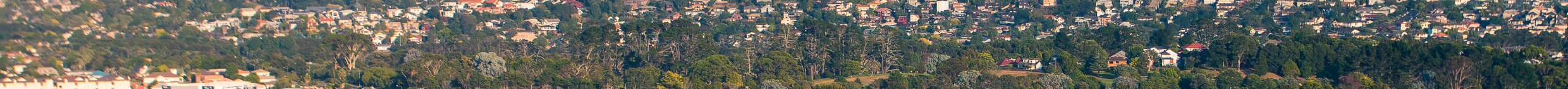

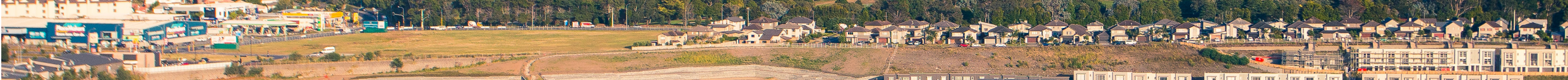

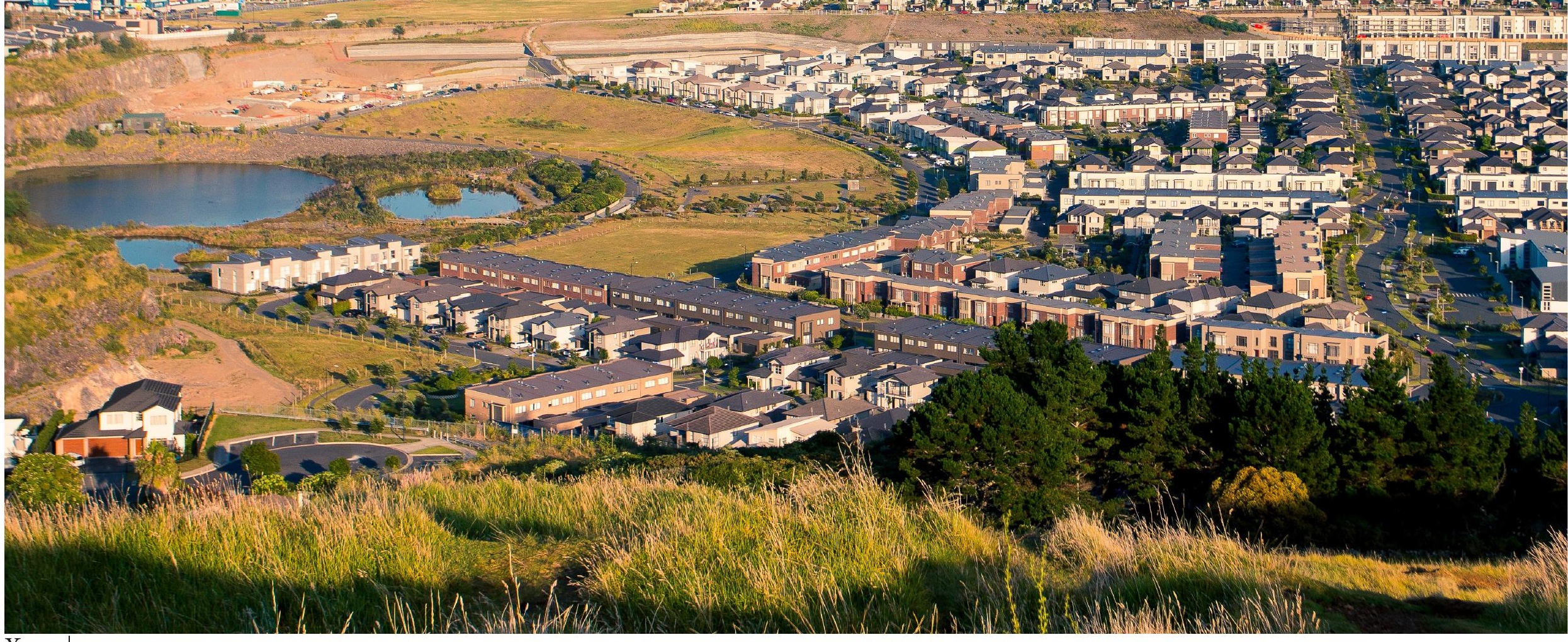




\section{CONTENTS}

1.0 Introduction 1

2.0 Literature Review 16

3.0 Auckland Shopping Centre Survey 29

Preliminary Design 'A' -Survey Sketch Planing 43

4.0 Precedents 49

Preliminary Design 'B' -Context-less Site Planning $\quad 73$

$\begin{array}{ll}5.0 \text { Program } & 79\end{array}$

Preliminary Design 'C' -Context Planning 93

$\begin{array}{ll}\text { 6.0 Design Strategies } & 105\end{array}$

Preliminary Design 'D' -Botany Town Centre 113

$\begin{array}{ll}\text { 7.0 Design Case Study } & 119\end{array}$

8.0 Exegesis and Conclusion 173

List of Figures \& Bibliography 185 


\section{ONE}


INTRODUCTION

| 1 


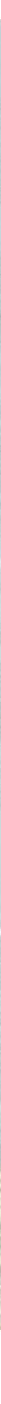




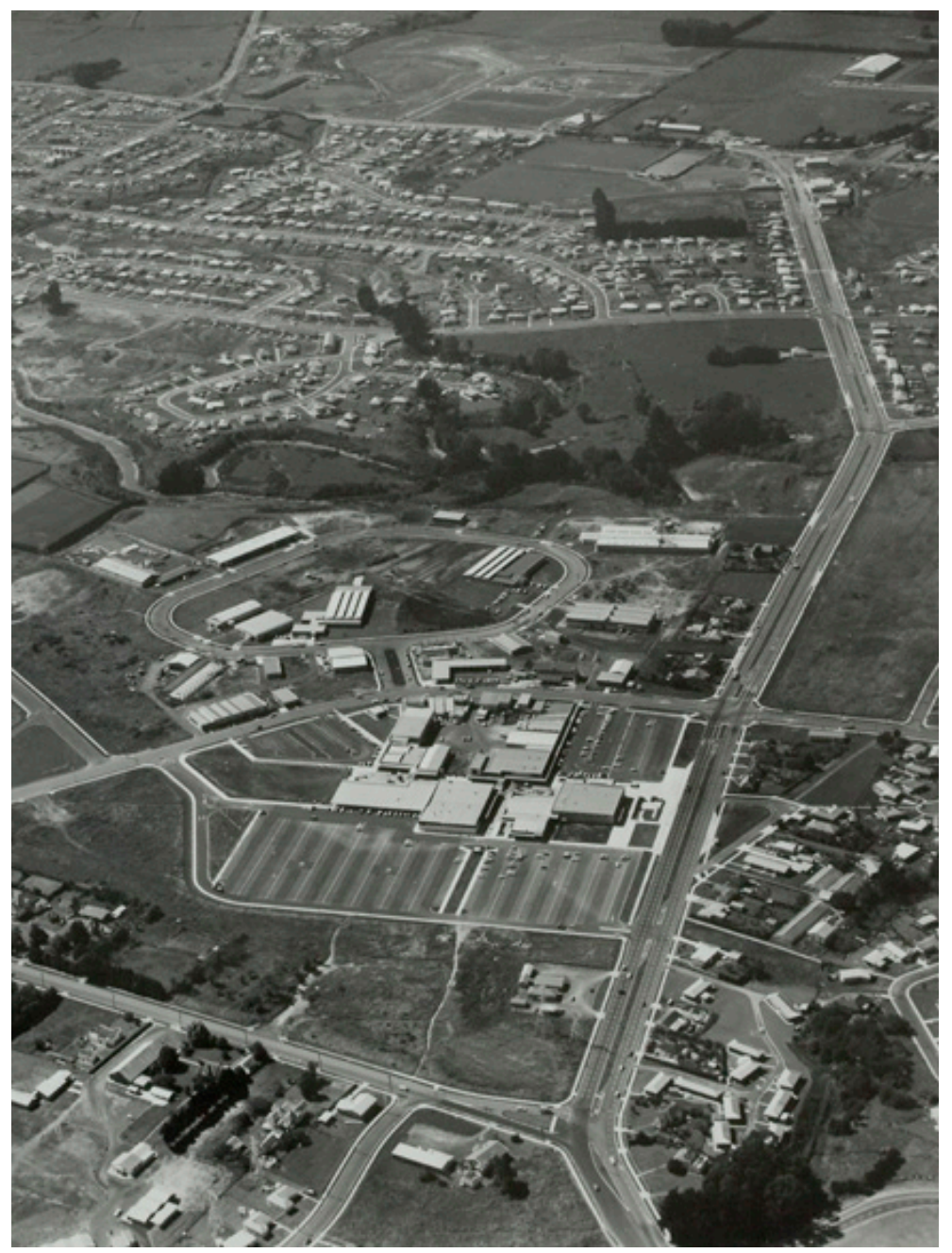

Fig 3. 
This thesis investigates the intensification of in suburban shopping centres in the Auckland region combining three themes: new urbanism; retail theory and ecology. It explores how ecology can be used to contribute to intensification to form a new urban environment and retail experience. Utilising the natural environment to reimage the suburban shopping centre as a centre where people can work, live and consume with a strong connection to the environment.

\subsection{INTENSIFICATION OF UNDERUTILISED SITES}

Auckland is the fastest growing city in New Zealand with the population predicted to increase by more than one million people over the next thirty years. The council promotes an image of the "most livable city" but this is far from the truth. The region suffers from poor land management resulting in the issues associated with urban sprawl. Development is continuing on the less expensive land at the fringes thereby threatening the surrounding pristine natural amenities. The Auckland City Unitary Plan sets the goal of intensification by proposing new zones in the District Plan that allow for increased maximum heights and smaller lot sizes. However, in the suburbs there is significant opposition to intensification due to the population's culture of the outdated quarter acre dream and from the disturbance a high-rise would create in their quaint sheltered suburb.

The suburban shopping centre typology when originally constructed contributed to the issues of urban sprawl. But as the city has grown outwards these sites are now located in central areas and can themselves be a remedy to urban sprawl. Shopping centre sites have vast expansive surface parking areas that underutilise the now far more valuable land. The singular or small combined ownership of these underutilised areas simplifies the transition to increased scale and density and, with their existing large scale commercial buildings, development is less likely to be opposed by surrounding residents. These shopping centre sites and associated land provide a real opportunity for future intensification in suburbia.

\subsection{RETAIL ENVIRONMENTS}

Suburban shopping centres were once the heart of suburbia and were celebrated for providing a new and different retail environment. People enjoyed these centres because they were easily accessible and provided all their amenities in one location. The original mall took the form of an internal pedestrian street with small retail shops organised around two or more larger anchor stores. These spaces were enclosed with internal courtyards utilising light wells to flood the area with natural light. It was a space to escape the weather due to the HVAC systems which created a constant comfortable environment. Shopping centres were very popular and this success led to the global expansion of this typology. Over time the centres have been redeveloped due to developers and corporations testing new ideas to stay popular in the ever expanding competitive market. To date, architects have had a very small role to play in this evolution.

There are over twenty suburban shopping centres located in Auckland (fig4). The highly competitive market has resulted in centres 'dying' or being retrofitted to stay current. According to the 


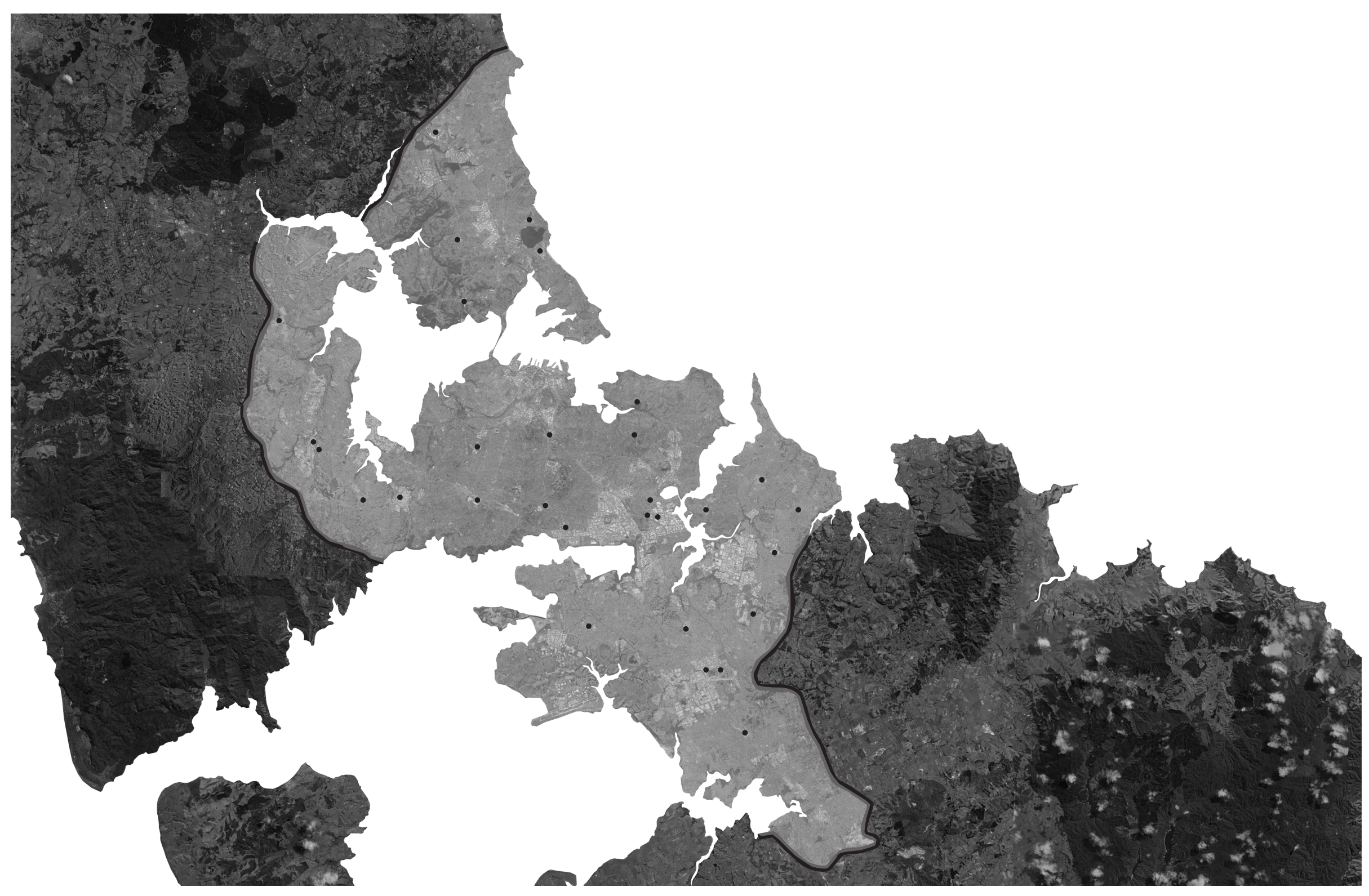

Fig 4.

| Auckland Region \& Shopping Centre Locations | 2015 


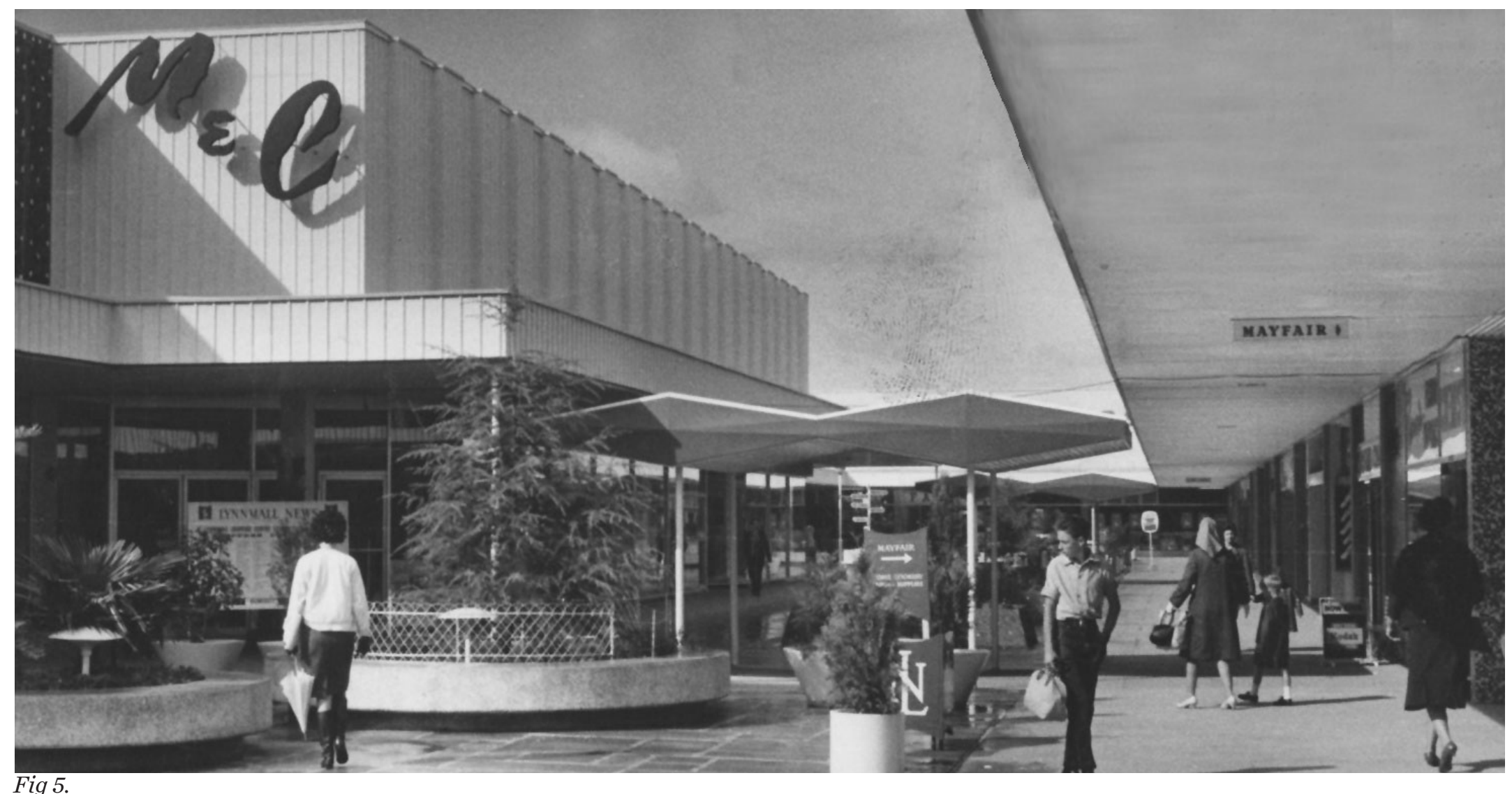


company RCG, "Shopping centres only last 10 years then customers become bored" (RCG Ltd).

There is minimal variation in the environment and consumer experience between suburban shopping centres in New Zealand. This lack of diversity and the certainty that suburban shopping is no longer the latest trend, combined with poor quality architectural elements and poor urban environments, is leading the decline of this once renowned typology. Shopping centres need to offer a new retail environment rather than the constant similarity. There is an opportunity to explore a new retail experience that will provide a point of difference, returning to the original success of the suburban shopping centre typology. 


\subsection{ECOLOGY AS A SYNERGY BETWEEN URBAN \& RETAIL}

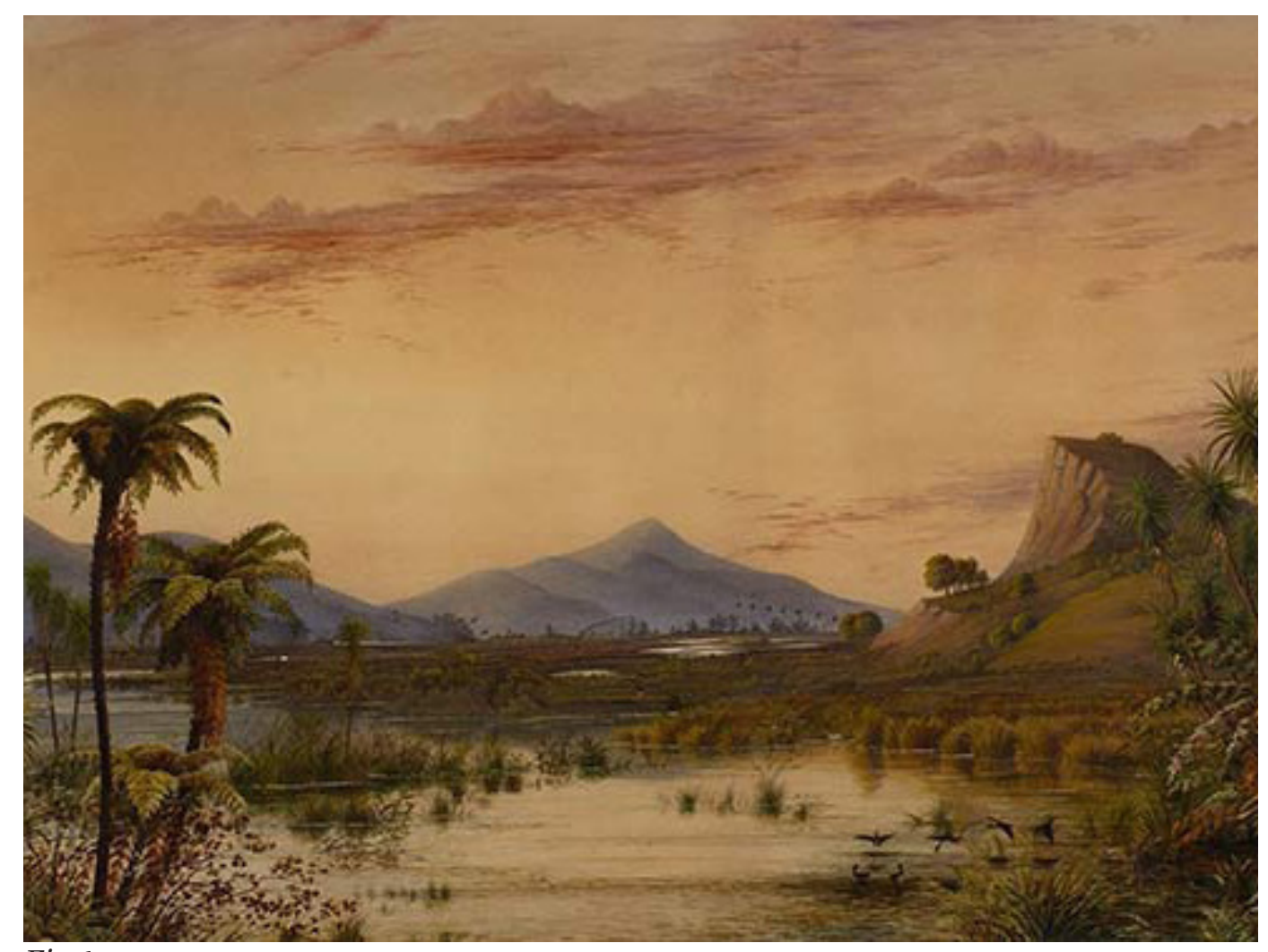

Fig 6.
The intensification and habitation of land destroys and disconnects the natural systems of a region (fig6). This results in poor diversity and the loss of species in the urban environment. Masterplanning fragments and disrupts ecosystems and has the potential to irreversibly effect the species within them.

$$
\begin{aligned}
& \text { Every species that dies out is } \\
& \text { the loss of an adventure with } \\
& \text { future... we also lose ecological } \\
& \text { complexity, and hence the } \\
& \text { diminution of constitutional } \\
& \text { relationality of nature. (Muller, 20) }
\end{aligned}
$$

In the Auckland region the natural landscape and ecosystems have been significantly fragmented by the settlement of human population. It is estimated that only $27 \%$ of indigenous land cover remains, mostly located in the Waitakere and Hunua Ranges and on the offshore islands (Fig7). There are a number of ecosystem types consistent in the region: coastal lowlands; consolidated sands; hill country; volcanic hills; mainland lava forests; wetlands; coastal broadleaf forest and kauri forest. The ecosystems in a number of districts of the Auckland region, including Tamaki, Awhitu and Manukau, are severely depleted due to industrialization. The Auckland region contains a large number of New Zealand's threatened species as well species unique to the region. These include the Pateke, the banded rail, the New Zealand dotterel, the Auckland green gecko, the Hochstetter's frog and the Northern New Zealand dotterel. (Lindsay, Wild and Stacey, 28). About 
$17 \%$ of land is secured as public open space, with the majority of this land lying on offshore islands. As the population continues to increase there is a need for intensification that relinks and rebuilds the fragmented ecology within the mainland areas. Urban ecological design will not only strengthen the endangered species but also provide a natural connection and sense of place to the people.

Enhancing and reconnecting the natural ecology creates the potential to redefine urban and retail environments, mitigating the problems of hybridisation. By utilizing ecology for intensification it can produce a context driven urban environment the inhabitants can identify with place. There are opportunities to improve connectivity for pedestrians, cyclists and public transport allowing a separate network from the typical dominant road infrastructure. The application of ecology in the retail environment creates a site specific condition that is forever changing and growing. Ecology can bring a theatrical experience to shopping, in the form of an 'eco-spectacle', and consumers can experience nature in a new light. An 'Eco-spectacle' can create a new image for the shopping centre as a place of environmental conscious consumption. Ecology can bring variation to intensification and provide and answer to the problems stated in previous paragraphs (1.1\&1.2).
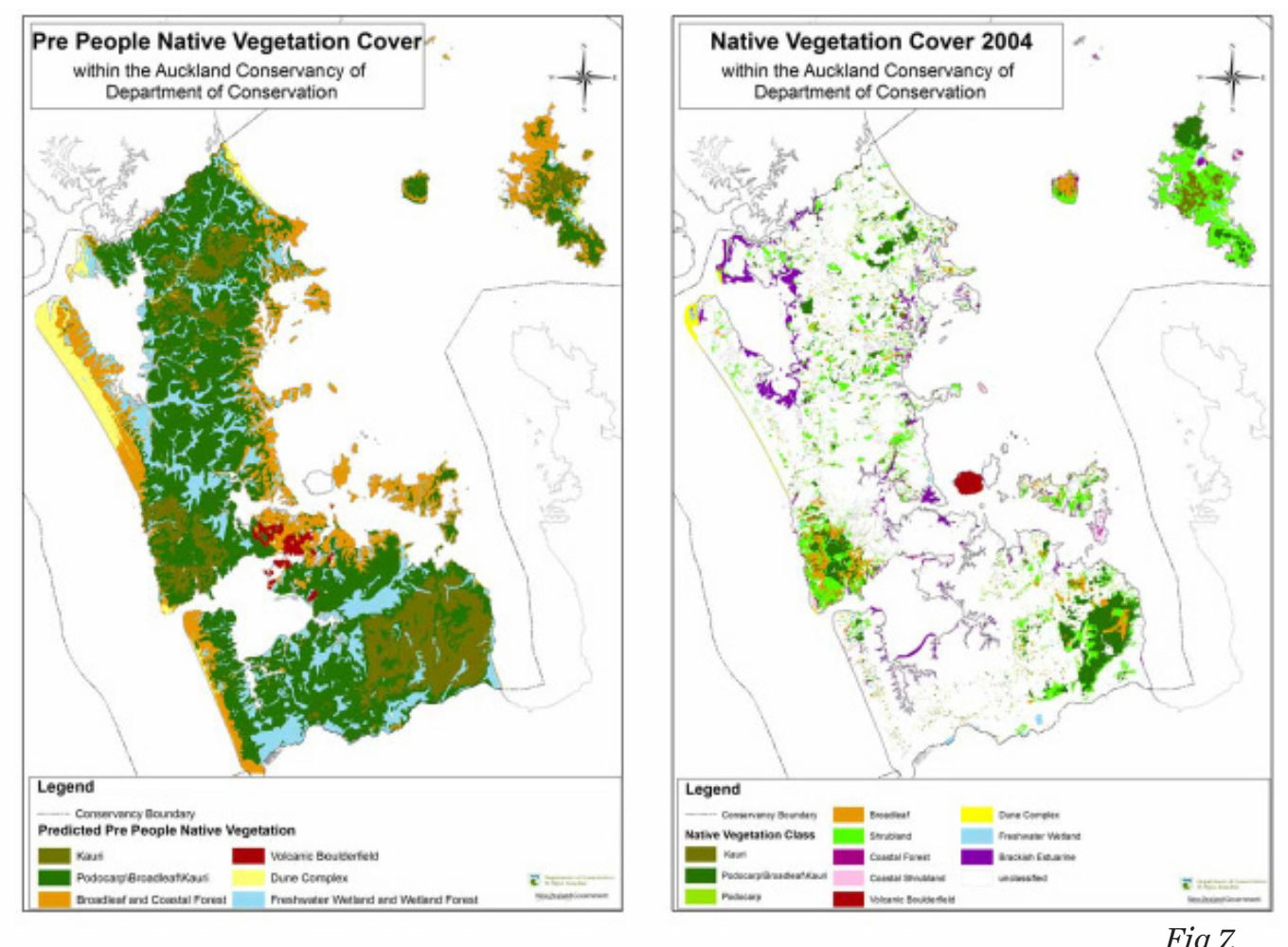

Auckland's native vegetation cover | Department of Conservation 
| 1.4 RESEARCH QUESTION |

HOW CAN ECOLOGY BE USED TO RE-IMAGE RETAIL ENVIRONMENTS IN A NEW INTENSIFIED SUBURBAN CENTRE? 


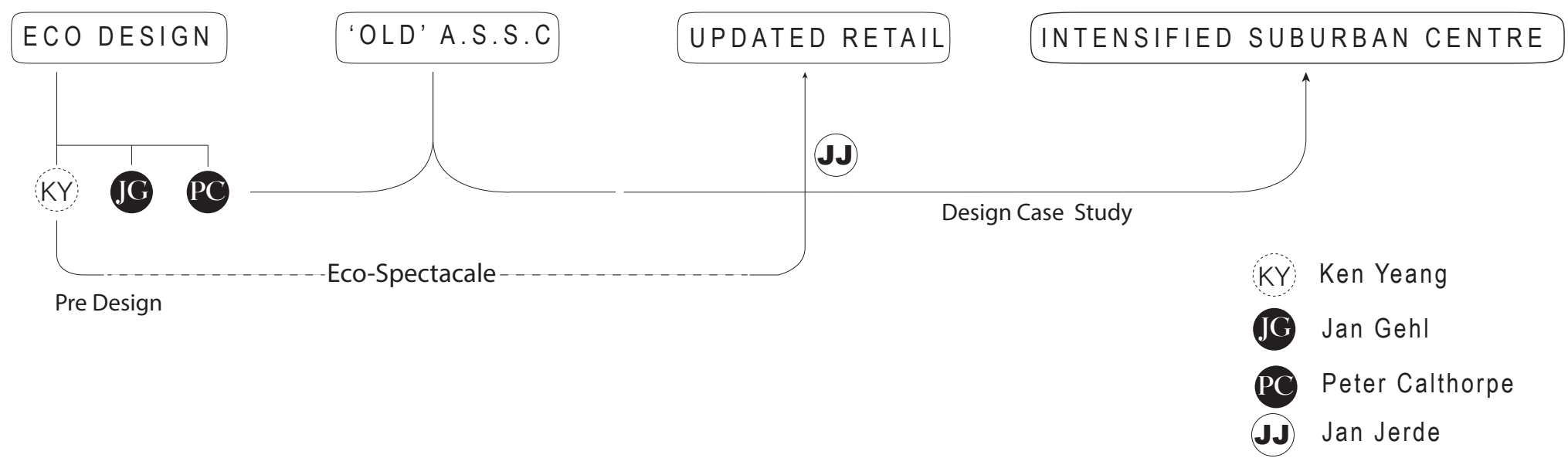




\subsection{PROPOSITION}

This thesis proposes the redevelopment of a suburban shopping centre in Auckland with the aim of intensifying development and creating a new retail experience while repairing the regions fragmented ecology. The redevelopment will introduce residential and commercial activities to the site at an intensity that exceeds the current unitary plan zoning rules in a low rise residential context. The conceptual framework of this research is grounded in three bodies of work: (i) urbanism theories of Jan Ghel and Peter Calthorpe; (ii) introducing the spectacle to retail of Jon Jerde and (iii) Ken Yeang's ecology strategies to resolve and answer the problems from hybridisation. This framework is further defined in chapter 2.0.

\section{URBAN}

The redevelopment will create a new urban environment that will be well connected to its surrounding context thus repairing the current disconnection that these sites face. It will provide strong connections for all modes of transit (pedestrian, cycling, public transport \& private transport). There will be a large focus on promoting walkability within the site which will be achieved by reducing surface car parking, breaking down the large retail block size and humanizing spaces. The project will add higher density housing, office spaces and a civic aspect combined with retail to create a suburban centre that is a catalyst for further intensification within its area.

\section{RETAIL}

The research will explore ways of providing a theatrical experience to achieve a new retail environment. Utilising and enhancing the natural ecology as a means to provide a new experience and image to the complex; combining consumption and environmentalism for a new age of shopping that is focused towards the preservation of the environment. The ecology will create an identity that appeals to both the residential and retail components. 


\section{ECOLOGICAL MASTERPLANNING}

The objective of this thesis is to enhance and repair the sites ecology, relinking it to the larger regional systems. It will explore ways to combine elements of intensification with ecology to form a heterogeneous ecosystem where humans and threatened species can live in a thriving environment together. The design will work at both the urban scale and architectural scale exploring the interface between the ecological and architectural elements of the retail, commercial and residential components of the redeveloped centre.

\section{ISSUES}

The amalgamation of the residential, retail, and commercial components combined with ecology generates challenges and uncertainties:

- Integration of scale between the large retail and commercial functions with the smaller residential components.

- Mitigation of the conflict between the theatrical retail spaces and the intimate residential spaces.

- Balance between pedestrians and vehicles.

- The hierarchy of the different circulation routes and the application of non-conventional ambiguous space - it's neither completely private nor completely public.

- $\quad$ Servicing to buildings with unconventional access

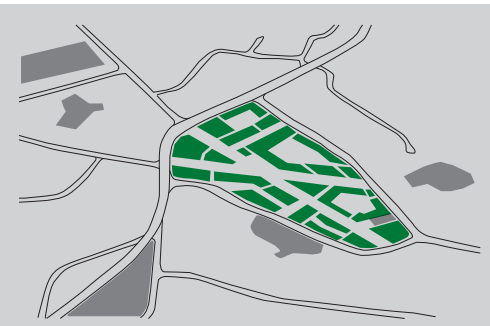

Intensified Suburban

Centre

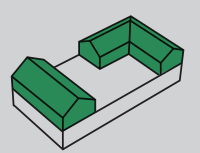

High Density Housing

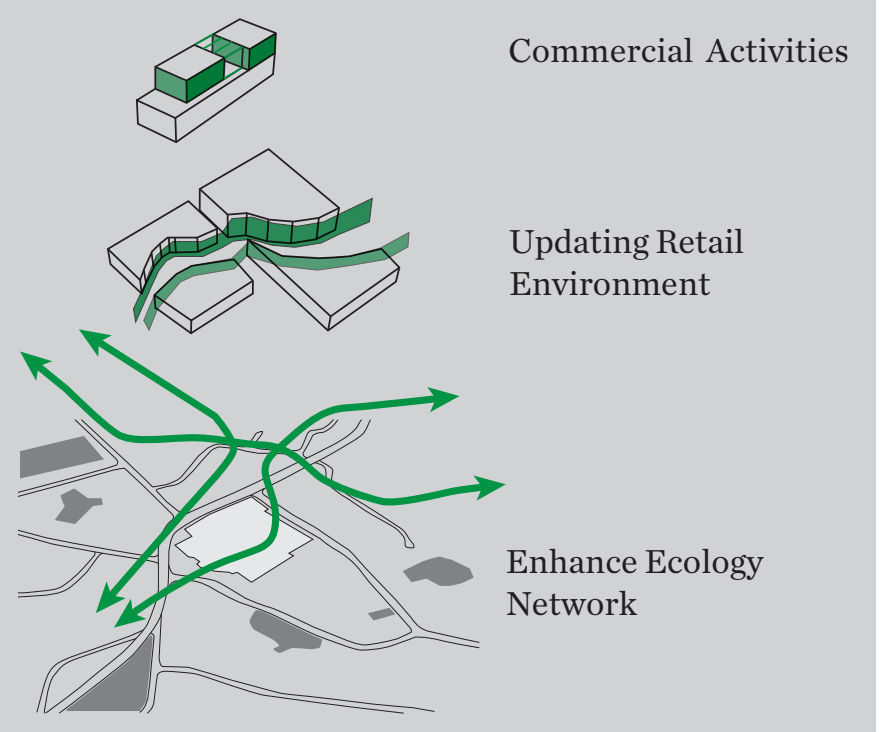




\subsection{METHOD}

The research utilises an empirical approach. The methodology is best explained by the diagram (fig8). There is an amalgamation of two inquiry stages: research through external resources and research through design. Each process shifts in and out of these stages forming the body of the design investigation. The cyclic nature of this research allows for an in-depth inquiry on the research and draws conclusions that can be applied to similar shopping centre redevelopments elsewhere. The thorough investigation through map-based analysis and other secondary data creates a robust framework for experimentation in the reiterative design process.

\subsection{RESEARCH STRUCTURE}

[2.0, Literature Review] The thesis is initiated with the investigation of three bodies of work: urbanism by Jan Ghel and Peter Calthorpe which analyses the strategies for interconnectivity and human scale; retail theory by Jon Jerde which introduces the notions of a theatrical shopping experience and eco-master-planning by Ken Yeang which explores the strategies for enhancing ecology with respect to urbanism, retail theory and eco-master-planning. The hypothesis is proposed that repairing and enhancing the ecology has the opportunity to facilitate the hybridisation of urbanism and retail theory, providing a new identity to the urban environment and a unique shopping experience.

[3.0, Auckland Shopping Centre Survey] The research then explores site and context, analysing thirty shopping centres in Auckland through map diagramming thus providing a foundation for design investigation.

$14 \quad$ |
[Preliminary Design (PD) 'A', Survey Sketch Design] The first Preliminary Design explores master-planning sketch design that defines urban design criterion for further testing.

[4.0, Precedence] A two part study on existing projects; the first analyses redeveloped shopping centres at the urban scale, the second explores projects that are an amalgamation of natural systems and architecture assessing how the architecture can sustain and enhance ecology. The chapter defines design strategies that can be applied to Auckland's context.

[PD 'B', Context-less Site Planning] A rapid design exercise experimenting with planning definitions taken from the literature (Ghel, Calthorpe \& Yeang) on three 'context-less' sites. The process establishes a set of urban design criteria to apply to site.

[5.0, Program Analysis] The dissection of the hybridity that the project encompasses, defining the intended programmes and the combined configuration of retail, residential, recreational and civic functions. Four existing projects are examined to establish a set of design strategies.

[PD ' $C$ ', Concept Planning] AA conceptual sketch design for four Auckland centres, Kelston Shopping Centre, Westfield St Lukes, Highland Park and Botany Town Centre, investigating the connection of ecology combined with urban design criteria.

[6.0. Design Strategies] This chapter identifies the design strategies for the Urbanism, the Eco Spectacle \& Retail, and the Ecology components of the project derived from the research conducted from the earlier chapters.

[PD ' $D$ ', Botany Town Centre] The final preliminary design stage testing and application of the established design strategies to the Botany Town Centre site. A rapid drawing stack design process was utilised to develop a sketch masterplan for the centre creating the framework for further developed design.

[7.0, Design Case Study] This chapter shows the developed design for the Highland Park site, presenting site and context analysis of the suburb and for the Tamaki Ecological district and identifying transport strategies to complement the intensification of the suburb. The initial and development sketches that explore the design strategies to reach the final outcome are displayed, conveying the intended urban and architectural form. The documentation is arranged by breaking down the scheme at the urban scale and then exploring the architectural scheme for one of the development's civic anchor blocks that combines retail, a cinema complex and housing functions together with the ecology. The design case study is critiqued in the exegesis at the end of the chapter, analysing the success of the three components and their integration.

[8.0, Conclusion] The final chapter of the thesis provides conclusions of the design research process, identifying the significant findings and their relevance to the discipline. The avenues for further research are also explained. 
| Research Method |

Research Inputs

$\downarrow$

Design Research Outputs

2.0 Litreture Review

Summary \& Design principles

issues \& stratergies

$$
\downarrow
$$

(3.0) Survey of existing suburban shopping centres

Summary \& Design issues

and objectives

(4.0) Precedents $\downarrow$

- Redeveloped Shopping Centres

Amalagamation of natural sytem \& architecture

Summary \& Design principles, objectives \& stratergies

5.0 Program Analysis

Summary \& Design strategie and criteria

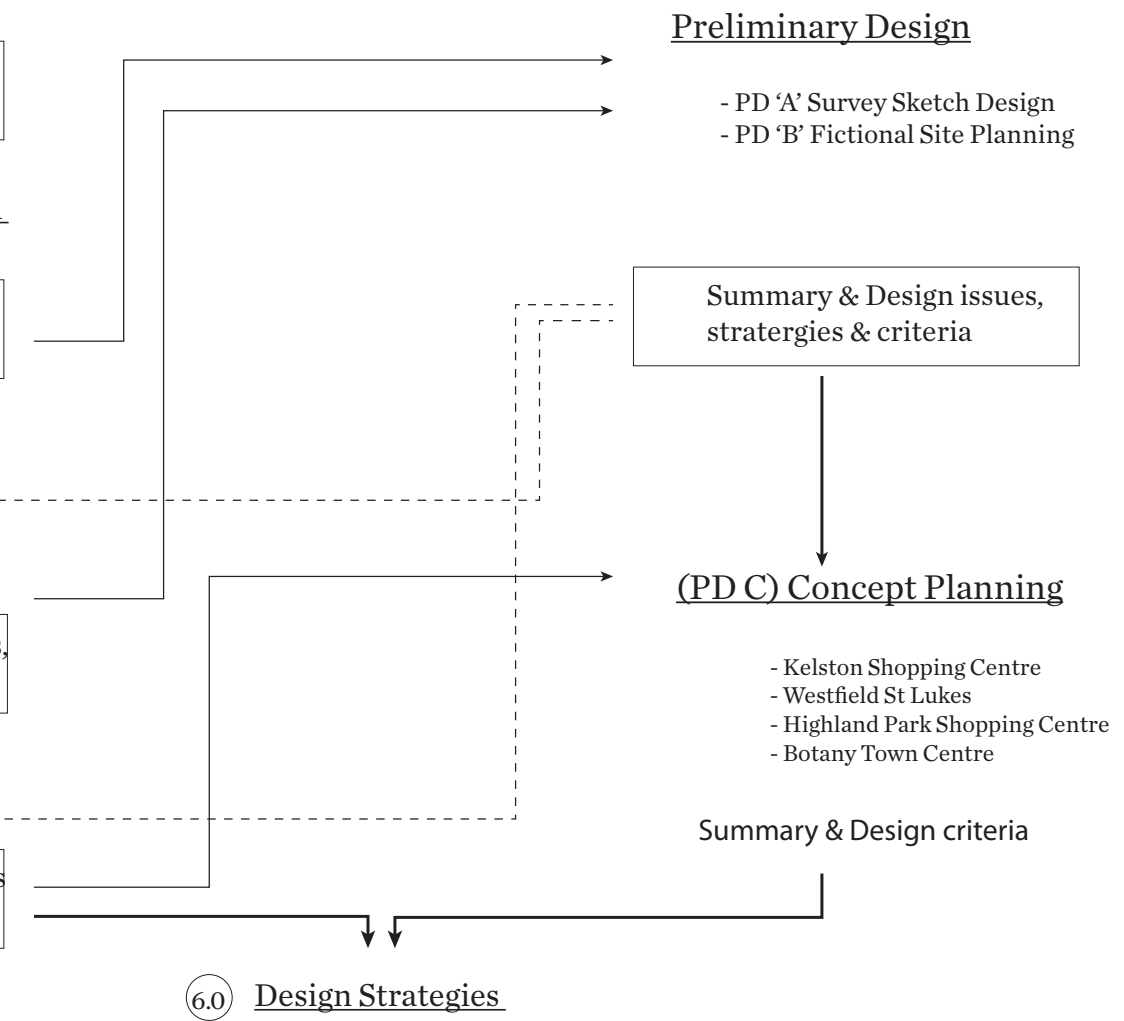

(PD D) Botany Town Centre

Fig 8.

\begin{tabular}{|c|}
\hline \multicolumn{1}{|c|}{ Reflection } \\
7.0 Design Case Study \\
$\frac{\text { - Highland Park Shopping Centre }}{\text { Exegesis \& Conclusion }}$ \\
\hline
\end{tabular}




\section{TWO}




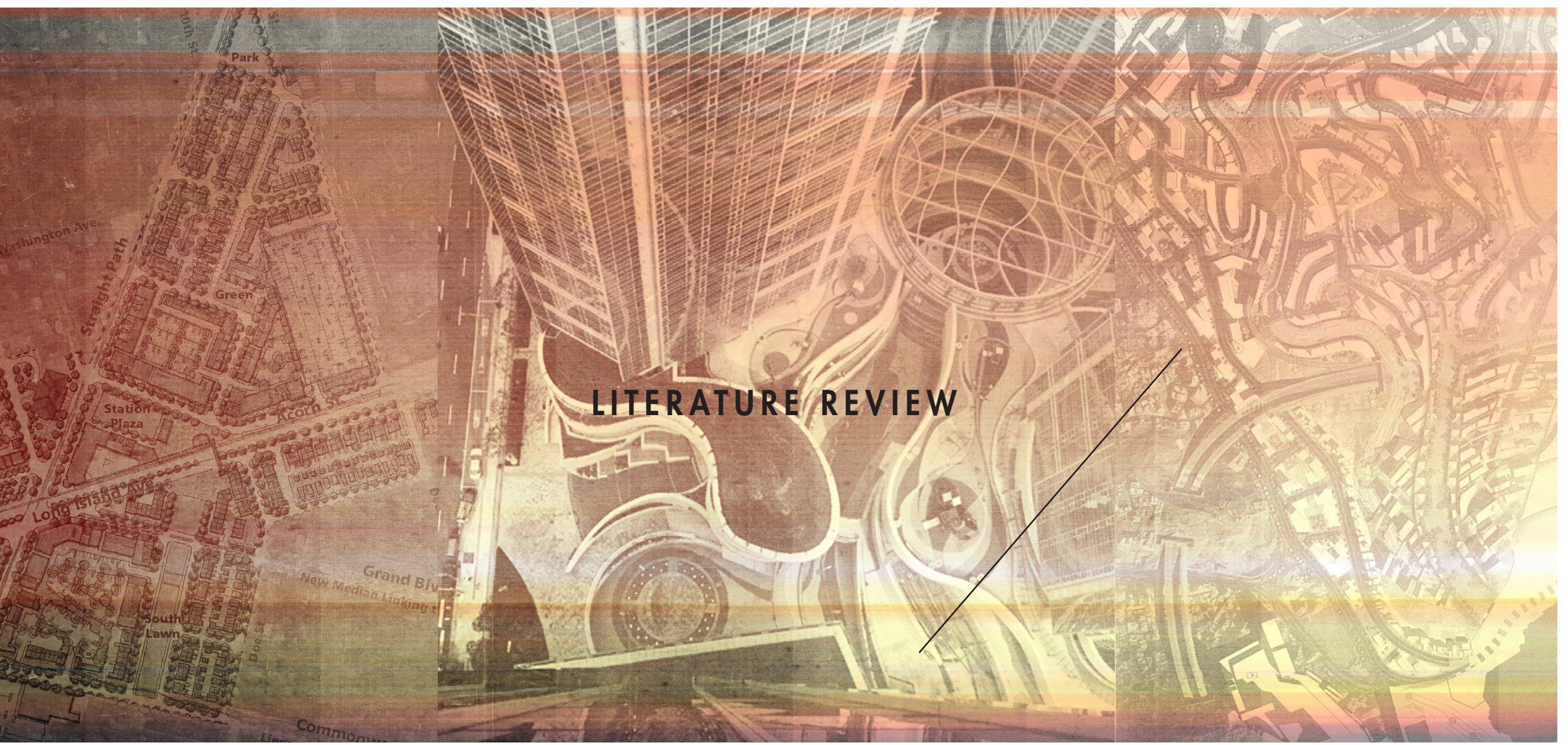


Suburban shopping centres were once celebrated for being exciting and a different shopping experience to anything that already existed in the city. The early shopping centres experimented with new ideas of public urban space, testing pedestrian domains, interior "streets", separation of cars and people and collectivised amenities. Today the city has expanded beyond its limits resulting in issues of urban sprawl that also threaten the natural ecosystems at the regions fringes. There is a lack of variation between shopping centres and the retail experience is the same, suburb to suburb, city to city and even possibly country to country.

This literature review chapter is split into three components: (2.1 Urbanism) explores new urbanist theory from Peter Calthorpe and Jan Gehl that analyses interconnectivity and human scale; (2.2 Retail Theory) investigates Jon Jerde and the notions of a theatrical shopping experience; (2.3 Ecological masterplanning) that analyses Ken Yeang's eco-masterplanning strategies.

\section{1 URBANISM}

Peter Calthorpe and Jan Gehl are both new urbanists located in America and Denmark respectively. Their different approaches towards interconnectivity and human scale can be applied to give a more urban condition to the suburban context. The proposed development is neither urban nor suburban, but a combination of the two creating a unique condition. Recent shopping centre redevelopments (chpt 4.0) have attempted to copy cities but have failed due to their lack of organic growth. Therefore this thesis is arguing that a new kind of urban centre is an amalgamation between urban and suburban, recreation and work, market and home, public and private, and natural and manufactured.

Shopping centre sites are often disconnected from their context by the surrounding major arterial linkages. The redevelopment has to be inclusive and connect the diverse mix of programmes that are introduced to the site. Gehl's approach to interconnectivity is to make the block more permeable and limit car access to the city to achieve better quality pedestrian space and efficient public transport (fig9). He argues that large building projects require more streets and squares with a hierarchy structure of main streets, side streets and primary and secondary squares similar to old European cities (89). He also suggests that leaving cars at the city limits and having people walk into the city would create a more vibrant city (111). Gehl is heavily influenced by old European cities and contends for similar future urban environments, where spontaneous pedestrian activity can occur. He favours the pedestrian spaces at the expense of other forms of transit and argues against private developments with internal public space for taking people off the street.

Calthorpe's urban theories are of a more inclusive approach to the different modes of transport. Similar to Gehl, he argues that we should stop relying on the automobile and start favouring public transport and be rethinking our current method of city development. Instead of adapting the old city methods he thinks that the city should be inclusive towards all future modes of transit, and be about providing accessibility for everyone 
(90). A method to provide this accessibility is intensifying transit stops along a railway route with high density housing, commercial and retail activities, effectively creating a polycentric city (fig10). He states that arterial roads should be redesigned to provide access for multiple users public transport, bike, pedestrian and vehicular. Instead of the current arterials dividing the communities there needs to be a street system that connects them. The street system is contrived of avenues and boulevards that can also provide for heavy traffic without having to bypass centres (93).

The Auckland shopping centre sites are divided by large arterial roads moving heavy traffic through the suburbs. Calthorpe's theories for a street system that is inclusive of all modes of transport are more applicable to these sites. But adding more streets to the site could run the risk of diverting the traffic through the site unless planned correctly. The issue with making large arterial roads to provide access for all modes of traffic is that the space is limited on these suburban sites. If done incorrectly these large boulevard roads can lack human scale and further disconnect the site.

The intensification of large, high building masses on the site can create issues of losing human scale, resulting in a vast unfriendly pedestrian environment. Human scale is a significant contributor in place making. Ghel draws influence from the scale of old cities to construct human scaled environments. Utilising narrow streets, small spaces and buildings of modest dimensions, he creates a compact urban environment that people can move around and experience with
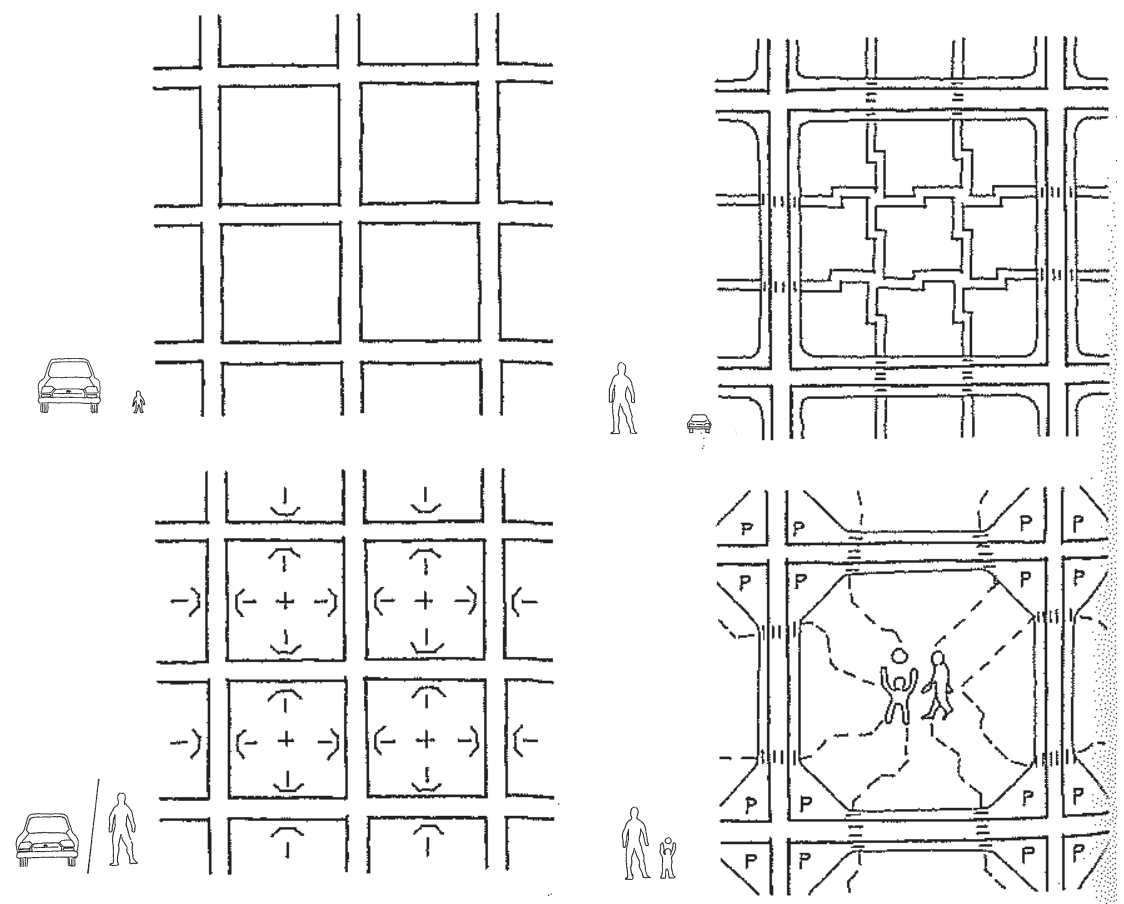

Fig 9.

Fig 10.

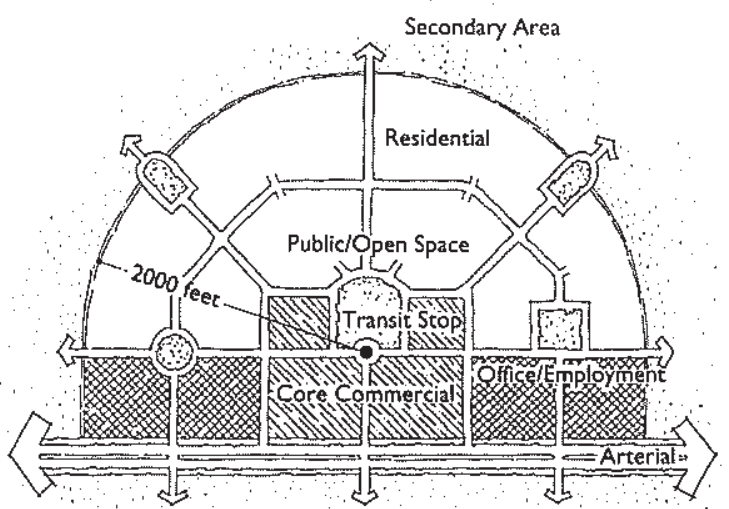


"considerable intensity" (69). However, retail format is large scale, lacks small spaces and it has more complexity than the typical town centre that Ghel proposes. Human scale will have to be achieved through other means.

Calthorpe addresses human scale through diversity, applying the ecologist's approach to urbanism. In ecology, diversity is the core to any successful ecosystem (figl1).

"In urban design, diversity implies more mixed, inclusive, and integrated communities... the principle of human scale brings the individual back into a built environment that has been increasingly shaped by remote and mechanistic concerns... It is a walkable city block rather than an auto dominated superblock; it is local and decentralized services and nearby destination... diversity is the key to resilience and adaptive capacities within any ecosystems" (45).

While both urbanists agree that it is possible to achieve human scale through the use of a finer grain, Calthorpe adds that diversity is a significant factor to its success. The challenge is, for a site that has large programmatic requirements, introducing and combining smaller scaled residential components without a conflict in the combination of scales. The complexity of intensifying the suburban context requires different solutions to that of the urban context. 


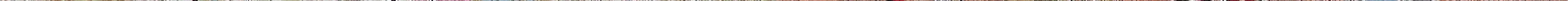




\subsection{RETAIL THEORY}

The suburban shopping centre was allegedly created by Victor Gruen in America during the 1960s (fig12). Gruen was interested in a new type of urban space. "His first step in remaking the American City was to build a vast, interior shopping concourse ringed by parking" (Herman, 468). The mall was something different that people had not experienced and this difference is what made them so popular.

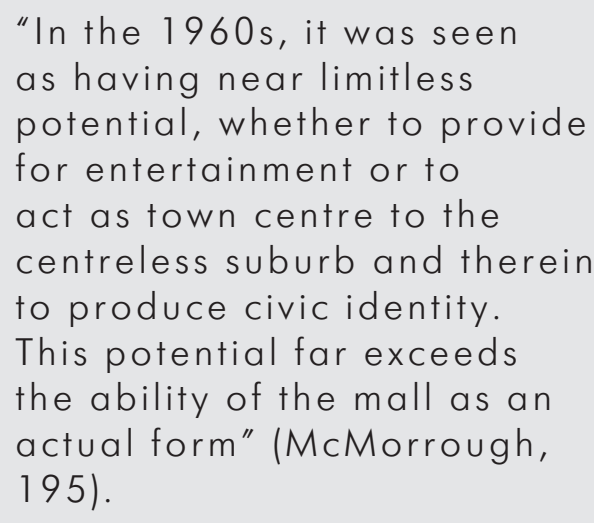

The centres provided glamourous internal public spaces, the scale and sheer size of the open areas gave a new experience to shopping in suburbia and contributed to their success as an amenity to the community. Periodically more shopping centres were introduced in a similar style and now generations of people have grown to become accustomed to the mall culture. This once new typology has now become just part of the fabric and these factors combine to the loss of their original experience (Herman, 465). The designing of shopping centres is an undesirable task in the architectural profession and many consider it 'non-architecture' with the result that few famous architects have designed using this typology. Architects consider housing, schools, museums, art galleries etc, more serious projects, and have seldom considered the shopping centre as an opportunity to create space and "foster urbanism" (Herman, 391). Jon Jerde is one architect who has built a successful career from designing shopping centres that have a unique retail experience compared to the typical mall (fig13). There is a spontaneous nature to his designs that he compares to the spectacle of the theatre. This section will explore Jerde's notions of spectacle and how theatrics can be used to transcend shopping.

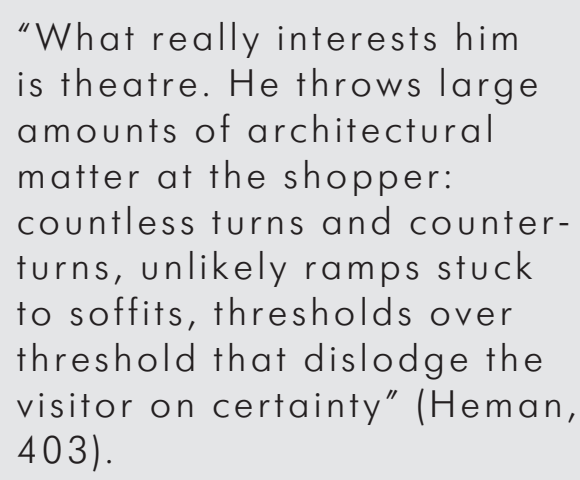

Jerde's centres are microcosms in the way that they mimic cities. He introduces multiple programmes and thresholds that create a charged intensity to form a communal experience between shoppers. The result is a spectacle that includes theatres, theme restaurants, light showers and water features to alter the consumer's consciousness (Herman, 406). The design strategy of "thresholds" adds value to this research by adding a spectacle experience to retail within the architecture. The thresholds are created by changing scales, providing multiple routes and changing levels.

Jerde wants his shopping centres to affect people in a similar way to a theme park and to change their conscious state as do the activity and light shows of Las Vegas. "the Fremont Street Experience... But this isn't urbanism; this is Ooohh-Aaahhrchitecture. This is mass spectacle" (Herman, 407). This research agrees that the idea of 'mass spectacle' could achieve a new retail experience, however the thesis contends that spectacle is more appropriate for shopping and visiting than it is as a residential environment. People will not want to live there 24/7. Therefore this issue of spectacle will be explored through circulation routes, directed towards the circulation of shoppers rather than residents.

In Asia, especially Hong Kong and Japan, the spectacle of shopping has successfully been combined with public/private infrastructure, blurring the difference between the train stations and shopping centres. Similar to Jerde's centres they create microcosms where the focus is on public activities such as learning, eating, posting mail, playing golf and even museum 


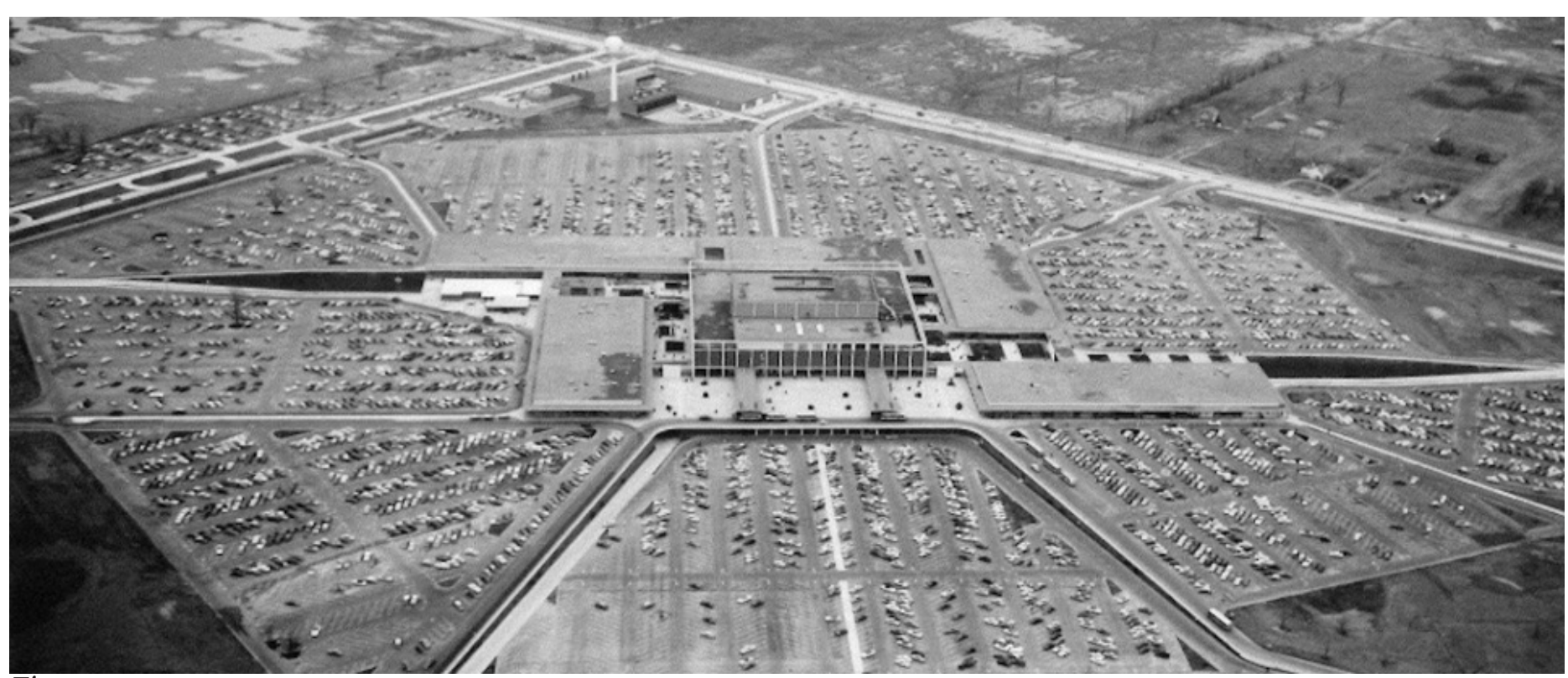

Fig 12.

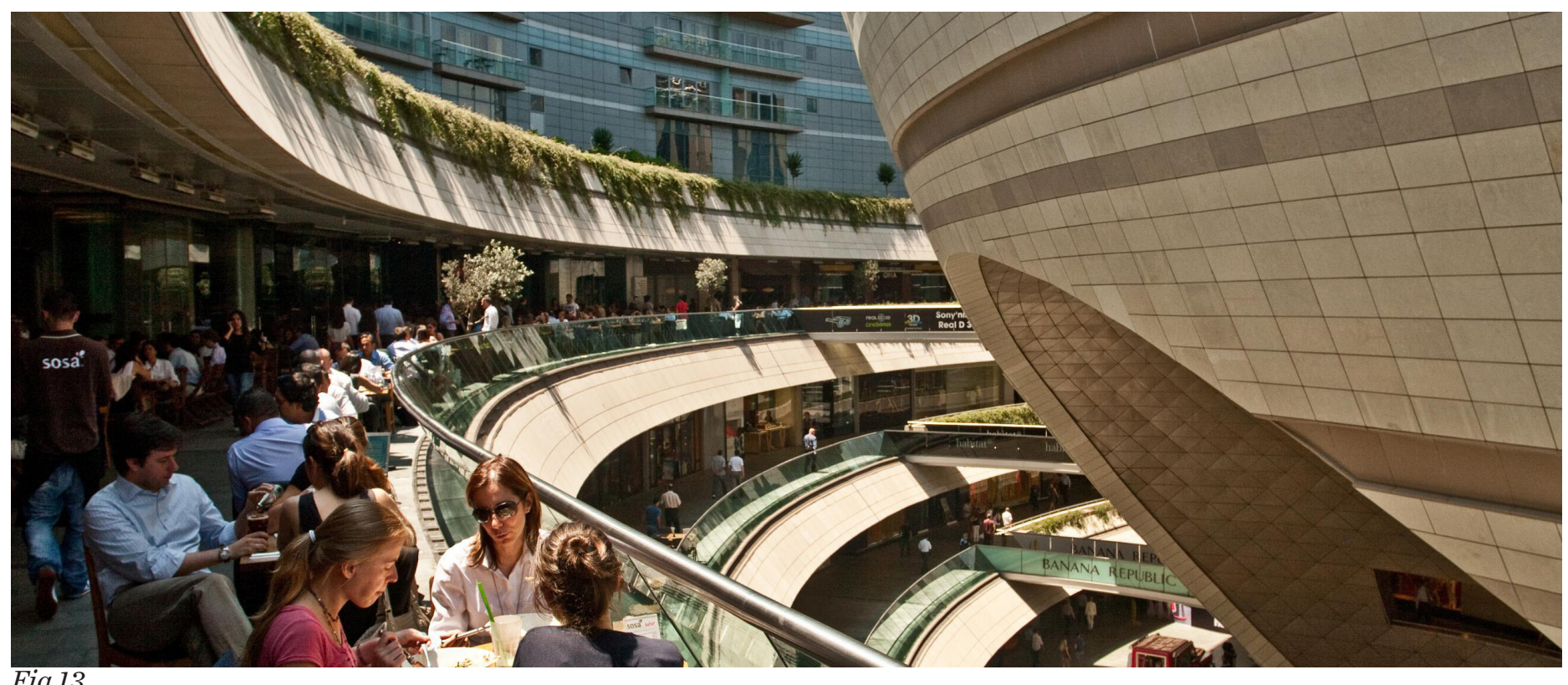




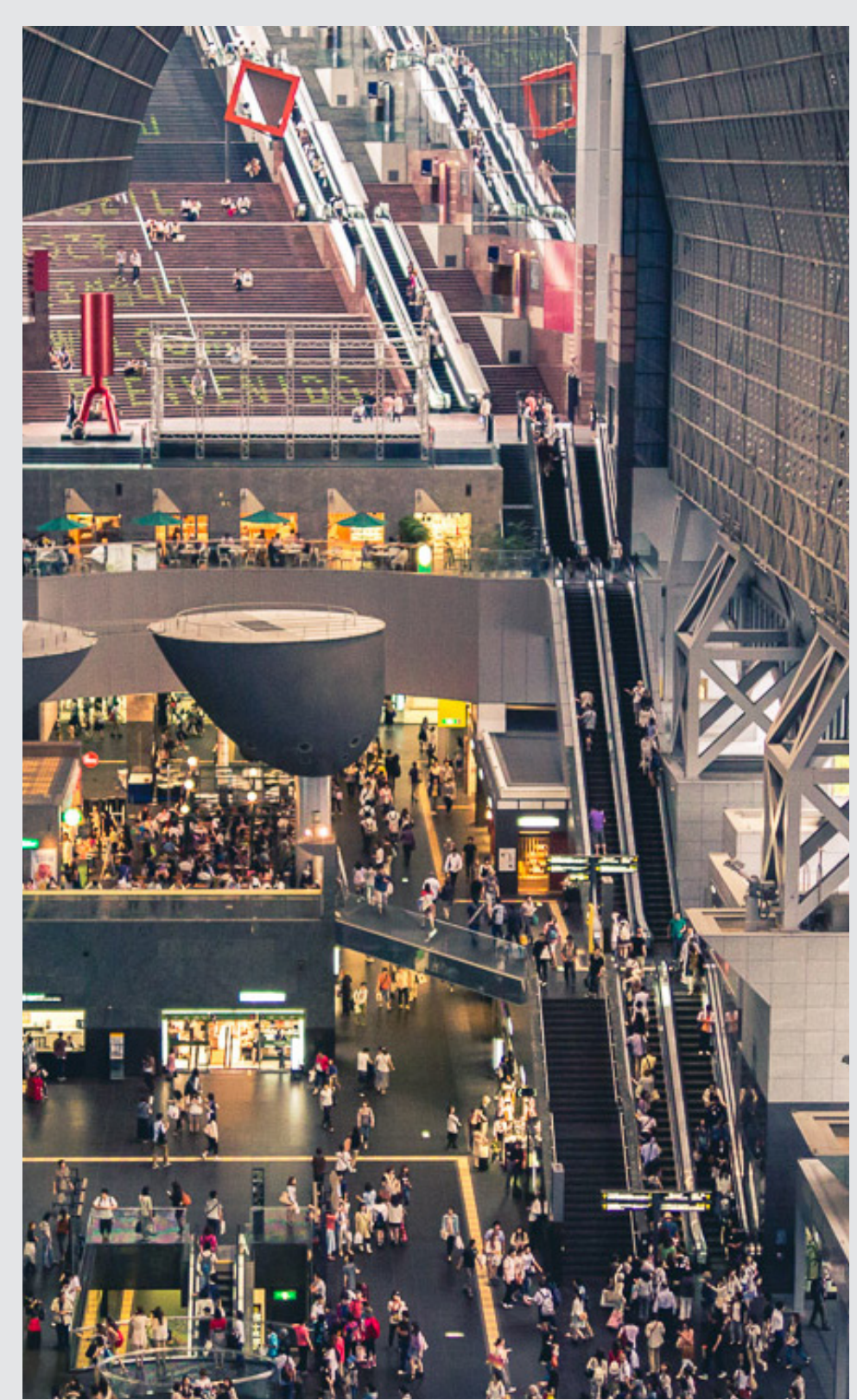

Fig 14 . going. These spaces have successfully dissolved shopping into the urban infrastructure and cultural institutions and therefore transcended the shopping centre. These spaces could perhaps be a "superior" model of shopping, as they are not operated for direct profit but instead promotion and experience of a brand (Matsushita, 243).

The idea of transcending the shopping centre benefits both the retailers and consumers. Consumers are attracted to these spaces for a theatrical experience rather than direct consumption and retailers will still profit. The microcosm nature of these centres provides an opportunity to fix the issues of the current urban evolution and test new ideas to move our culture towards a more environmentally sensitive future, resulting in less of an impact to the environment in which we occupy. This creates a miniature 'eco city' utilising ecology to re-image the suburban shopping centre.

\subsection{ECOLOGICAL MASTERPLANNING}

Ecological masterplanning is primarily concerned about reconnecting and enhancing the fragmented natural systems of the region and site. Yeang's theoris will contribute to the planning of a centre and also be used to mitigate the issues of scale and accessibility created when combining a theatrical retail environment with new urbanism. All three components are linked together through the movement of the pedestrian.

"relationship between shopping and urbanism indistinguishable from the issues of mobility: How to move people about, whether by foot, moving sidewalk, underground, or car" (Leong, 477).

Urbanism and retail theory have a conflict of scale, the urbanists are arguing for human scale while retail theory is 


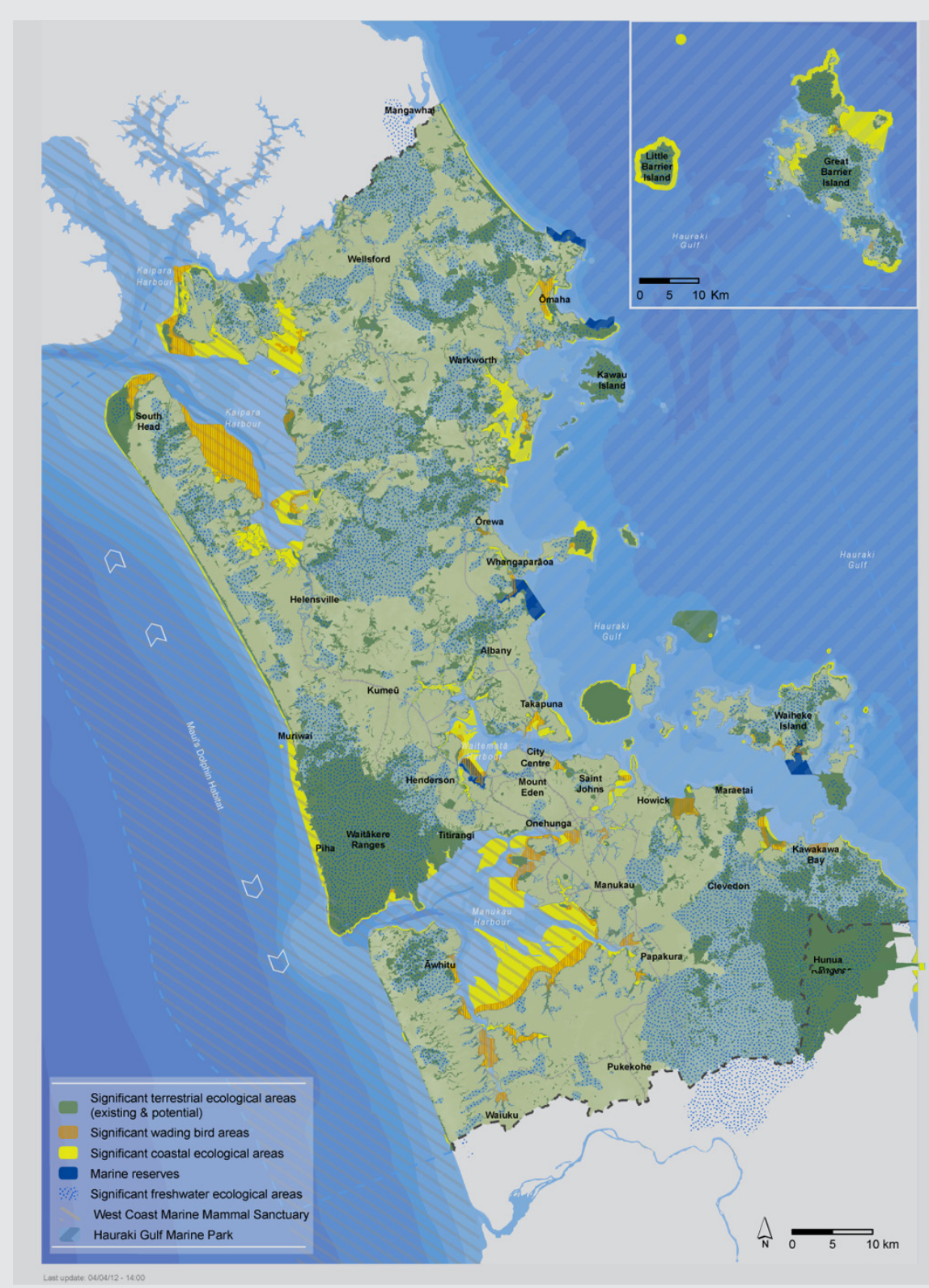

often concerned with the manipulation of human scale to create a spectacle. Yeang's strategies can be used to mitigate this problem and help contribute to a new urban space and shopping environment that is a united place responsive to context and ecology.

Urbanism is contributing to the degradation of natural systems. There is a large loss of diversity resulting from fragmentation of habitats (Muller,20). Plant and animal species are slowly dying and are forced to live on rural fringes. "Every species that dies out is the loss of an adventure with the future" (Muller, 20) (fig15). Yeang's strategies are focused towards eco-design. Each ecosystem is made up of organisms that are living in balance with their environment (37). So Yeang designs for future human populations as much as he designs for plant and animal species.

"A deeply ecological architecture intervention is one that creates more diverse urban habitat frameworks, filters and cleanses stormwater in order to improve biological conditions compromised waterways, fortifies the connective ecological tissue of neighborhoods and regions, and in other ways supports broader, regenerative landscape processes" (Muller, ix).

Yeang's theories towards enhancing ecology can be used for place-making. The architecture will become responsive to its context and form a sense of identity, home and community.

Fig 15. 
He states that roads and highways disconnect green continuous habitats, unlinking them and resulting in a decline in diverse ecology. Yeang's objectives are to conserve, enhance and re-link existing ecosystems, i.e. their plant and animal populations, natural and semi natural wildlife habitats and the ecosystems' characteristics of the local areas (Yeang, 15). The strategies he utilises for reconnecting the fragmented natural systems are eco-bridges, ramps and eco-under-crofts and extending ecological linkages vertically, from basement to rooftop (20)(fig16).

Yeang has similar motives to Calthorpe and Gehl in that he aims to reduce the use of the automobile. Likewise he is concerned with access and connectivity, attempting to achieve more walkable spaces. It's apparent through Yeang's masterplans that some basic urban principles are lost. His case studies are large scale, lacking any form of human scale and result in poor living environments (fig17). The buildings are long and large and have minimal variation along the façade and don't define the street edge. Large highways disconnect each block. The human environment on the street and the green spaces are uninviting and unsafe and therefore deny the goal of pedestrian connectivity. On a positive side the style of his architecture and planning is different to the typical new urbanism and creates an image of sustainability. This urban and architectural image provides a paradigm for people associated with the reconciliation with nature.

Yeang's projects usually incorporate a retail component, in the form of a pedestrian concourse and other pedestrian networks. Typically there are no large anchor stores but smaller retail outlets such as in the Jabal Omar Towers (fig18). The shopping experience is more similar to Jon Jerde's shopping centres than the suburban shopping centres in NZ, but does not include thematic spectacles achieved through light and water features. Instead the experience is created through the green infrastructure being interlaced through the retail, additionally these provide the ecological linkages Yeang strives to re-connect (190). Ecology provides the mechanisms to foster the integration of retail, commercial and residential forming a microcosm where humans and nature can interact peacefully together.
Fig 16.
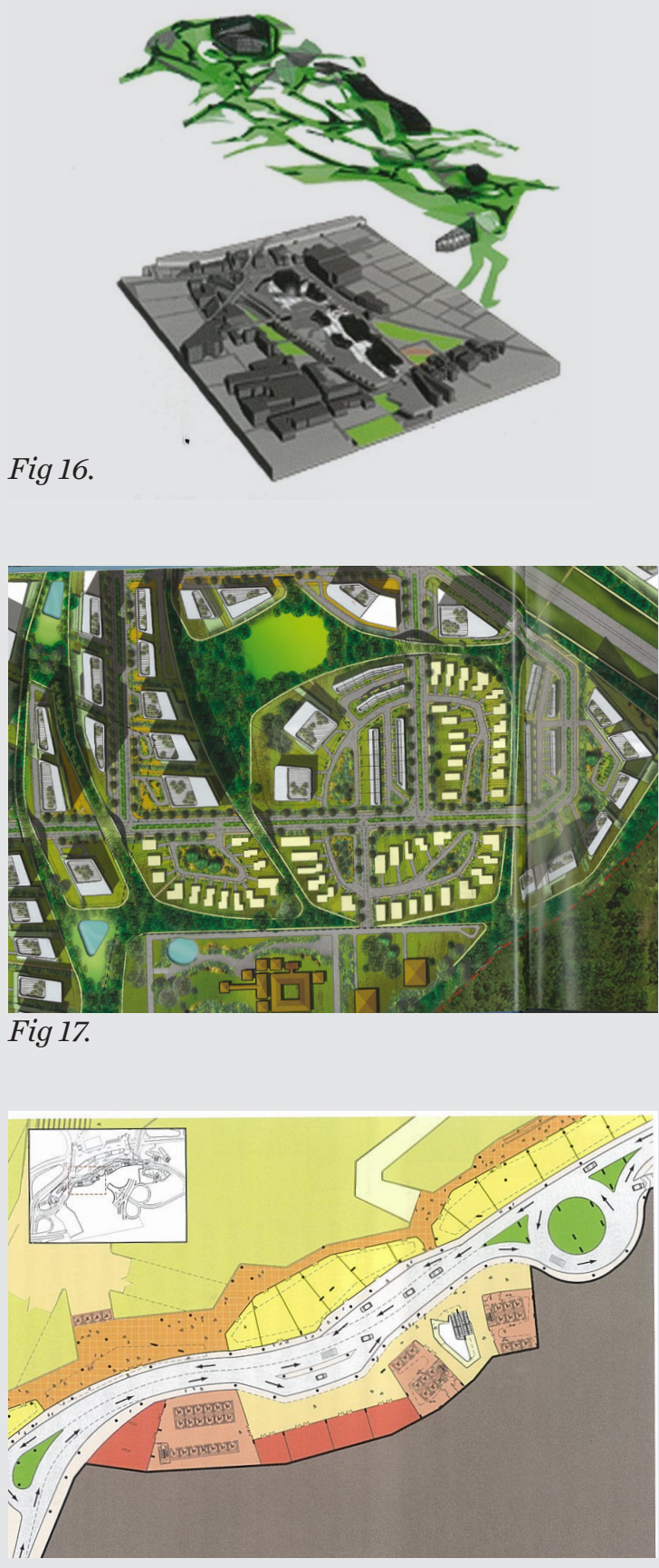

Fig 18. 


\subsection{SUMMARY}

Utilising the site's ecology creates an opportunity to create both a new urban and retail environment. Enhancing the regional and local ecology and at the same time improving interconnectivity, human scale and diversity provides a strong sense of identity, home and 'address' to an intensified suburban centre (fig19). The regional natural systems add to Jerde's spectacle in the form of an 'eco-spectacle' (fig20), which also promotes a new retail experience. Also ecology can be utilised as a method to dissolve shopping into the sites infrastructure and systems. The microcosm will become an amalgamation, combining urbanism, retail and ecology to form an alternative model for intensification in the Auckland region.
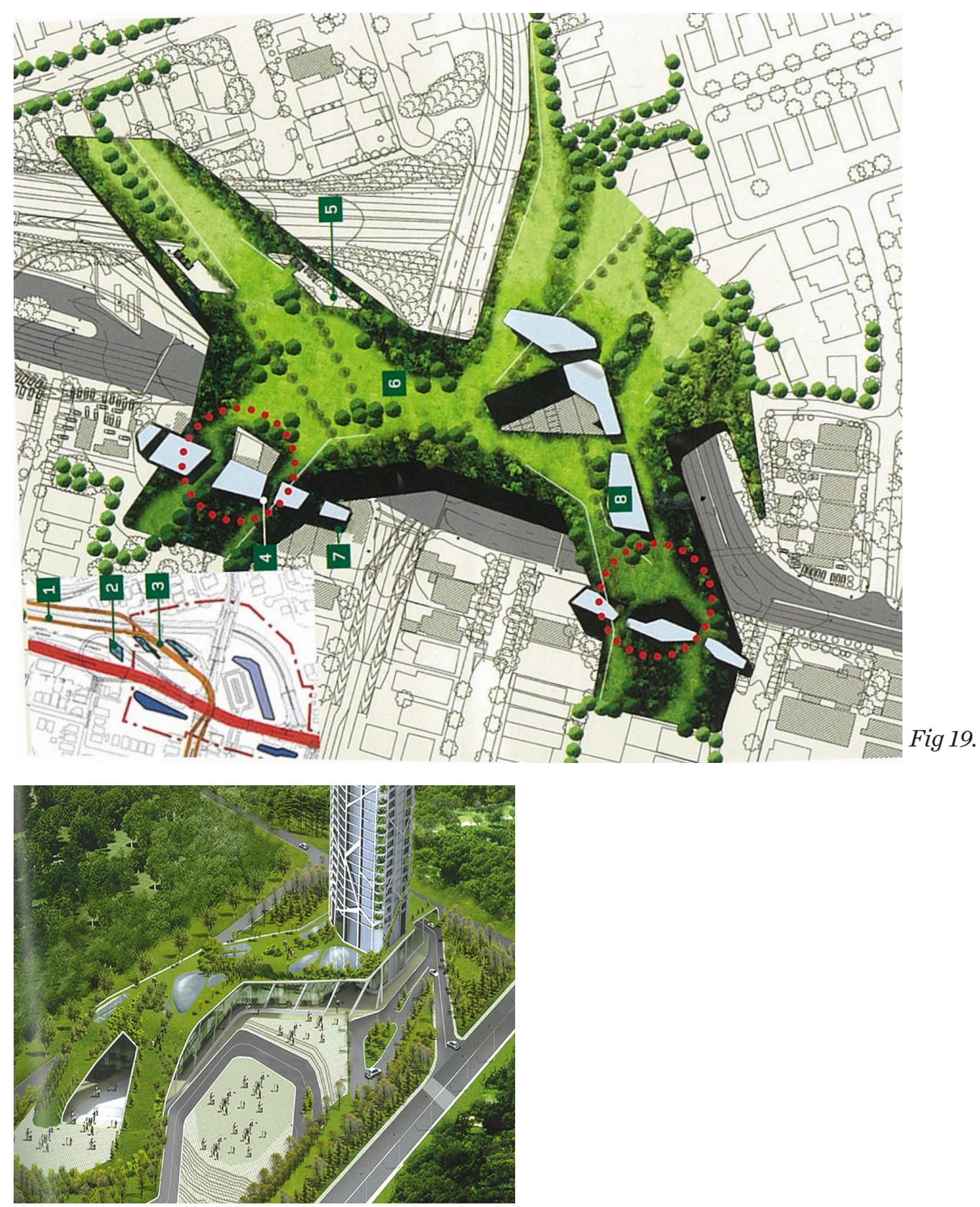

Fig 20. 
THREE 


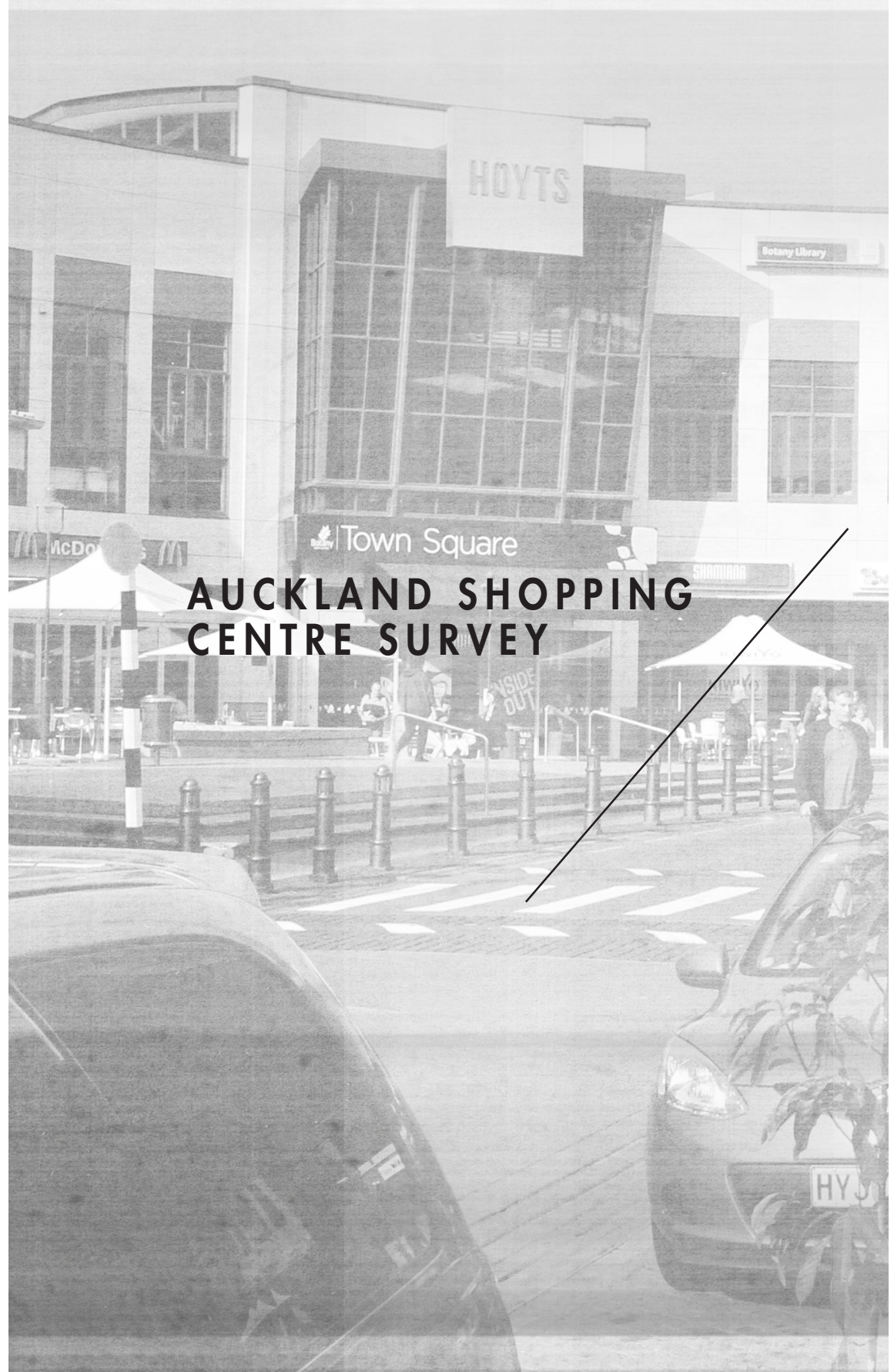


a. Abany Westfield

b. Milford Shopping Centre

c. Glenfield Westfield

d. Shore City

e. Highbury Shopping Centre

f. Westgate

g. Westcity Westfield

h. Waitakere Mega Centre

i. Kelston Shopping Centre

j. Lynn Mall

k. St Lukes Westfield

l. Mt Roskill Mega Centre m. Newmarket Westfield

n. Eastridge

o. Meadowbank Shopping Centre

p. Royal Oak Shopping Centre

q. Onehunga Dressmart

r. Mt Wellington Shopping Centre

s. Apex Mega Centre

t. Sylvia Park

u. Pakuranga Plaza

v. Highland Park Shopping

Centre

w. Shopping Centre

x. Botany Town Centre

y. Botany Junction Centre

z. Mangere Townc Centre

aa. Hunters Plaza

bb. Manukau Supa Centa

cc. Manukau Westfield

dd. Southmall

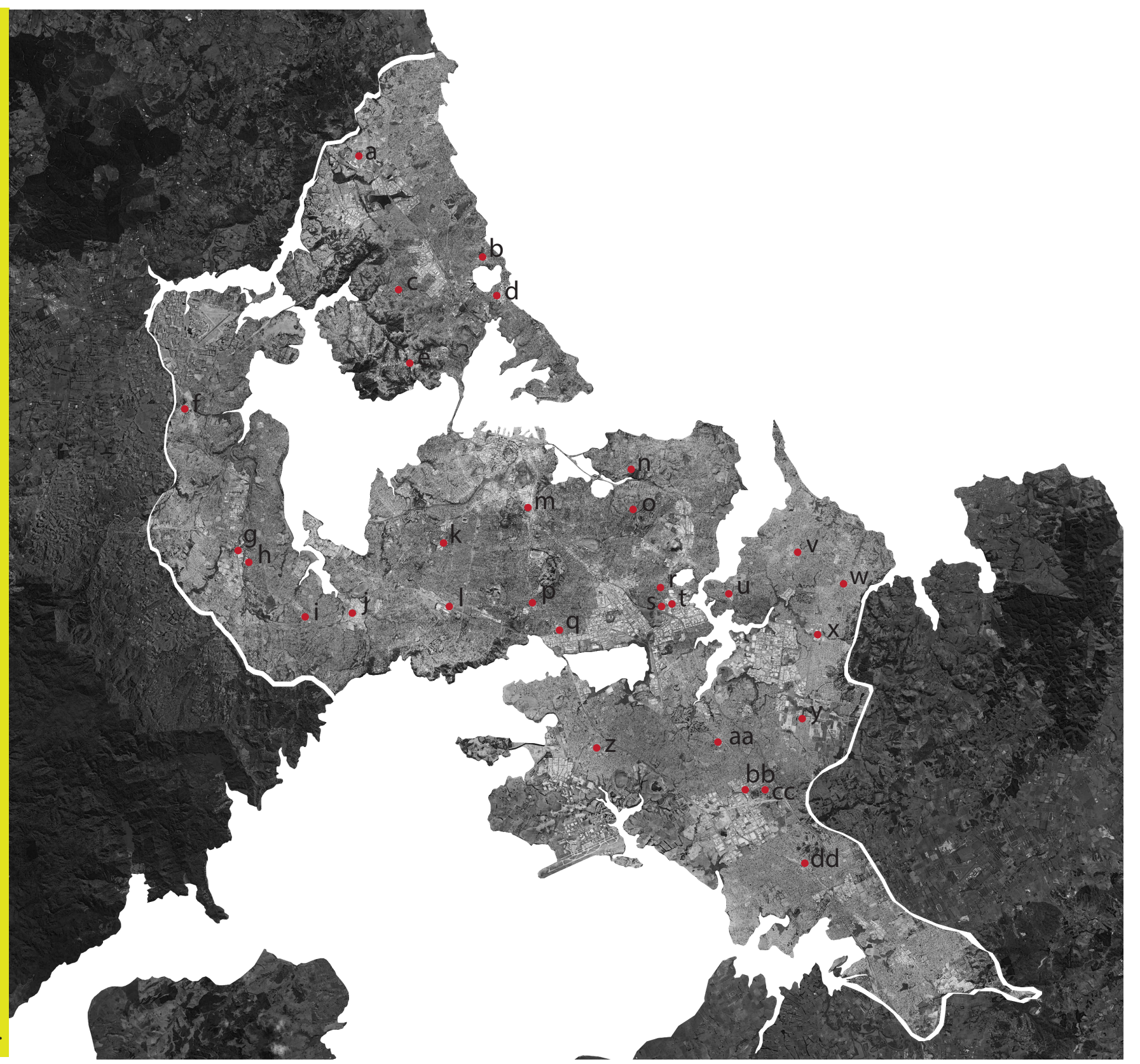




\section{AUCKLAND SHOPPING CENTRE SURVEY}

There are over thirty shopping centres located in Auckland City, consisting of small neighbourhood shopping malls, district shopping centres and mega centres (fig21). The first shopping centre built in Auckland was Lynn Mall which dates back to the 60 s and was once a thriving place (fig22 \&23). The largest centre is Sylvia Park opened in 2007 and boasts over 70,000m2 of retail space. Their lack of urban design principles and good quality architecture is contributing to the existing uneventful suburbia.

This typology can't be ignored and requires a creative response to make them integrate better into their context. In the survey the thirty shopping centres were analysed throughout the region, mapping out transport networks, open and green spaces and other existing amenities (education, shopping \& utility facilities) within a $5 \mathrm{~km}$ radius of the selected centre. A 500m radius figure-ground analysis was also undertaken to investigate the relationship between the shopping centre and its built context.

Each centre has different on-site conditions such as surrounding land use, site area, natural amenities and proximity to railway, motorways, main arterial roads, existing shopping centres and town centres etc. Therefore, each centre requires a different design strategy dependent on these factors. The survey establishes a starting point for the thesis, exploring potential sites to test design strategies. The full survey appears in the next page, four examples are provided on the following pages as illustrations.

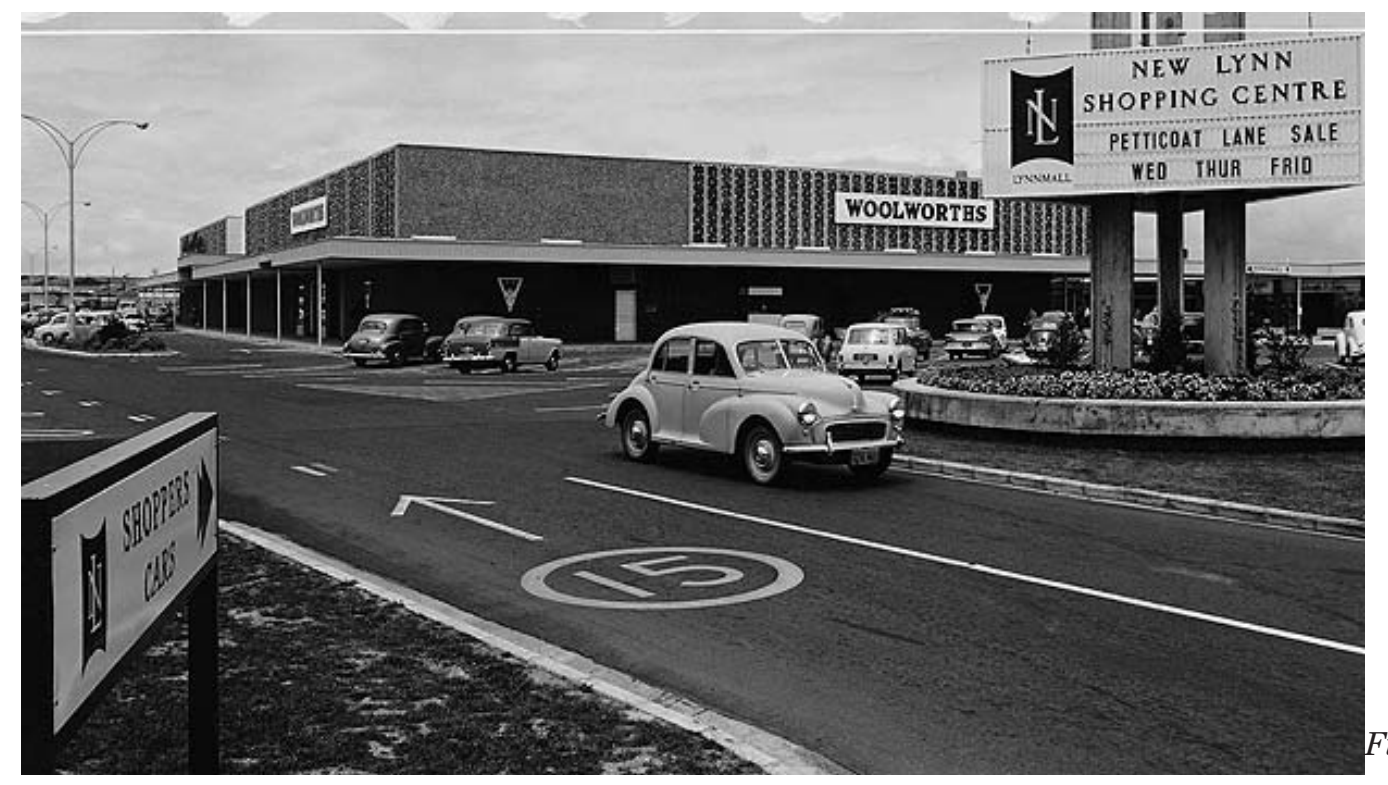

ig 22.

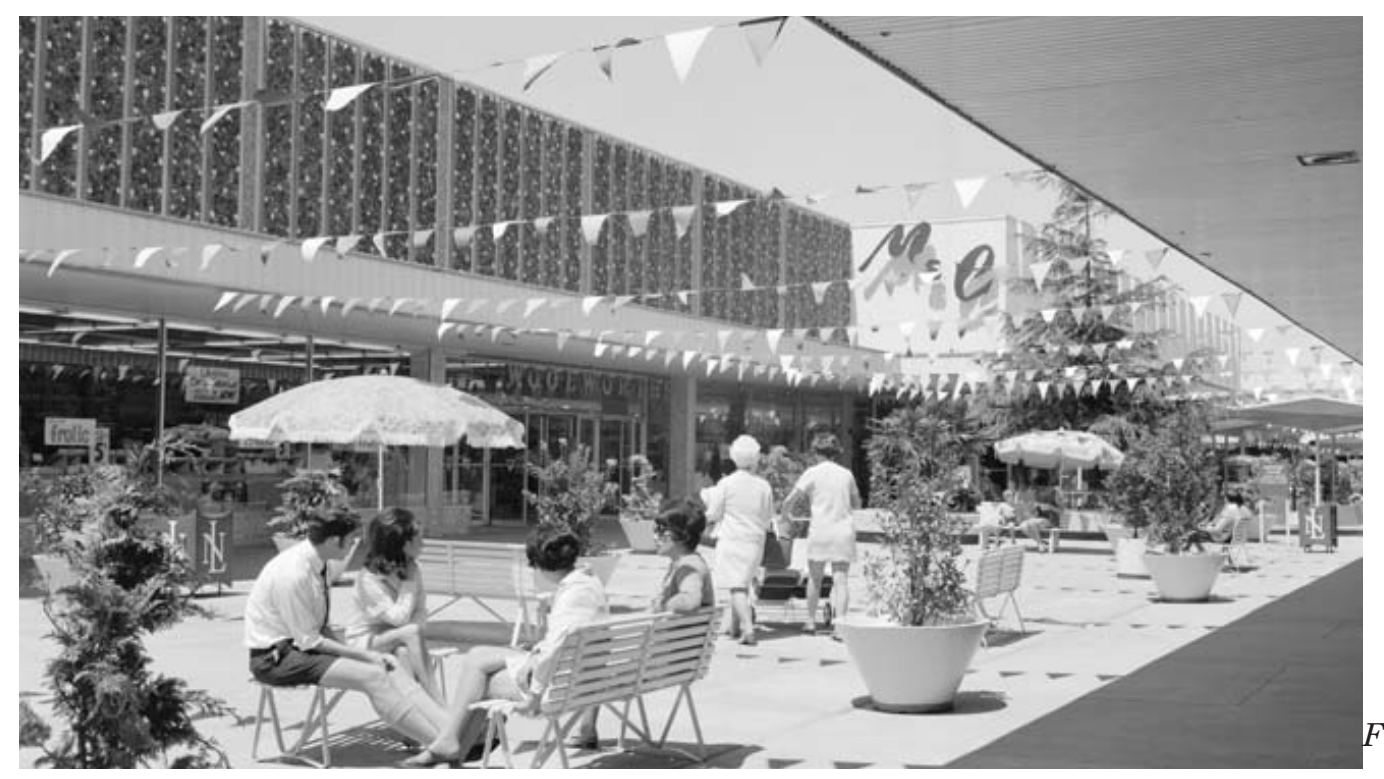

Fig 23. 


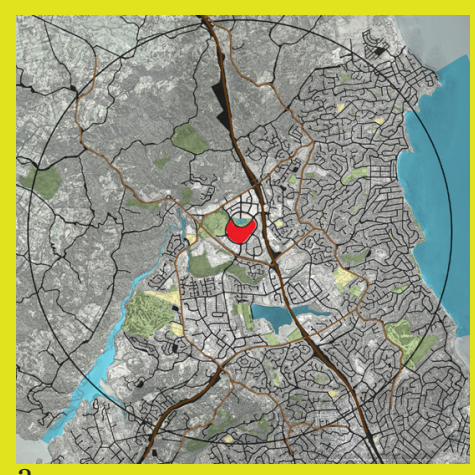
a.
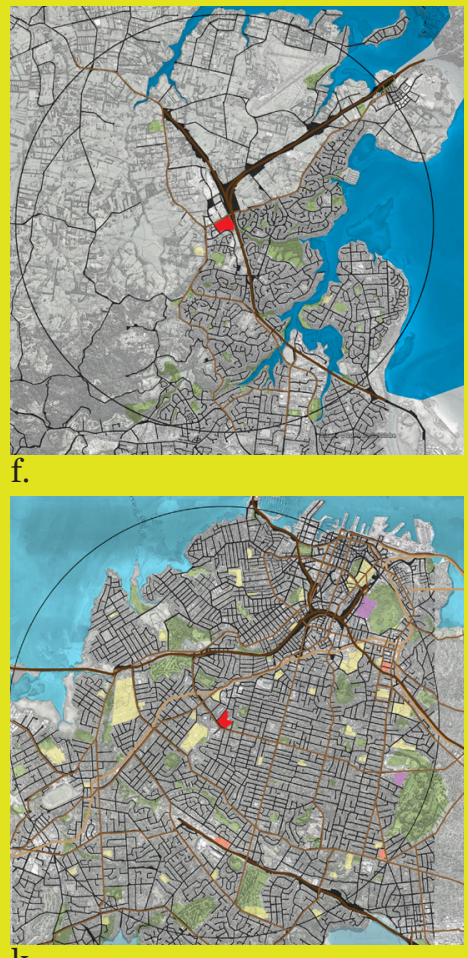

a. Abany Westfield

b. Milford Shopping Centre

c. Glenfield Westfield

d. Shore City

e. Highbury Shopping Centre

f. Westgate

g. Westcity Westfield

h. Waitakere Mega Centre

32

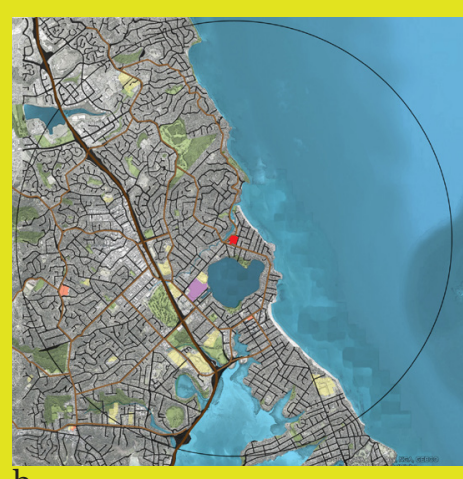

\begin{abstract}
b.
\end{abstract}
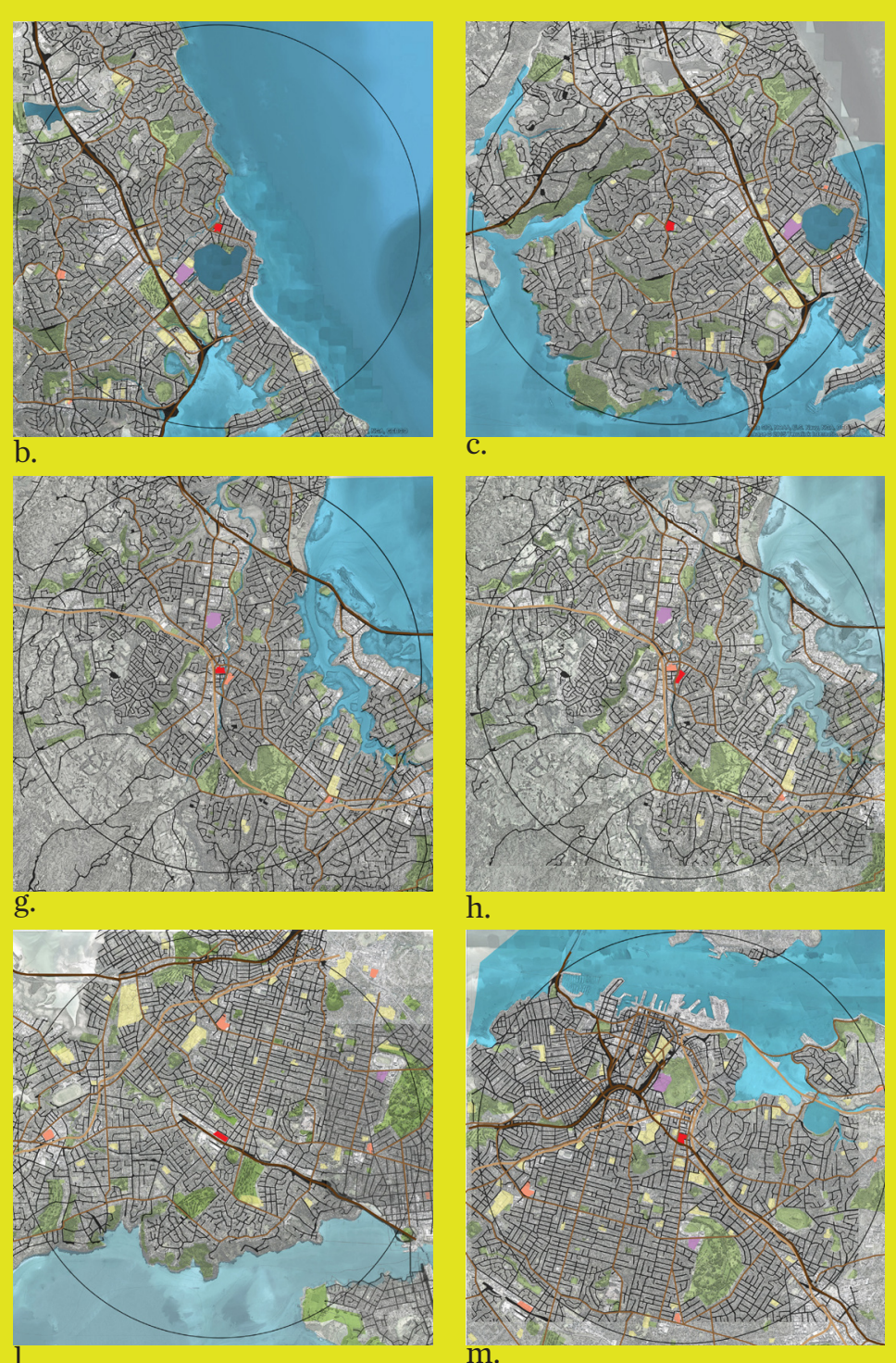

h.

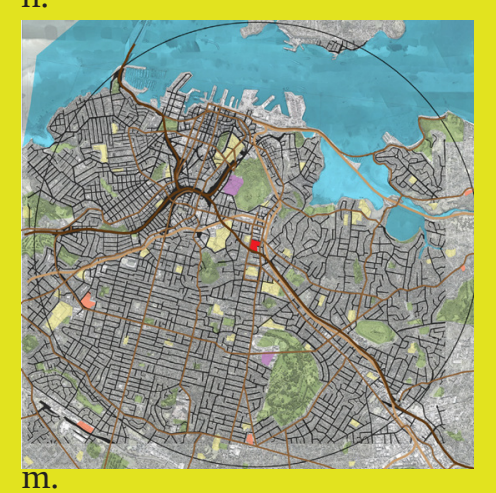

i. Kelston Shopping Centre

j. Lynn Mall

k. St Lukes Westfield

l. Mt Roskill Mega Centre

m. Newmarket Westfield

n. Eastridge

o. Meadowbank Shopping Centre

p. Royal Oak Shopping Centre

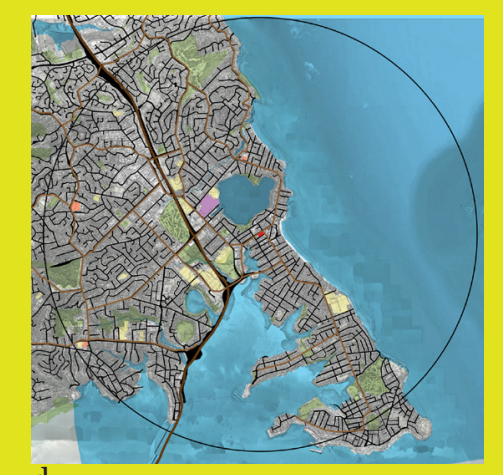

d.
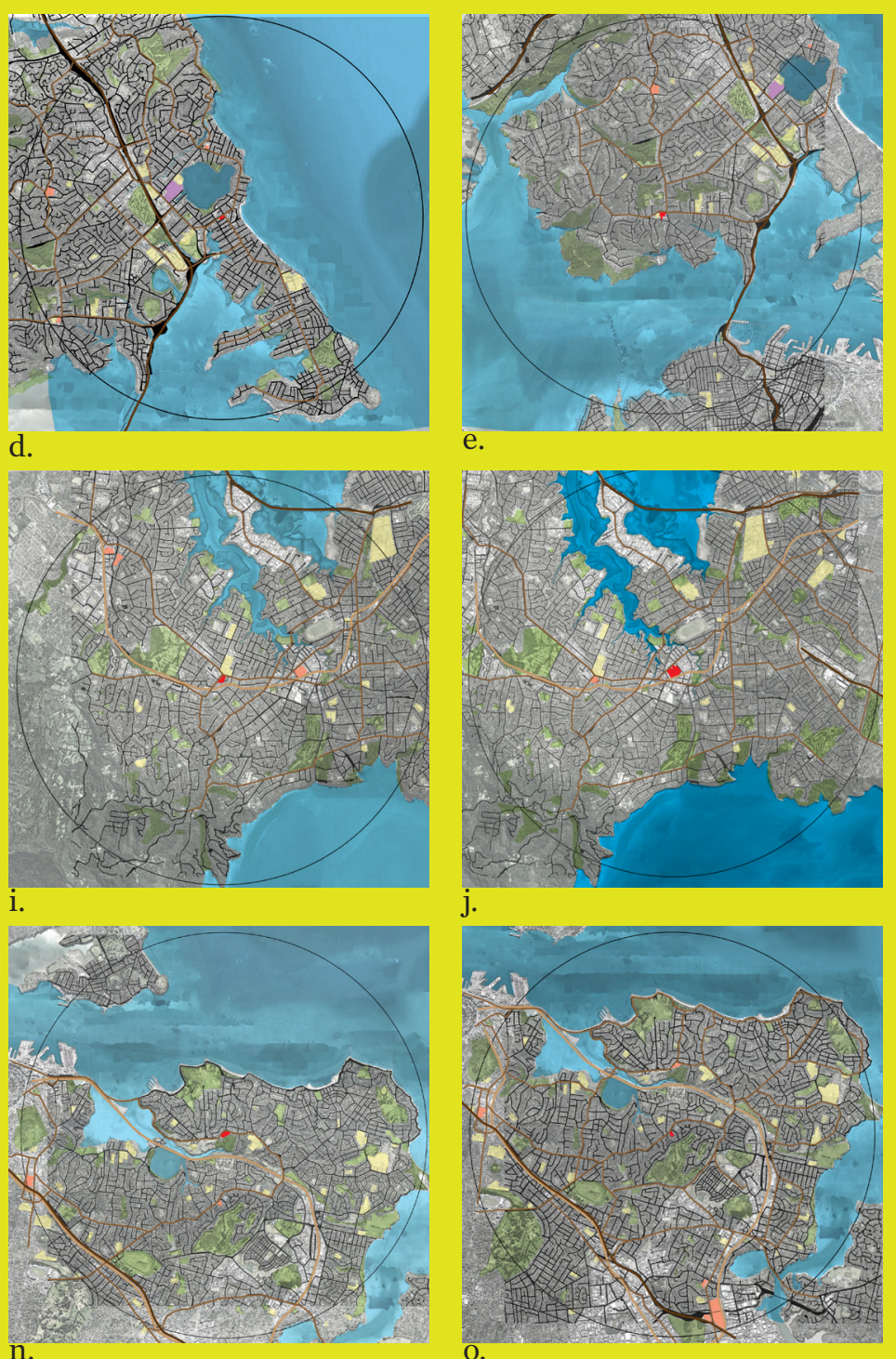

q. Onehunga Dressmart

r. Mt Wellington Shopping Centre

s. Apex Mega Centre

t. Sylvia Park

u. Pakuranga Plaza

v. Highland Park Shopping Centre

w. Meadowlands Shopping Centre

x. Botany Town Centre y. Botany Junction Centre z. Mangere Townc Centre aa. Hunters Plaza

bb. Manukau Supa Centa cc. Manukau Westfield dd. Southmall 

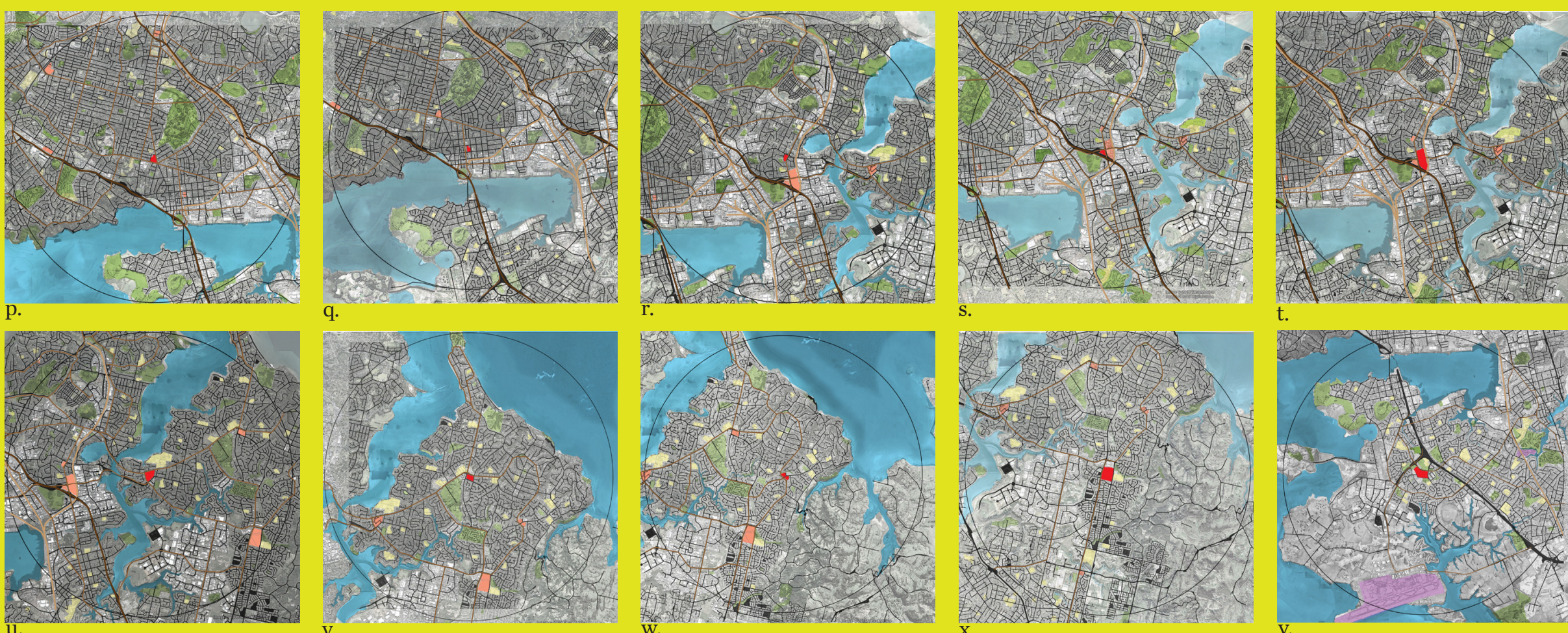
t.
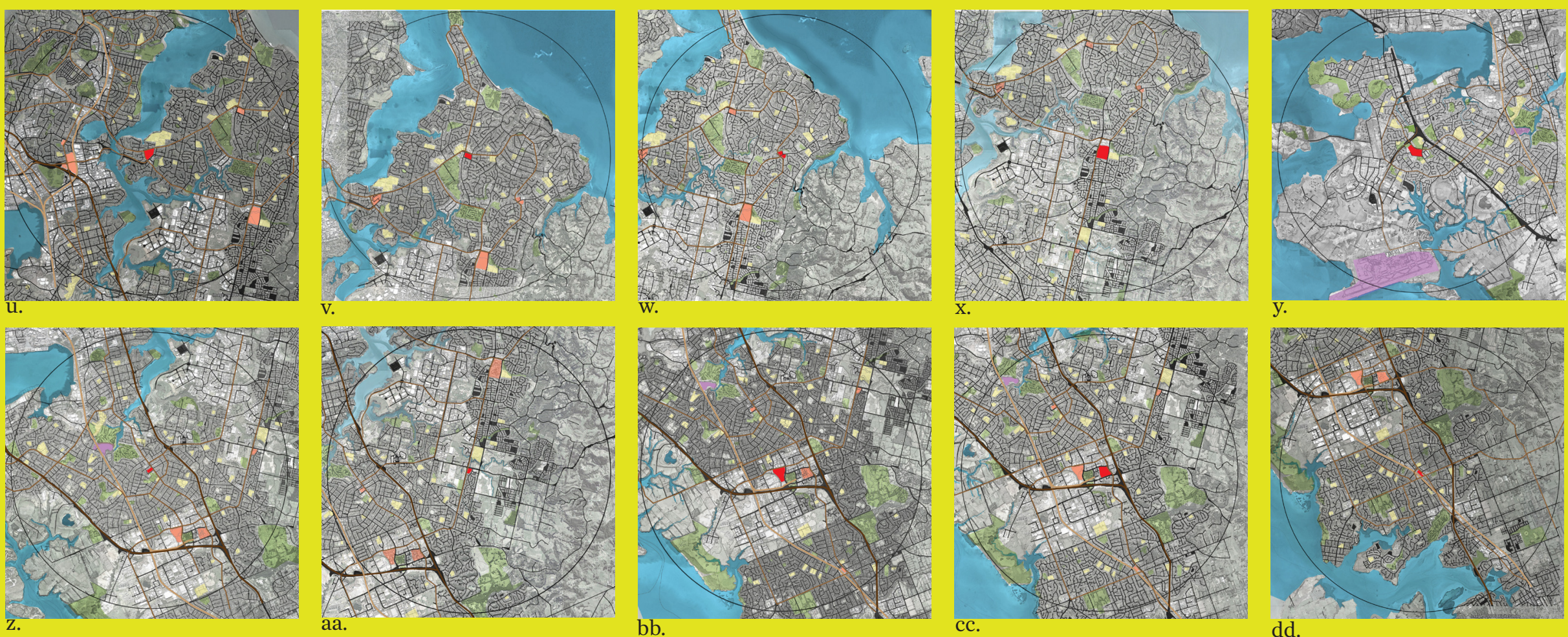

dd.

\section{AUCKLAND SHOPPING CENTRE SURVEY MAPS}

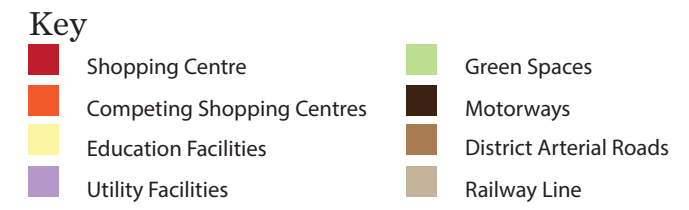

Fig 24. 
$1-1$

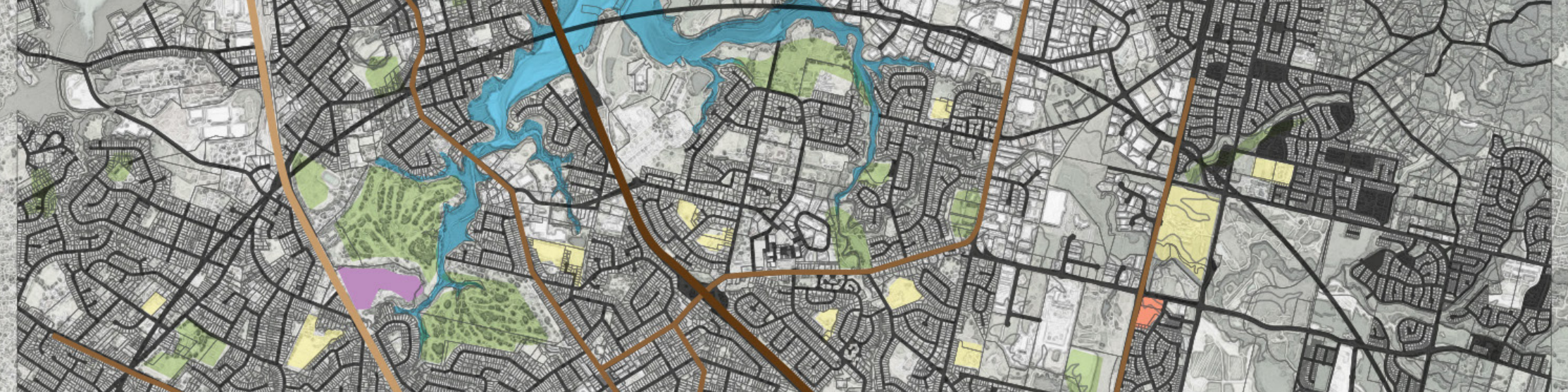

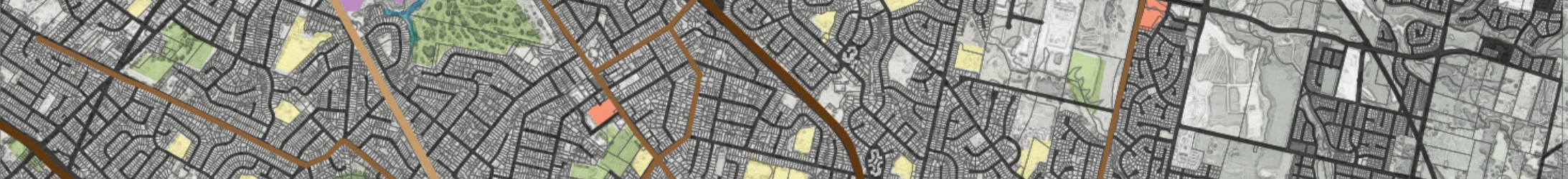

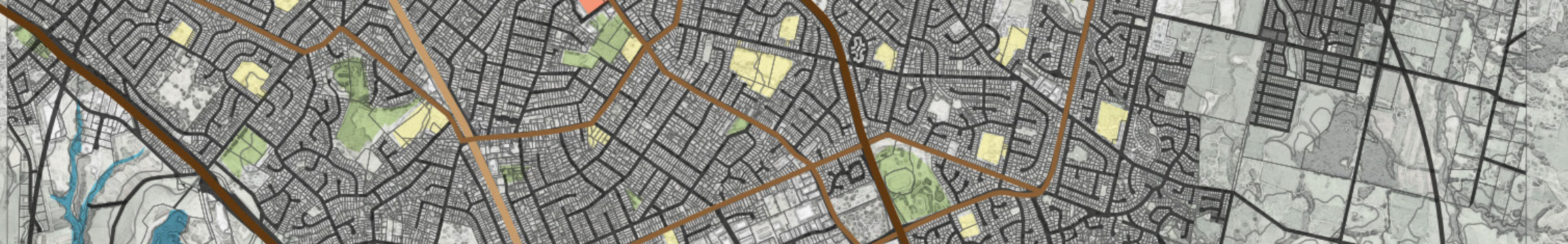

58 (5)

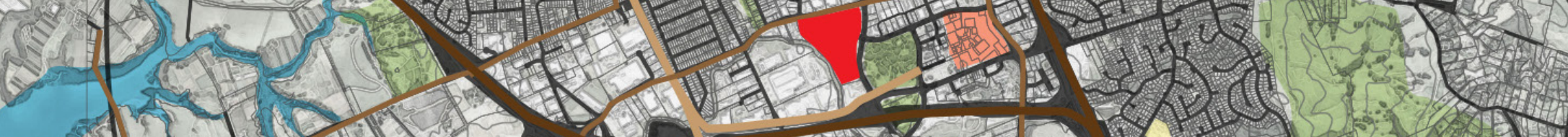

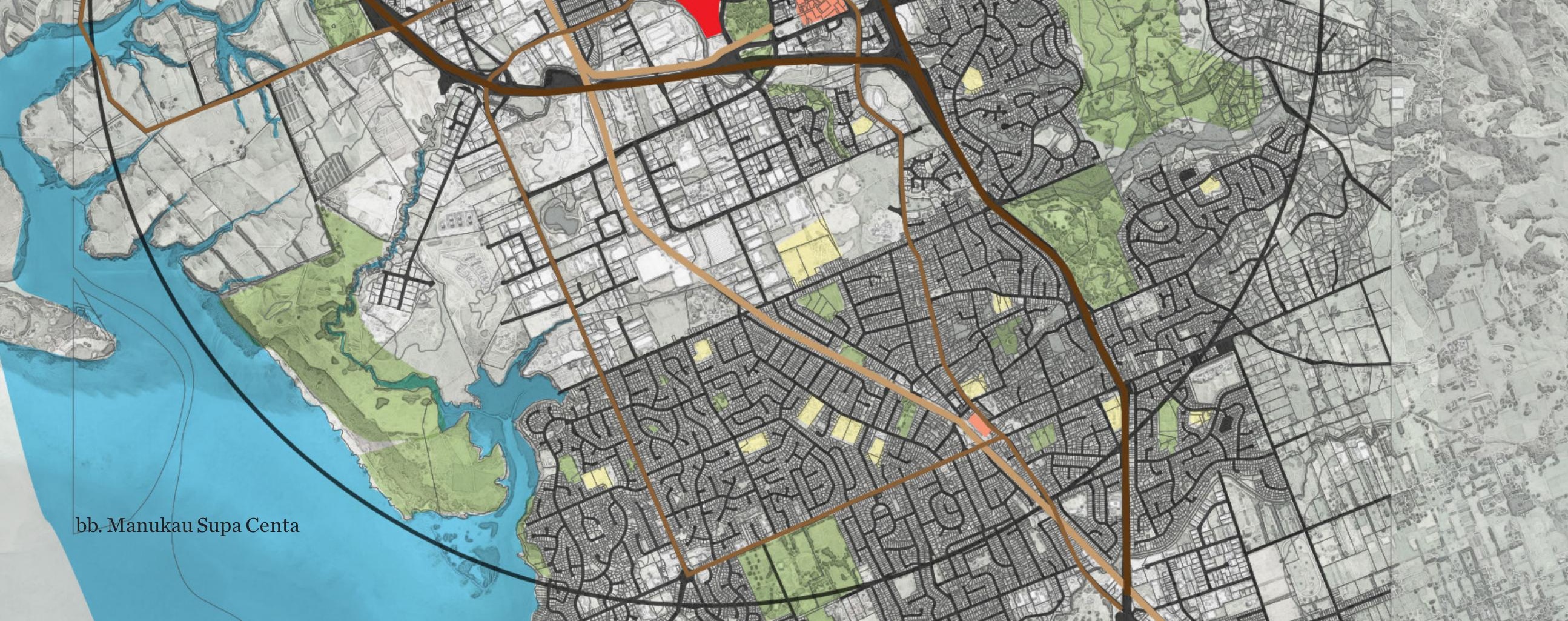



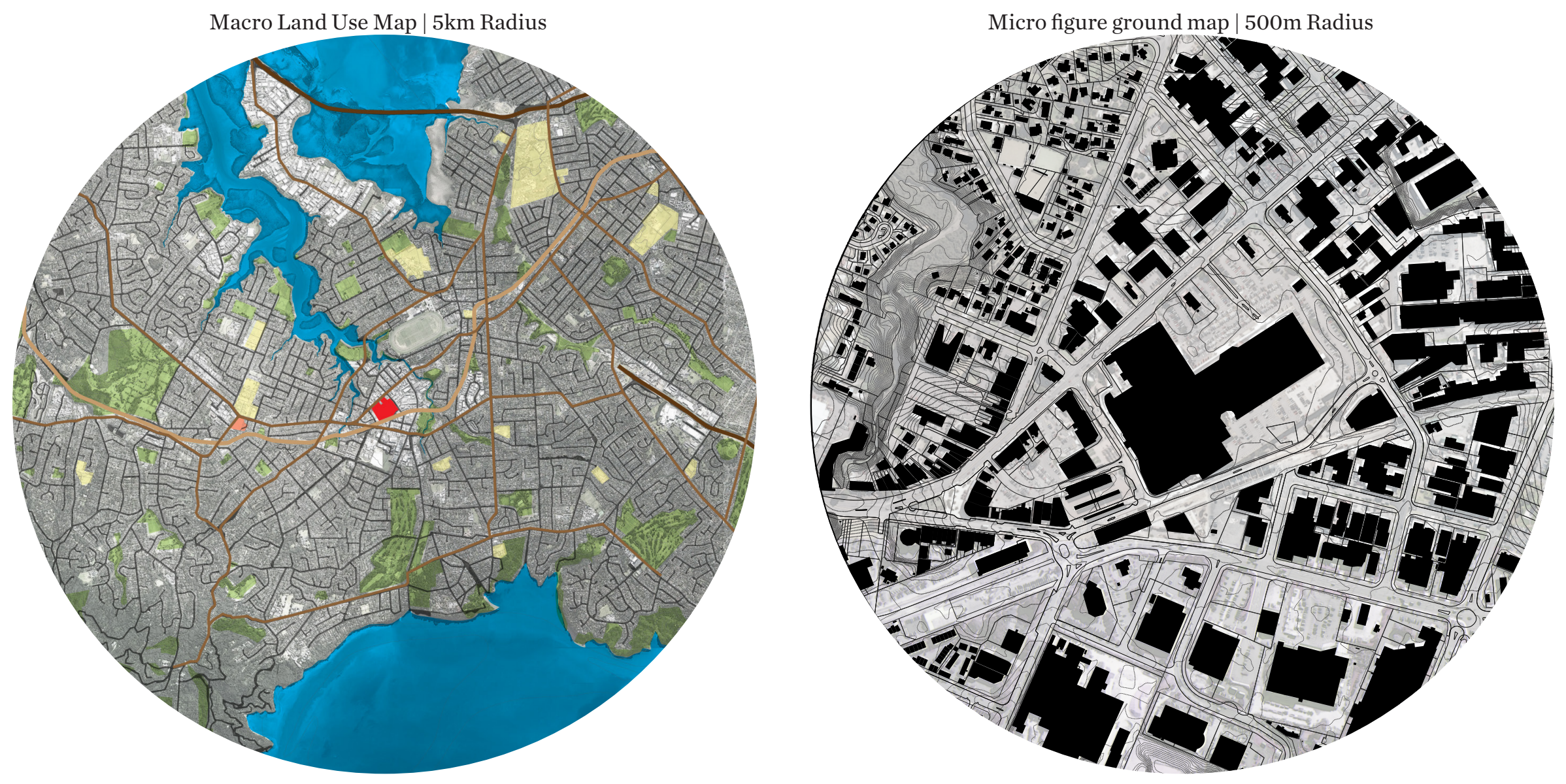

\section{J. LYNN MALL}

- $\quad$ Located in New Lynn 25 minutes from the CBD

- $\quad$ Existing town centre and transit station redevelopment plans

- $\quad$ Surrounding context is predominantly industrial

- Intensification of the site can support the densification plans for the area providing more residential, retail and commercial amenities to this growing business area as well as reconnecting the natural amenities along the north and south coasts.

Key
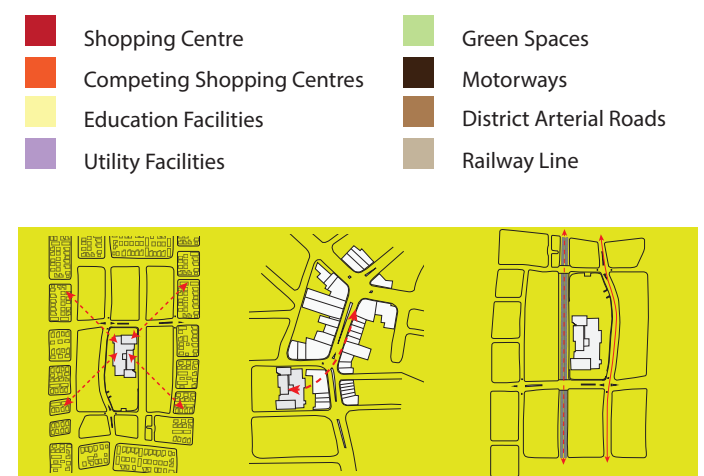


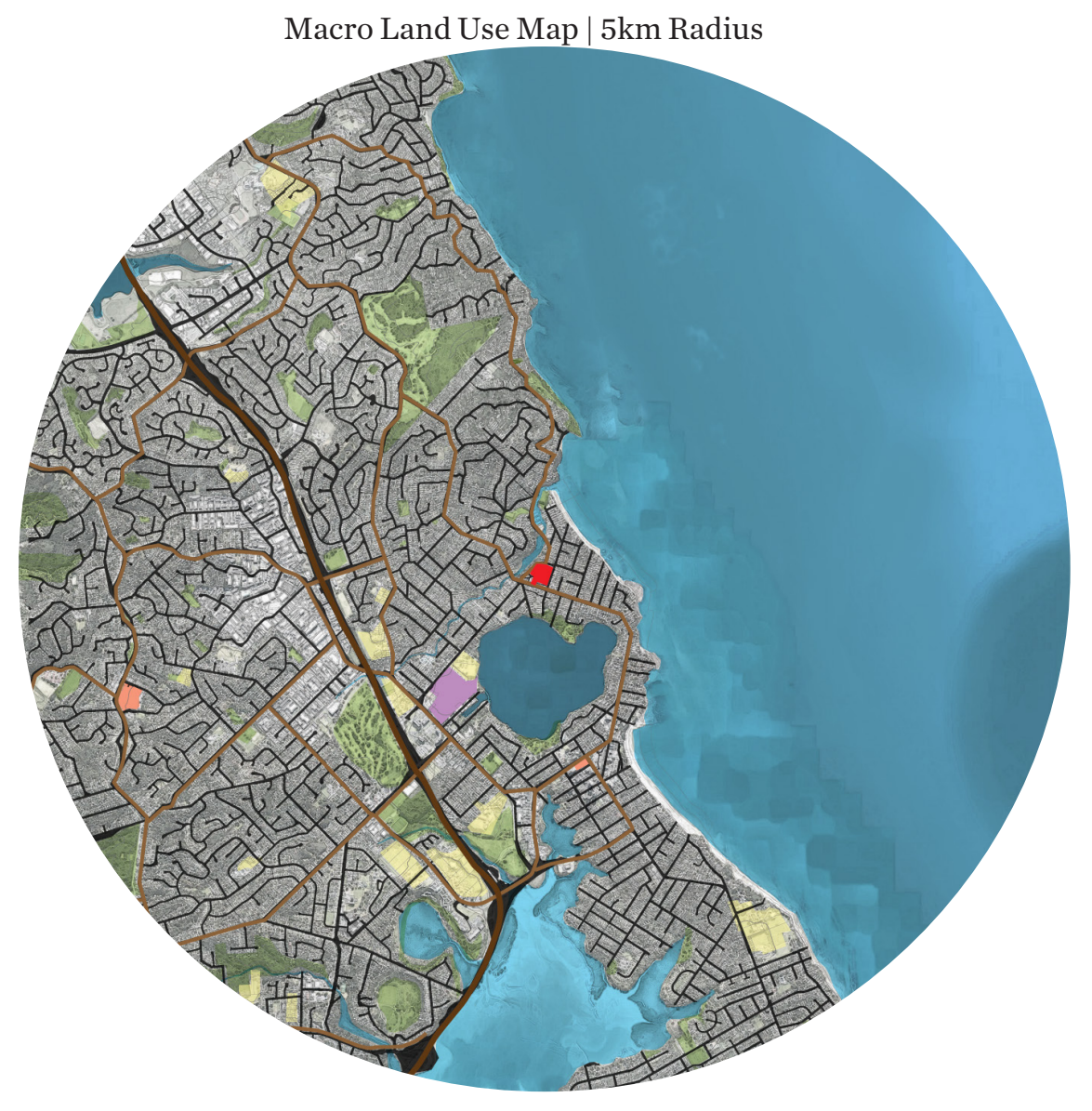

B. MILFORD SHOPPING CENTRE

- $\quad$ Located 10 minutes from central Takapuna on the North Shore

- $\quad$ The site backs on to a natural reserve, Wairua Creek, and is close to Lake Pupuke

- The shopping centre is located behind Milford's town centre

- Intensification can strengthen the natural amenities, creating a link between the creek and lake. Questionable how successful the retail and commercial elements would be due to the close proximity to Takapuna

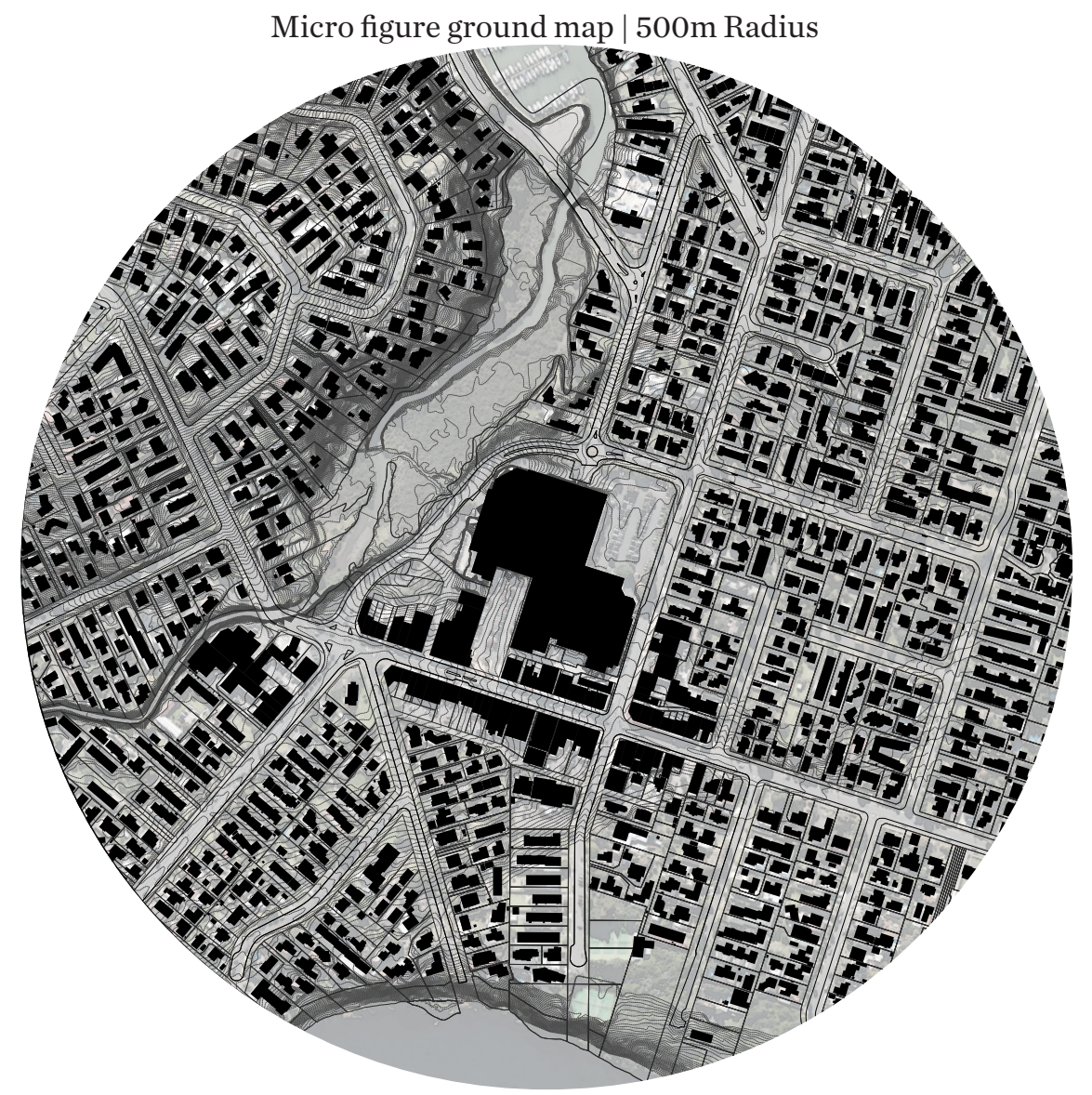

Key
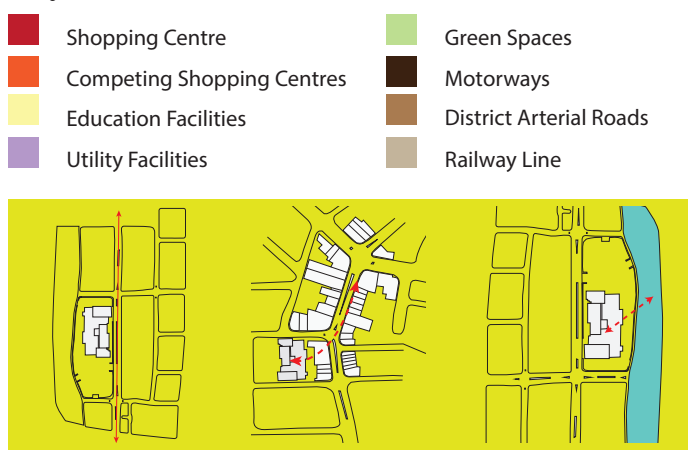


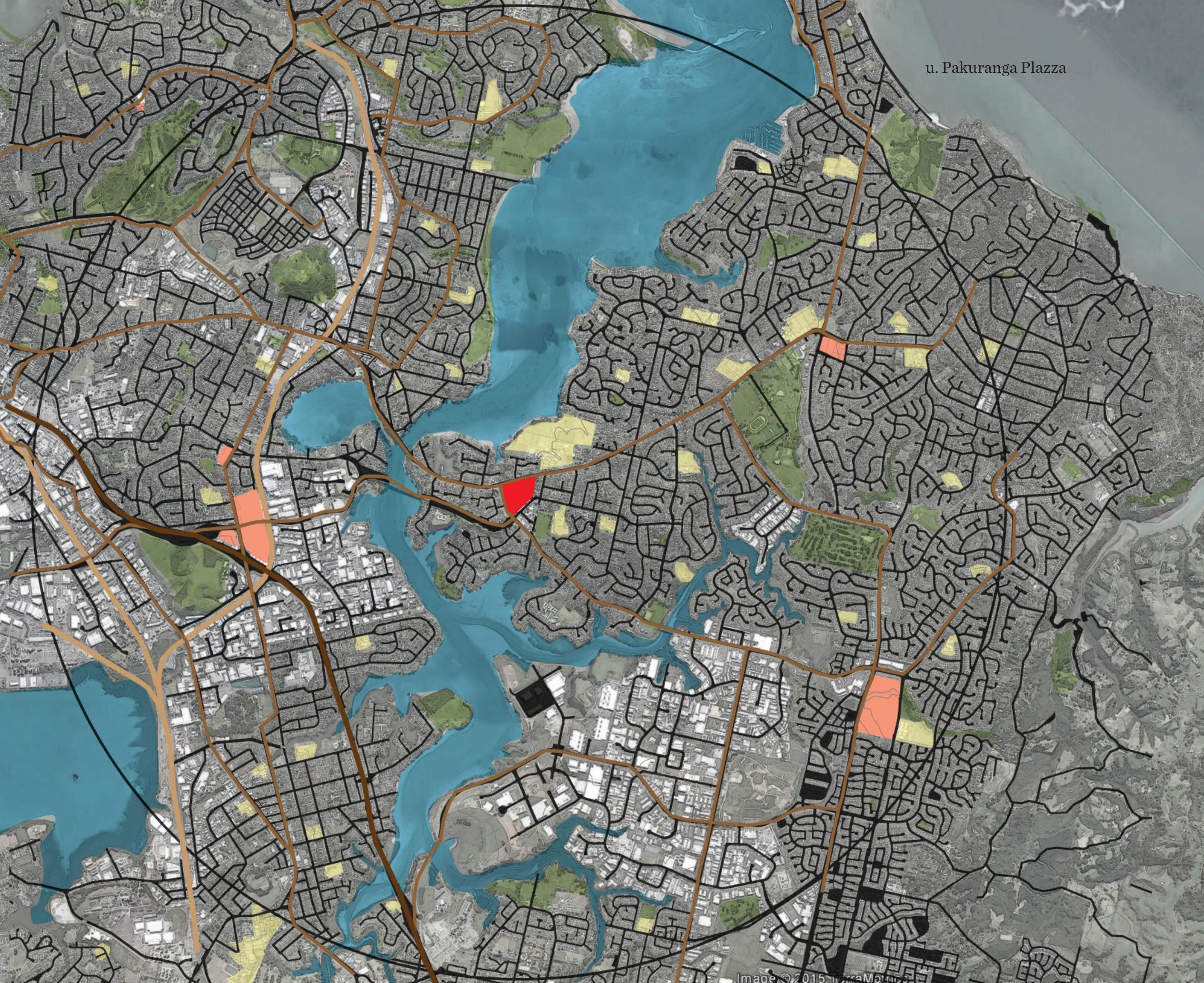




\subsection{SUMMARY}

Seven categories of shopping centres are defined through the survey and each has different implications for the redevelopment of the site.

- Located by railway lines.

- Located at intersection of arterial roads.

- Located along arterial road.

- $\quad$ Positioned next to natural amenities (parks \& waterways).

- $\quad$ Limited residential zones surrounding centre.

- $\quad$ Positioned next to motorway off-ramp.

- Located within an existing town centres.

The majority of centres fall within the 'located at the intersection of arterial roads' category due to the efficiency of arterial roads moving heavy traffic volumes, providing accessibility for many people.

Literature favours the category 'located by railway lines', because the stations create good hubs for transit orientated development. Vehicle miles traveled are reduced as commuting on the train becomes more convenient. However, only six centres are in this category, therefore investigating centres along arterial roads are more relevant in suburban Auckland.

The category 'positioned next to motorway offramp' is not explored in this thesis because of the significant issues of disconnection the motorway creates, and only three centres are in this category.

The 'located within existing town centres' category is also not explored in this thesis. The category is outside the scope of research because the redevelopment of the shopping centre site is directed towards supporting the existing town centre and not creating a new suburban centre.

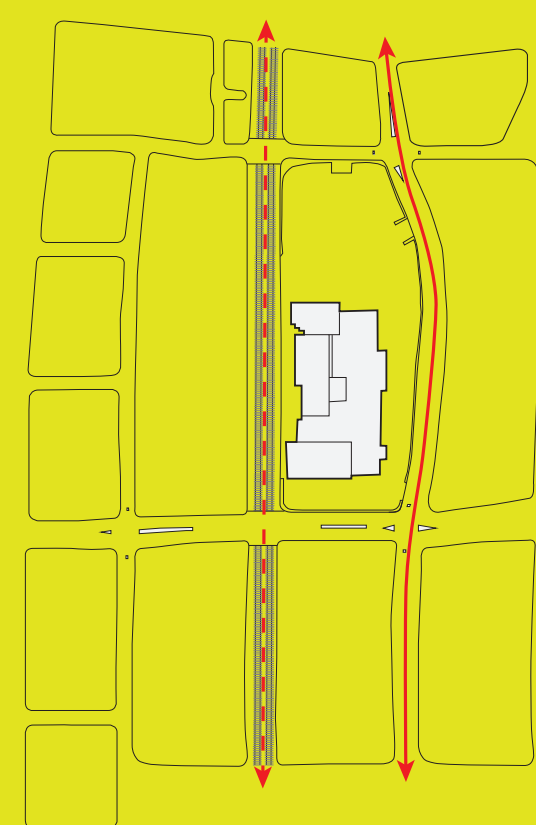

Railway

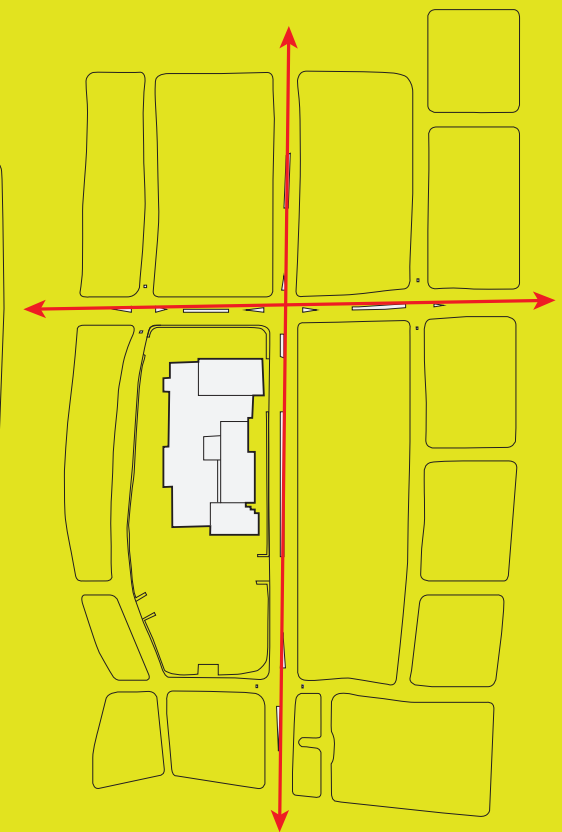

Intersection Arterial Road

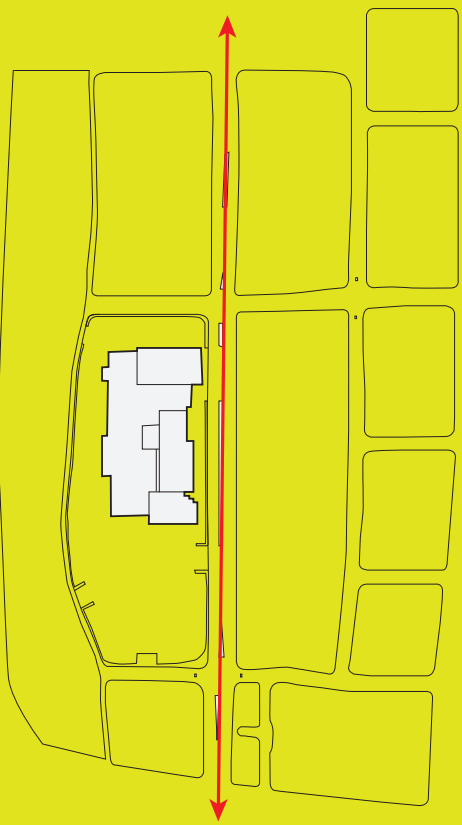

Arterial Road 


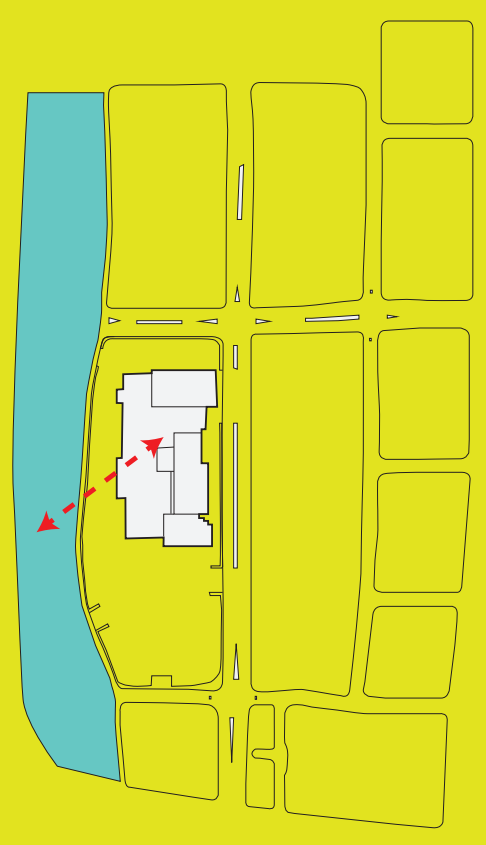

Natural Amenities

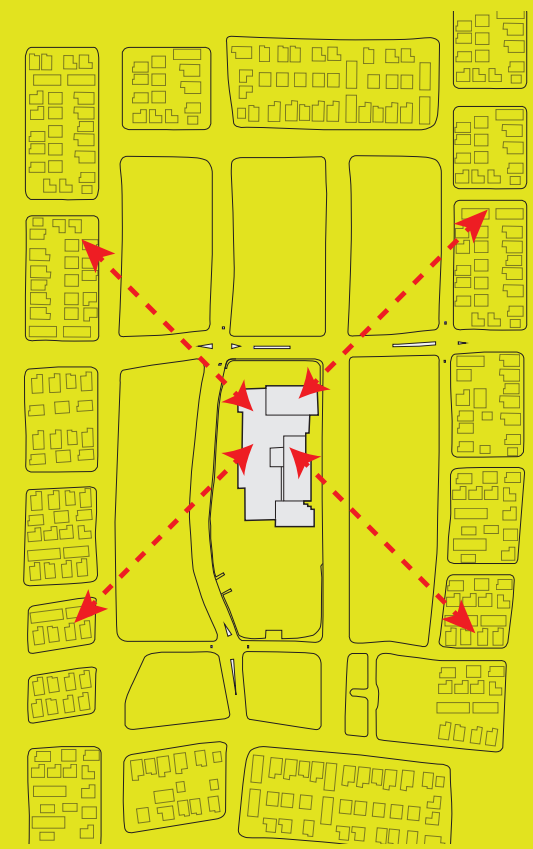

limited residential

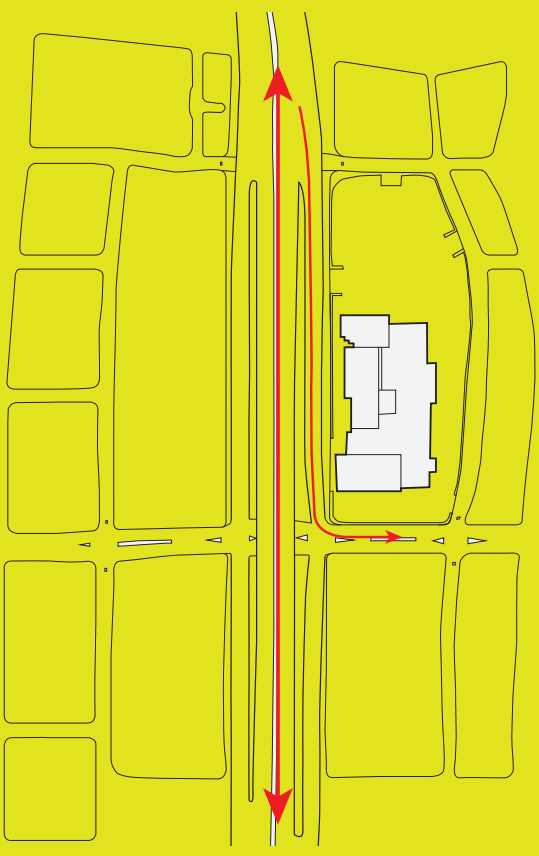

Motorway offramp

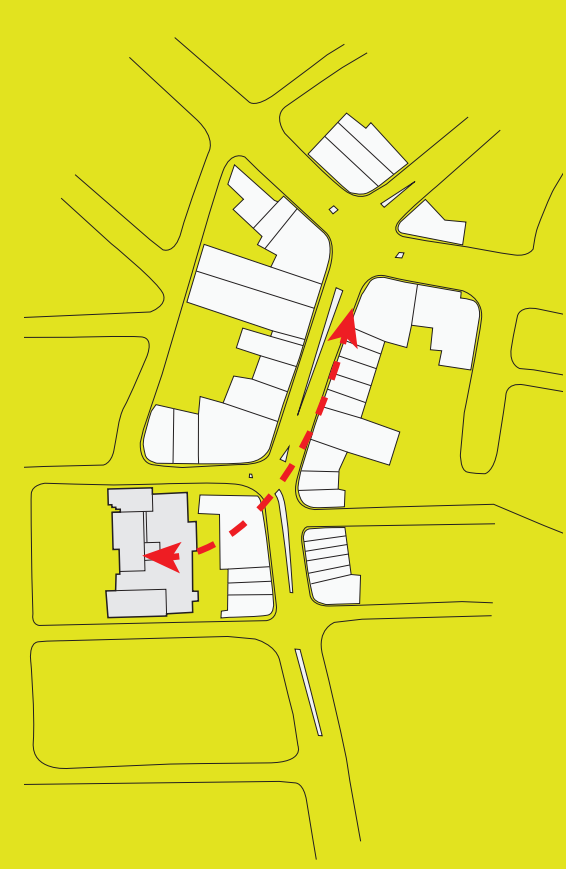

Existing Town Centre 

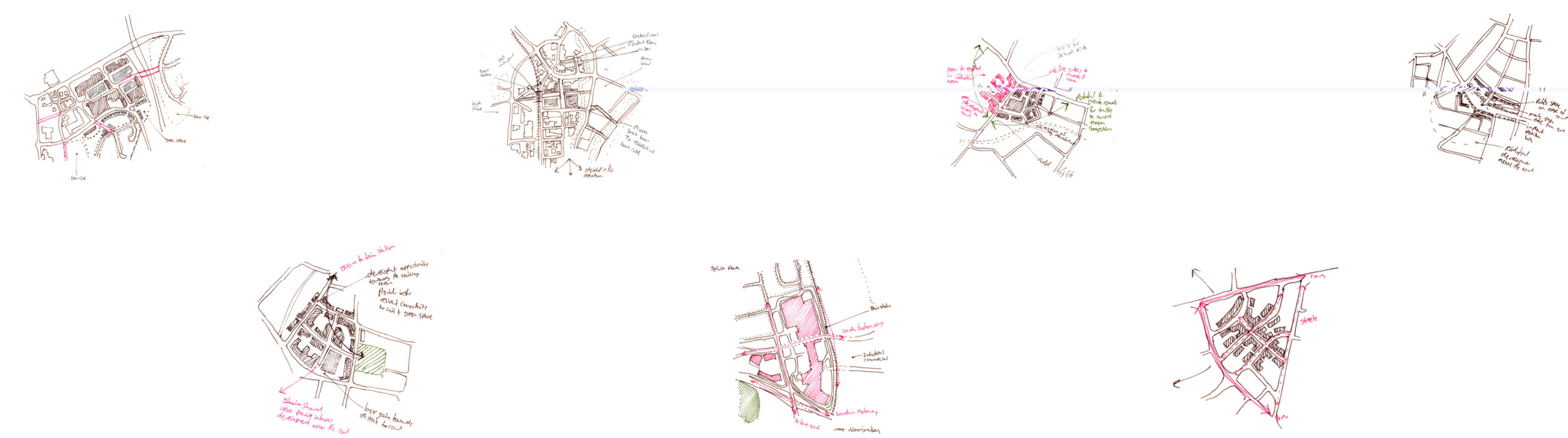

PRELIMINARY DESIGN A
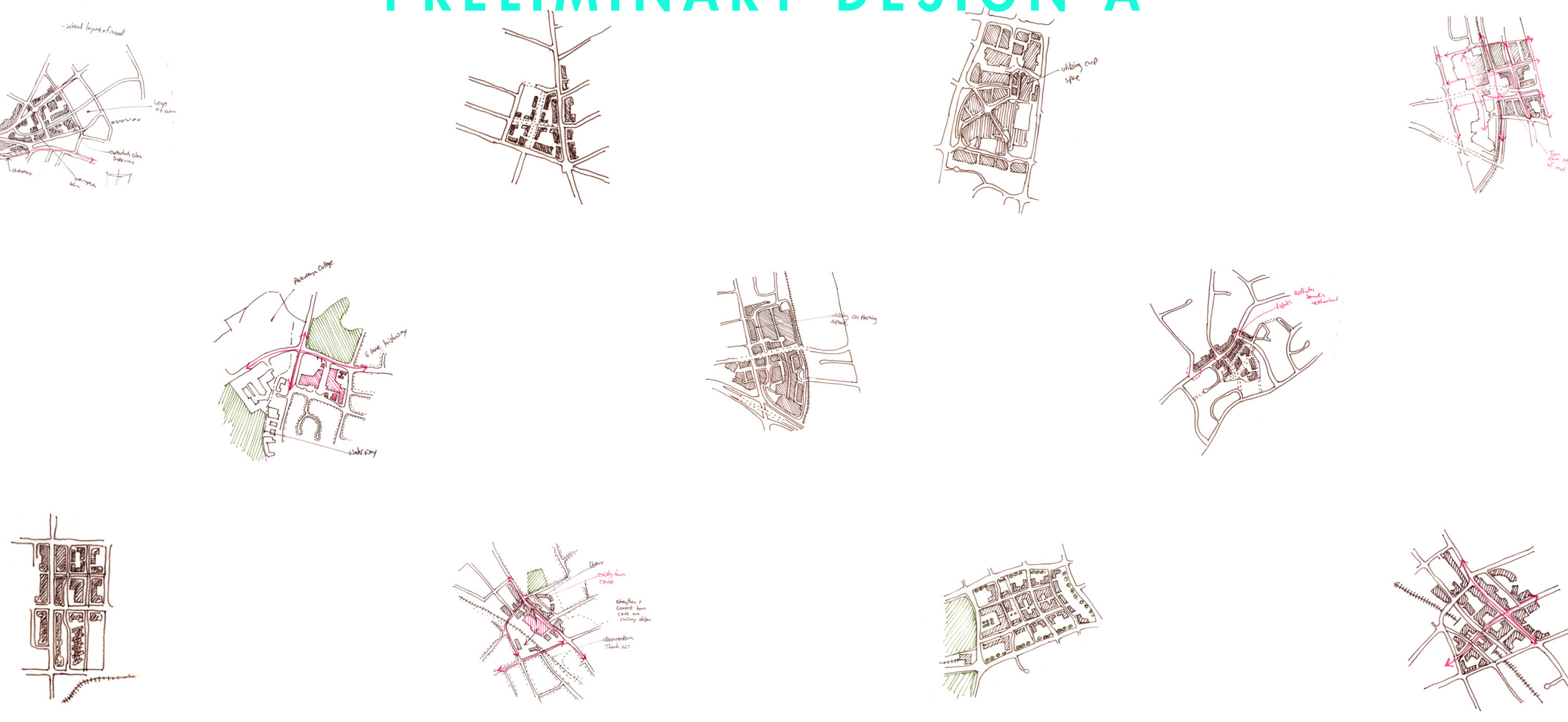


\section{SURVEY SKETCH PLANNING}

This chapter explores strategies for breaking up the shopping centre's large mass and activating the context for intensification. The analysis includes sketch masterplanning of ten of the centres. 


\section{MILFORD SHOPPING CENTRE (B)}

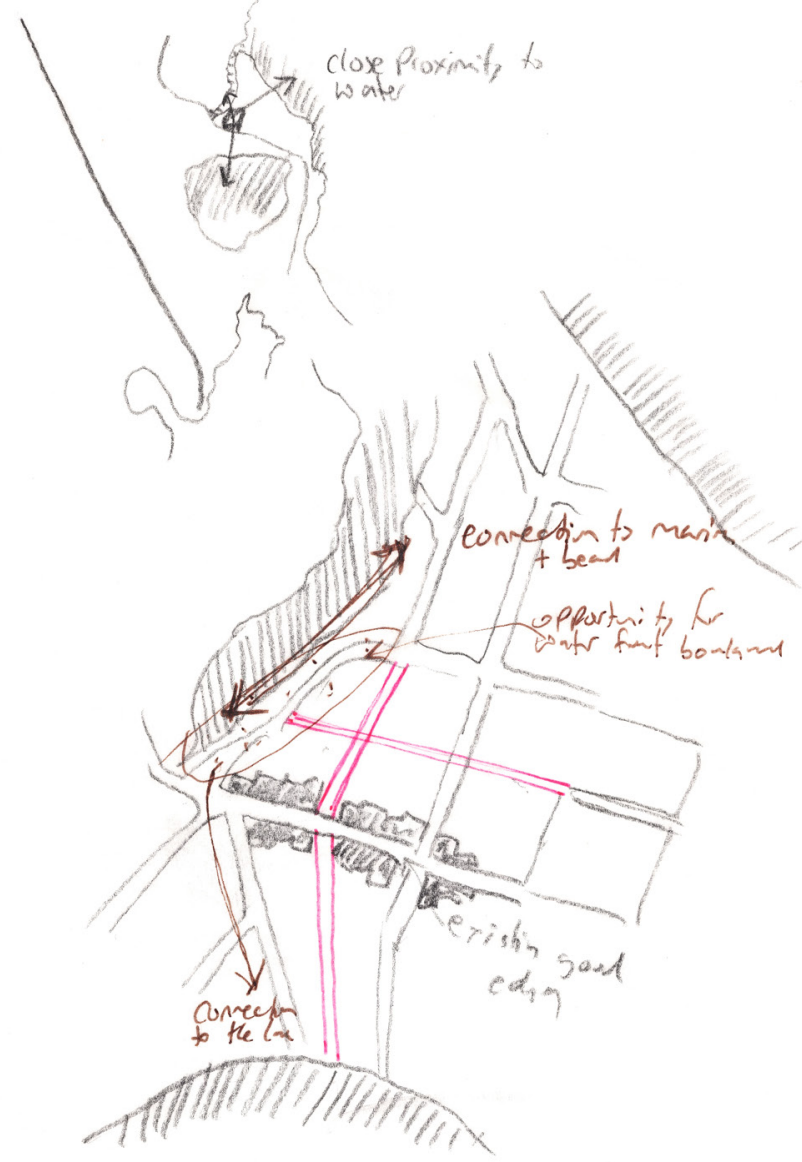

WAITAKERE MEGA CENTRE (H)
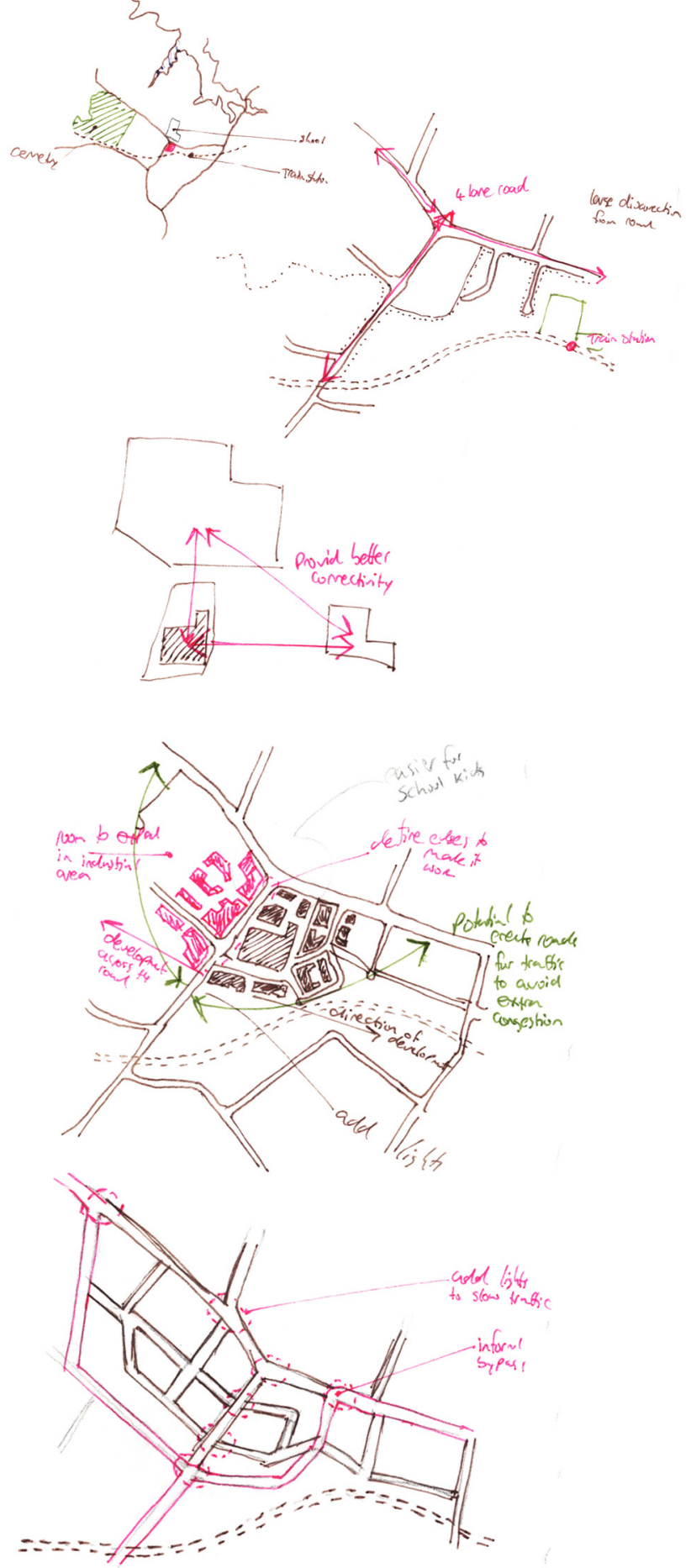
KELSTON SHQPPING CENTRE (I)

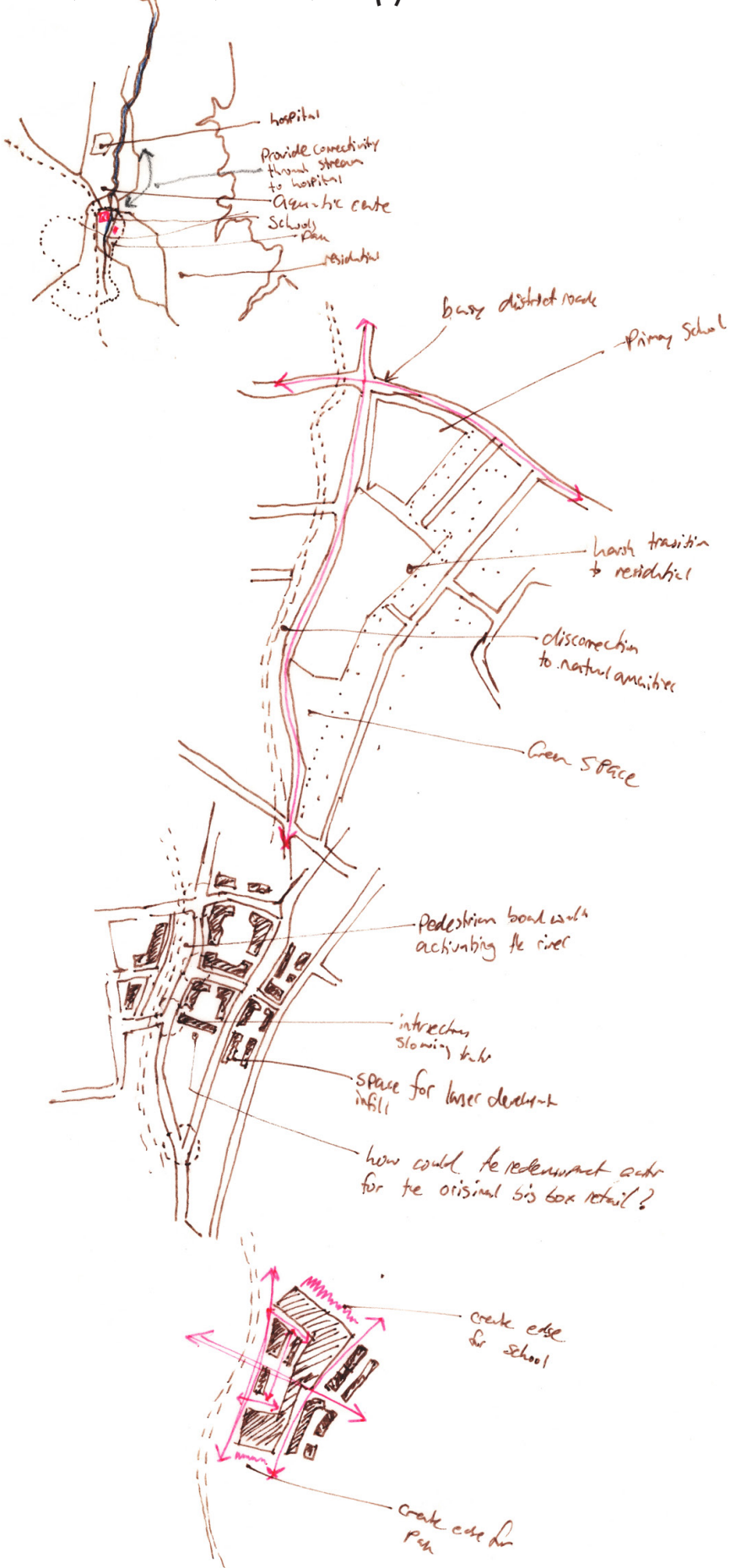

\section{ST LUKES WESTEJELD (K)}
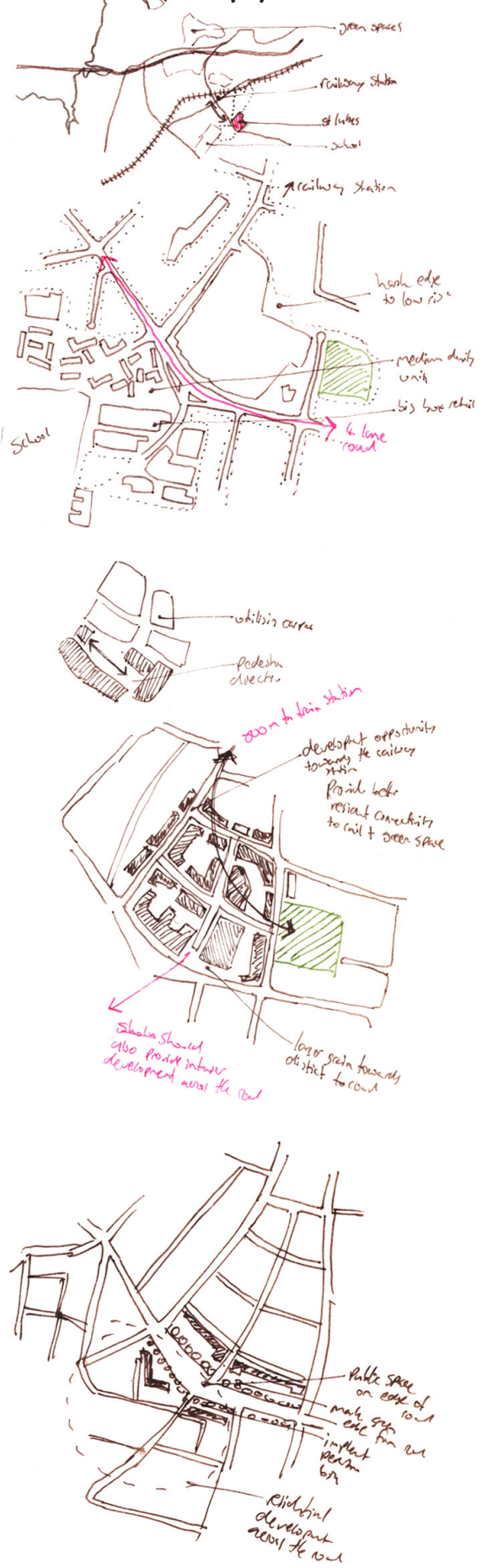


\section{ROYAL OAK SHOPPING CENTRE (P)}

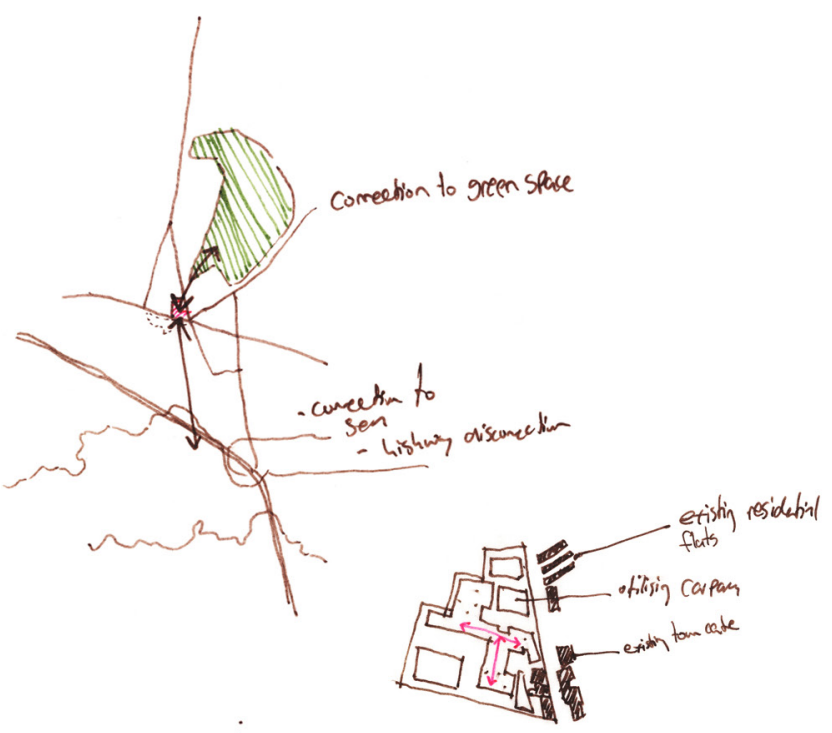

\section{PAKURANGA PLAZA (U)}
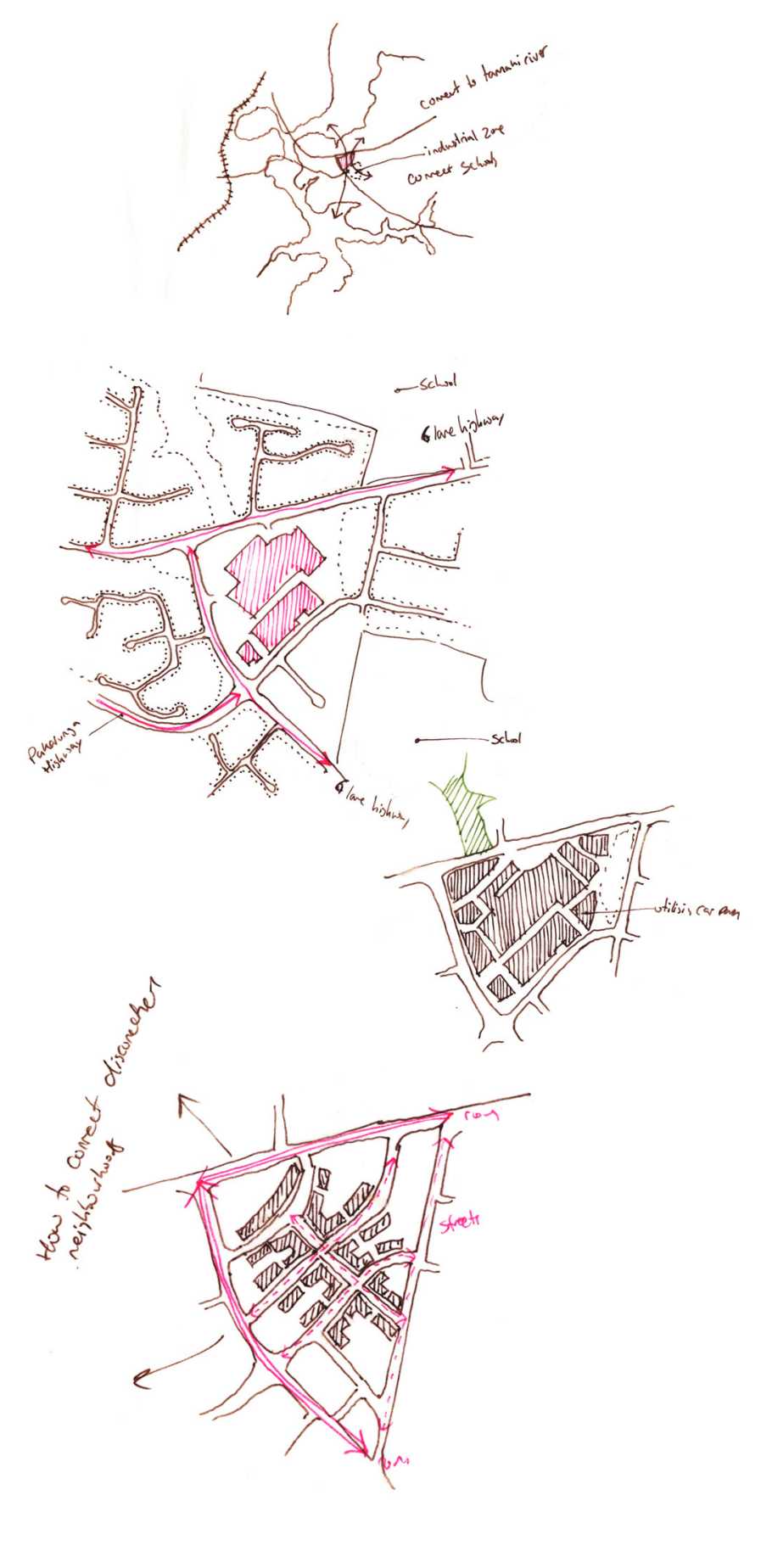

education
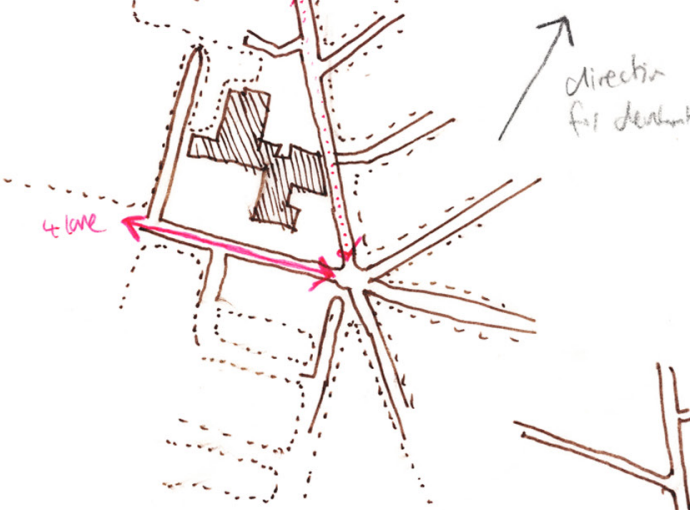

$+1$
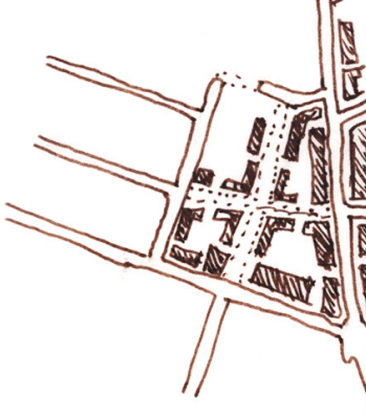

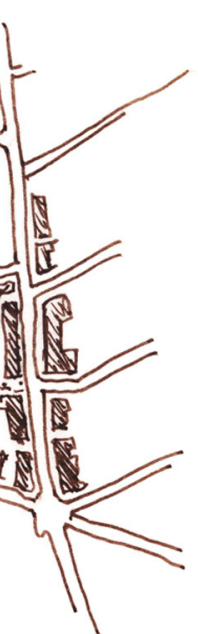


HIGHLAND PARK SHOPPING CENTRE (V)
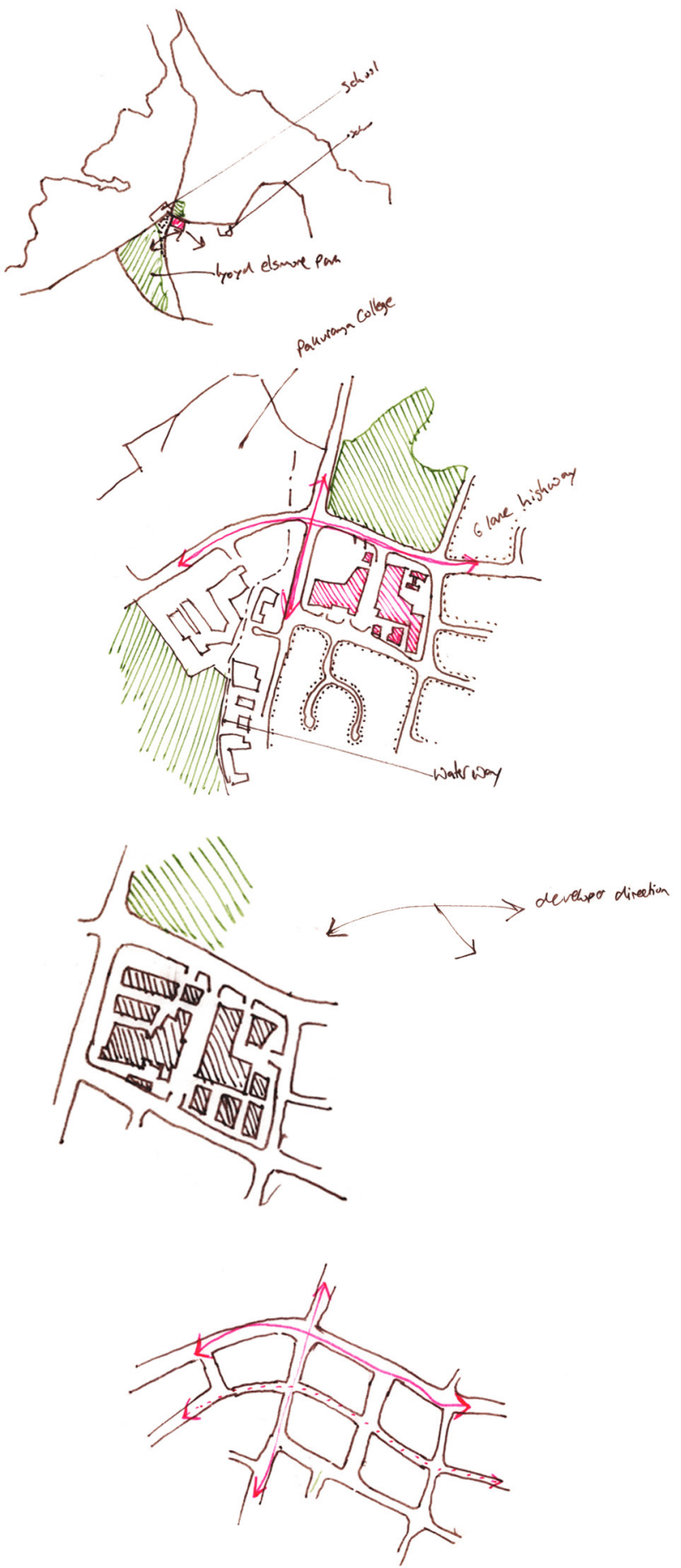

BOTANY TOWN CENTRE
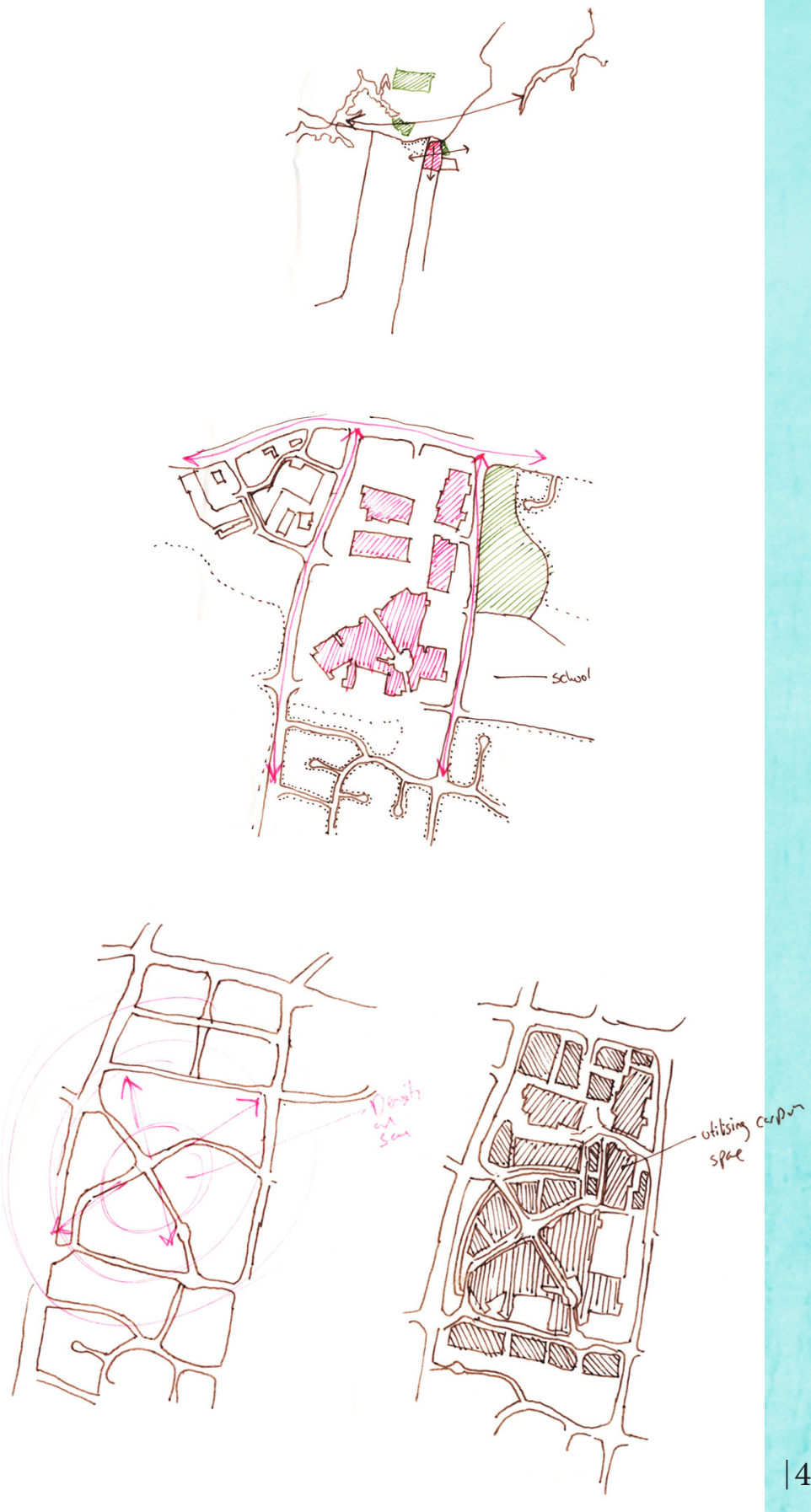


\section{MANGERE TOWN CENTRE}
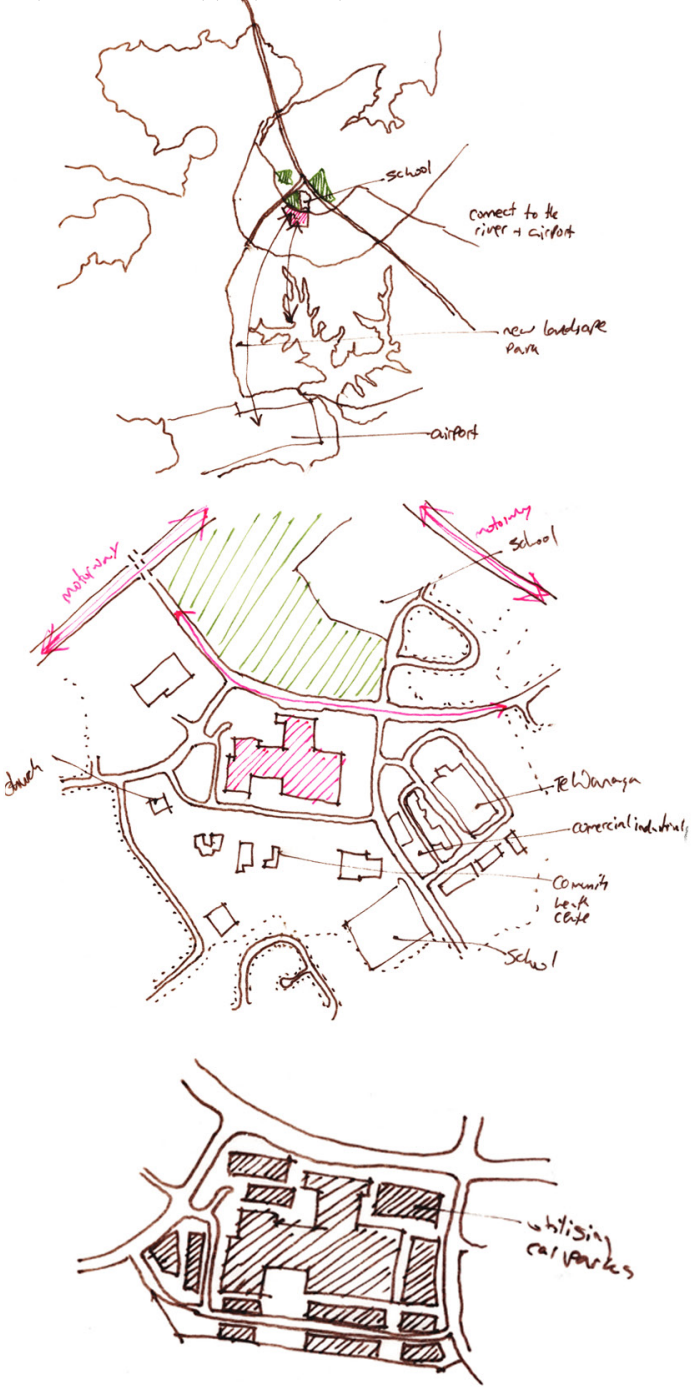

SOUTHMALL (DD)
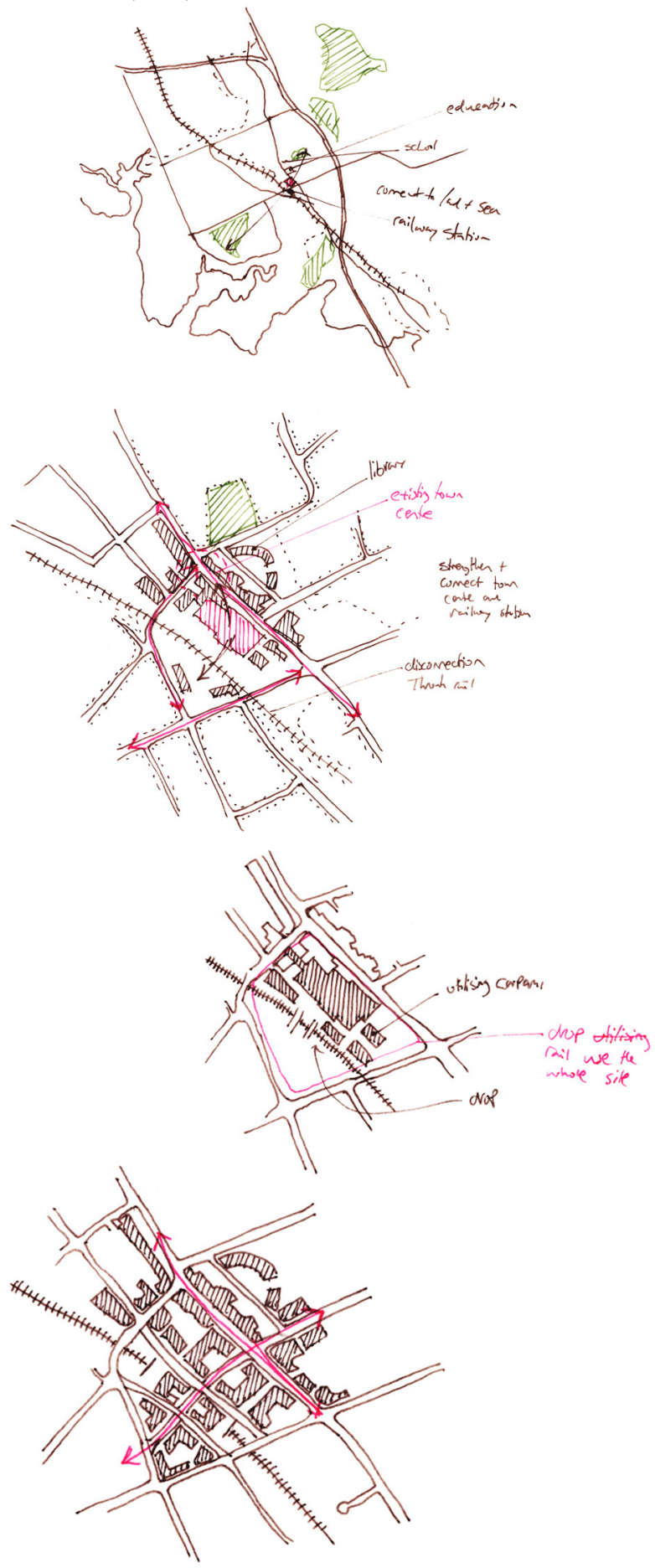


\section{SUMMARY}

The positioning of the building masses and their orientation towards the street front are factors that impact a

development becoming a catalyst for intensification of that area. Criteria for activating the suburb are listed below:

- Development direction- positioning on the arterial roads to direct the development in a certain direction.

- $\quad$ Self-Contained.

- Activating development either side of street.

- Activating intersection.

- $\quad$ Defining the street edge.

- $\quad$ Soften the arterial edges.

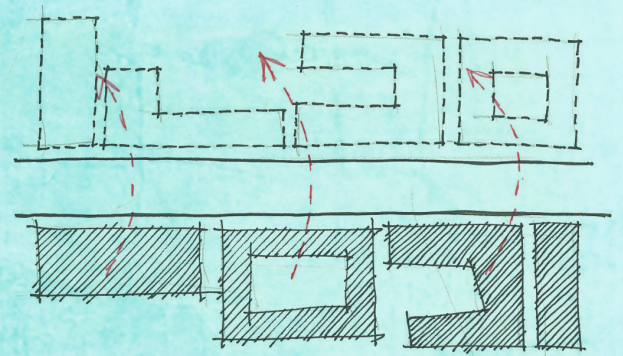

Defining Street Edge

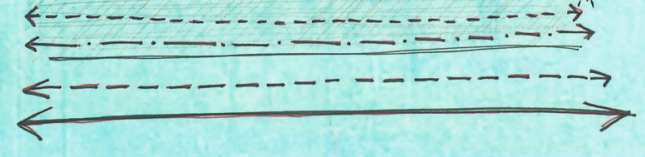

Soften Arterial Edges

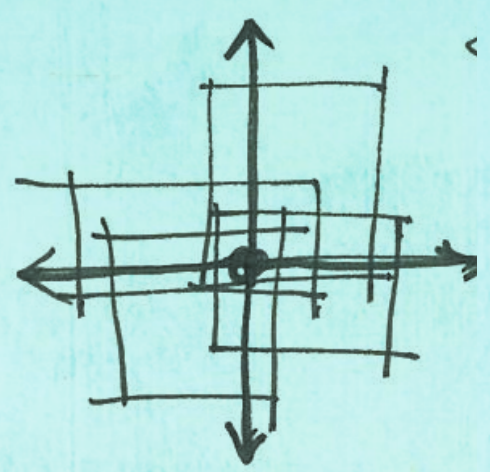

Development Direction

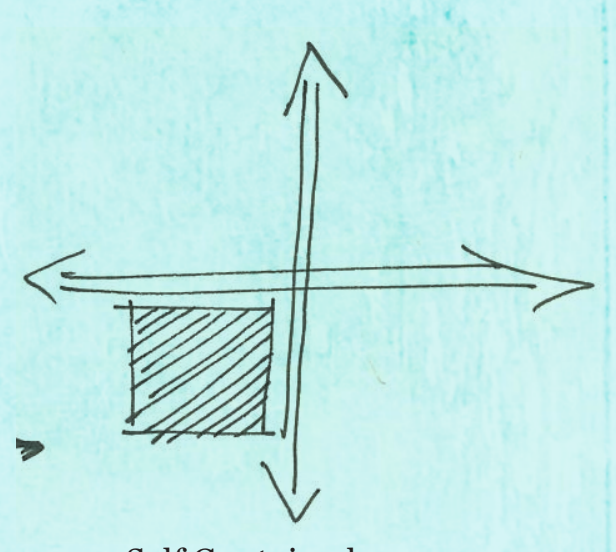

Self Contained

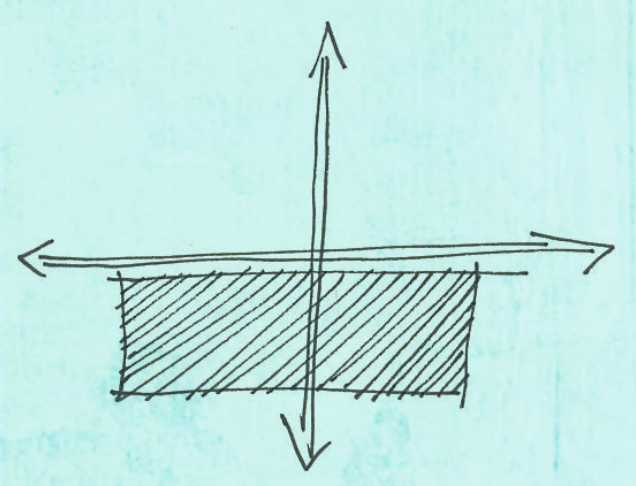

Activates Bottom Half of Context

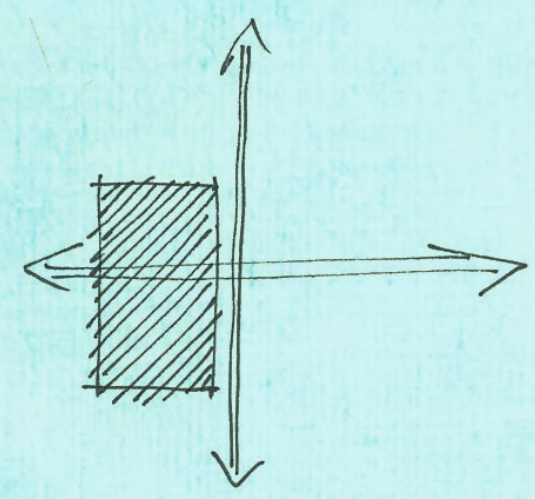

Activates Top \& Bottom of Context

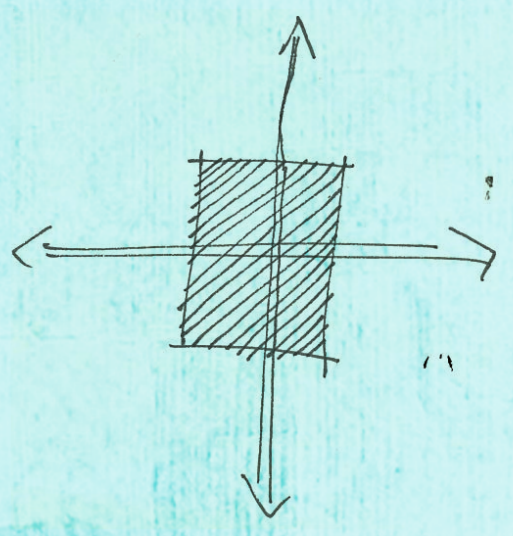

Activates Intersection 


\section{FOUR}

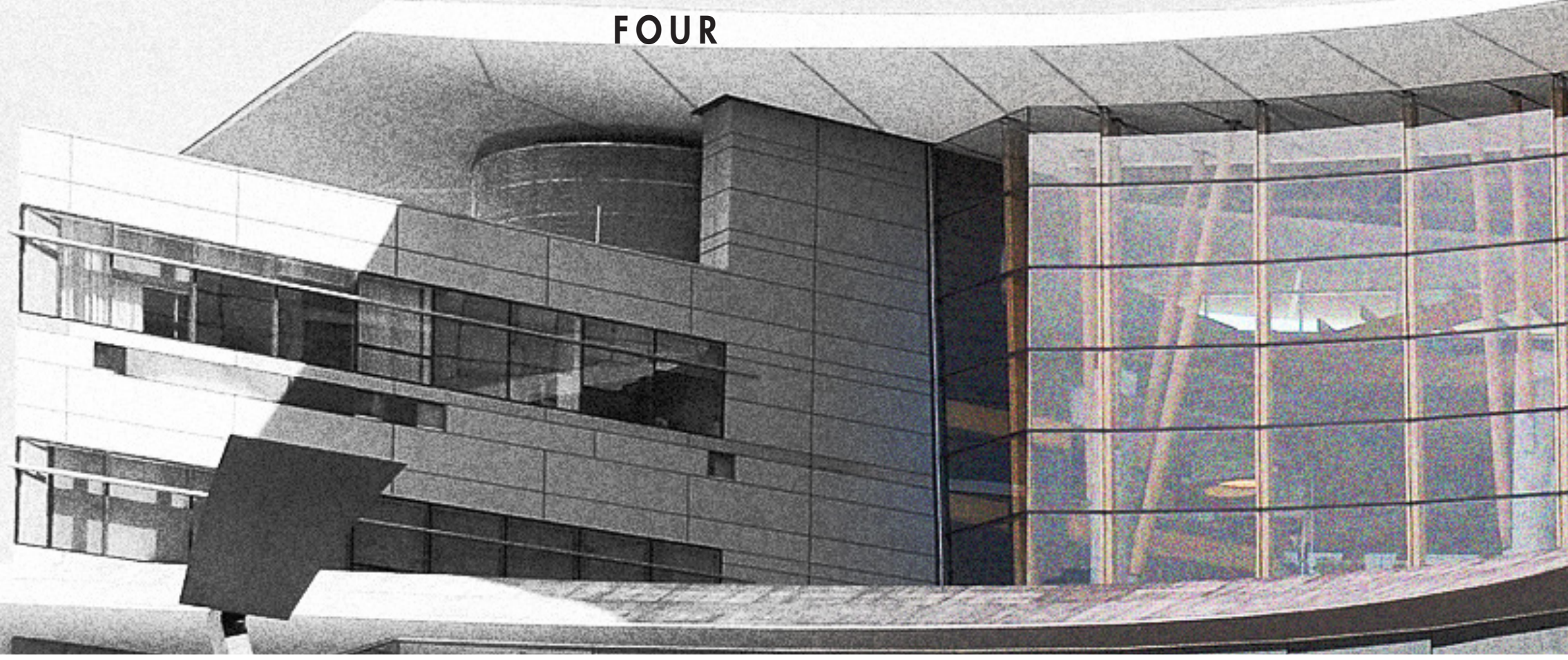




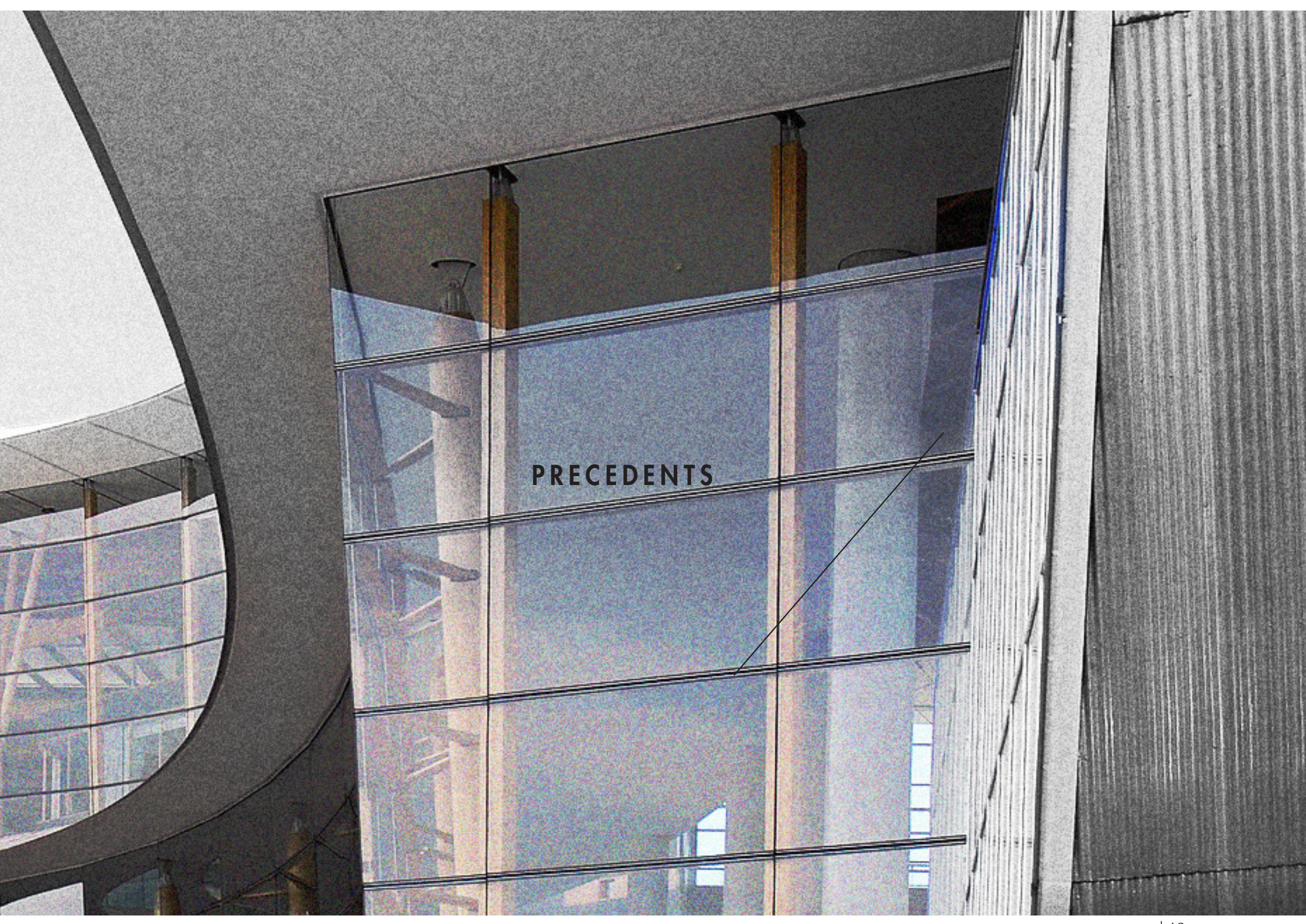


The redevelopment of shopping centre sites has complex issues of public and private space, large surface car parking requirements and treatment of existing building stock. International redeveloped shopping centre projects are explored analysing their urban planning, placement of programmes and how they address the issues as discussed in chapter 1. 


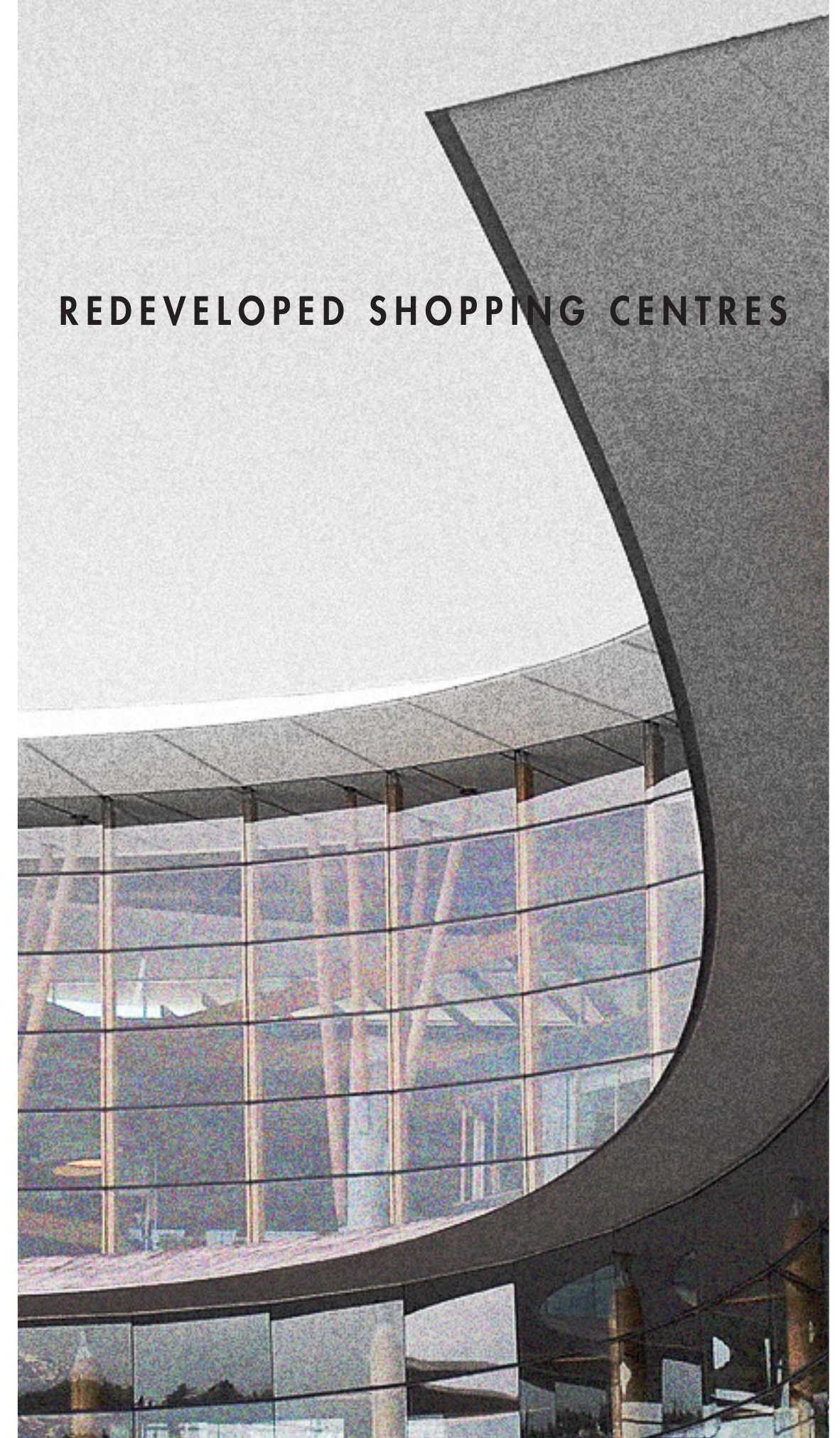




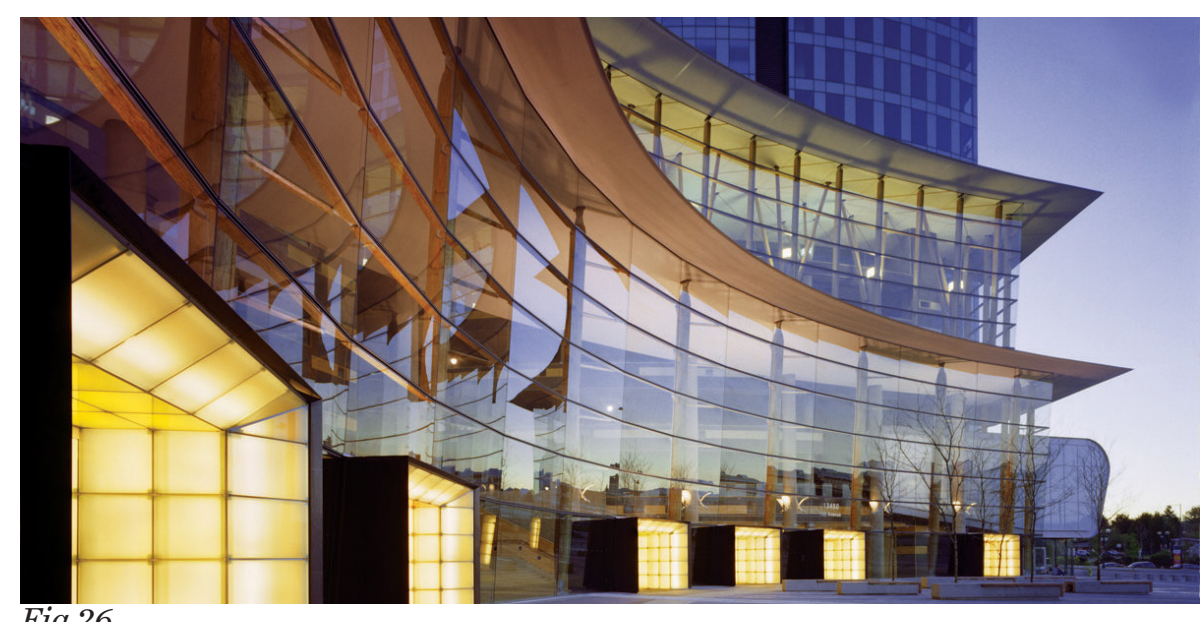

Fig 26.

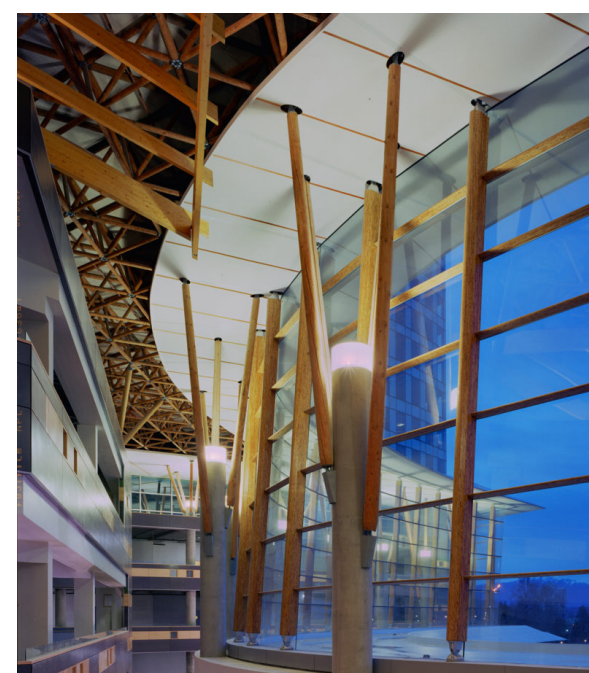

Fig 27.

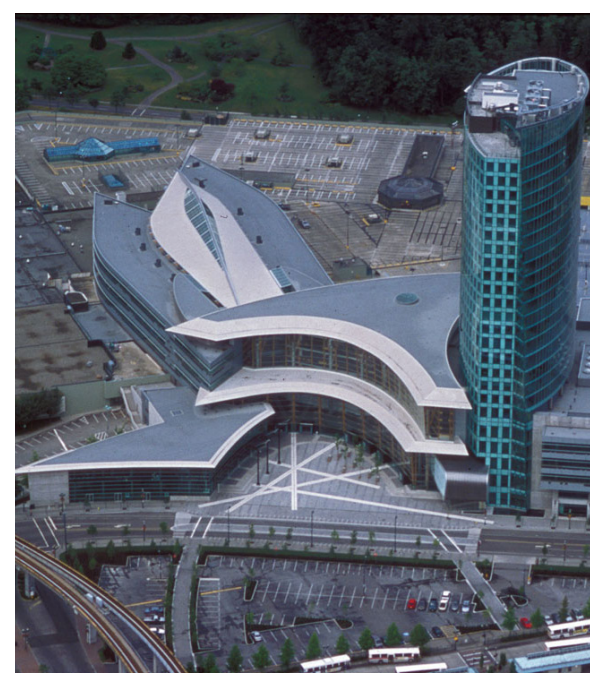

Fig 28.

\subsubsection{SURREY CENTRAL CITY}

Location: Surrey, British Columbia, Canada

Date: Completed in 2004, Bing Thom Architects

The redevelopment retained the original structure and built a university and office tower above it. The design opened up the north side providing a strong connection with the civic and government buildings of the city.

The additions have a high quality architectural finish, utilising a timber structure influenced by the local and regional culture. However, the connection on the south-side facing the public park is poor due to the limited permeability through the blank façade. The rooftop car-parking on the original mall provides a poor visual aesthetic view from the buildings above. 


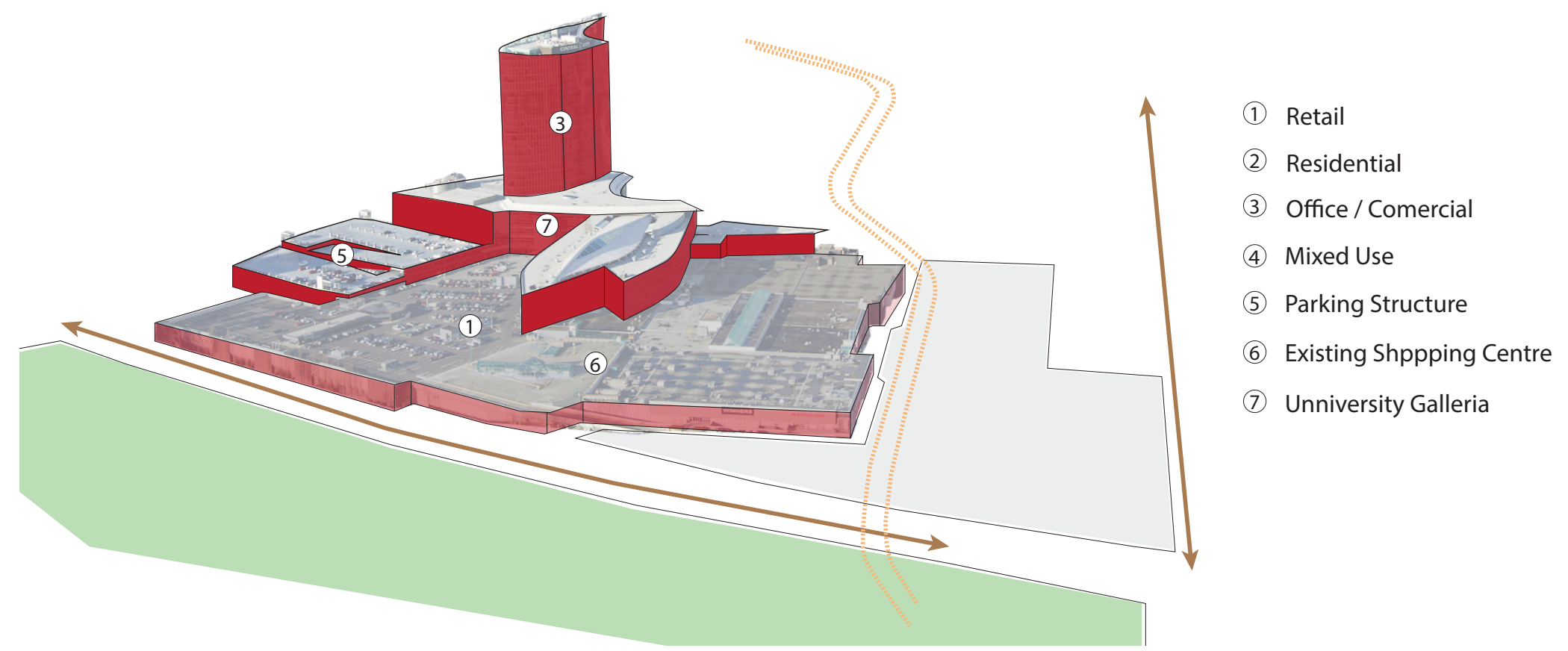

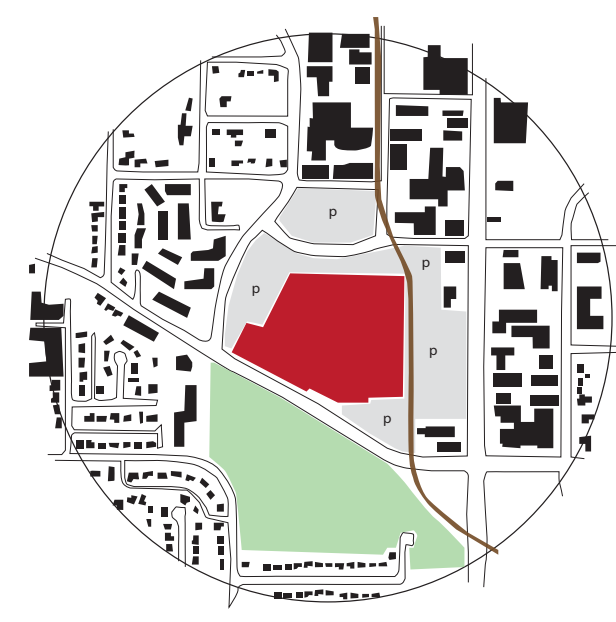

Original site \& context

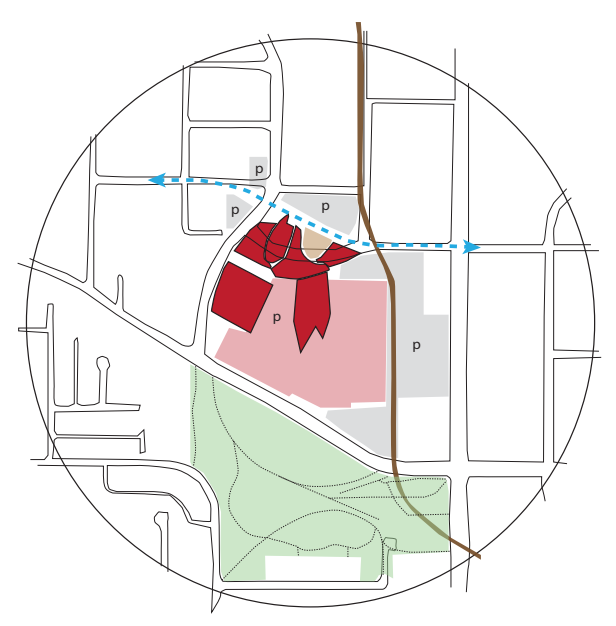

Redevelopment of centre

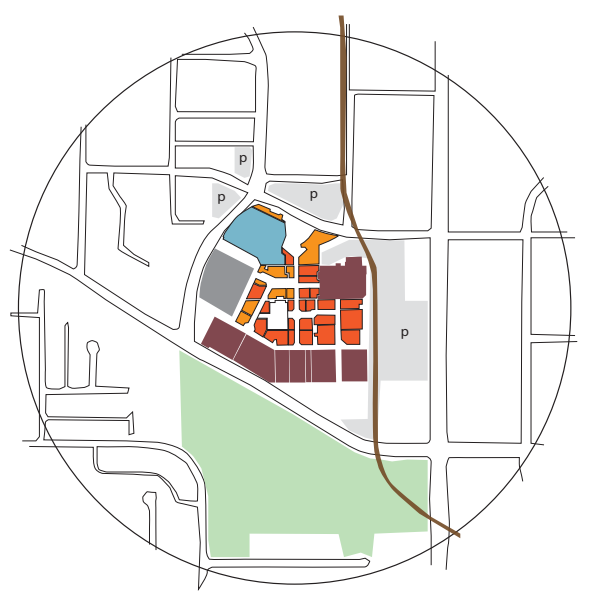

Programme planning
Retail

- Anchor Stores

- Residential

$\square$ Food

- Mixed Use

- Parking Structure

$\square$ Institution 


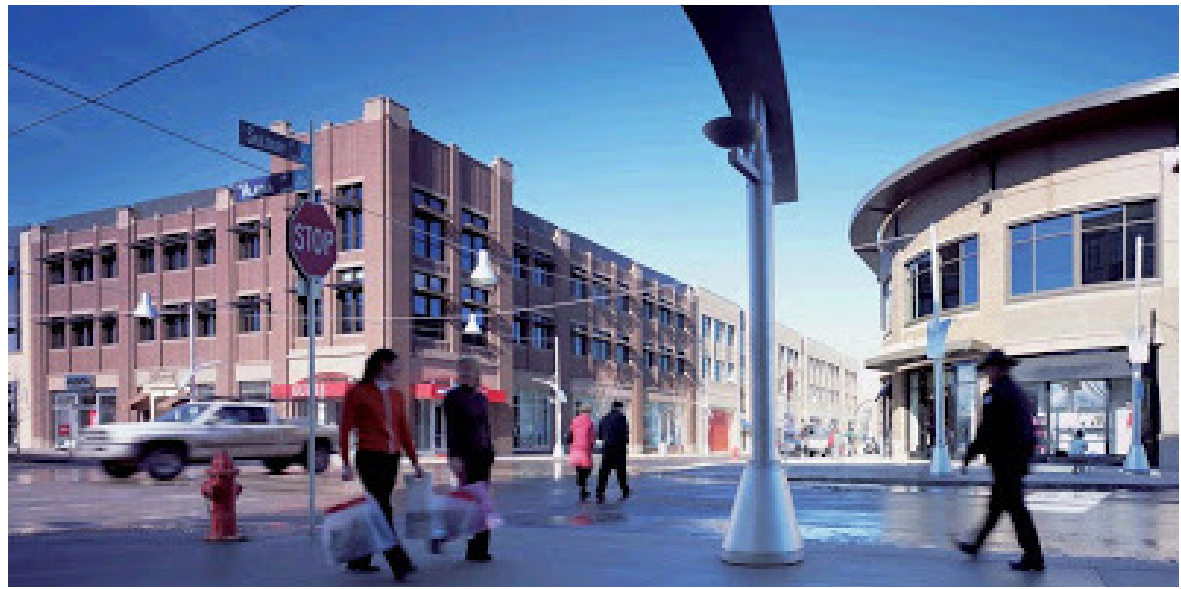

Fig 29.

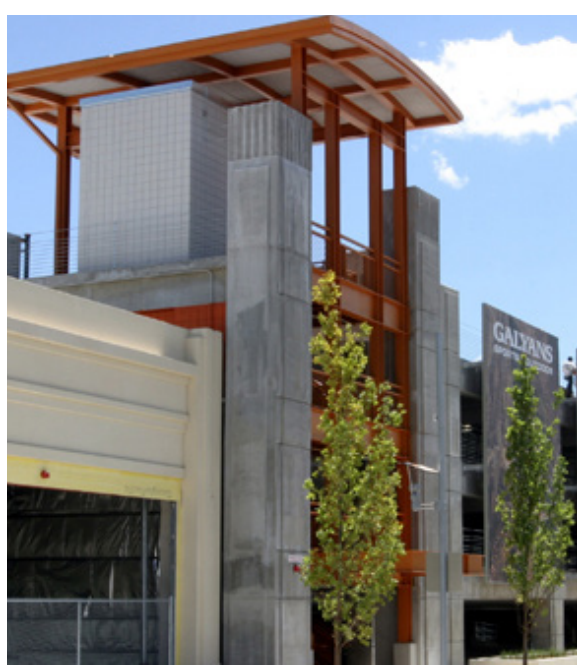

Fig 30.

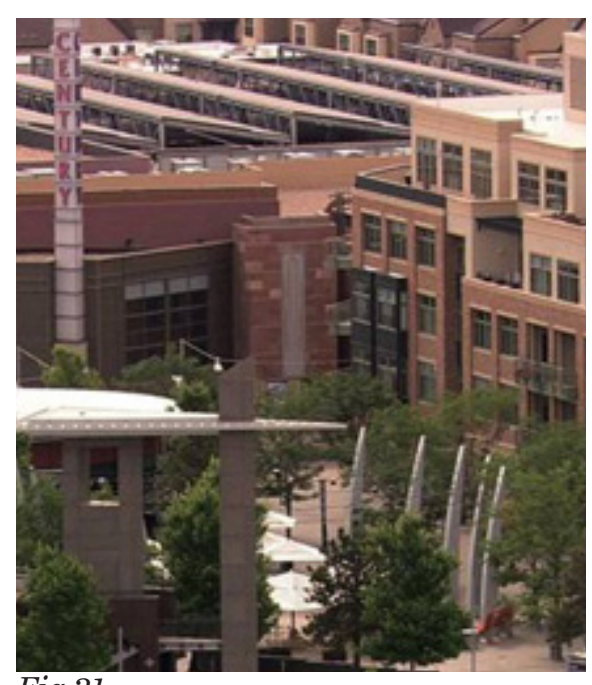

Fig 31.

\subsubsection{BELMAR TOWN CENTRE}

Location: Belmar District, Lakewood, Colorado, USA

Date: Original Mall opened in 1966, demolished in 2001, final phase 2011.

Architects: Elkus Manfedi Architects \& Van Meter Williams Pollack Architects

A 'new urbanist' character re-development demolished the original Belmar centre. The functions are arranged around an inward main street consisting of retail, office, hotel, events centre, movie theatres, art gallery and medium and high density housing.

The architectural character of the buildings lacks any variety, all building types (commercial, civic and residential) look very similar to one another. The residential buildings are fragmented around the centre and the mixed use buildings in the centre don't include a residential component. The internal configuration of the streets does not address the disconnection issue from the arterial roads. The surface car parking on the edges diminishes the pedestrian experience and therefore the experience is limited to a couple of central streets. 


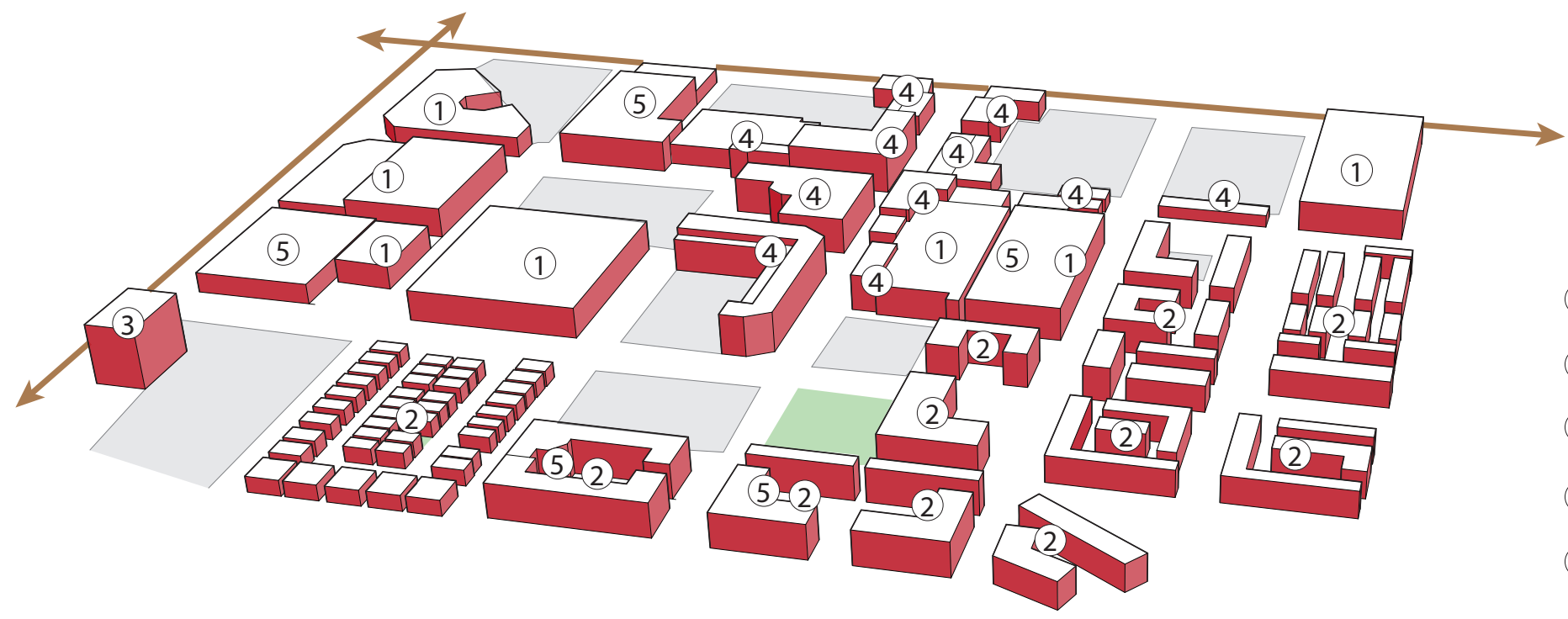

(1) Retail

(2) Residential

(3) Office / Commercial

(4) Mixed Use

(5) Parking Structure

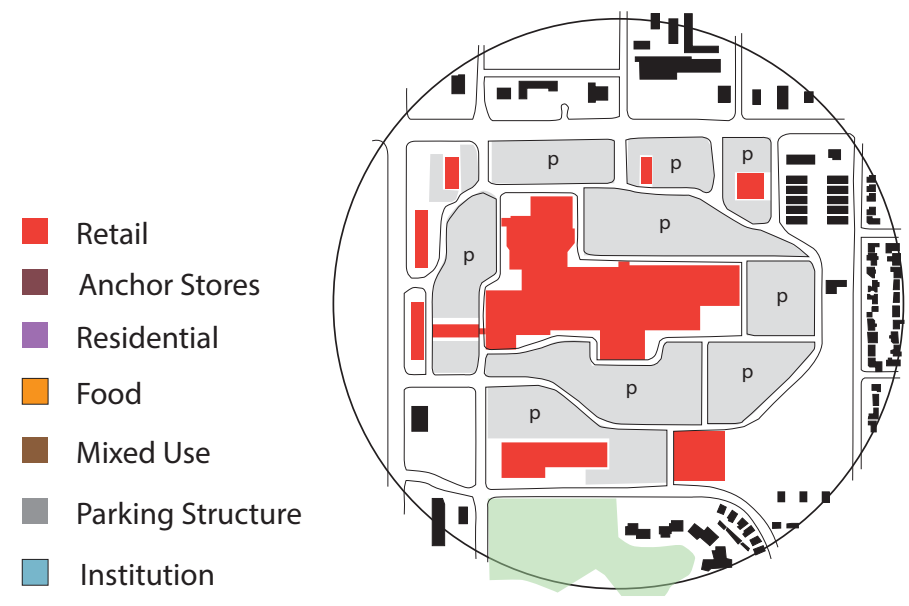

Original site \& context

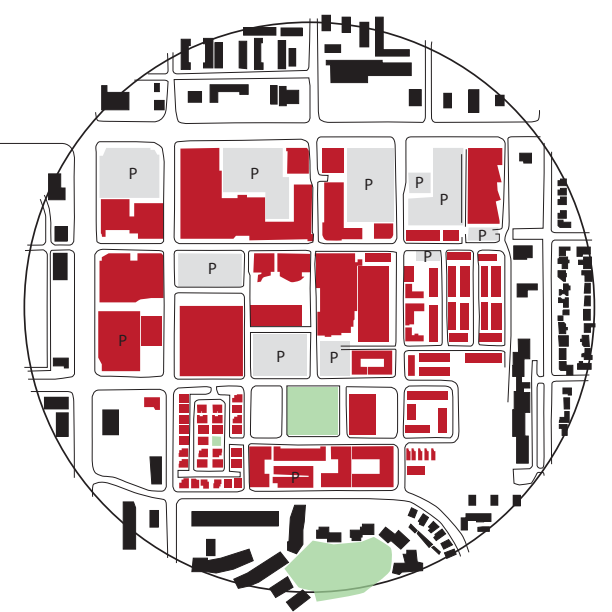

Redevelopment of centre

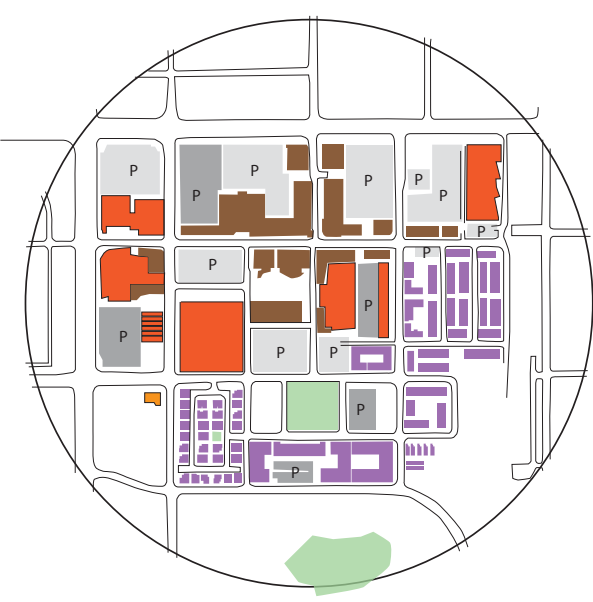

Programme planning 


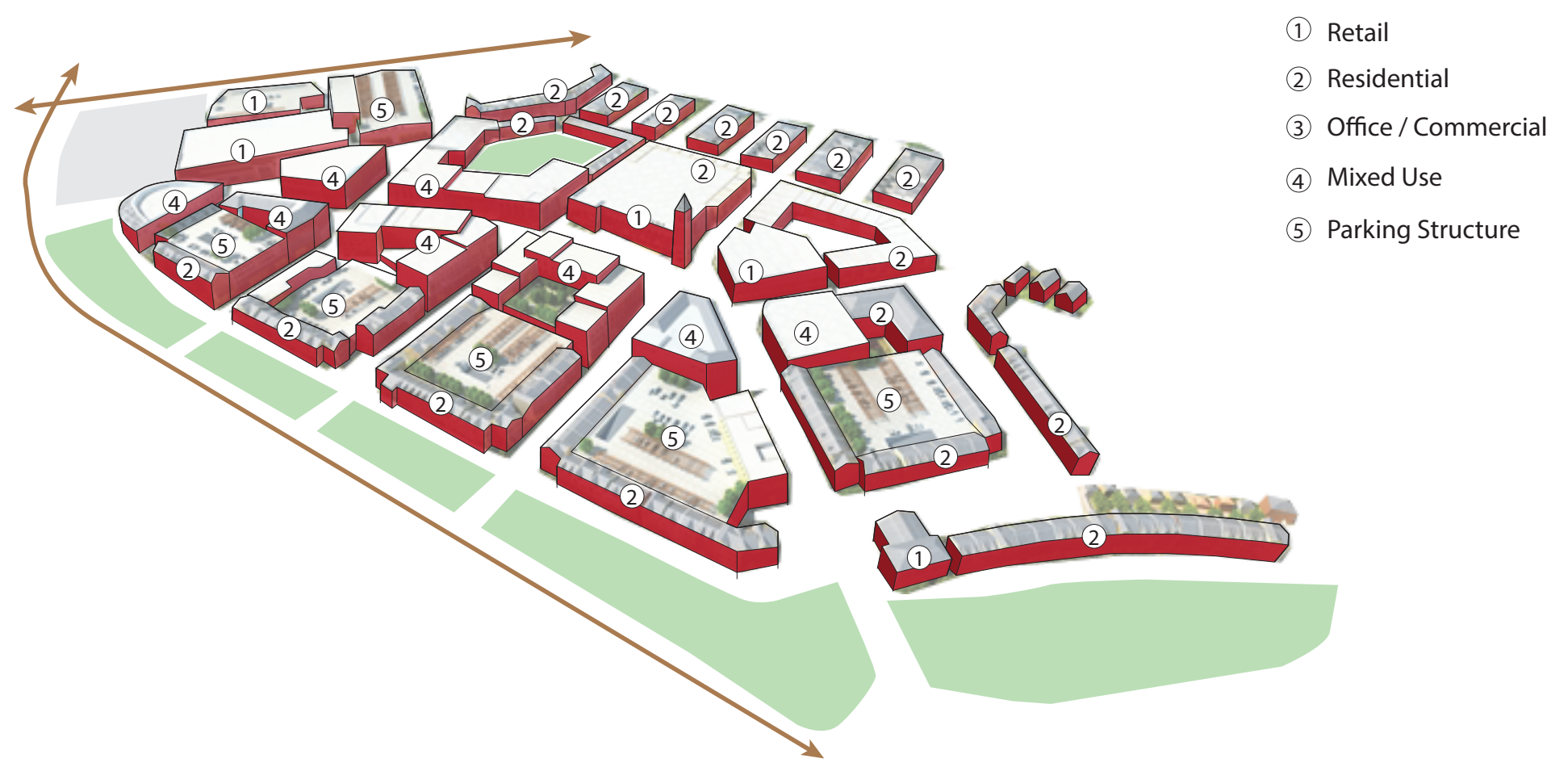

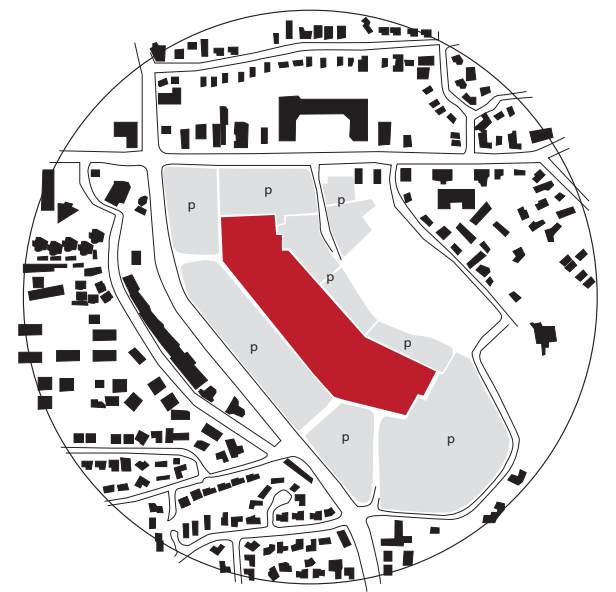

Original site \& context

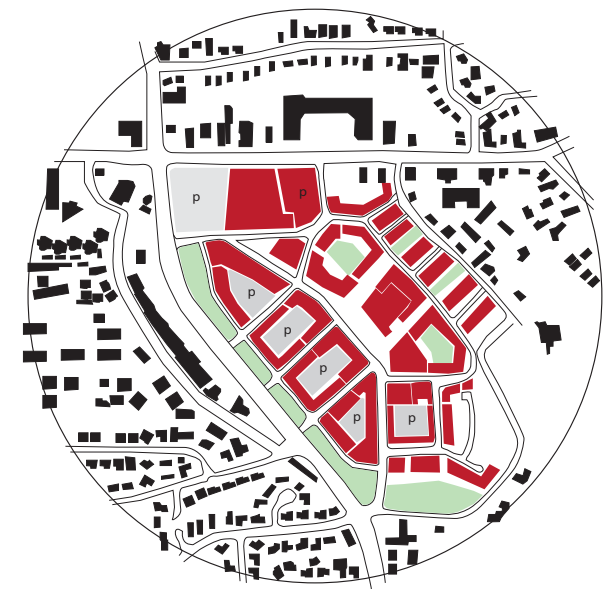

Redevelopment of centre

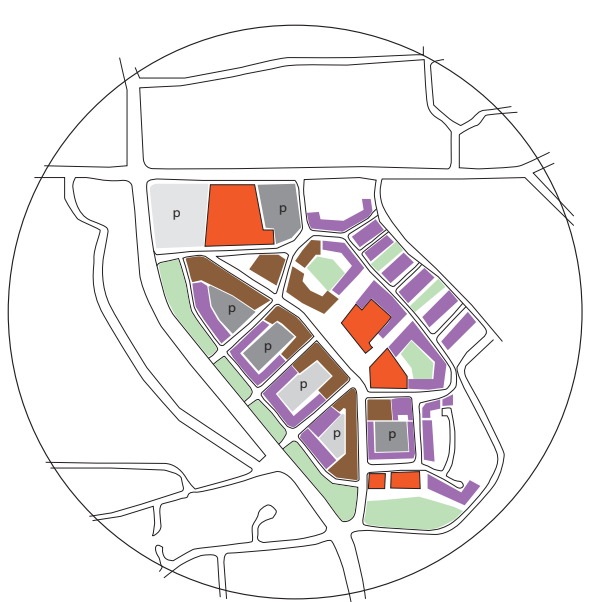

Programme planning retail

anchor Stores

- Residential

$\square$ Food

- Mixed Use

- Parking Structure

$\square$ Institution 


\subsubsection{COTTONWOOD MALL}

Location: Holladay, Utah, USA

Date: Original 1962 Mall demolished in 2008

- Planning proposal stage

Town Centre proposal for the site consisting of fragmented programmes including mixed use, retail, office and residential. The scheme places the parking in the interior of an urban block.

The development pattern is internally focused and lacks connectivity and accessibility to the surrounding context. This pattern does not help future intensification of the area. The architectural character of the proposal is mediocre and lacks diversity. The proposal mimics an old European village style, complete with false ornamentation and a clock tower.

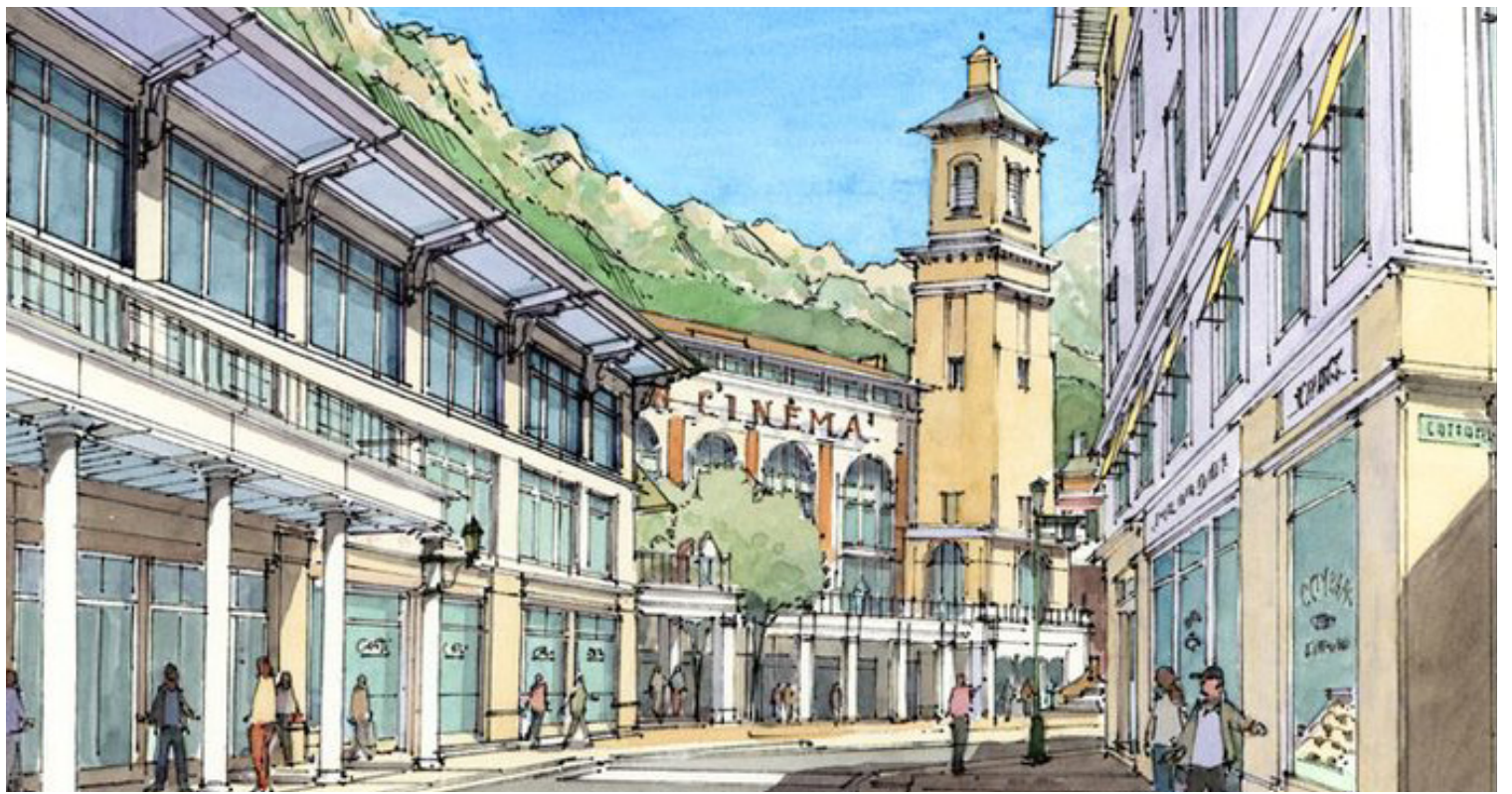

Fig 32 .

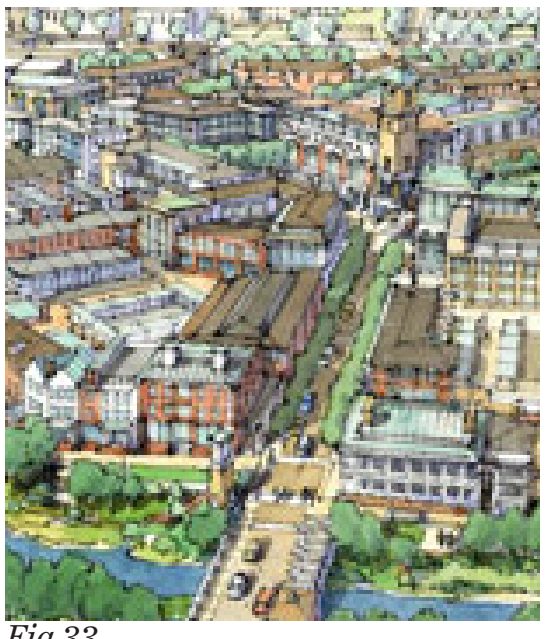

Fig 33.

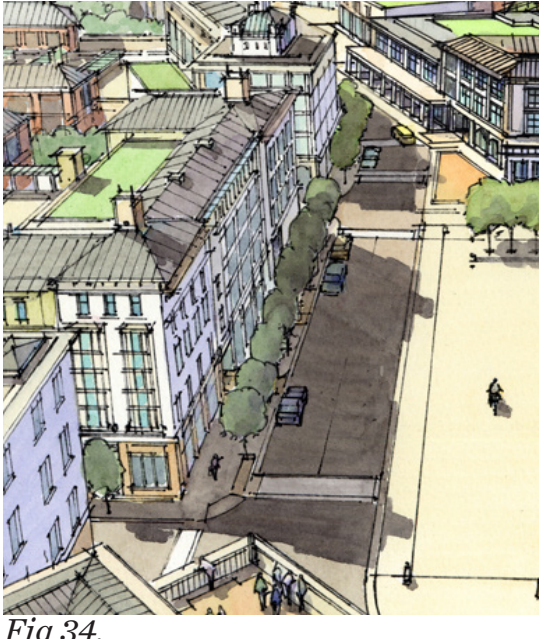

Fig 34. 


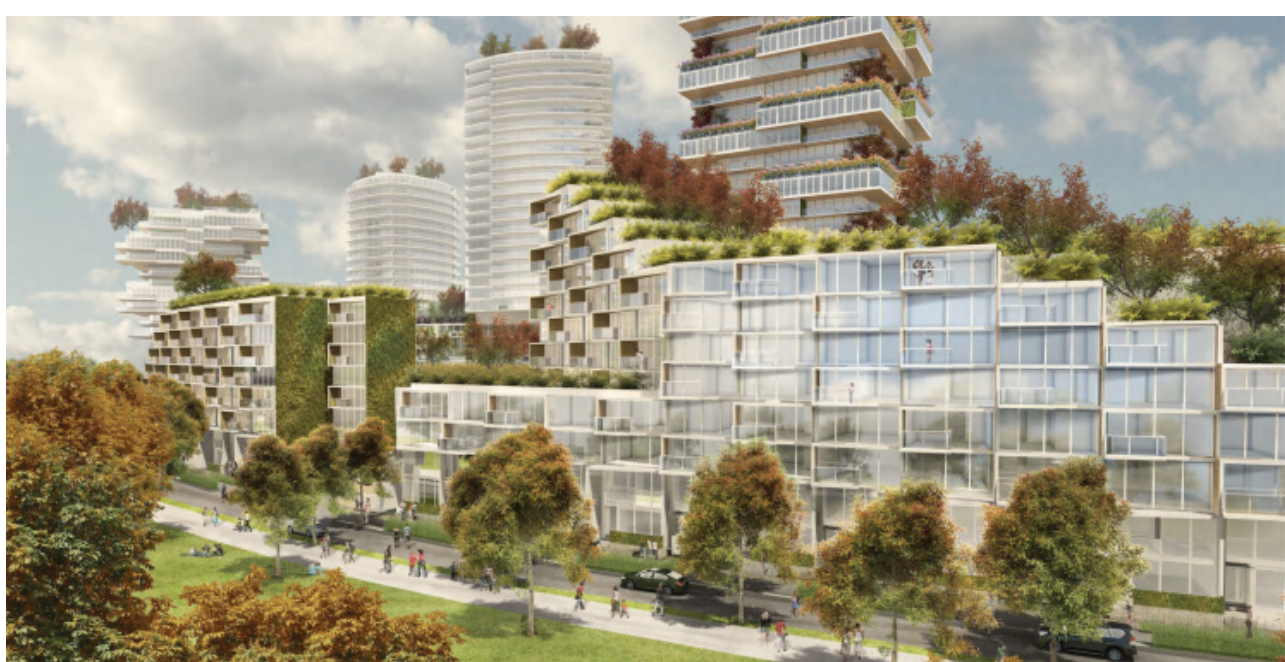

Fig 35.

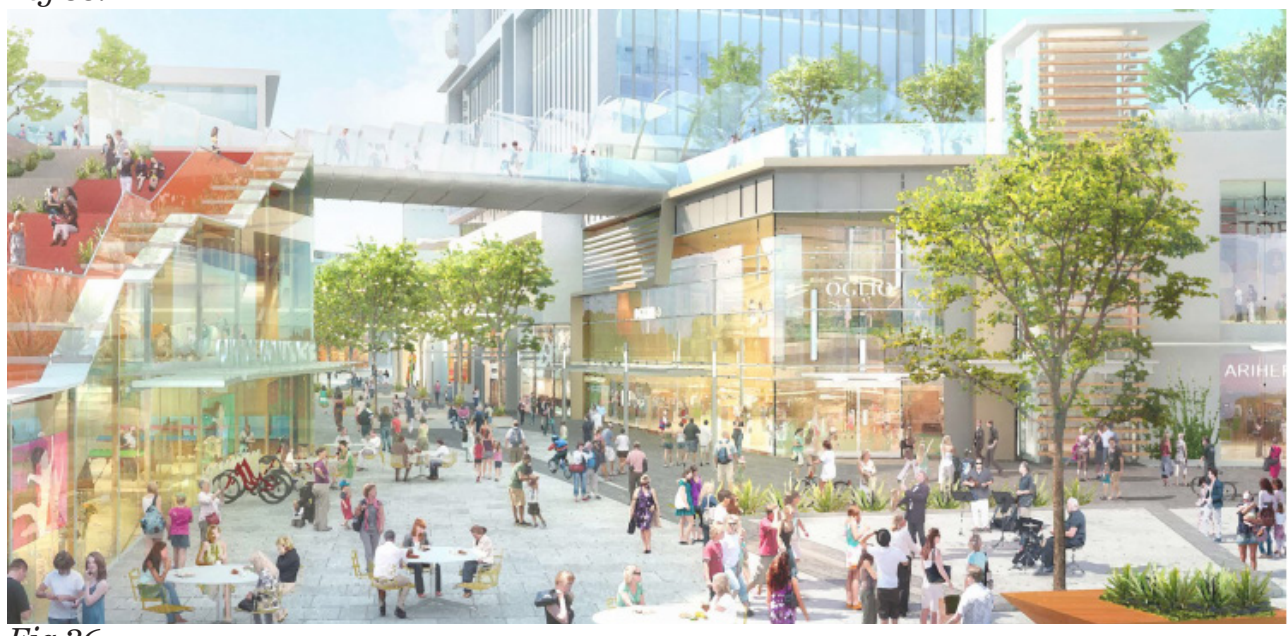

Fig 36.

\subsubsection{OAKRIDGE CENTRE REDEVELOPMENT}

Location: Oakridge, Vancouver, British Columbia, Canada

Date: Original Shopping Centre opened in 1959 - Current proposal for redevelopment.

Compared to the previous redevelopments this development incorporates a large environmental aspect to the design, by constructing a large green roof/ park above the original shopping centre. The new buildings are mixed use and have residential towers that surround the park and define the edge of the site. The objective was to add a different type of retail experience to the site.

The proposal is similar to Ken Yeang's eco master planning theories and it would be interesting to see how realistic and successful the large green roof is. Would it be compromised due to costs and what would this do to the development? The planning integrates well into the context and would potentially form a catalyst for intensification in the area, but there is a large scale shift between the neighbouring buildings and the proposed town centre. 


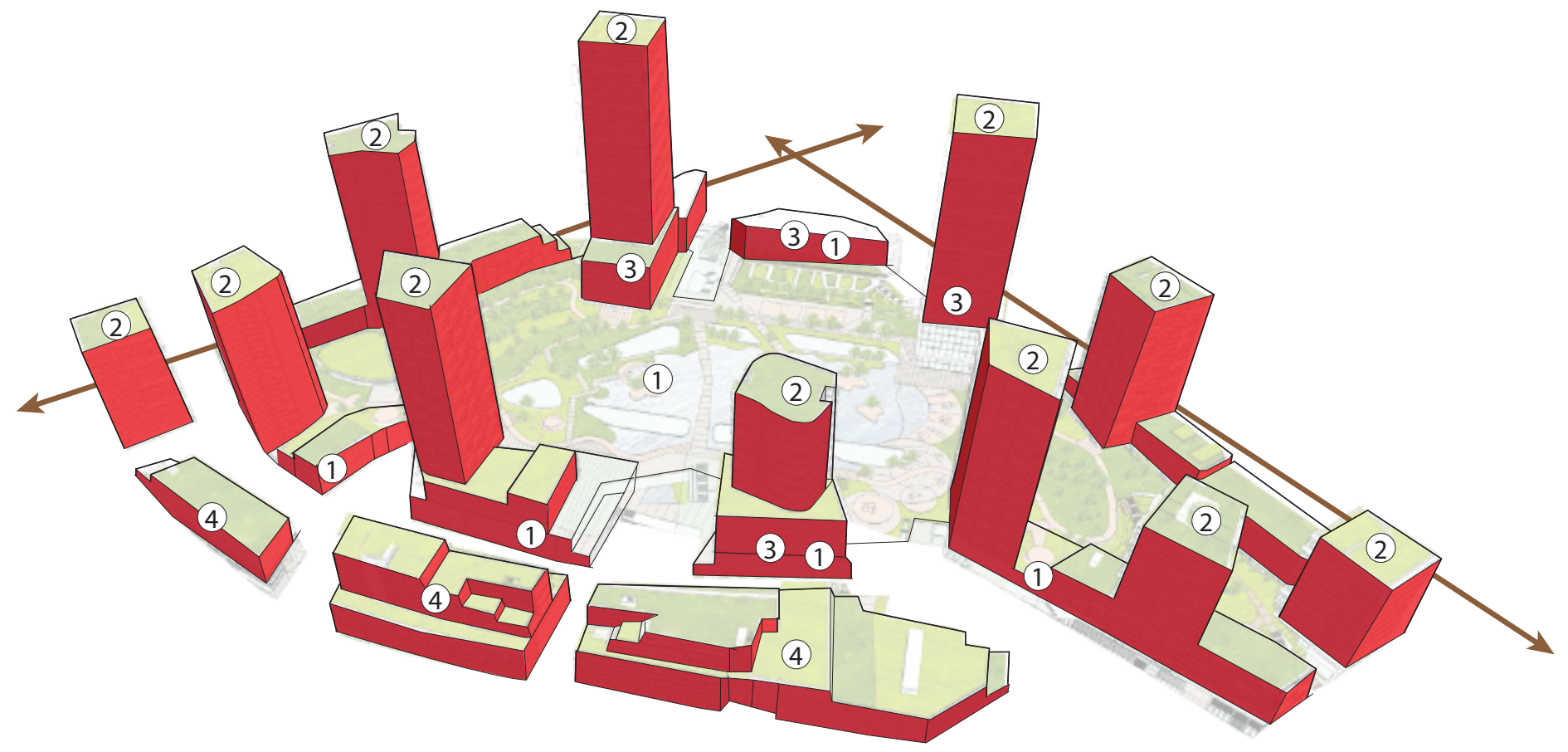

(1) Retail

(2) Residential

(3) Office / Comercial

(4) Neighbourhood \& Civic Centre (Mixed Use)

- Retail

- Anchor Stores

- Residential

$\square$ Food

- Mixed Use

- Parking Structure

$\square$ Institution

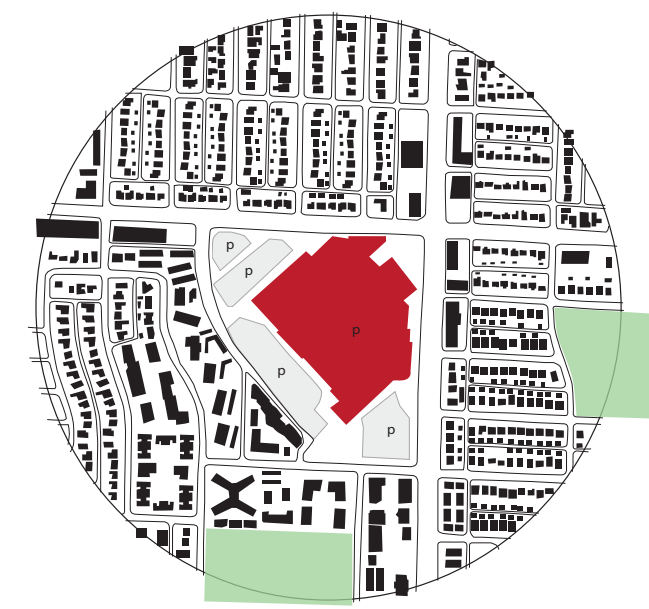

Original site \& context

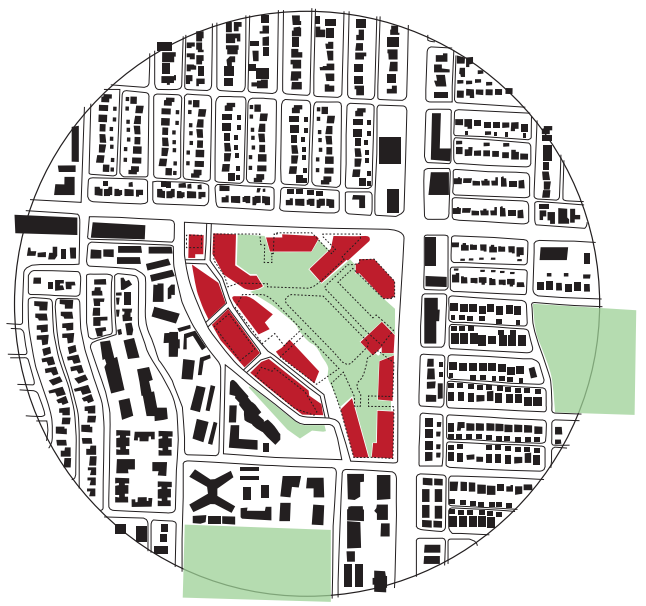

Redevelopment of centre

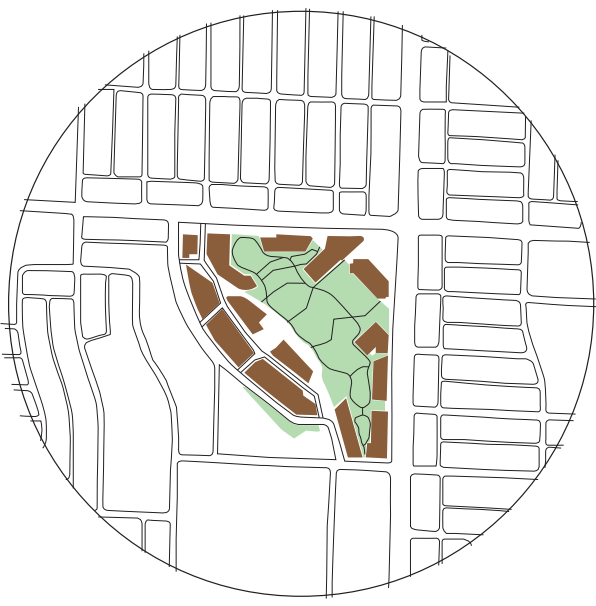

Programme planning 


\subsubsection{SUMMARY}

The majority of the analysed centres have poor architectural quality and character, as well as limited capacity to activate intensification of the surrounding architecture. Design strategies for intensifying these sites are derived from below as:

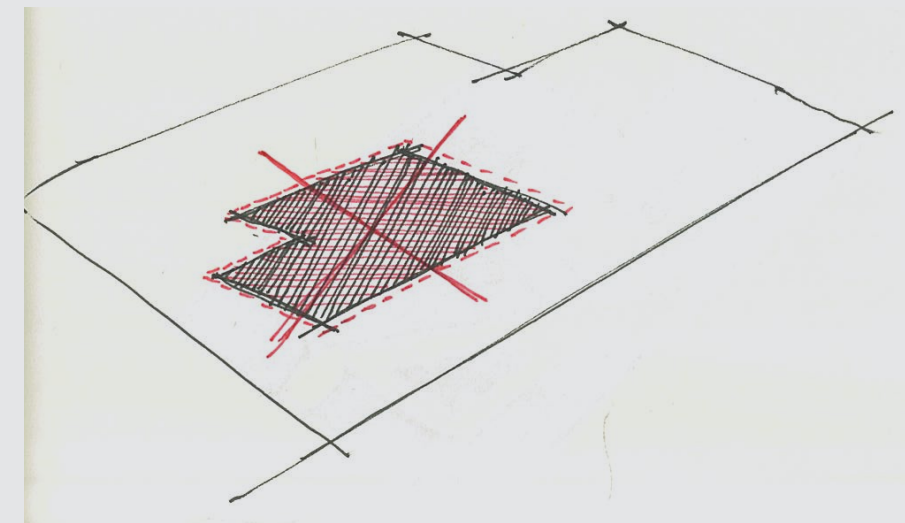

Removing Original Mall

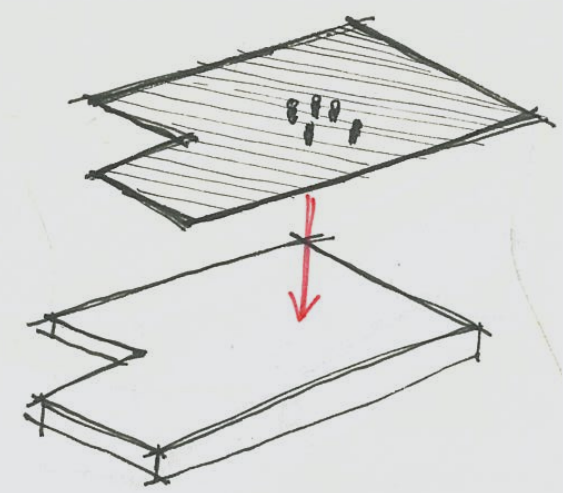

Convert Existing Mall Roof into Public Spcae

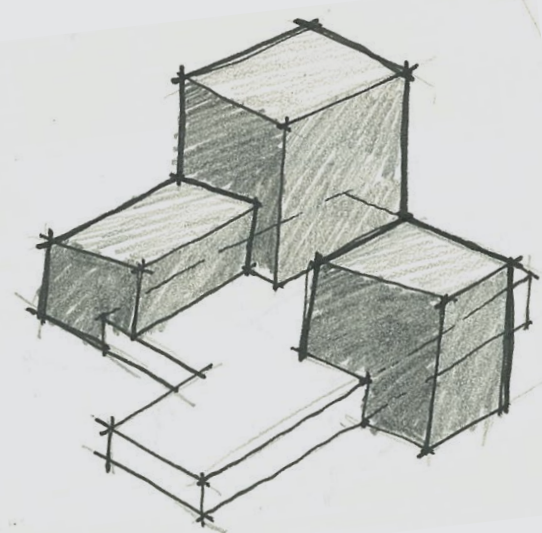

Add Built Additions Above Original Mall 


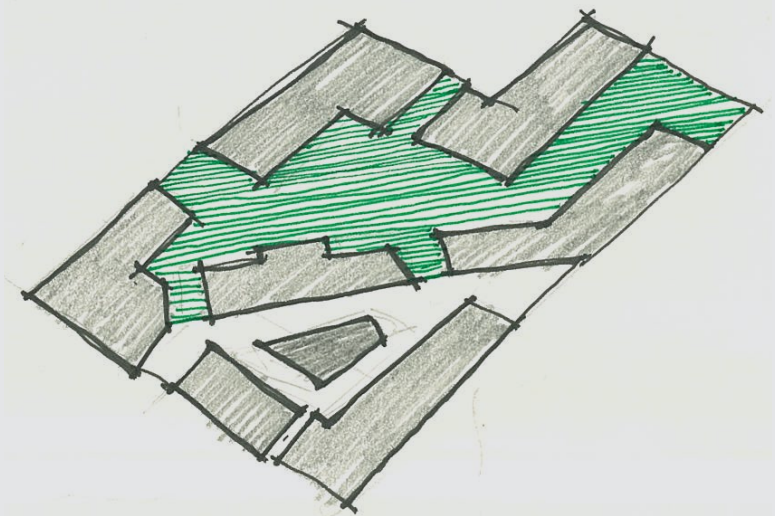

Define Street Edge \& Develop Central Green Space

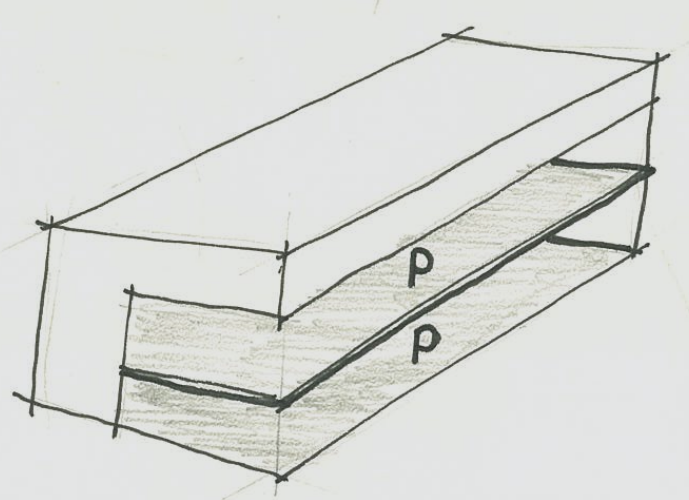

Limit Parking to Structured Parking and Underground Parking

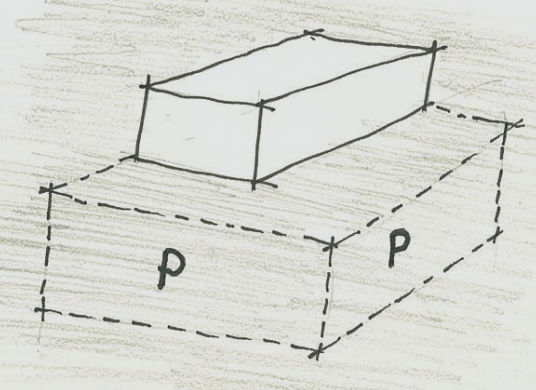




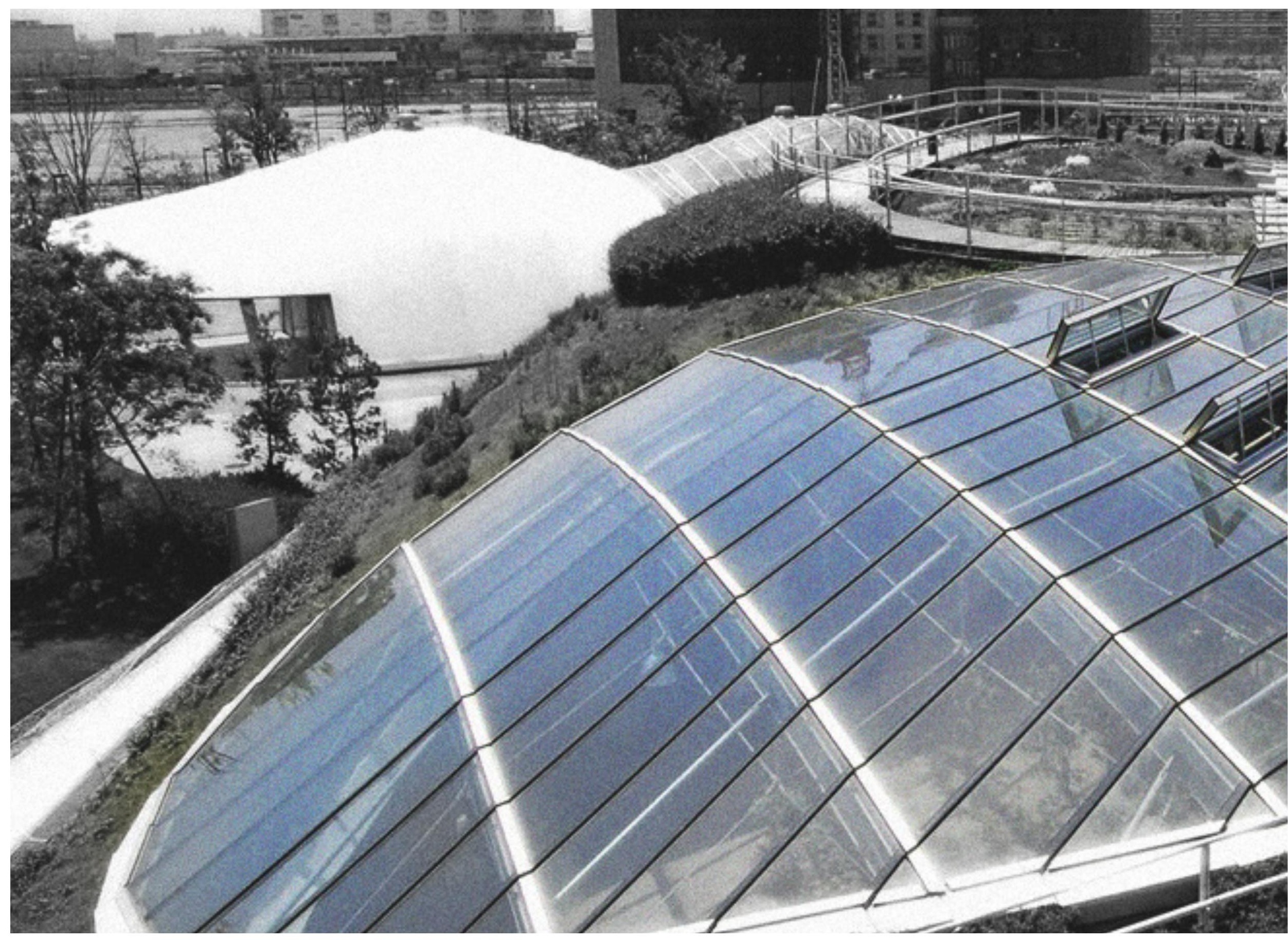




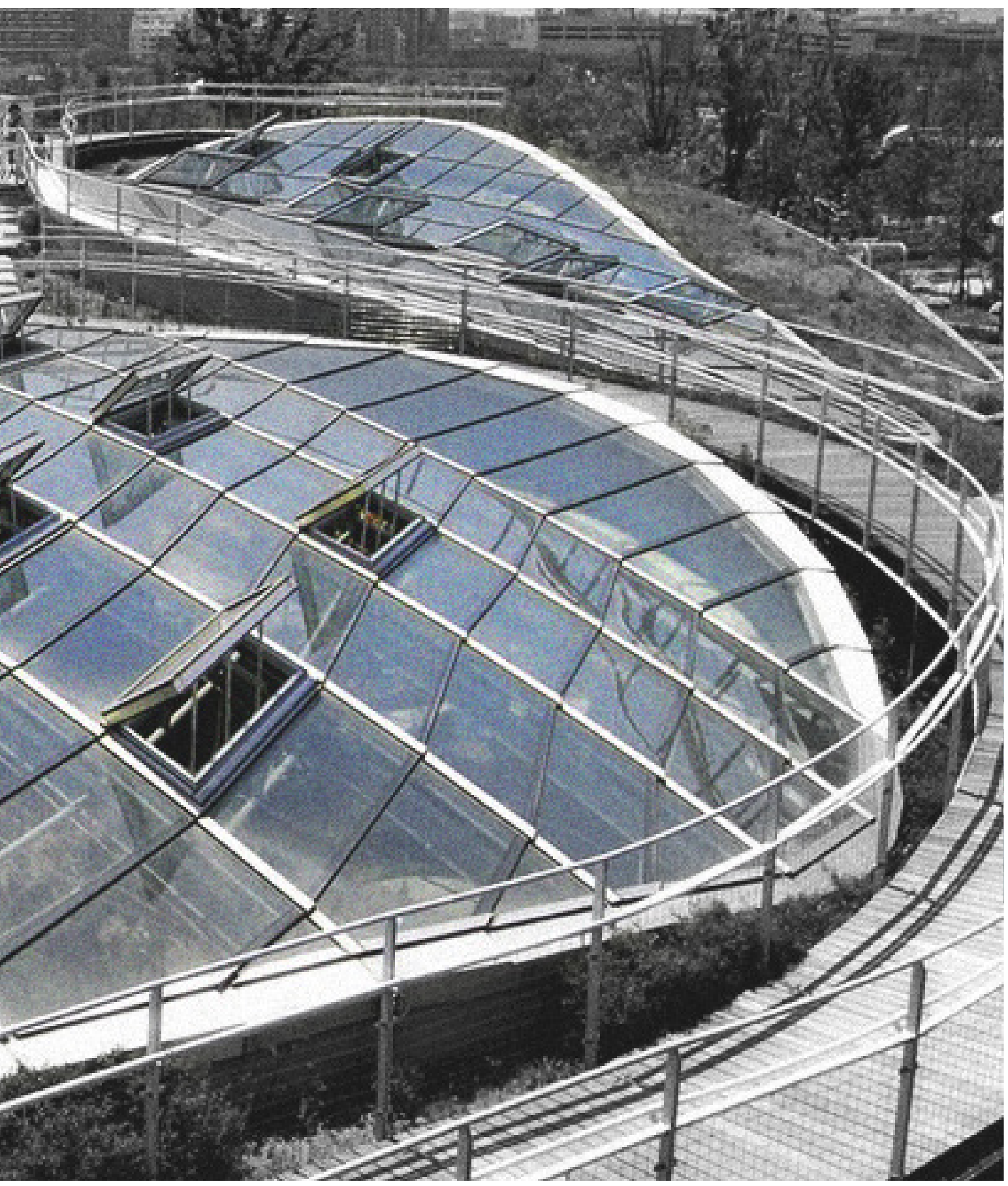

\section{AMALGAMATION OF NATURAL SYSTEMS AND ARCHITECTURE}

\section{2}

The integration of natural systems and architecture are examined, exploring project strategies for the architecture to enhance and sustain ecology all as one system. Each project has a different approach towards expressing the relationship of landscape and built structure. 


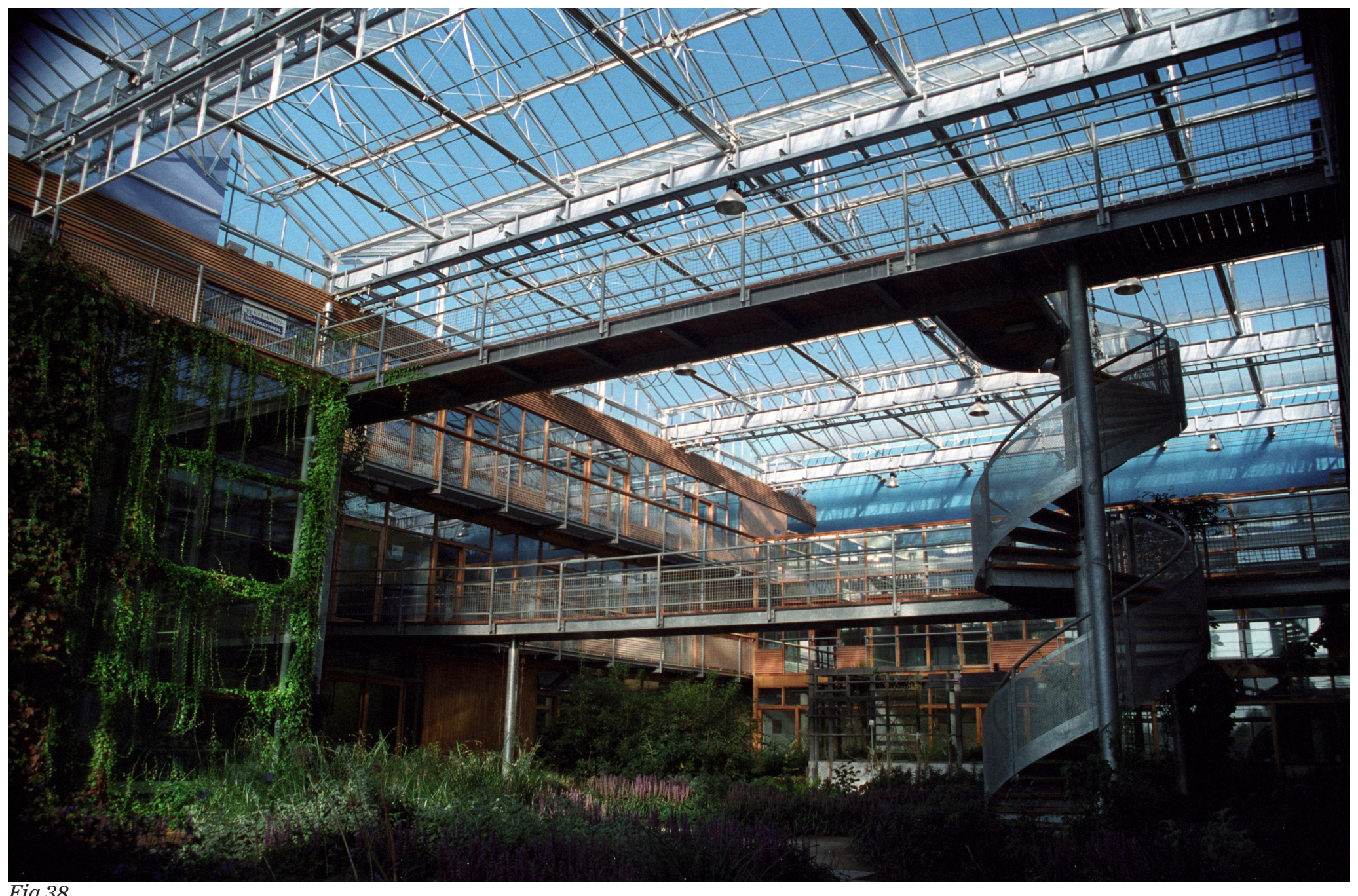

Fig 38. 


\subsubsection{DUTCH INSTITUTE FOR FORESTRY AND NATURE RESEARCH}

Location: Wageningen, The Netherlands Date: Completed in 1998

Architect: Behnisch Architekten

The building utilises multiple green houses that subdivide the office spaces. The green houses provide a space for vegetation to grow in a temperate climate. Each garden represents a regional biotype consisting of a grassland garden, a marsh garden and a woodland garden. The offices are passively heated and ventilated due to the stack effect between two green houses. They capture and retain the warmth in the winter and channel and cool the wind in the summer. The office buildings collect the storm-water through a moss sedum roof that is then used to irrigate the gardens.

The gardens frame the architecture while the architecture conventionally defines the gardens. The design strategy was influenced by the remaining ecological qualities of the landscape and creating a diverse new habitat, where the vegetation could sustain insect and animal species in harmony with humans.
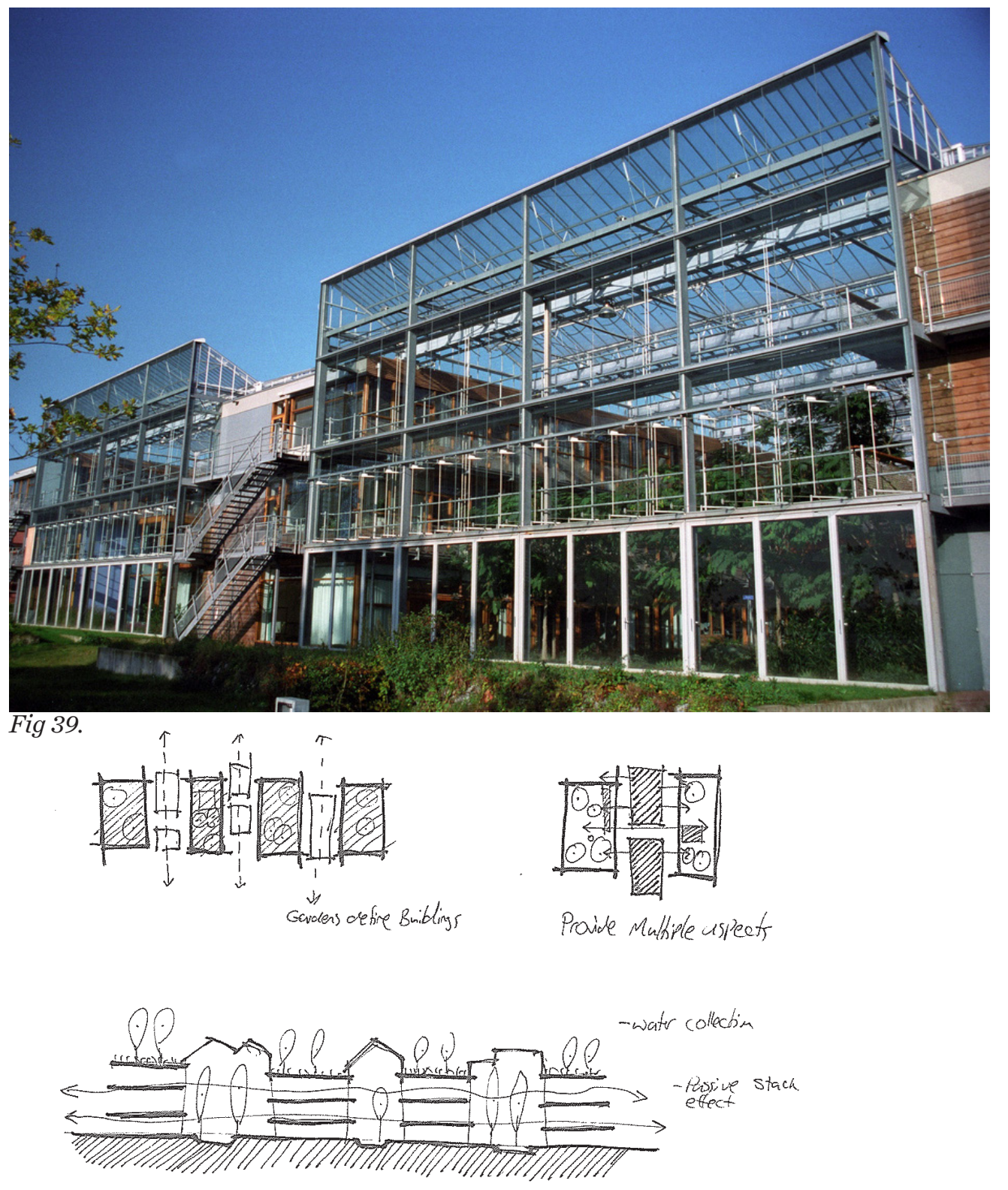


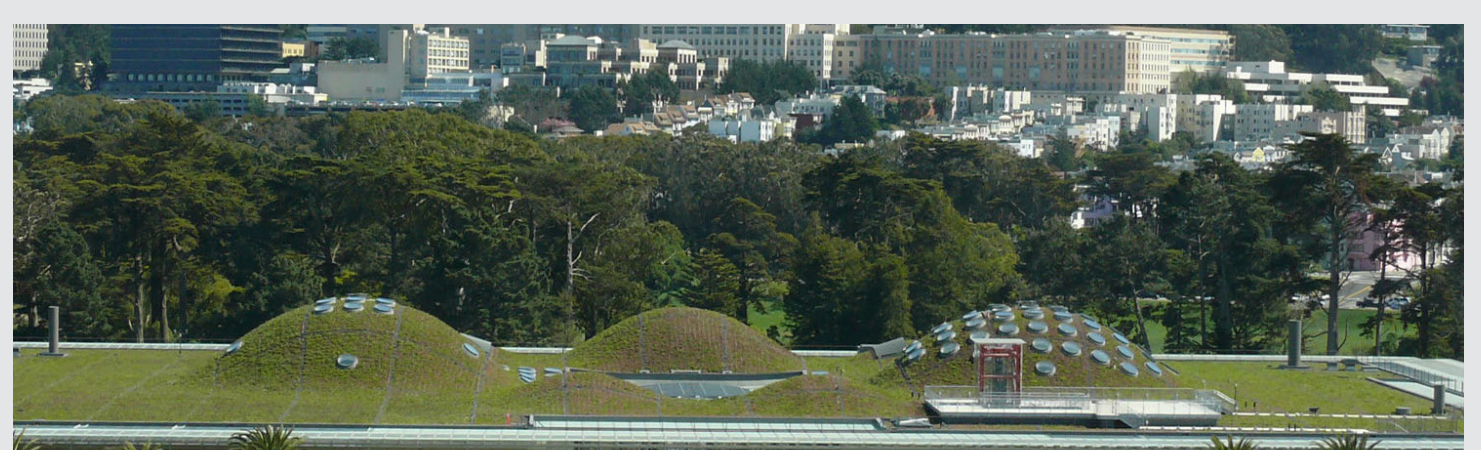

\subsubsection{CALIFORNIA ACADEMY OF SCIENCE}

Location: Golden Gate Park, San Francisco, California, USA

Date: Completed in 2008

Architect: Renzo Piano

The building functions as a botanic garden with an undulating green roof that references the surrounding hills. The green roof supports Californian native species and the public has limited access to the roof. Internally there are green houses that contain over 50 plant species. The building utilises passive design whereby the roof collects rain water, reduces the heat island effect and moderates temperature extremes.

The curved form of the roof creates different topographic conditions, as some parts will be in shade and have different lighting conditions, therefore it would support greater biological diversity than a flat roof. The ecological strategy is the creation of a habitat that is an extension of the local topography. The plants on the roof produce berries that attract animal and insect species, such as hummingbirds, bumble bees, moths and butterflies. The design strategy is to lift up an undulating landscape and place a conventional rectilinear building underneath so the roof acts as a canopy. 
^ Undulating bubble shape green roof $\mid \mathrm{v}$ View inside greenhouse | vv texture of green roof $\mid$
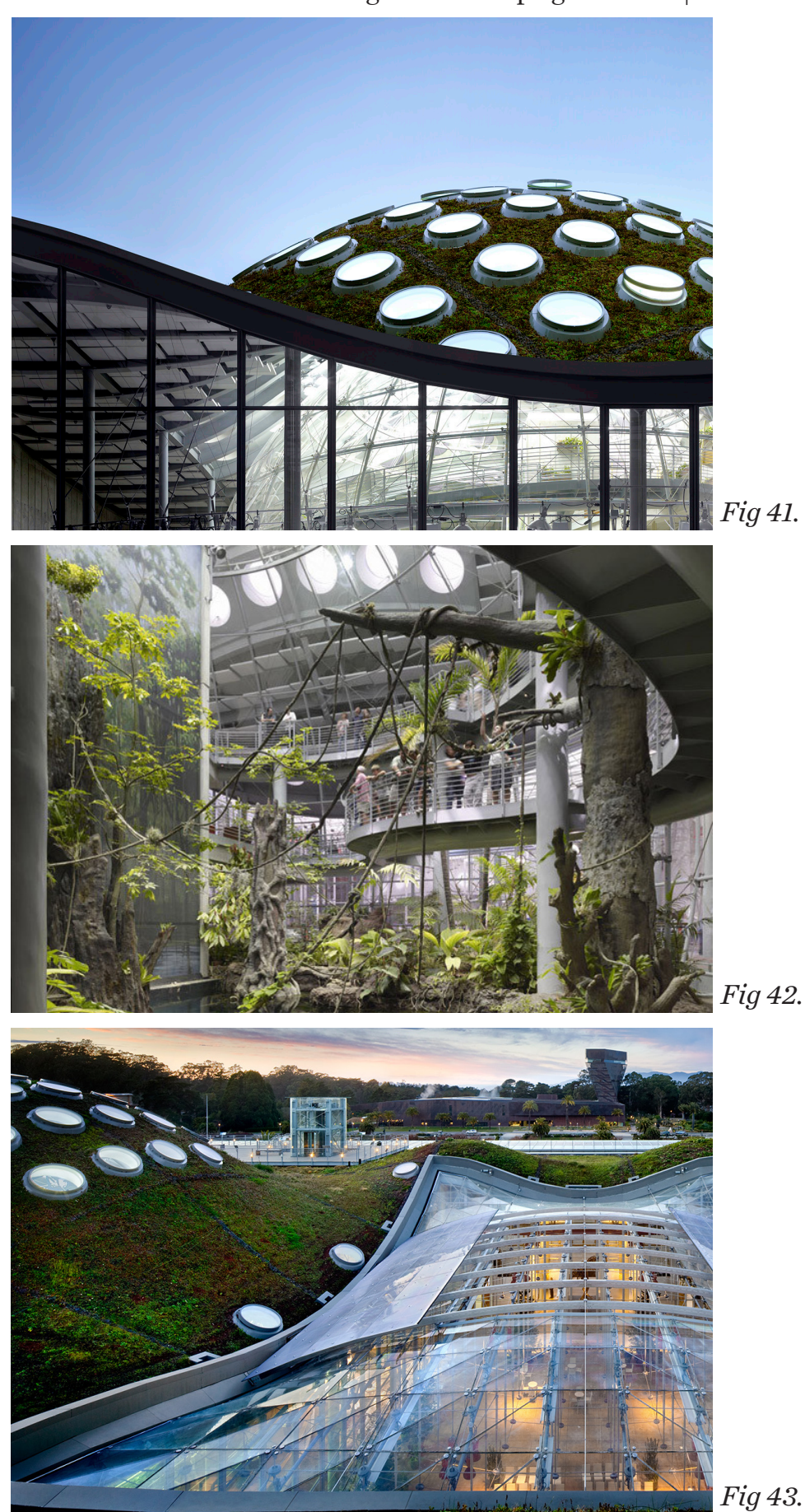


\subsubsection{GRIN GRIN PARK, FAKUOKA}

Location: Island City, Fukuoka, Kyushu, Japan

Date: Completed in 2005

Architect: Toyo Ito

The project has successfully blurred landscape and architecture in that there is no autonomous object but rather a new topographic environment with undulating landscape forming a spatial spiral for people to gather within. The facility houses a botanic garden and consists of three covered green houses, described as similar to pearls on a string.

The design strategy is that of a lattice/ shell structure that forms the landscape and architecture, acting similar to a green roof. The organic form further conveys the relationship to ecology and landscape, but results in inefficient space planning for non-garden programmatic requirements. The building has a language that separates ecology, circulation, internal spaces and road networking, through the use of elevated walkways, glass canopies and the arching structure over the road.

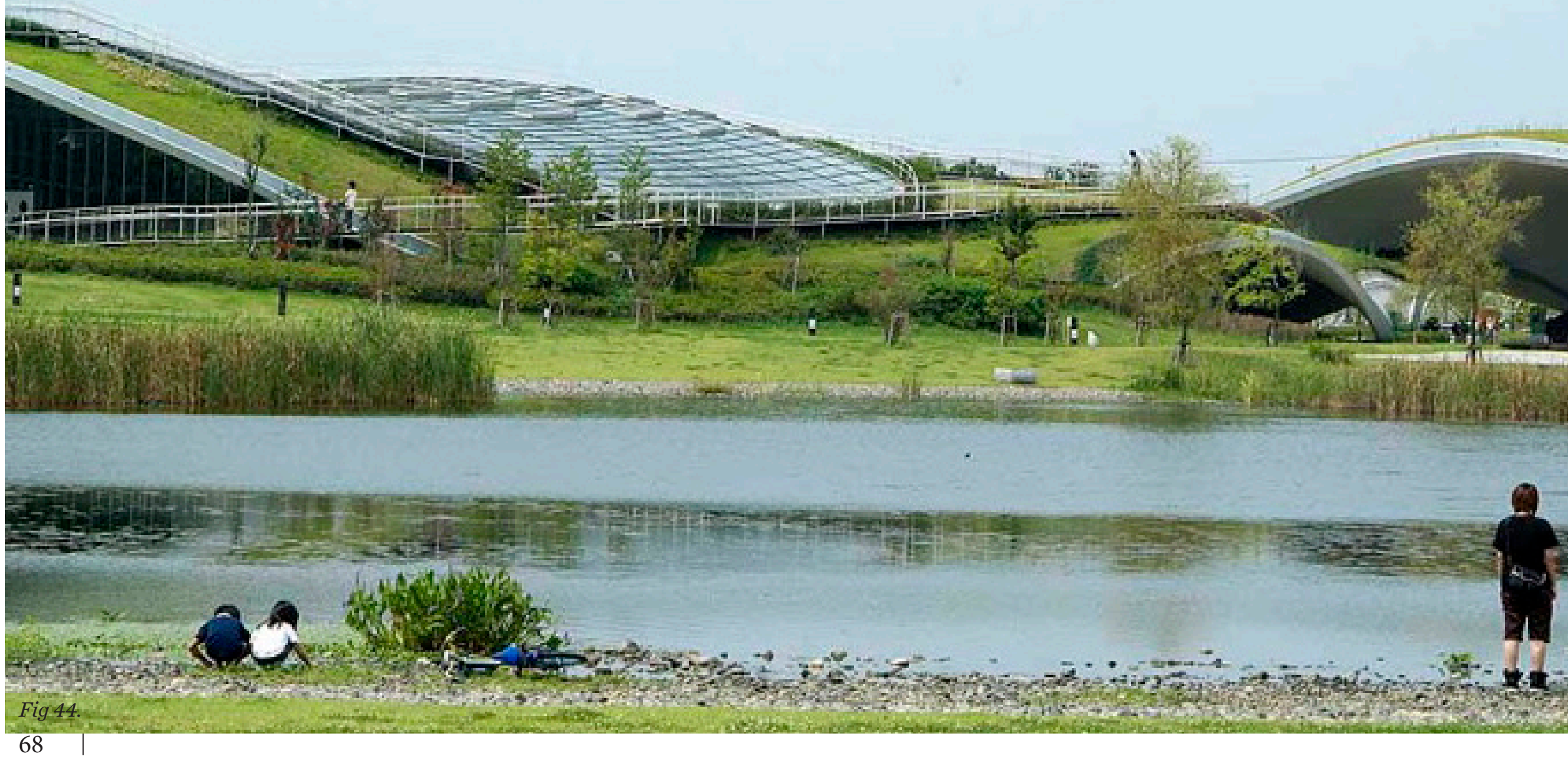




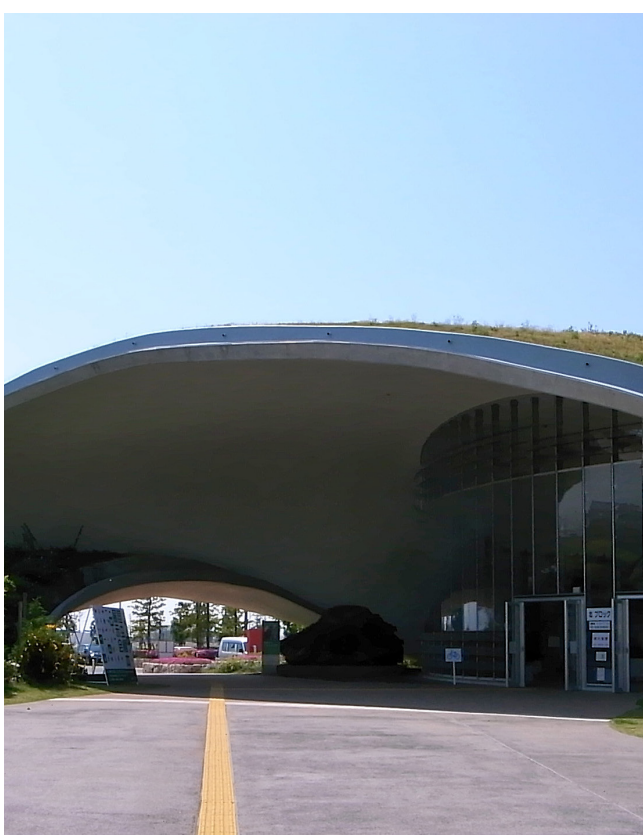

Fig 45.

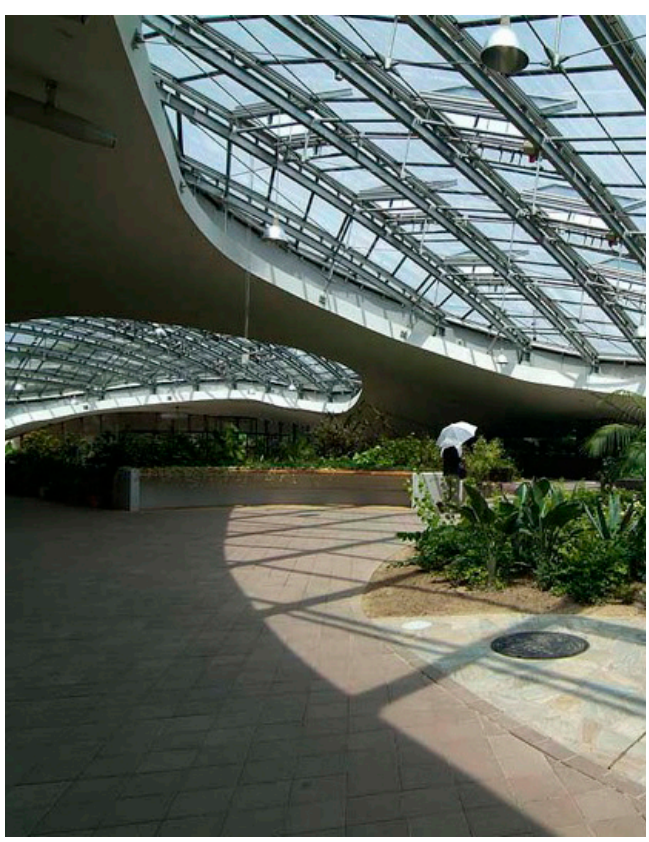

Fig 46 .

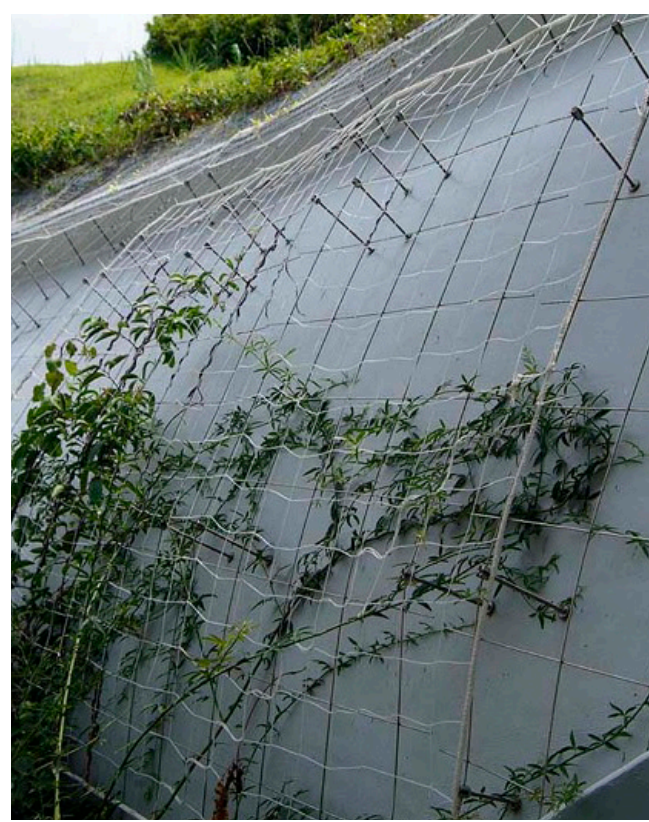

Fig 47 .
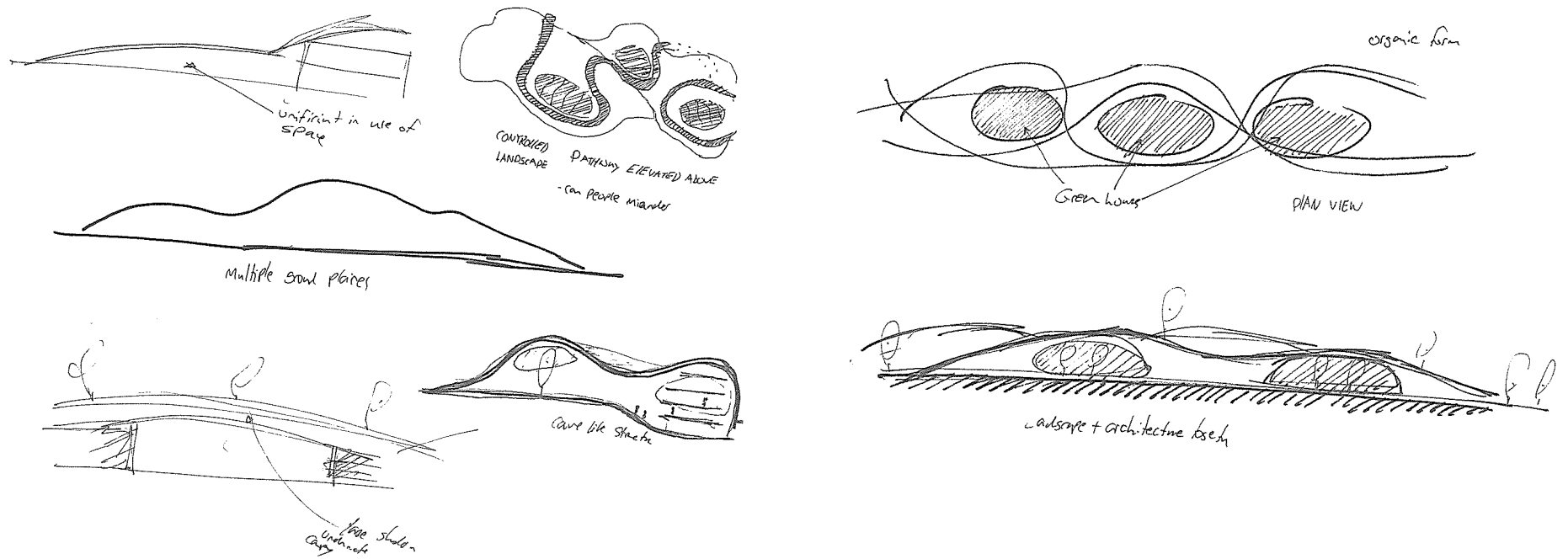

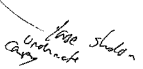

^Anaylsis of the organic form | 


\subsubsection{SUMMARY}

Each of these projects contain green-houses and a type of green roof which together contribute to the architectural integration with landscape. The projects all have a botanical focus either for research or spectacle. Integrating this botanical focus into a suburban centre will provide further legitimacy towards enhancing ecology and utilising green roofs and green-houses will provide a stronger 'eco-spectacle'. The greenhouses provide the opportunity for further horizontal and vertical circulation dissecting through the floor plates, making opportunities for the different functions at the different levels. An undulating green roof produces a secondary ground plane which can break up the height of buildings and separate different user groups from each other, such as separating consumers and residential occupants.
| Testing strategies implementing greenhouses into multileveld mixed use centre |

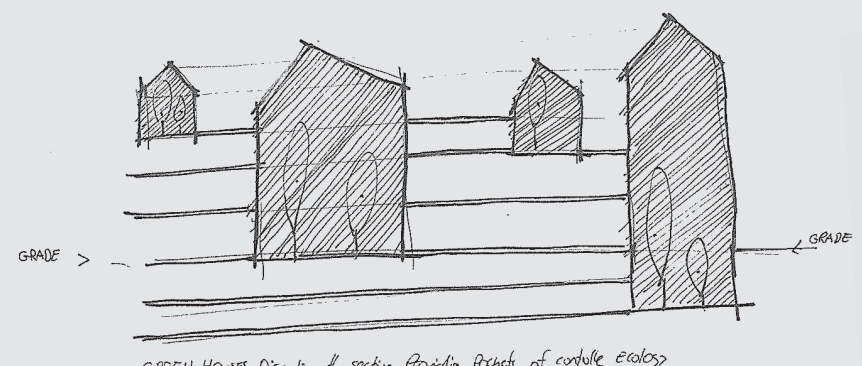

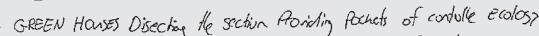

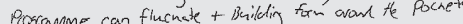
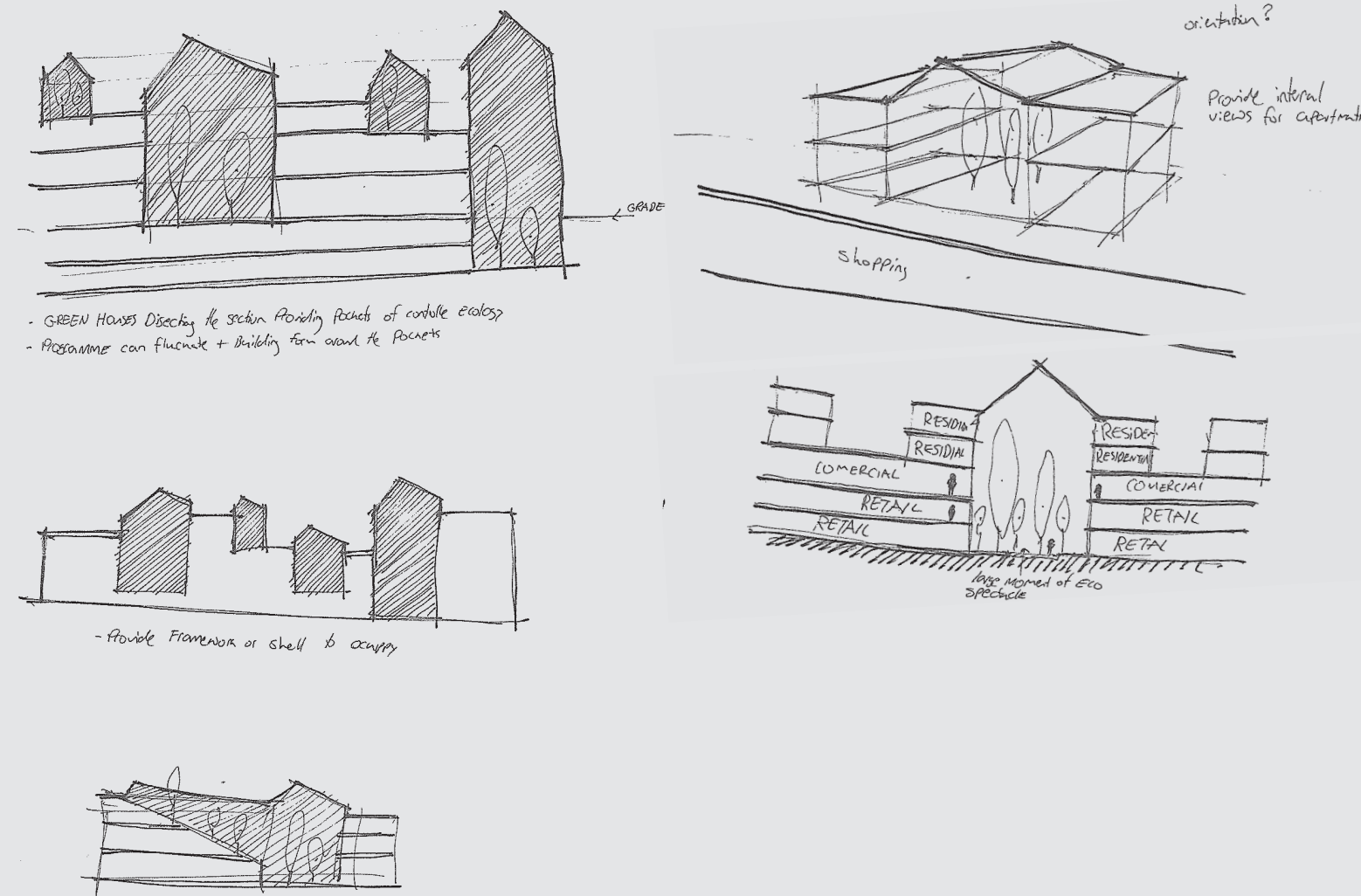

- custed throus sectin - Teraced aren Howe

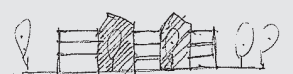

FORAAC STRAIEGy - sepervie but intorinted Ecolosy 


\section{| Utilising a canopy roof to seperate different spaces |}
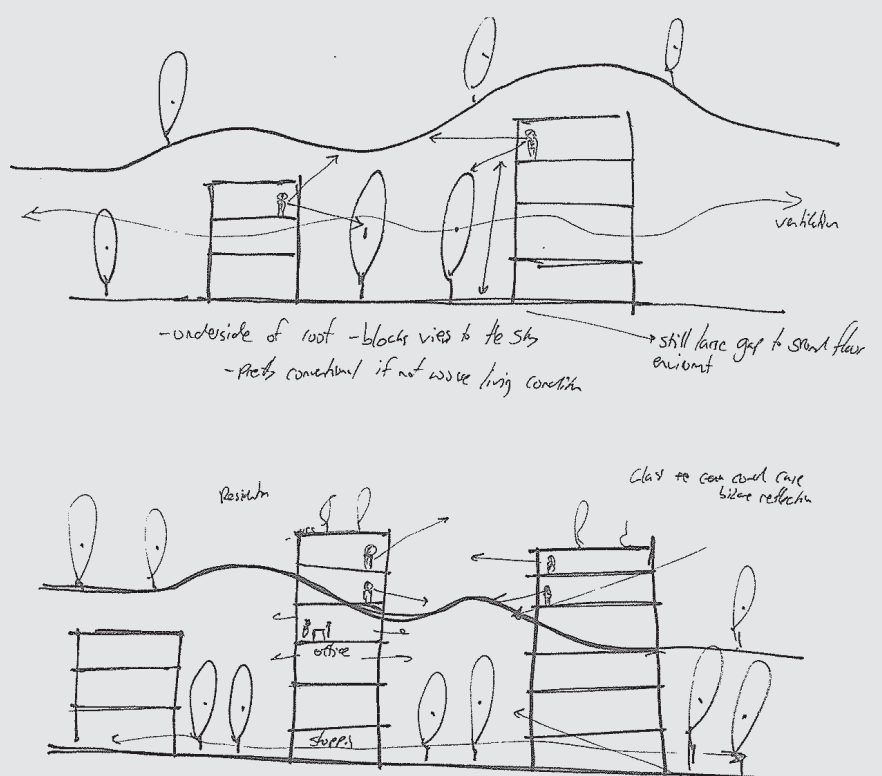

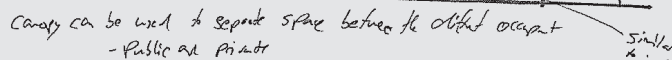

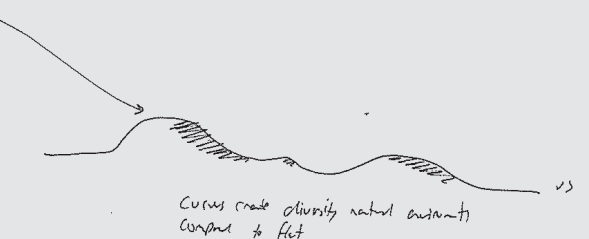

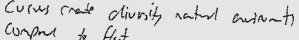

\section{| Utilising two landscaped levels roof and ground}
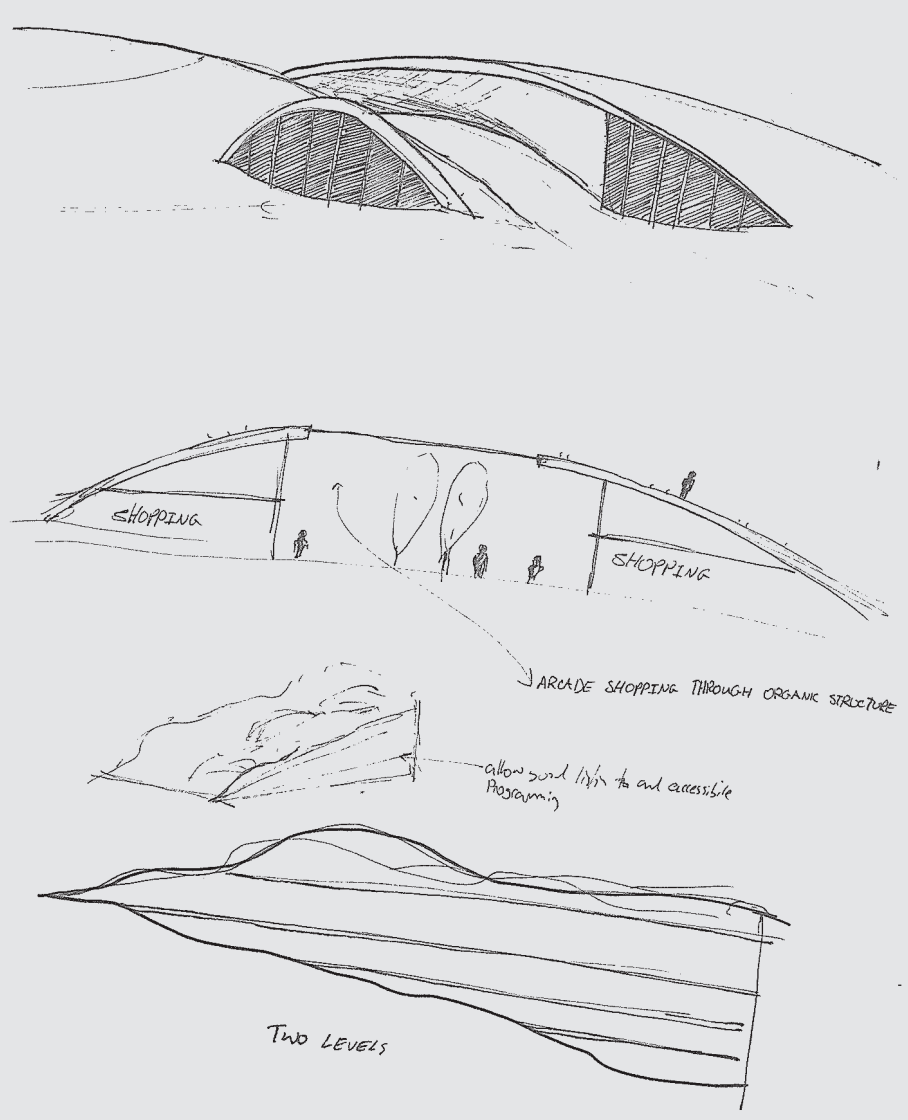


\section{CONTEXT-LESS SITE PLANNING}

Context-less site planning involves sketch design of the five site scenarios established in chapter 3.1. The process involves three reiterations: (i) initial sketch design; (ii) new-urbanism strategies of implementing road networks, pedestrian paths and squares and (iii) eco-masterplanning testing eco bridges and green corridors. The sketch design of the situations, 'along arterial road', 'intersection' and 'railway tracks' are displayed below. 


\section{ALONG ARTERIAL ROAD}
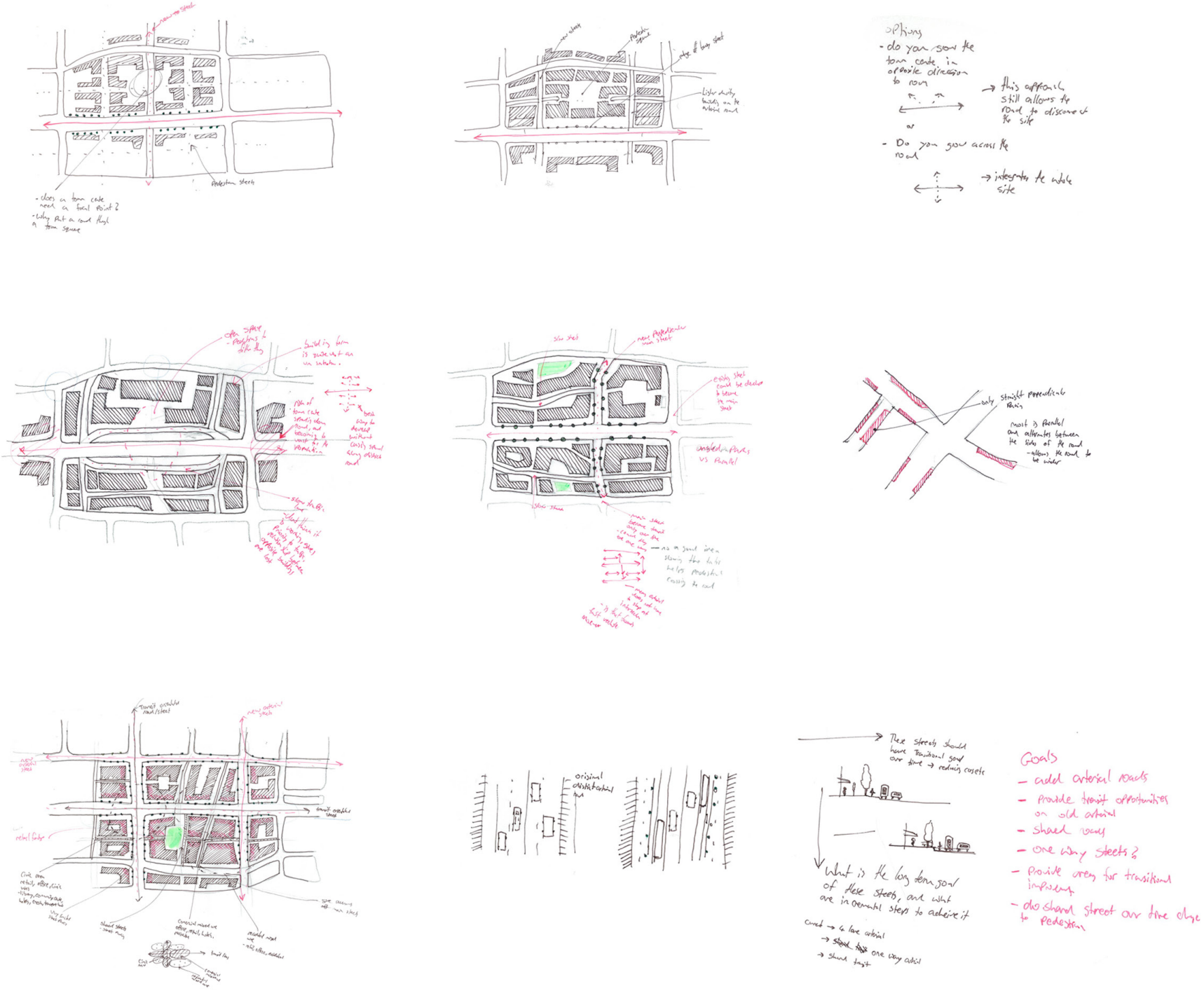


\section{INTERSECTION}
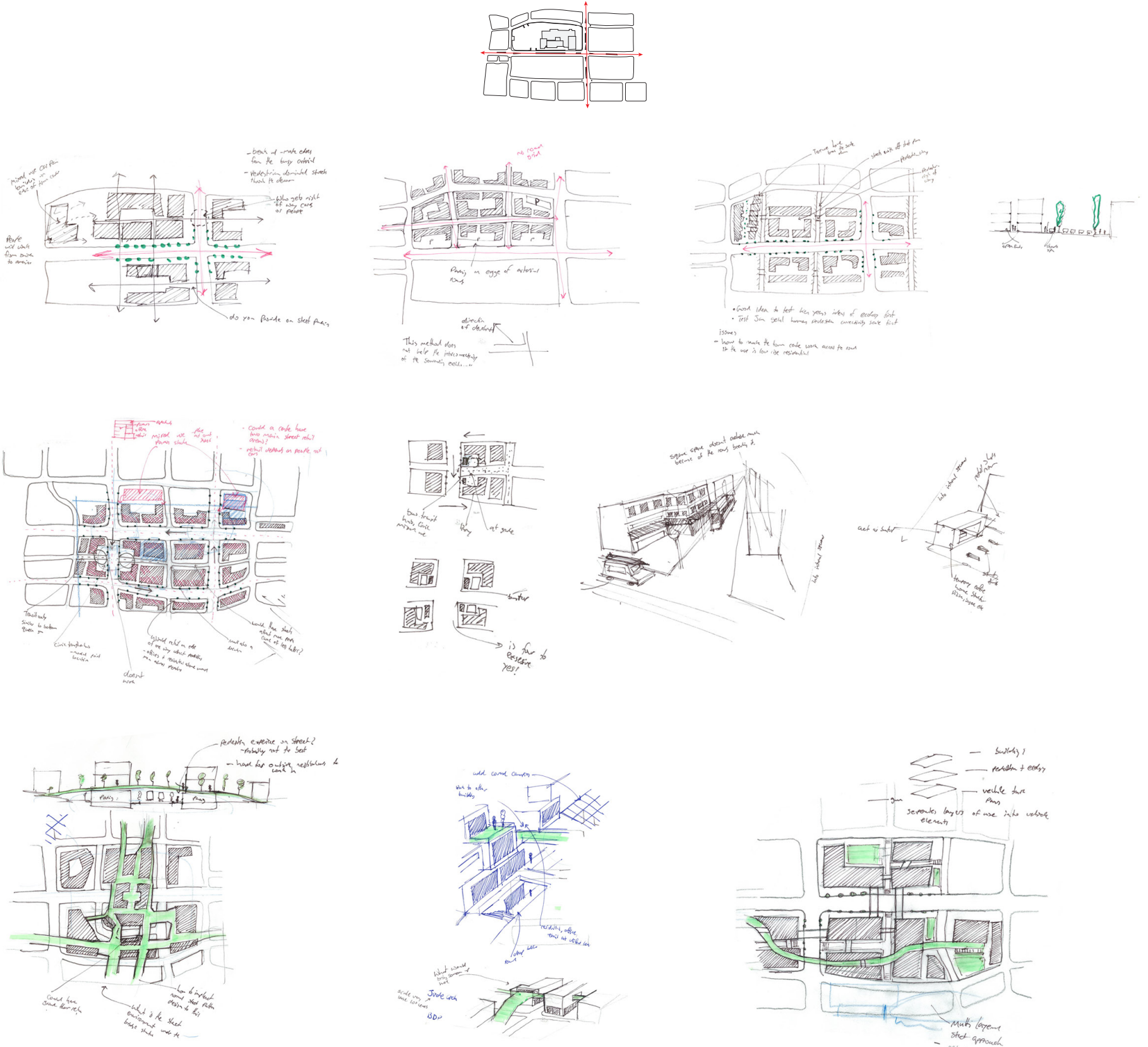

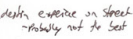
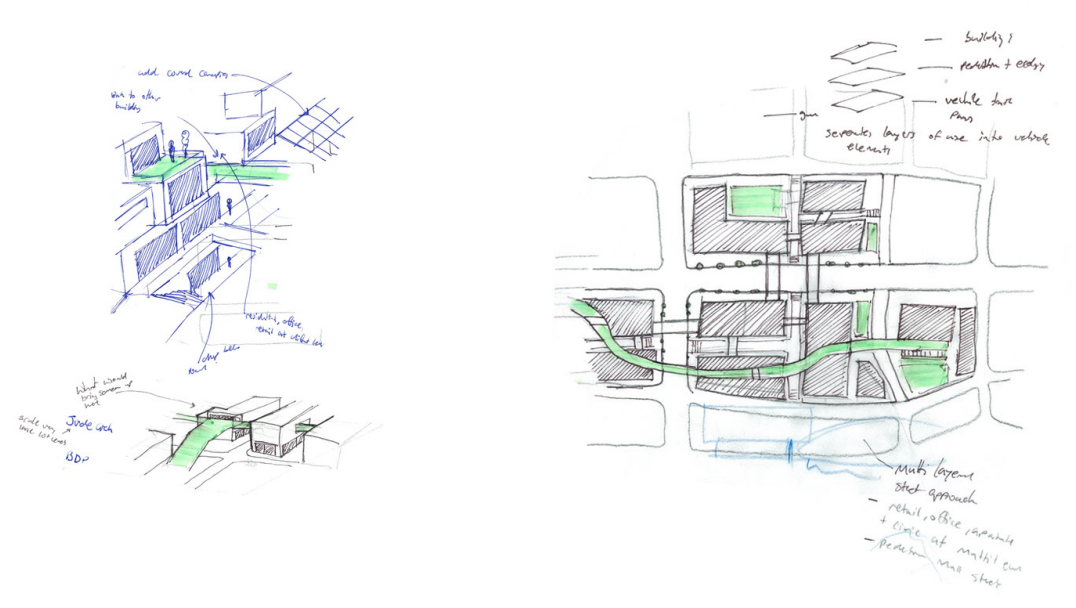


\section{RAILWAY TRACKS}
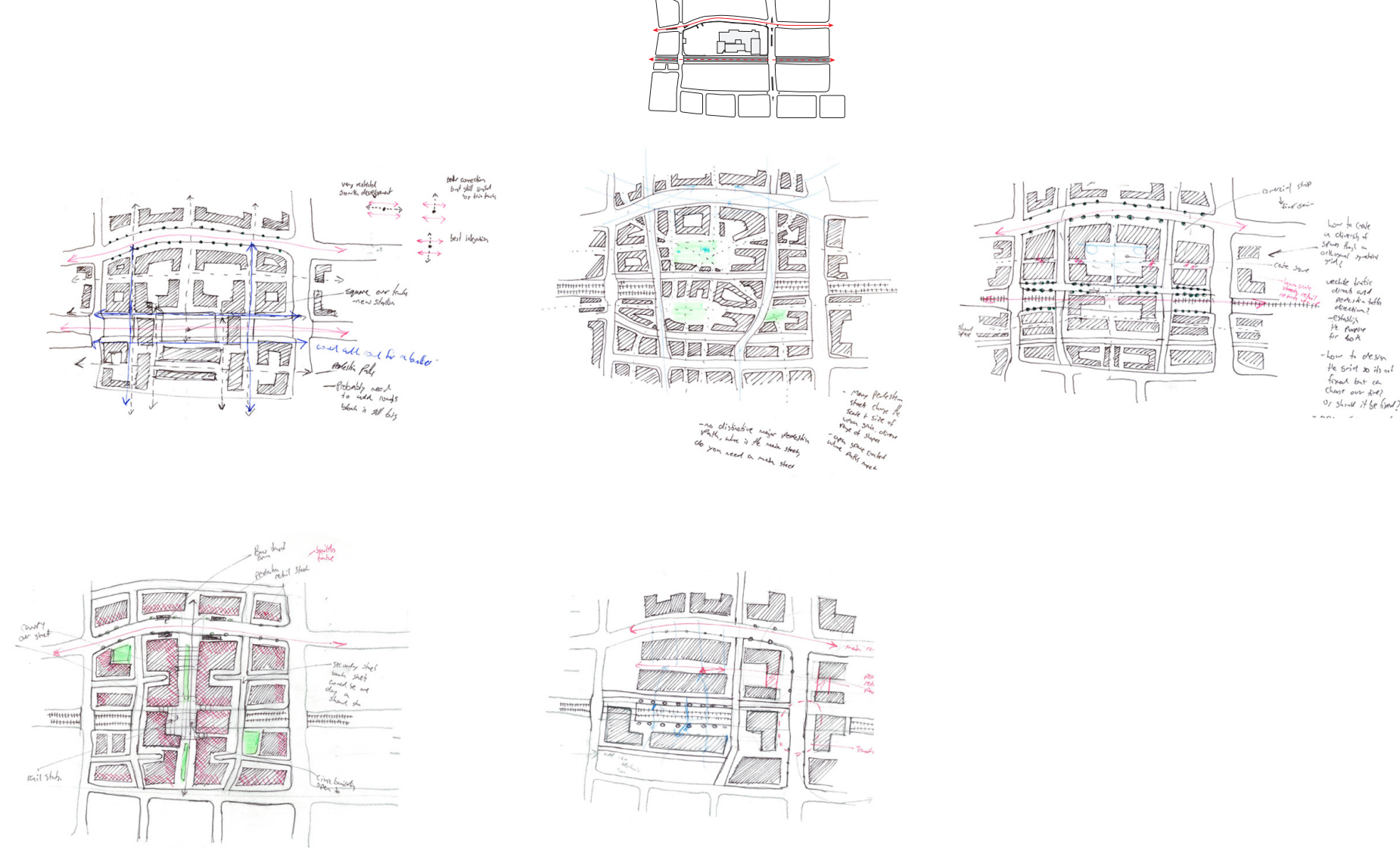

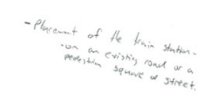
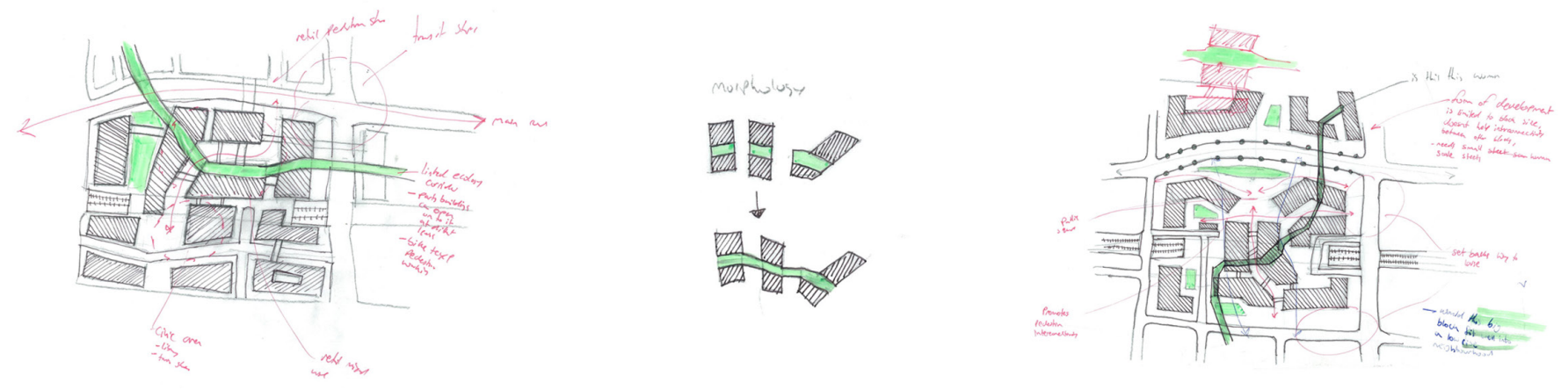


\section{SUMMARY}

The strategies that evolved through this experimentation were universal and could be applied to any of the site situations. As the process evolved each situation built on and clarified ideas from the previous situation. The outcome proved the assumptions that each situation would need their own individual design strategies wrong.

\section{Planning strategies:}

- Dynamic Street grid (corners, curves and asymmetrical)

- Highline corridor for pedestrian and cycle amenity

- Develop at the intersections

- Secondary road networks split the traffic on the grid

- Diversity of building footprint and size
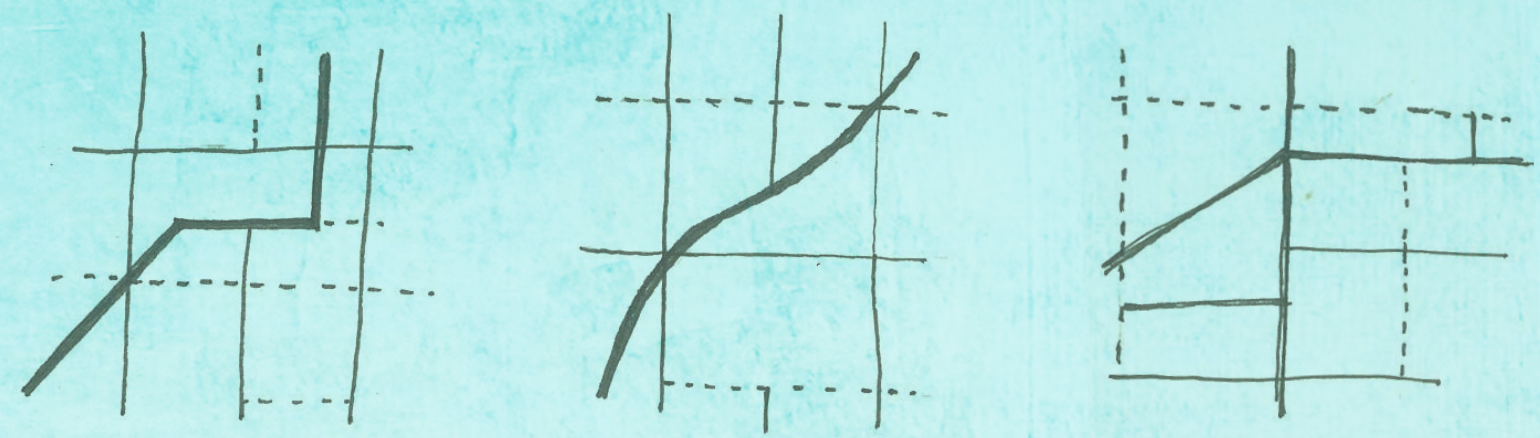

Dynamic Street Grid (Corners, curves \& asymimetricy)
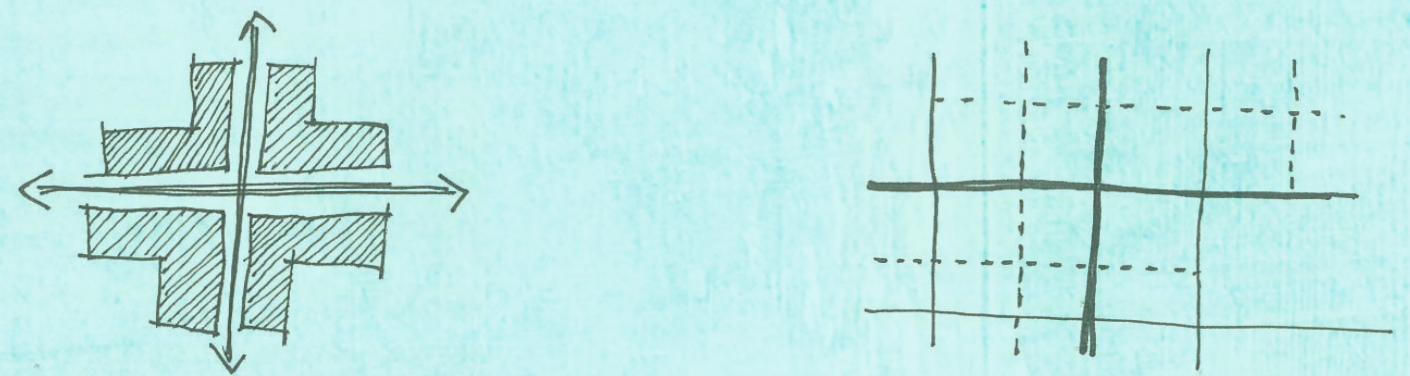

Intensify Intersections

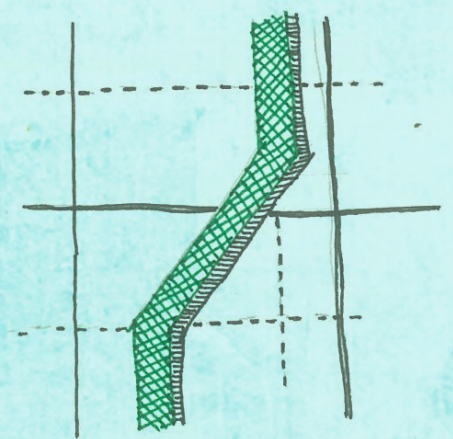

Highline Green Corridors
Secondary road networks splitting traffic along the grid

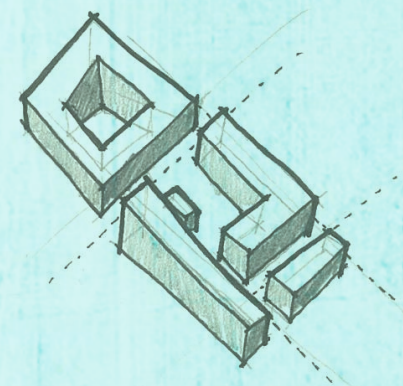

Diversity of foorprint \& scale 


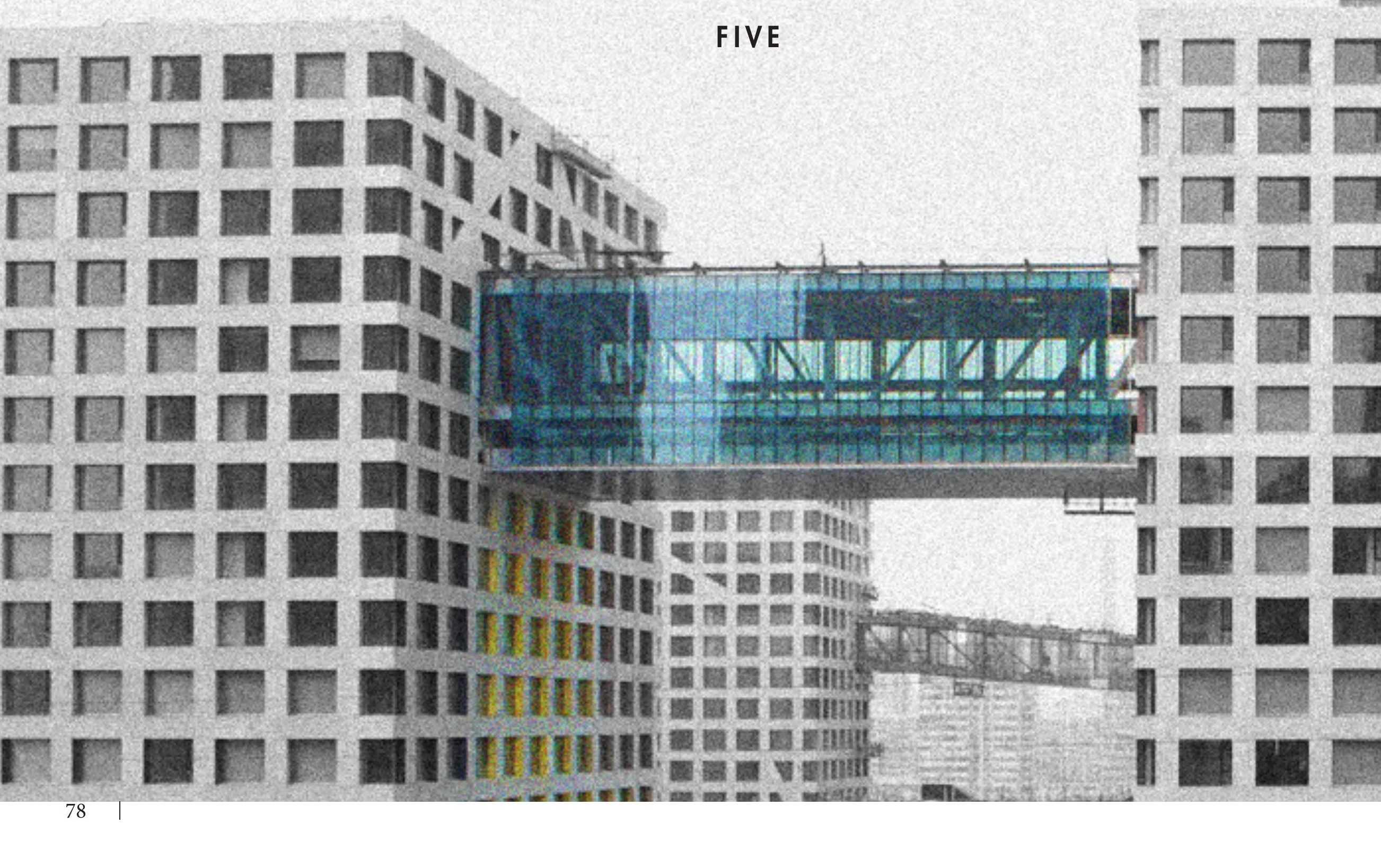




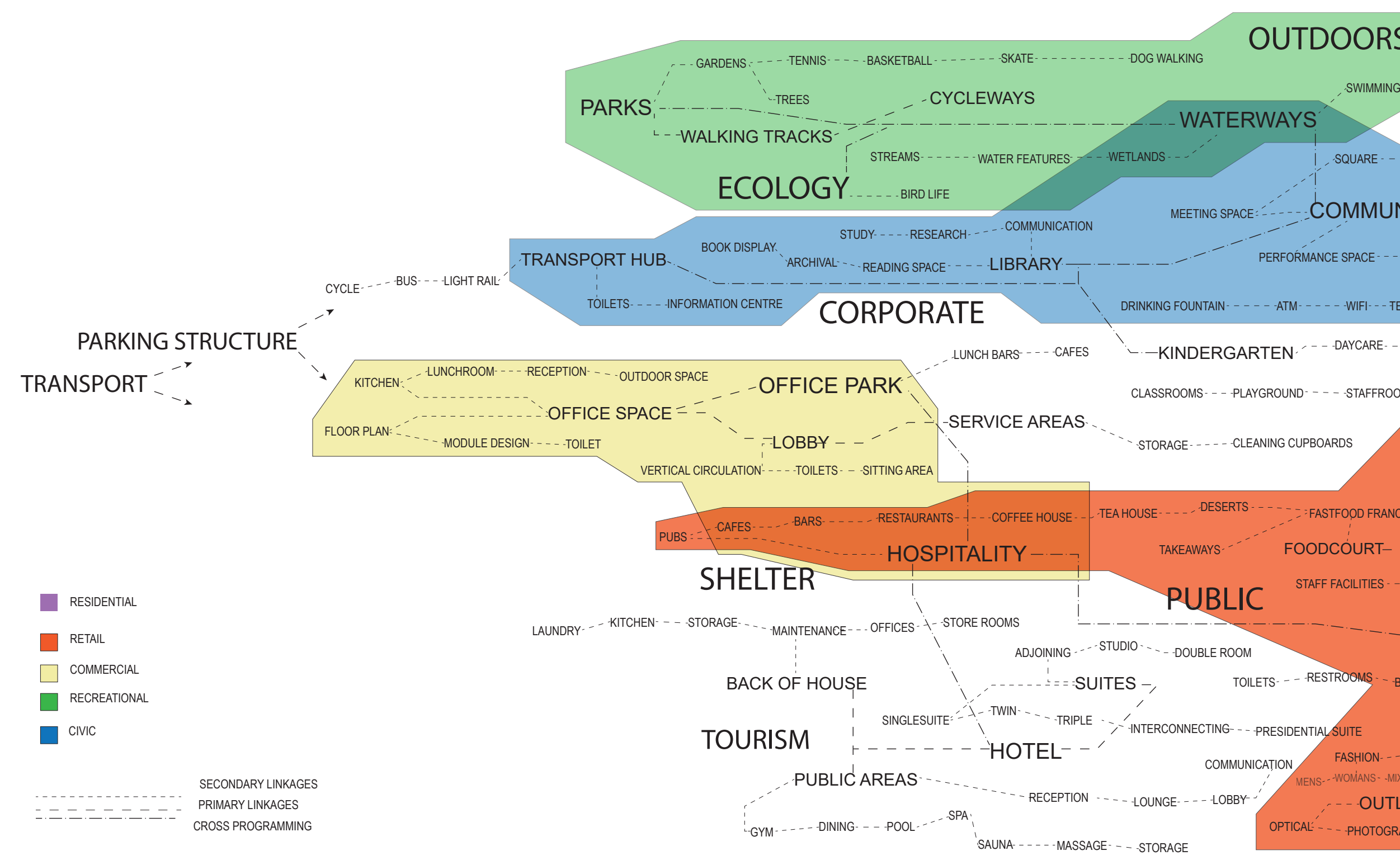




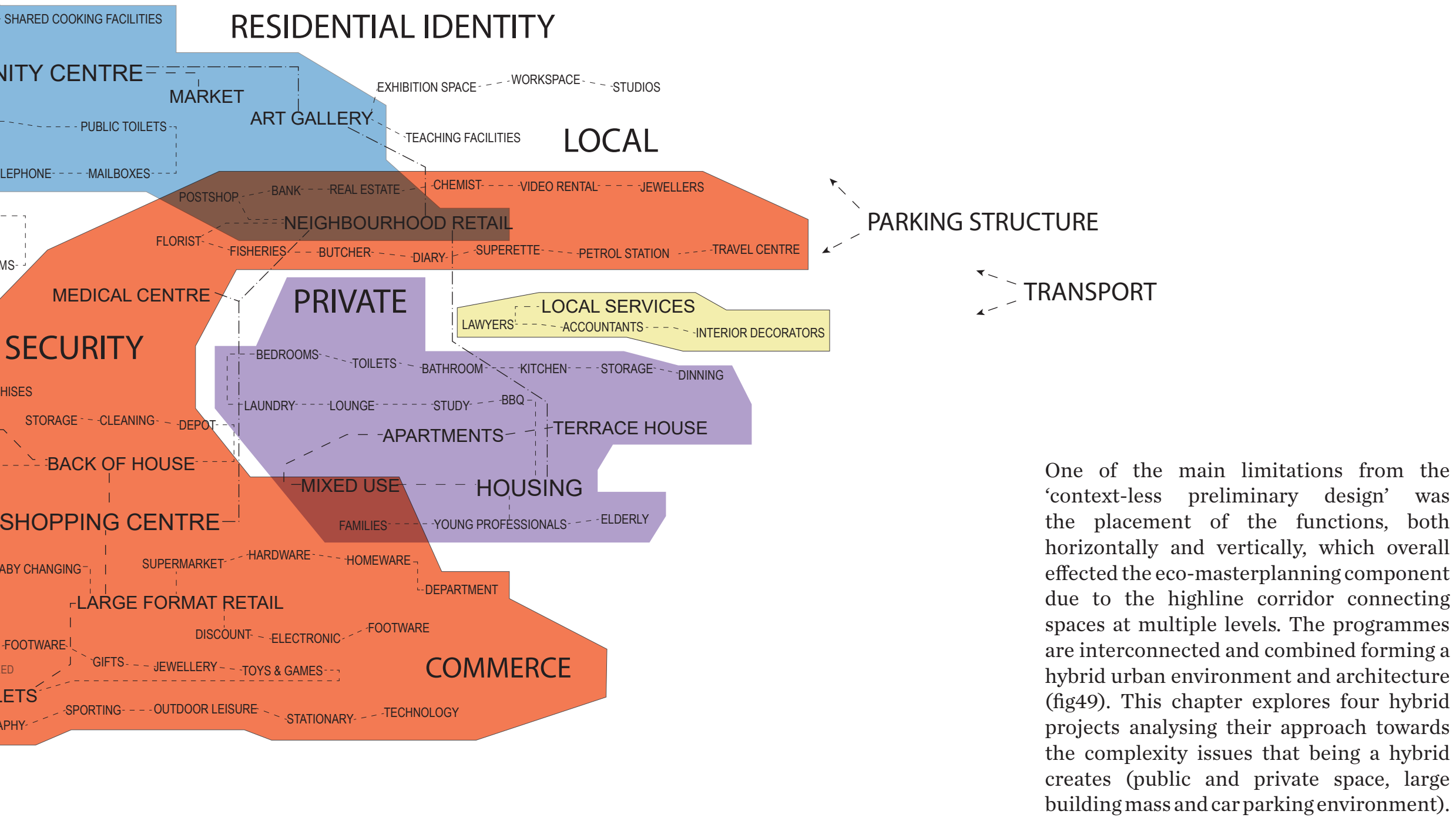

One of the main limitations from the 'context-less preliminary design' was the placement of the functions, both horizontally and vertically, which overall effected the eco-masterplanning component due to the highline corridor connecting spaces at multiple levels. The programmes are interconnected and combined forming a hybrid urban environment and architecture (fig49). This chapter explores four hybrid projects analysing their approach towards the complexity issues that being a hybrid creates (public and private space, large building mass and car parking environment). 


\subsection{RED HILL RISE PROJECT | MAXWAN + MS ARCHITEKTI}

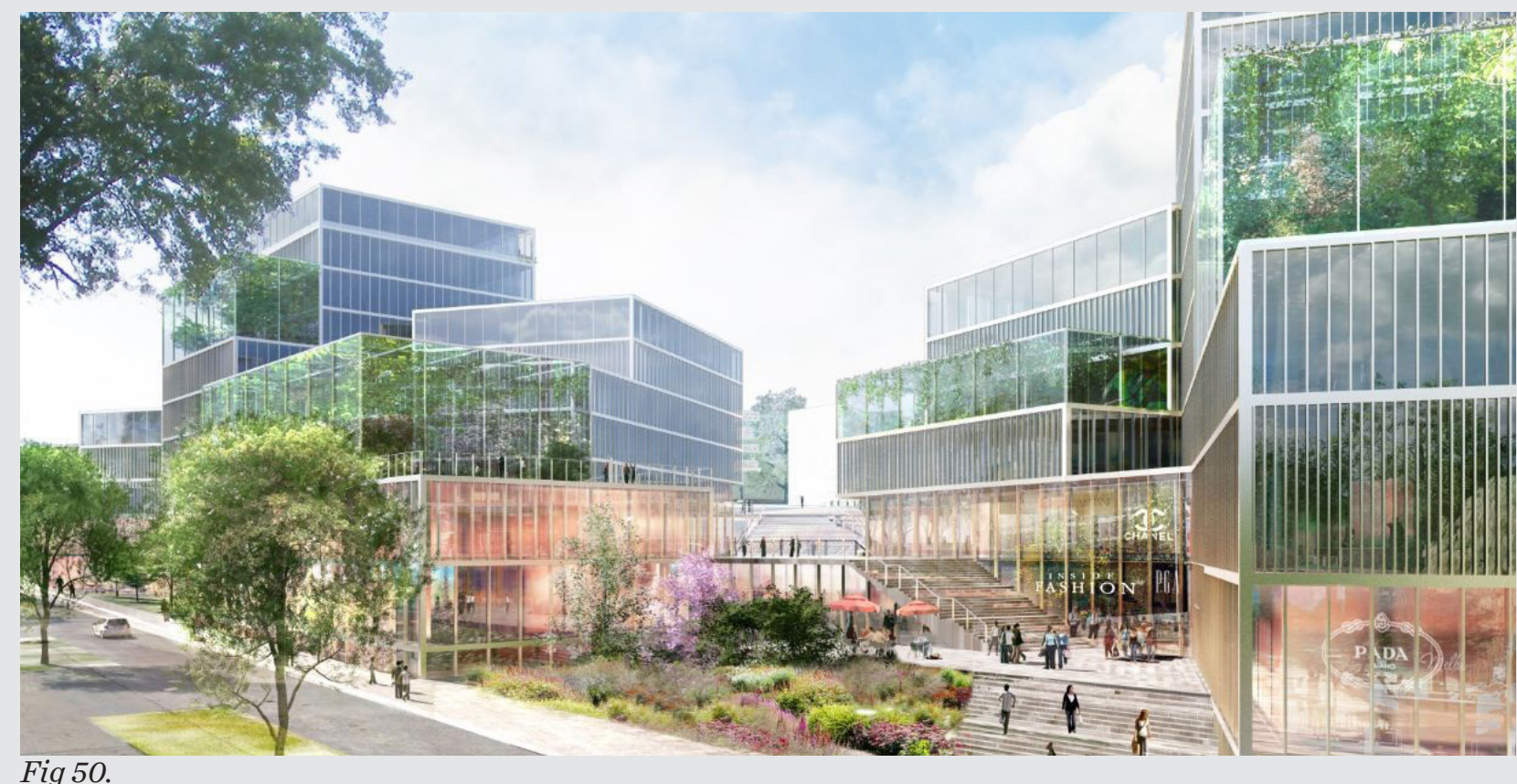

Location: Prague, Czech Republic

An intensified development located above a metro station that combines offices and retail programmes. Programmatic Strategy utilises the site's gradient to make multiple ground levels that naturally progress down the site. The bulk of the building is broken through the use of rooftop terraces.

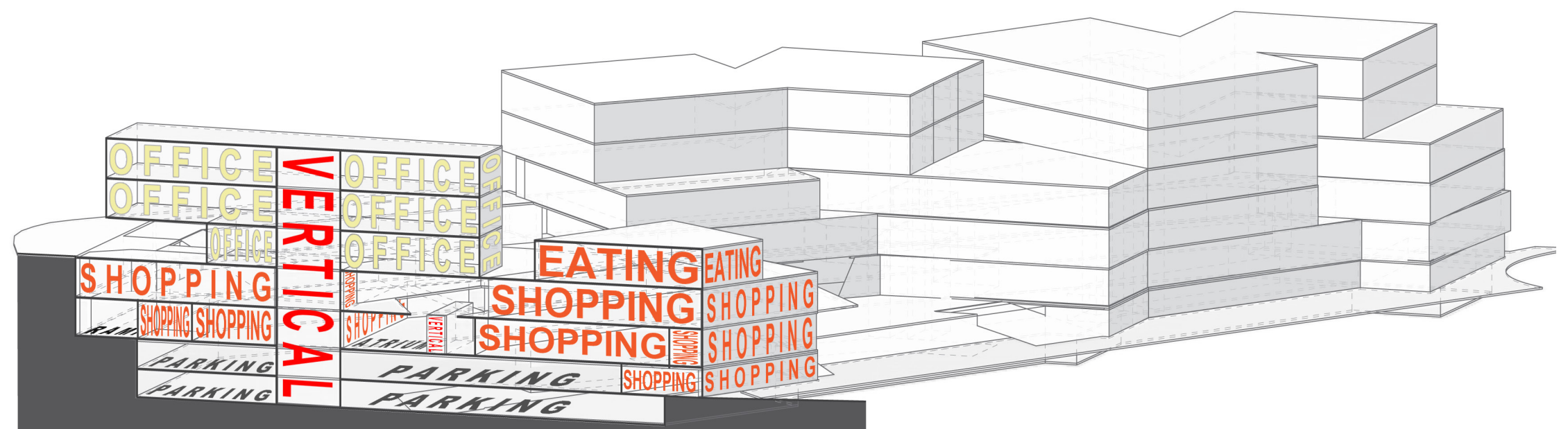




\subsection{HOLBAEK HAVENBY | KULLEGAARD}

Location: Holbaek, Denmark

This project is a hybrid made up of a parking structure, supermarket, shops, restaurant and residential apartments. The differentiation of the public and private spaces successfully breaks up the large mass of the structure. The rooftop garden above the car park creates residential identity for the occupants as well as providing them with an open space.
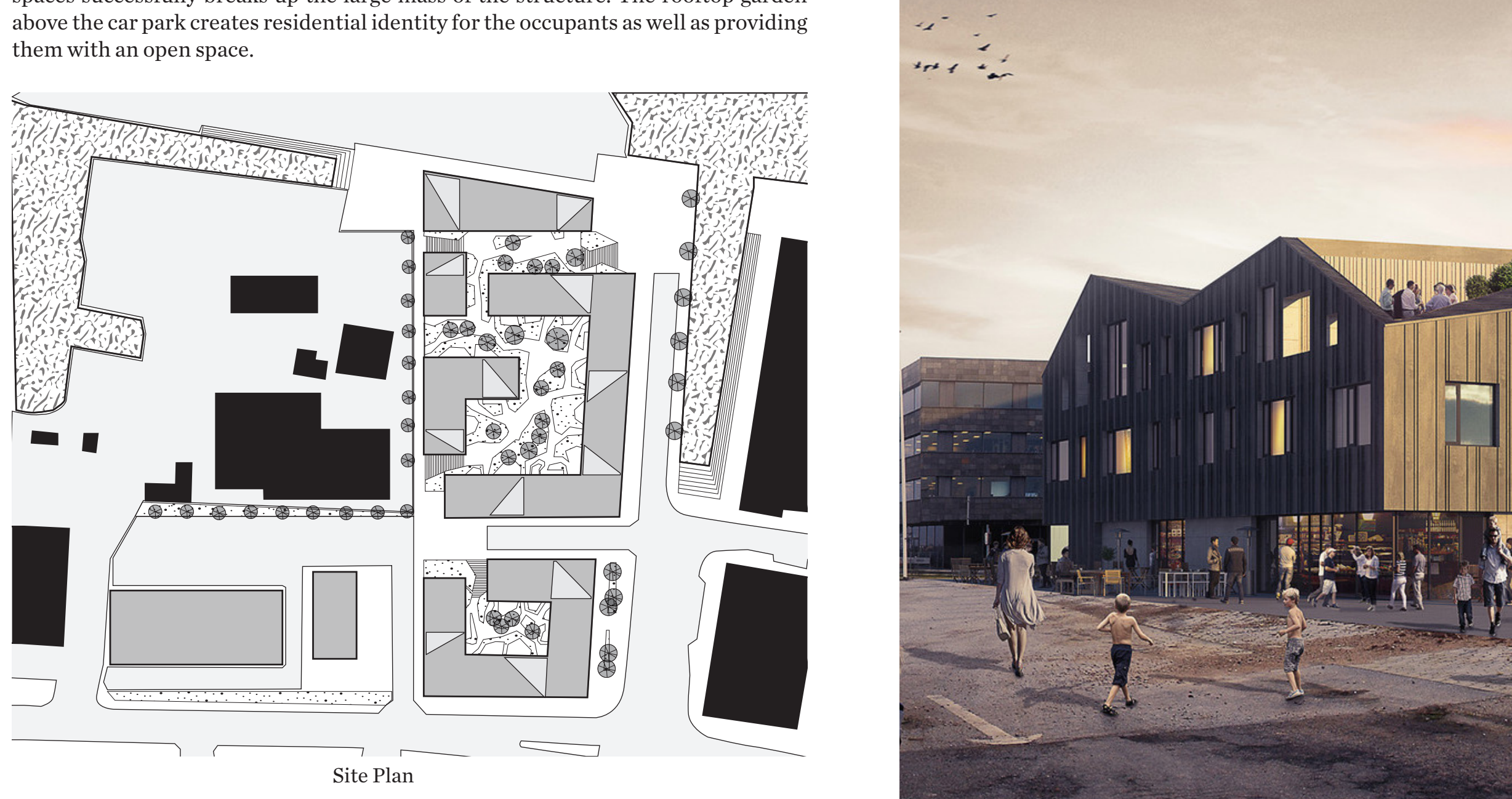


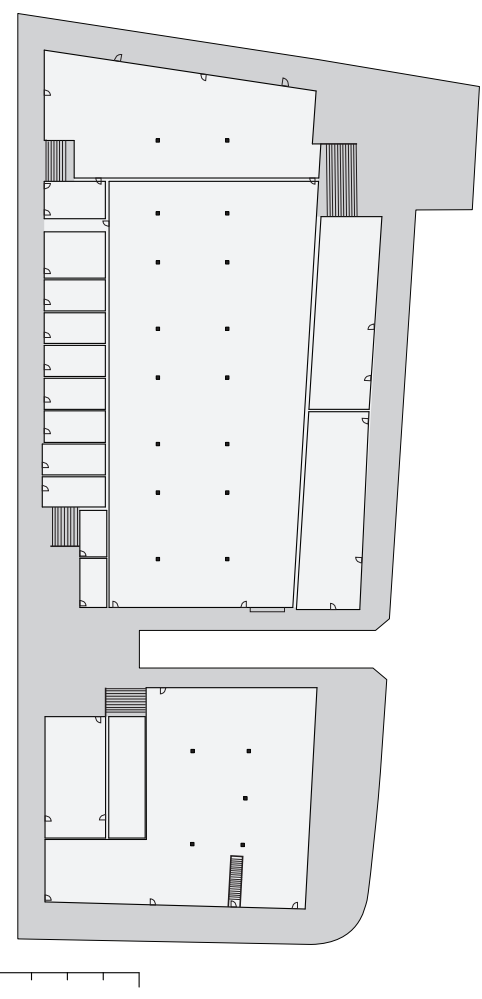

Ground Floor Plan
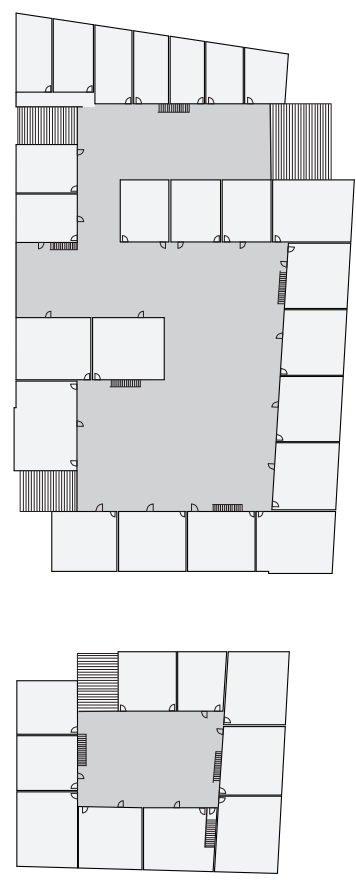

$\square, \quad, \quad$

Level 1 Floor Plan

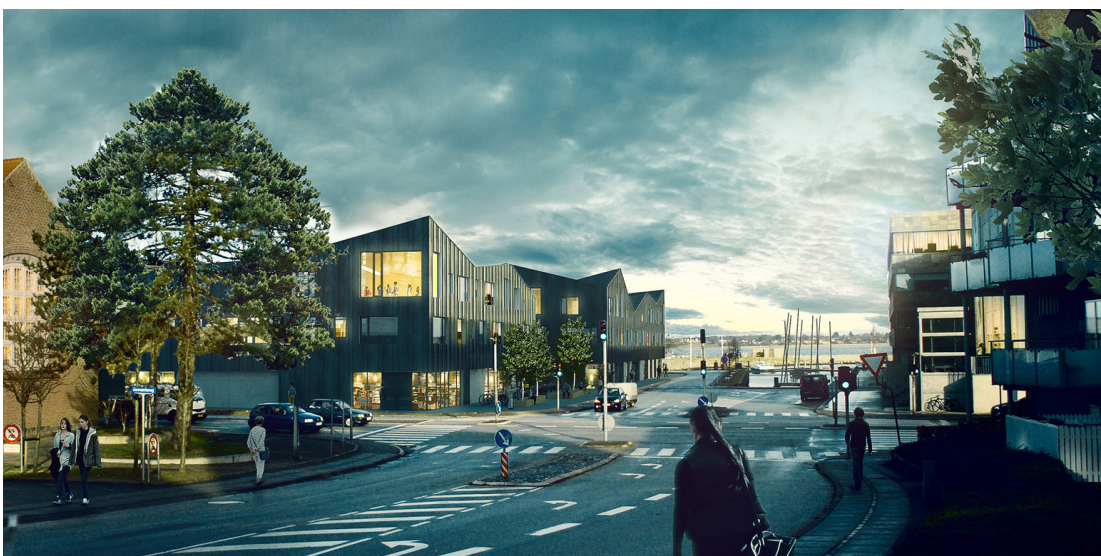

Fig 53.

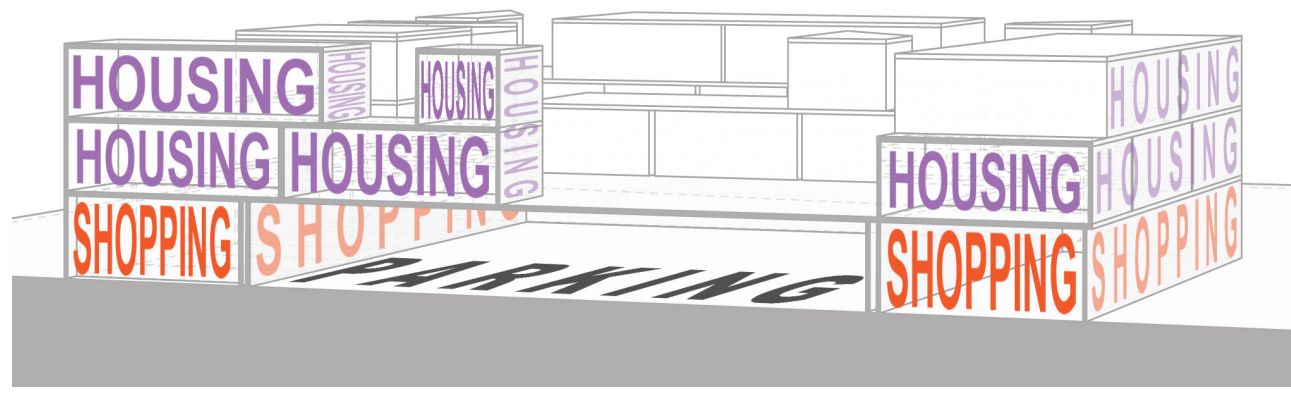

Distribution of programs sectional diagram

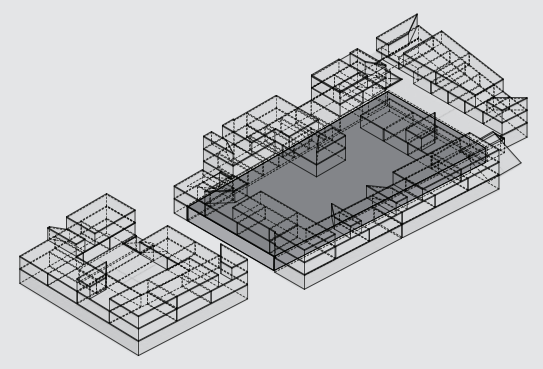

Parking

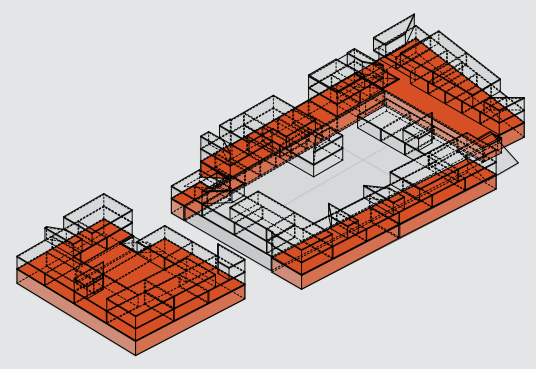

Retail

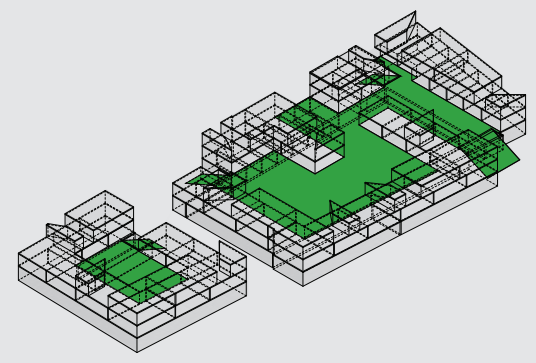

Park

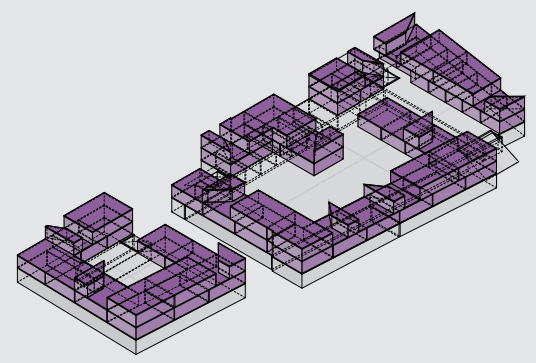

Residential 


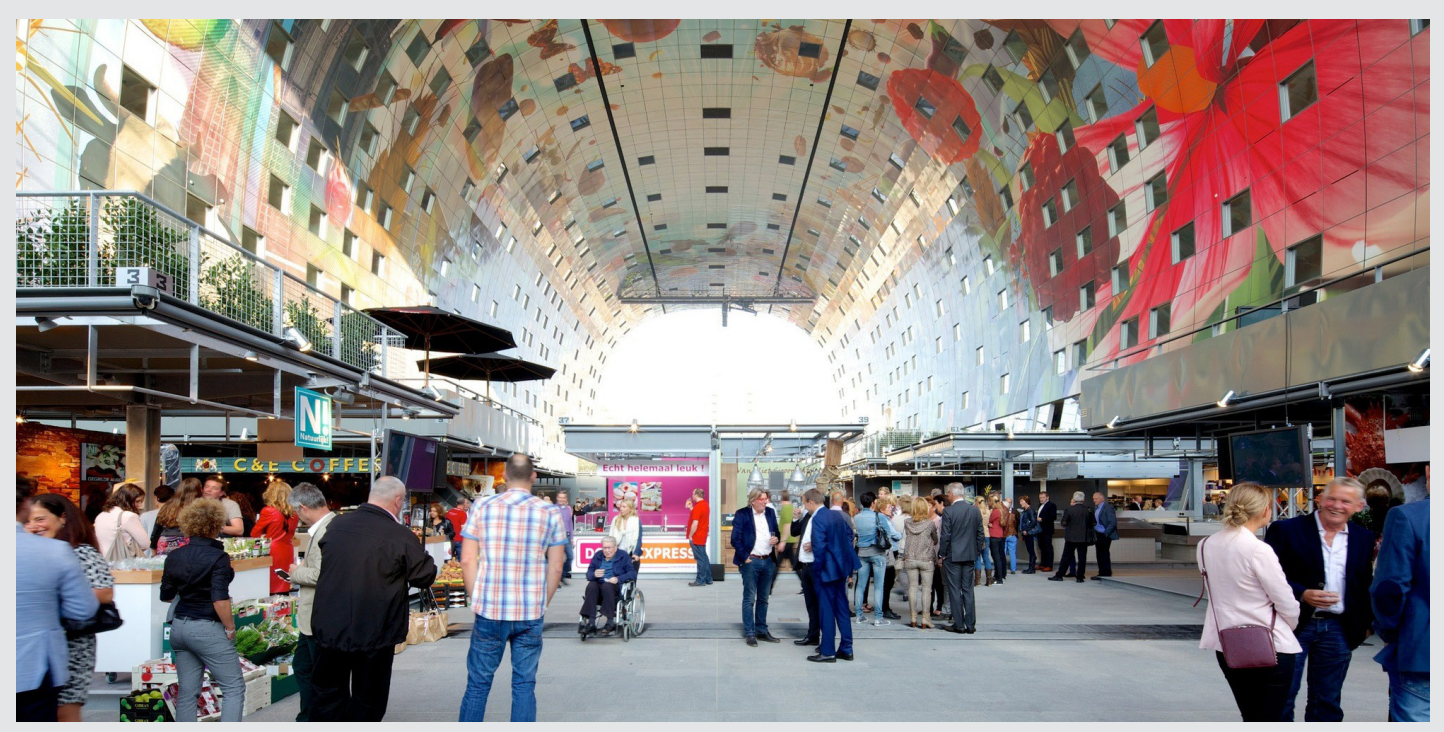

Location: Rotterdam, The Netherlands

Date: 2014

The combination of arcade, apartments, shops, markets, supermarket and parking creates a new hybrid in the distinctive form of an arch. A large vertical void is used to connect the underground parking and supermarket to the market space on the ground floor, providing natural light to this otherwise sterile environment. The residential apartments are serviced by multiple vertical cores, a maximum of 4 apartments per lift.

Fig 55.

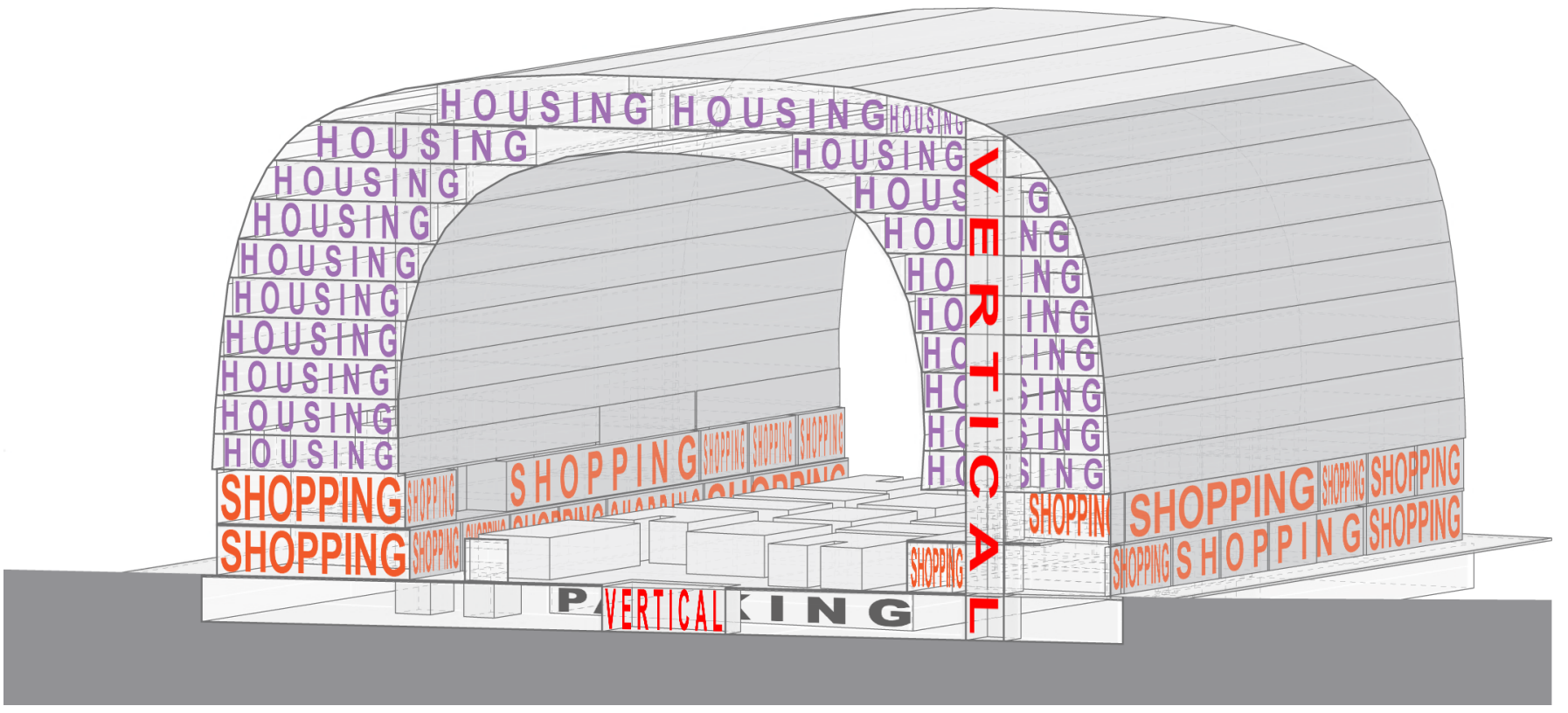




\subsection{LINKED HYBRID | STEVEN HOLL}

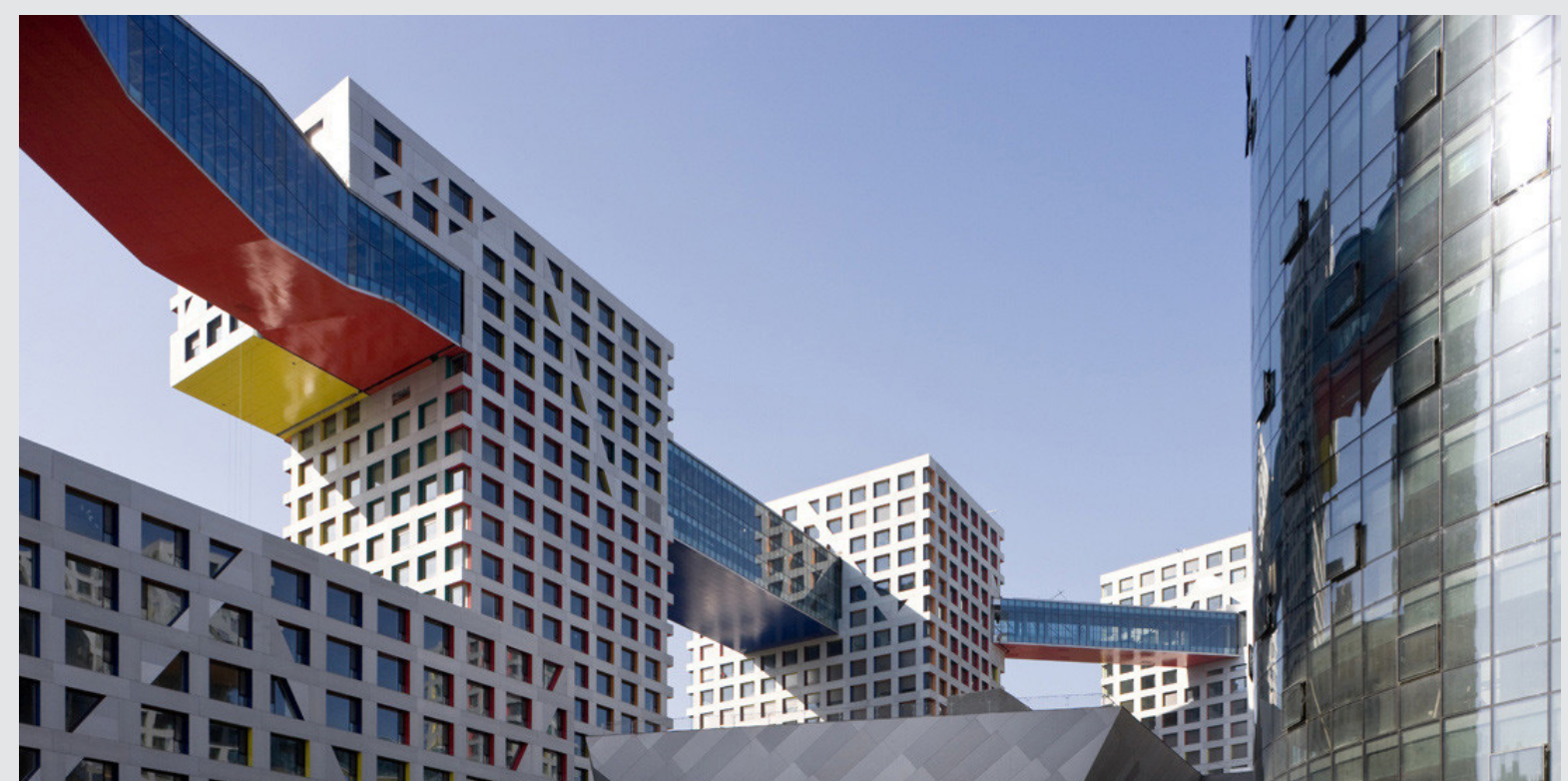

Location: Beijing, China

\section{Date: 2009}

The project has a multitude of buildings that combines retail, parking, office, civic and residential into an inter-connected hybrid. Roof top terraces successfully break up the mass and provide amenity to the different programs. The towers are connected by a bridge and have civic uses such as art galleries, bars, cafes, a gym, pools etc and therefore generate public space on the higher levels of the buildings.

Fig 56.

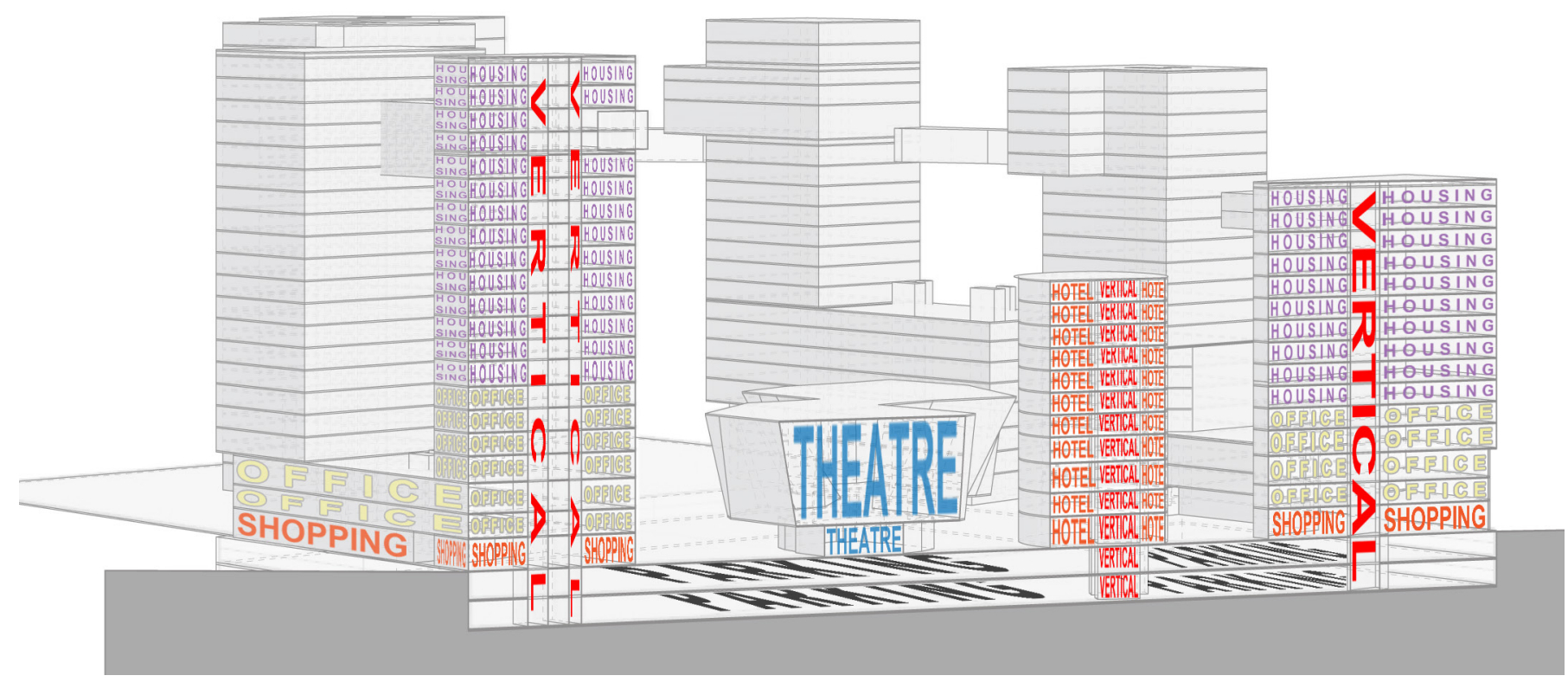




\subsection{SUMMARY}

Each project successfully combined multiple programs with a high quality architectural result. Rooftop terraces and large vertical voids were utilised across all the projects to break up the mass, provide private space, differentiate function and open up underground spaces. Utilising these techniques provided a multiple ground level public space at different levels, achieving an environment that is diverse and intriguing to experience.

\section{Project Strategies:}

- Multiple public levels

- $\quad$ Breaking the mass through rooftop terraces

- $\quad$ Dissolving parking structure with retail

- Intersecting interior spaces with naturally lit voids

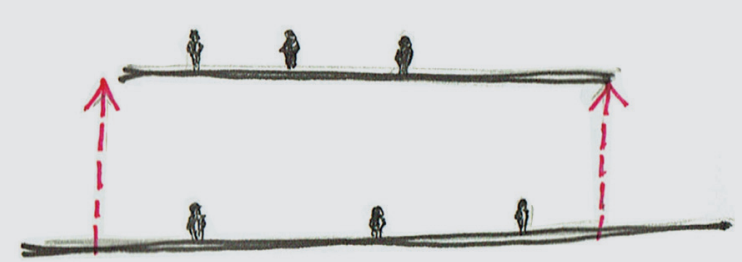

Multiple Public levels

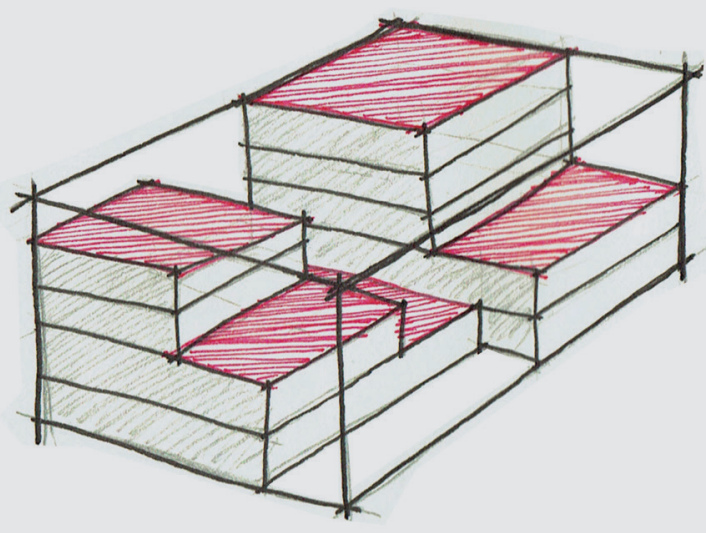

Rooftop terraces breaking up large mass 


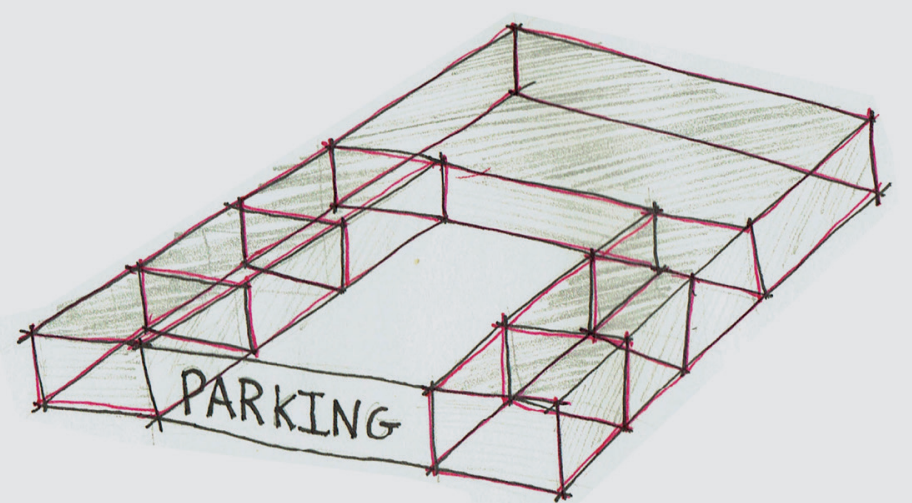

Dissolving parking structure with retail layer

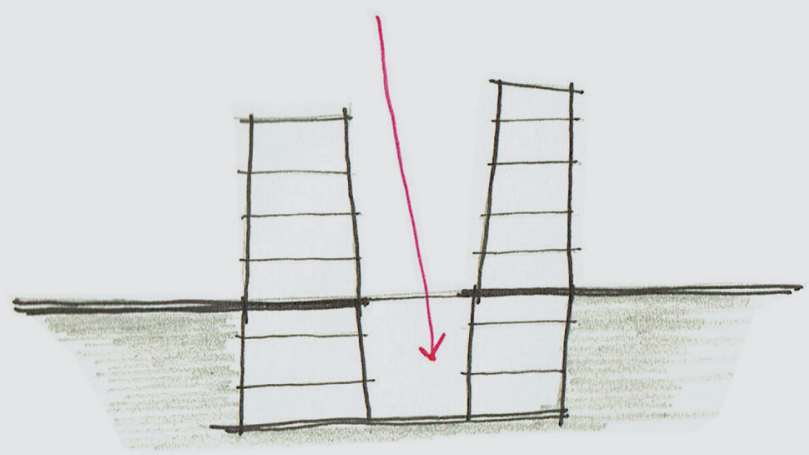

Voids naturally light interior spaces 


\section{CONTEXT PLANNING}

Context Planning explores conceptual master planning for four shopping centres in Auckland. Two centres were chosen out west and two out east, consisting of Kelston Shopping Centre, Westfield St Lukes, Highland Park and Botany Town Centre. Each site has different demographics, topographic conditions and natural features. Some centres are thriving while others have vacant leases. 


\section{WEST AUCKLAND}

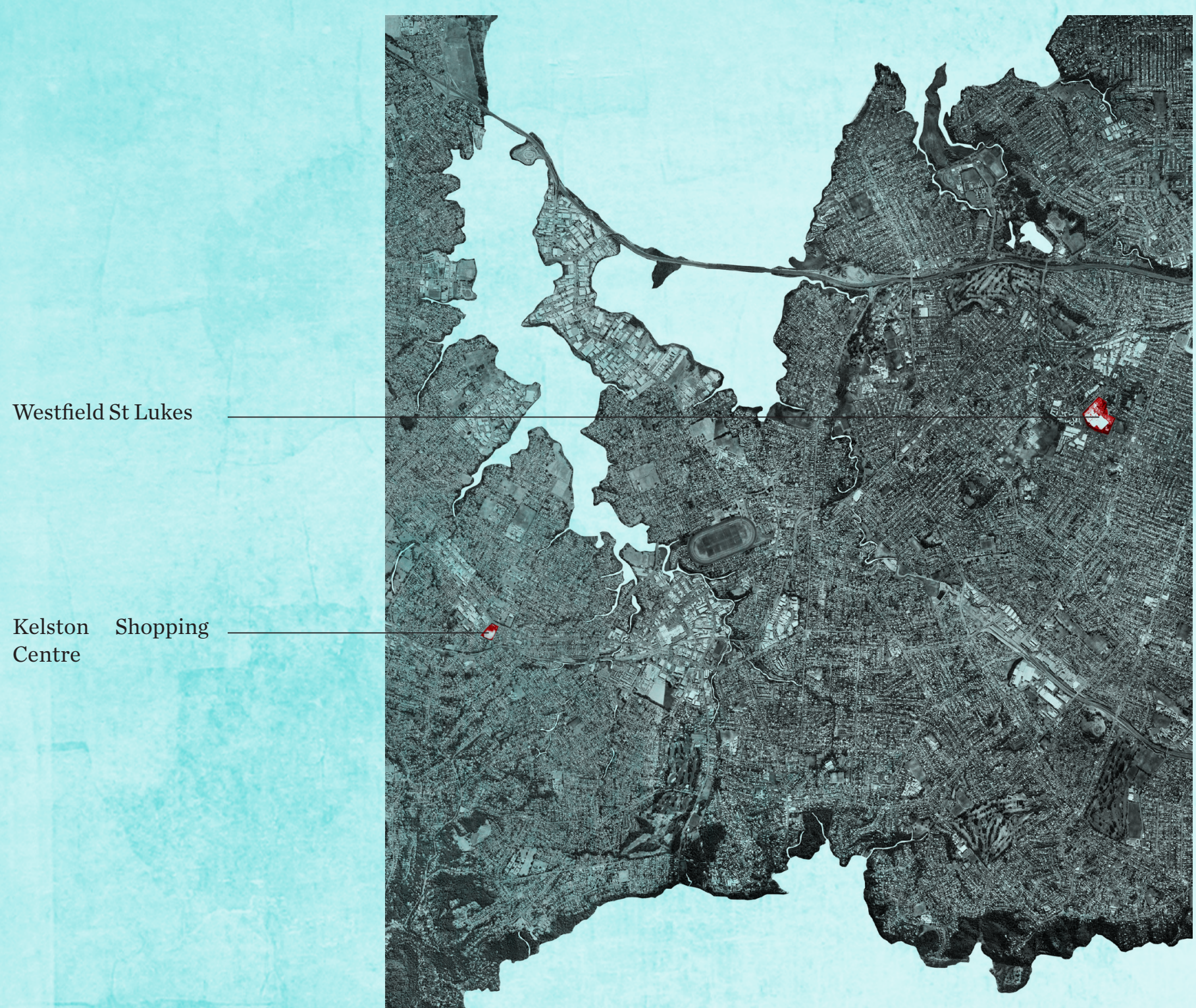




\section{EAST AUCKLAND}

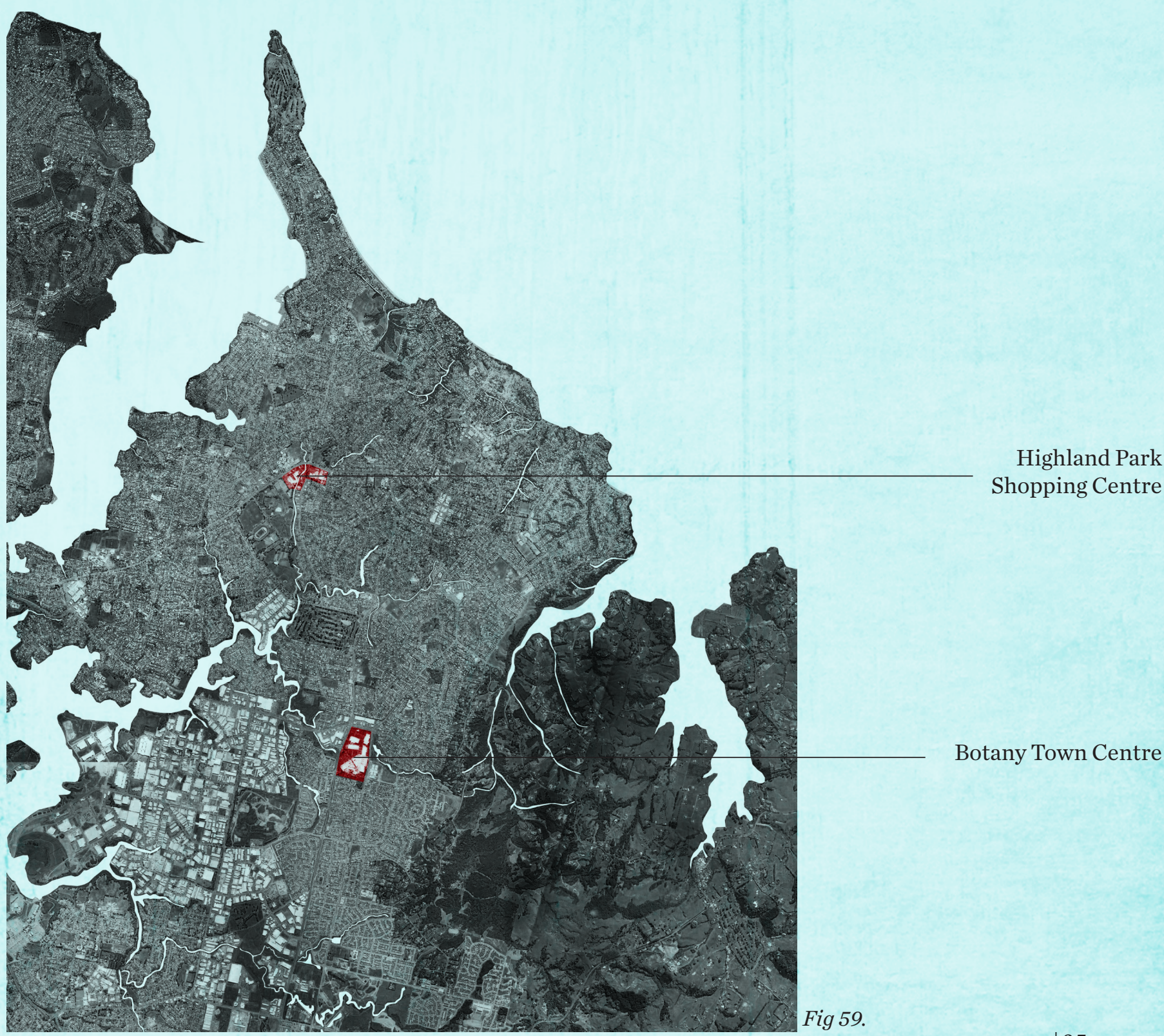


NATURAL WATER SYSTEMS WEST

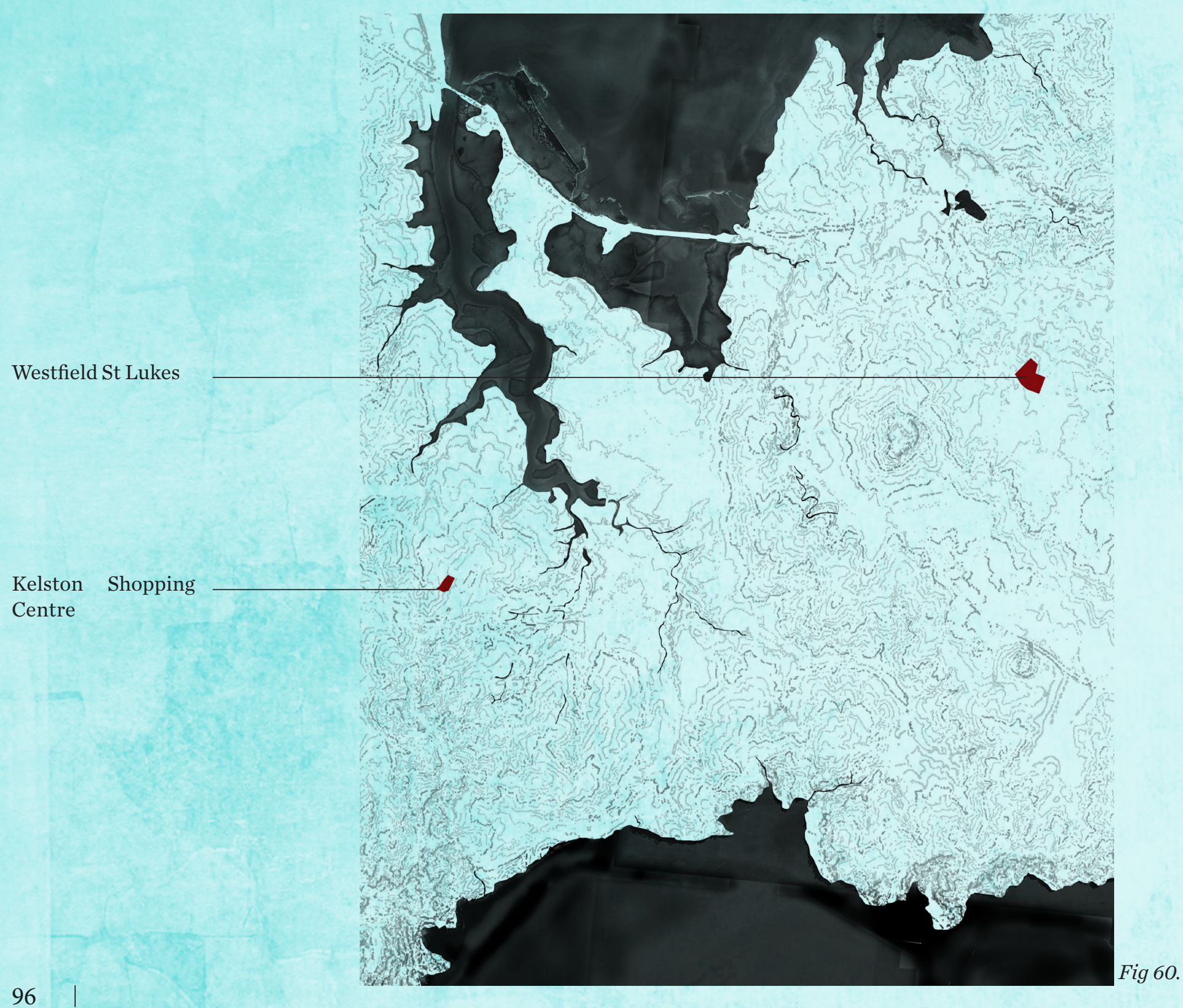


NATURAL WATER SYSTEMS EAST

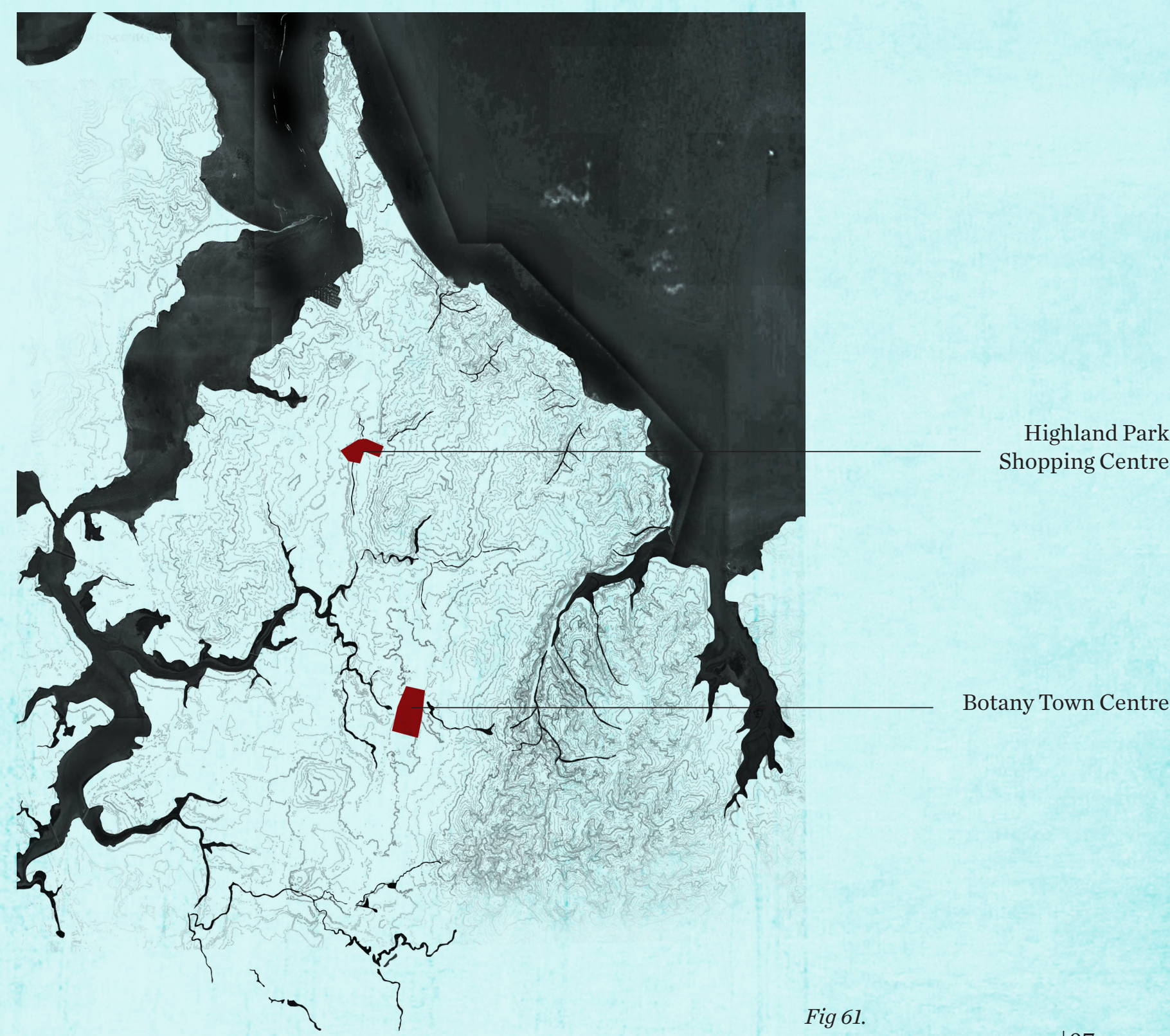




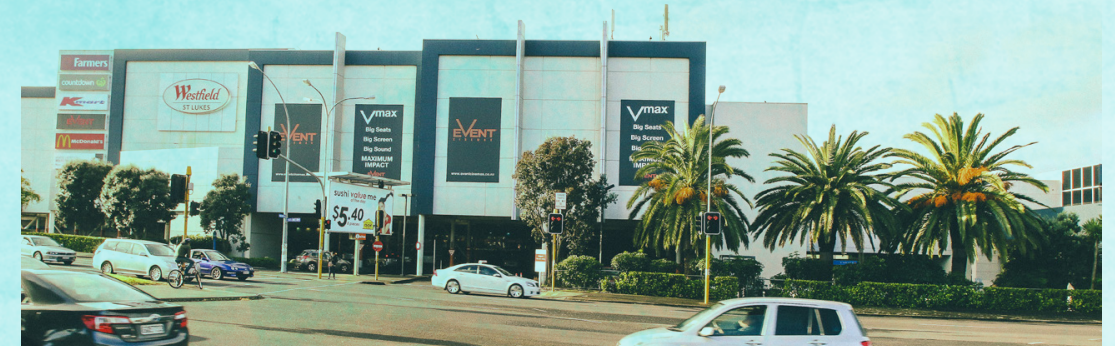

Westfield St Lukes

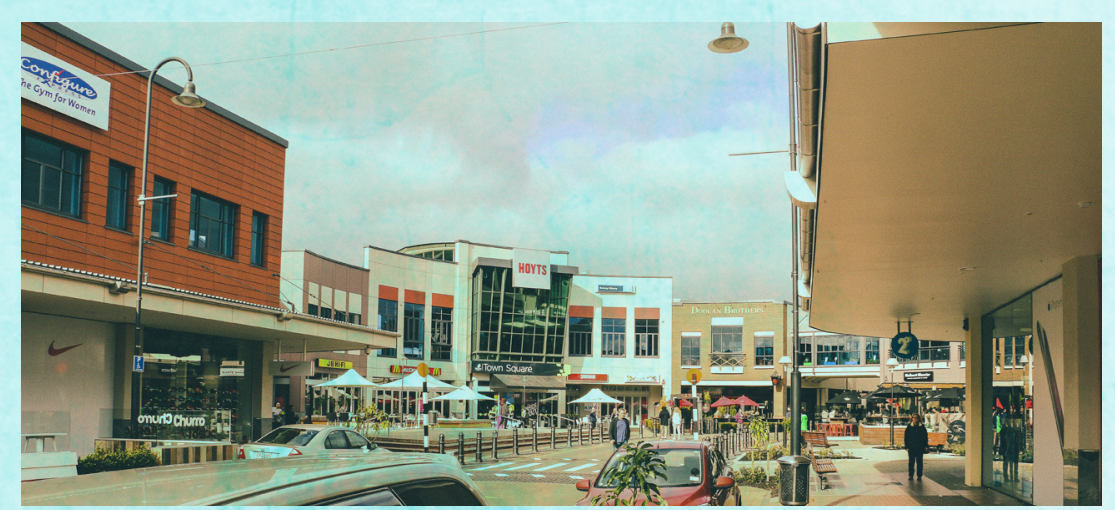

Botany Town Centre

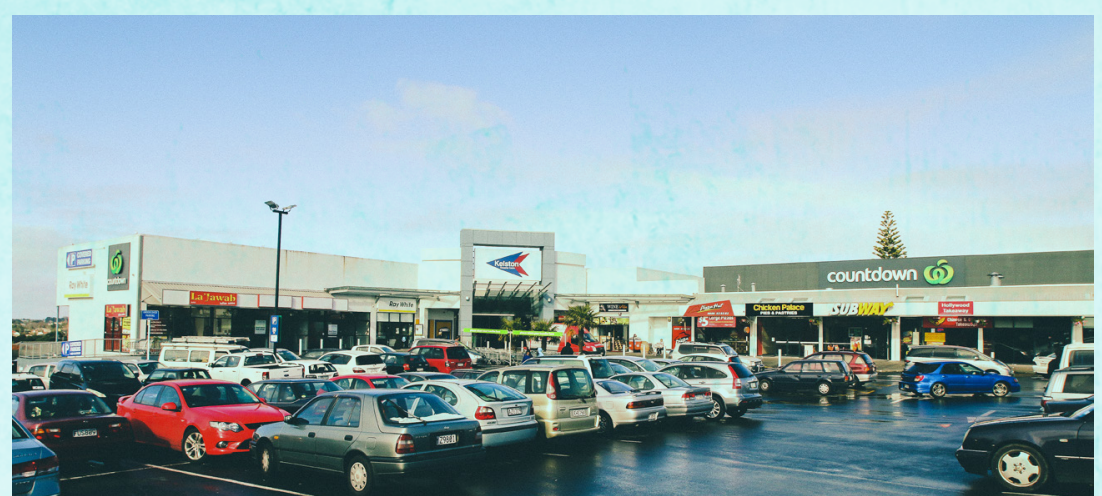

Kelston Shopping Centre

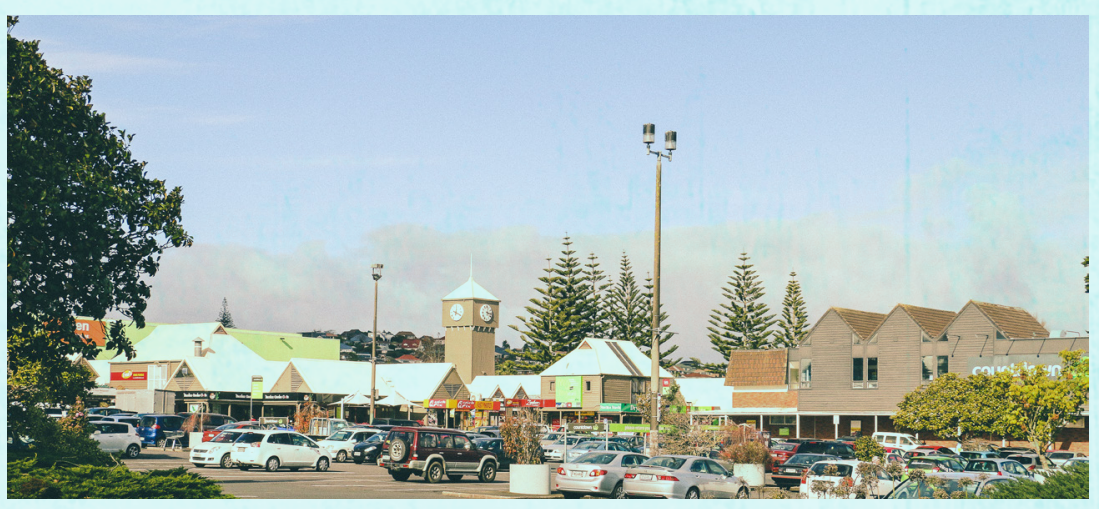

Highland Park 


\section{WESTFIELD ST LUKES:}

Strategies

- Intensify towards the railway station (800m up Morningside Drive).

- $\quad$ Retail existing structure and open up the internal pathways to the natural environment.

- $\quad$ Connect green spaces located to the east and south of site.

- Implement a highline green corridor to respond to the disconnection on St Lukes Rd.
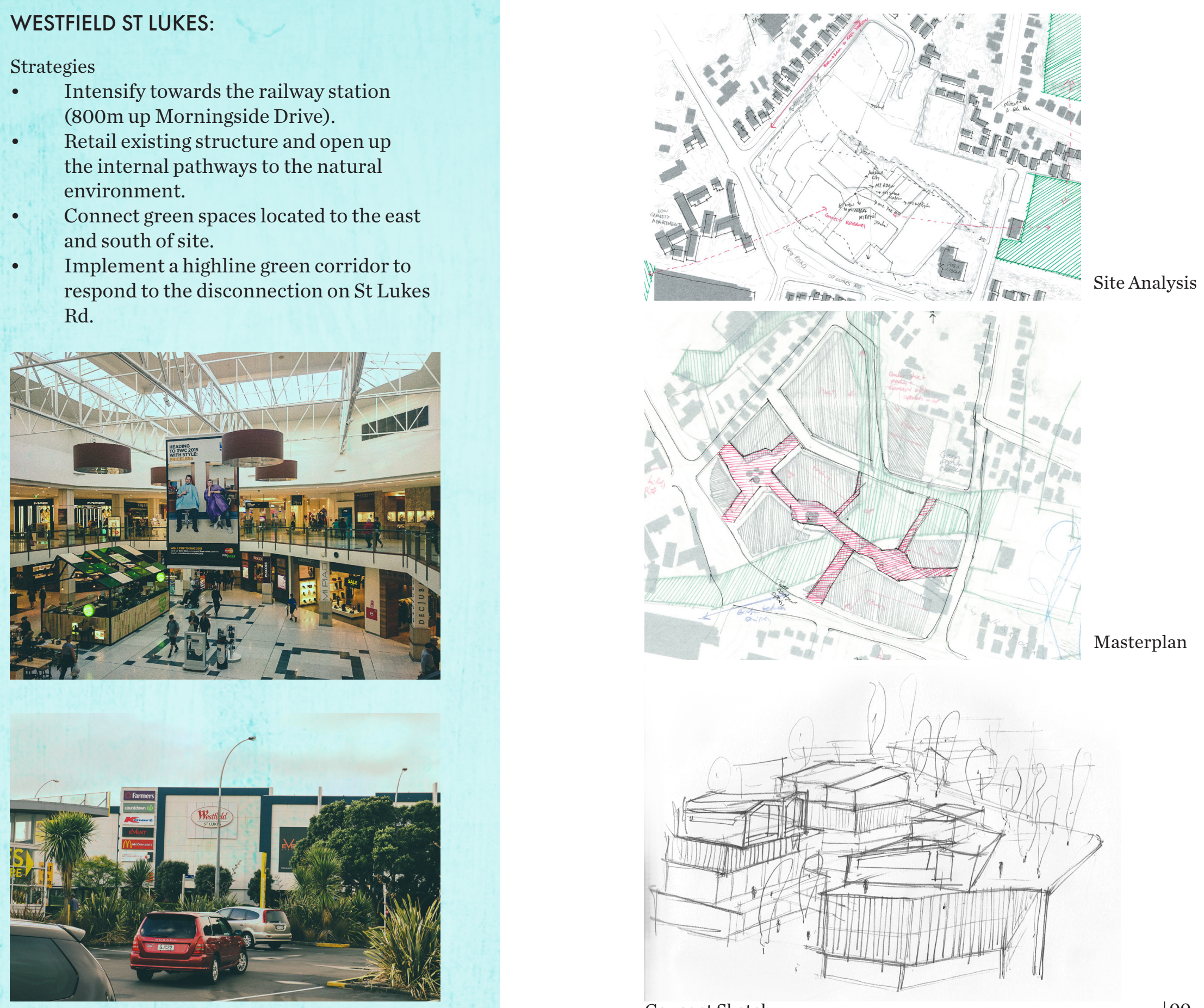


\section{KELSTON SHOPPING CENTRE:}

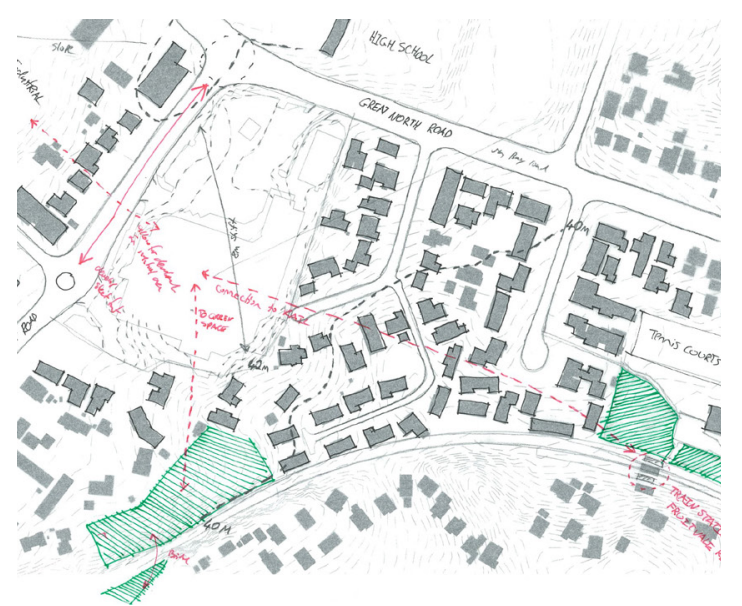

Site Analysis

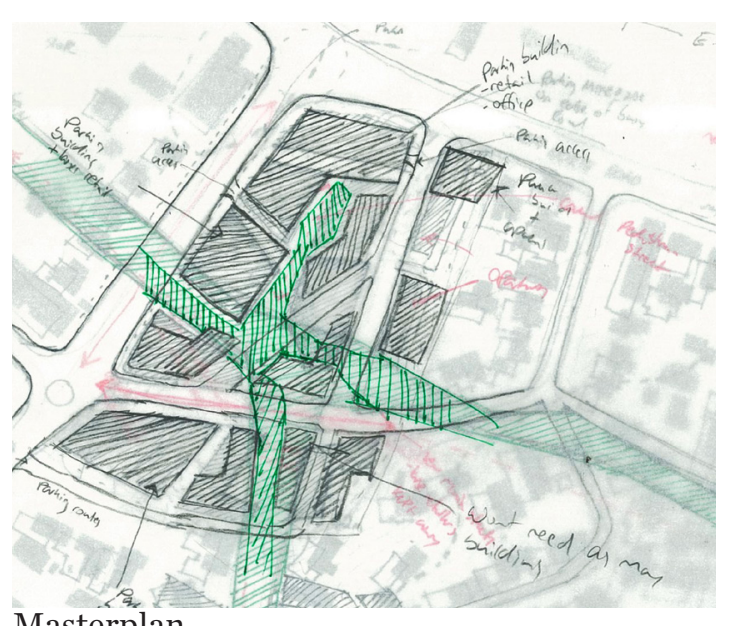

Masterplan

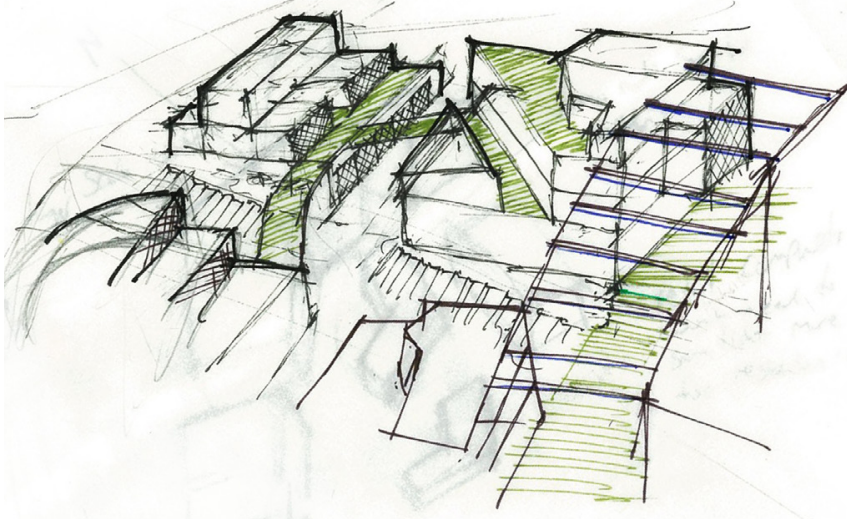

Concept Sketch

The only centre that is located in proximity to a railway stop.

Strategies

- Intensification to support the current development in New Lynn.

- Create strong pedestrian linkages towards the railway stop.

- Green corridor connecting railway and centre with pedestrian routes.

- Define street on West Coast Rd, supporting future intensification on the opposite industrial site.

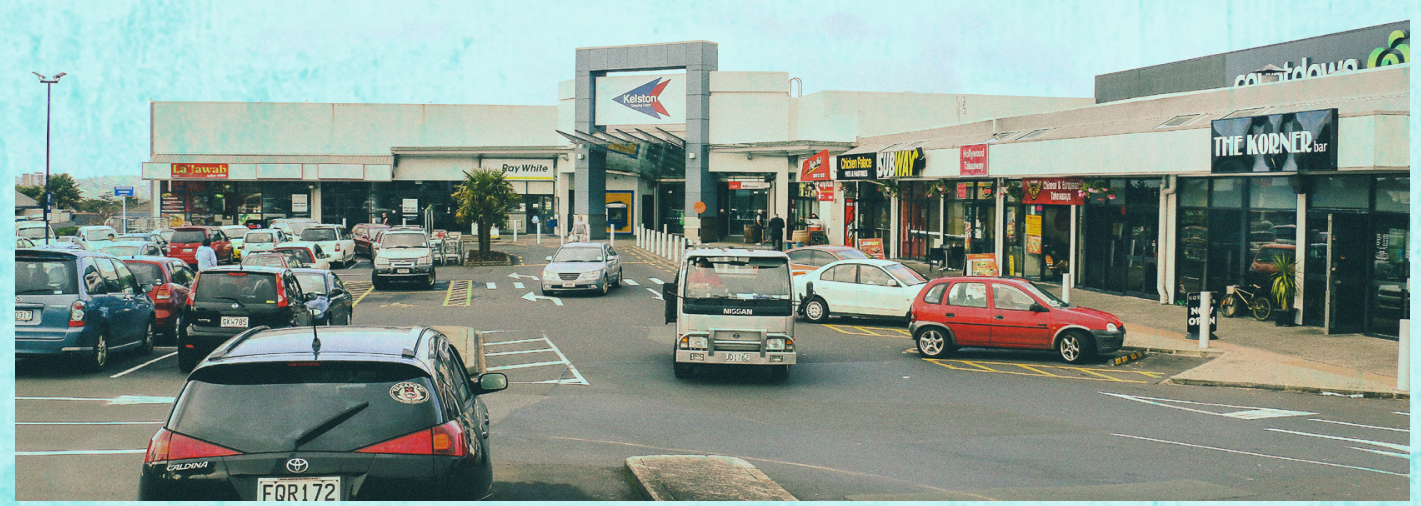




\section{HIGHLAND PARK:}

Strategies

- $\quad$ Provide a strong connection with Aviemore Drive.

- $\quad$ Build defining street edges, linked together with bridges.

- $\quad$ Enhance existing natural features by implementing green spaces between buildings.

- Implement a green pedestrian bridge over Aviemore Drive.

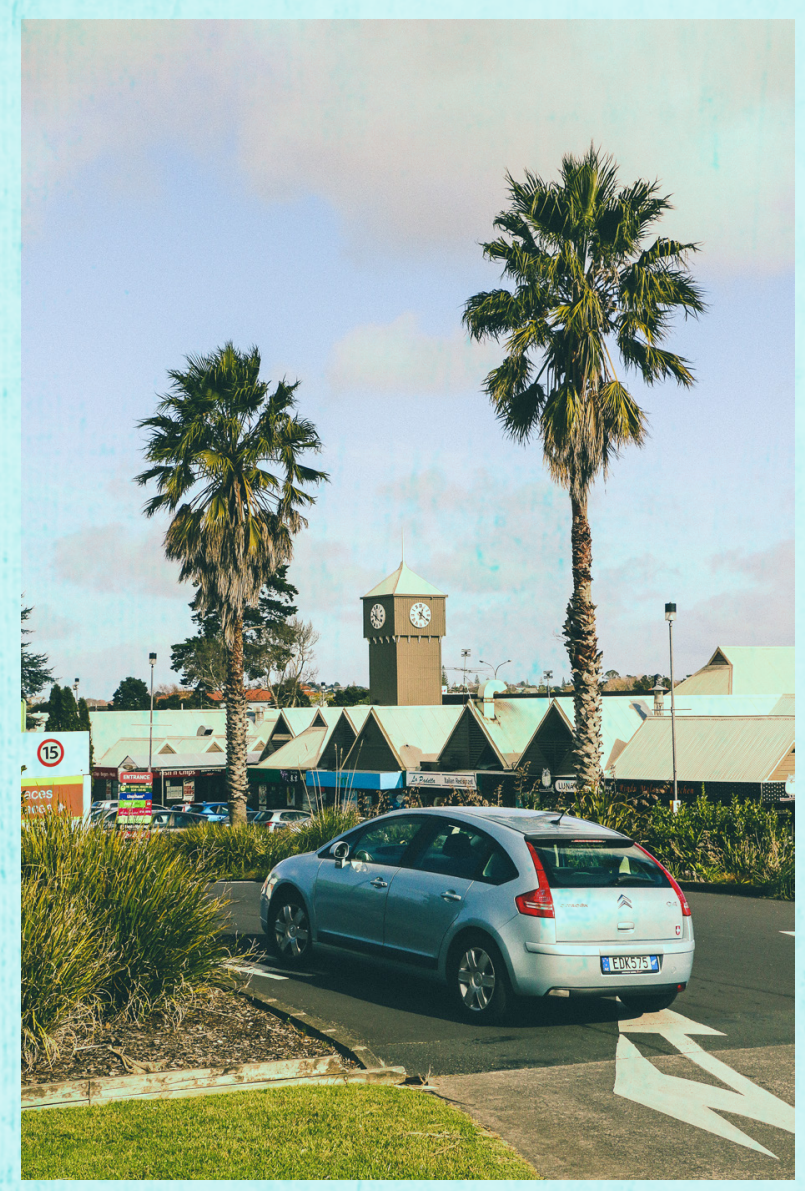

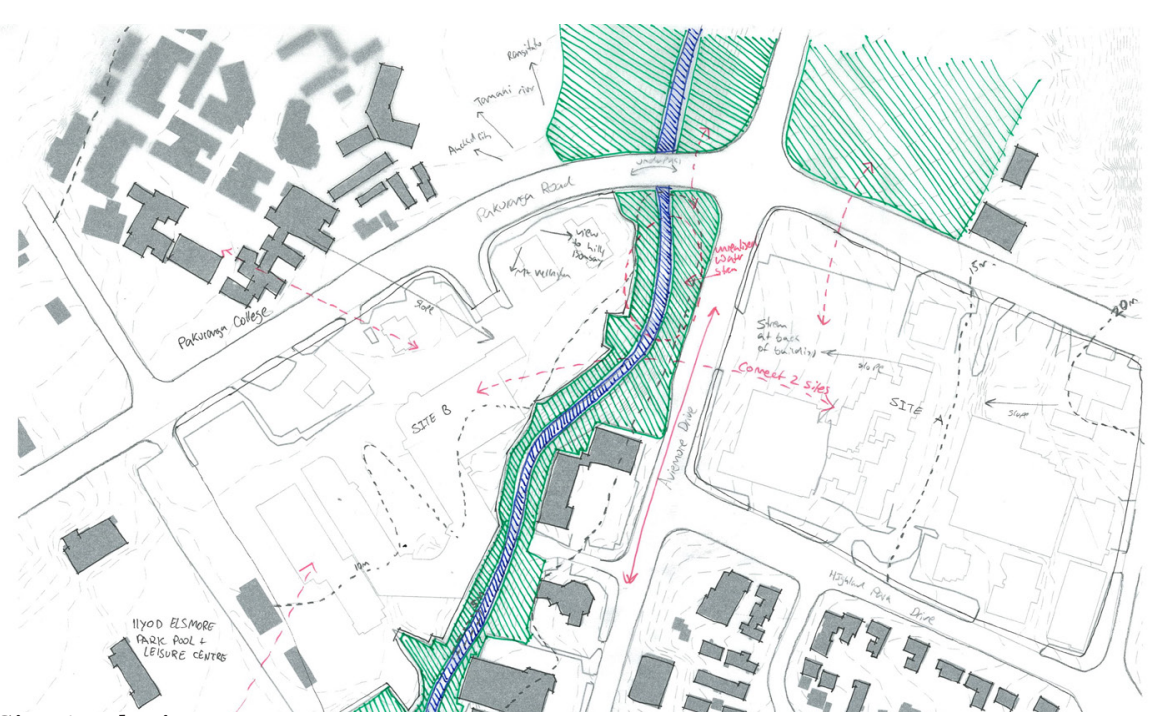

Site Analysis

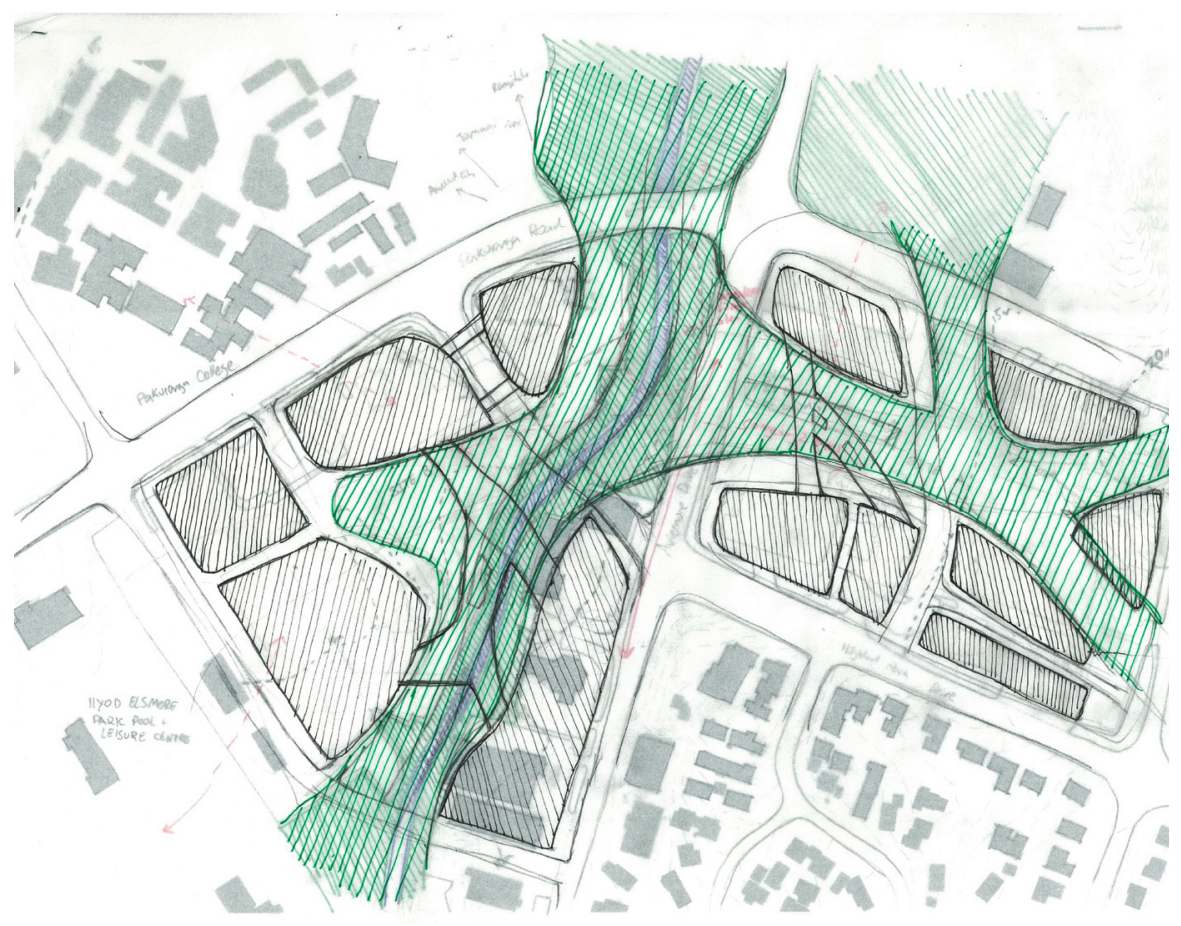

Masterplan 


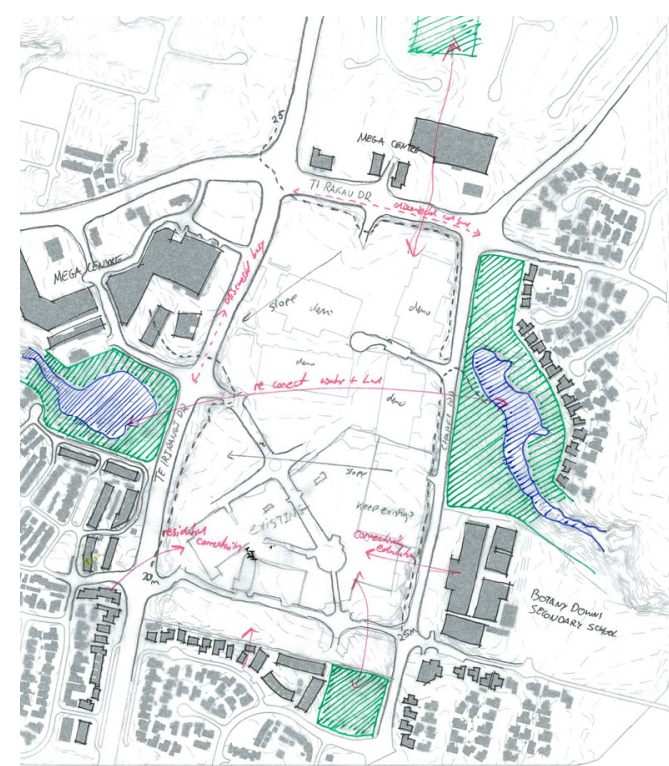

Site Analysis

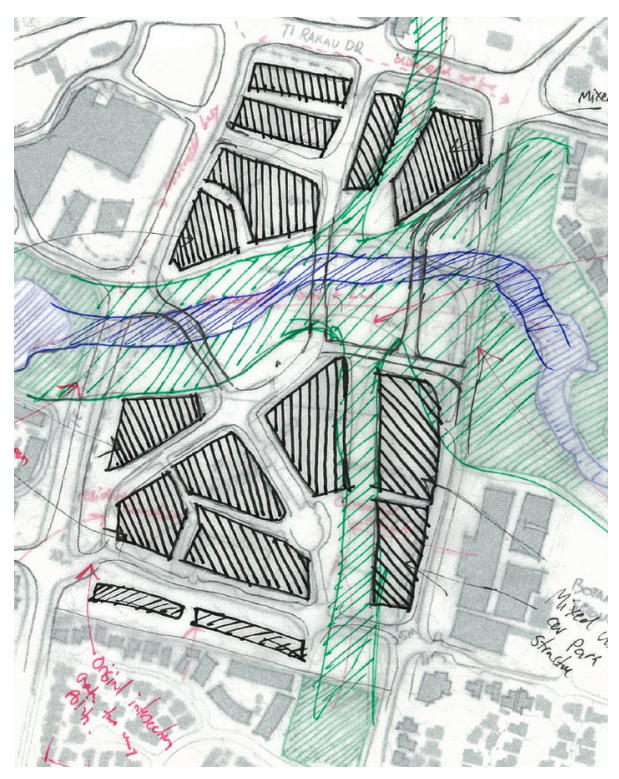

Masterplan
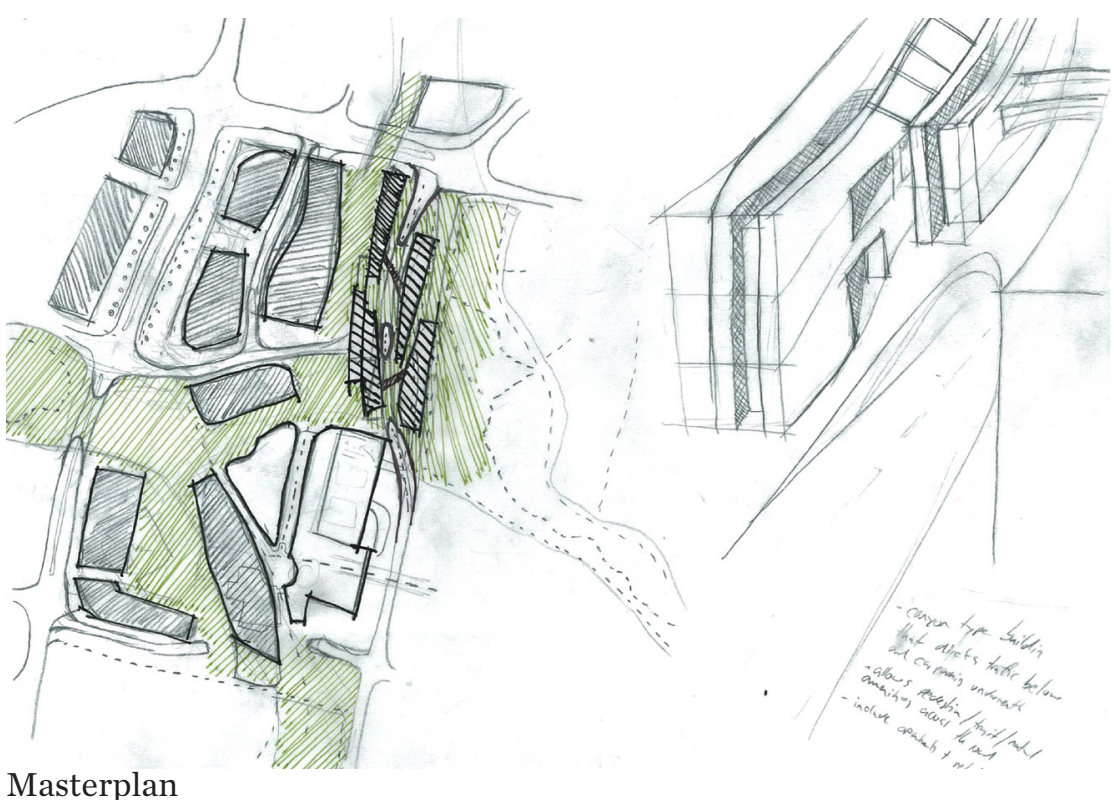

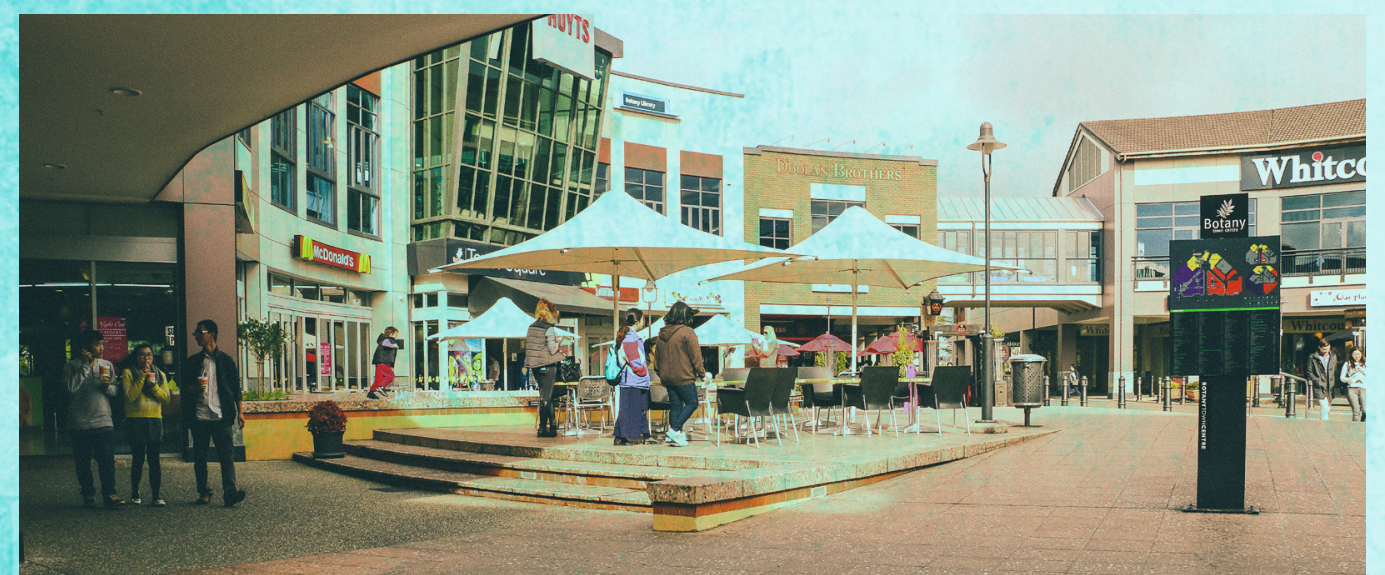

102

\section{BOTANY TOWN CENTRE:}

The larges site of the four.

Strategies

- $\quad$ Enhance and connect the east and west natural systems.

Retain part of the town centre.

Provide a retail pedestrian street in the north to south direction.

- Lower both east \& west arterial roads below ground, allowing a green belt to flow through the site. 


\section{SUMMARY}

This exercise suggested that the sites ecology can contribute significantly towards intensification and east Auckland has more fragmented natural systems than west. Re-connecting these systems can provide alternative commuting networks to the typical roads. Pedestrian and cycle paths in conjunction with light rail could be implemented through these enhanced green corridors. An issue that become apparent though this design stage, was the difficulty designing buildings on these large sites. The urban grain is a lot larger than the surrounding residential context. Design strategies for breaking up the large footprint will be explored in a concept for Botany Town Centre in the next Preliminary-Design chapter. 


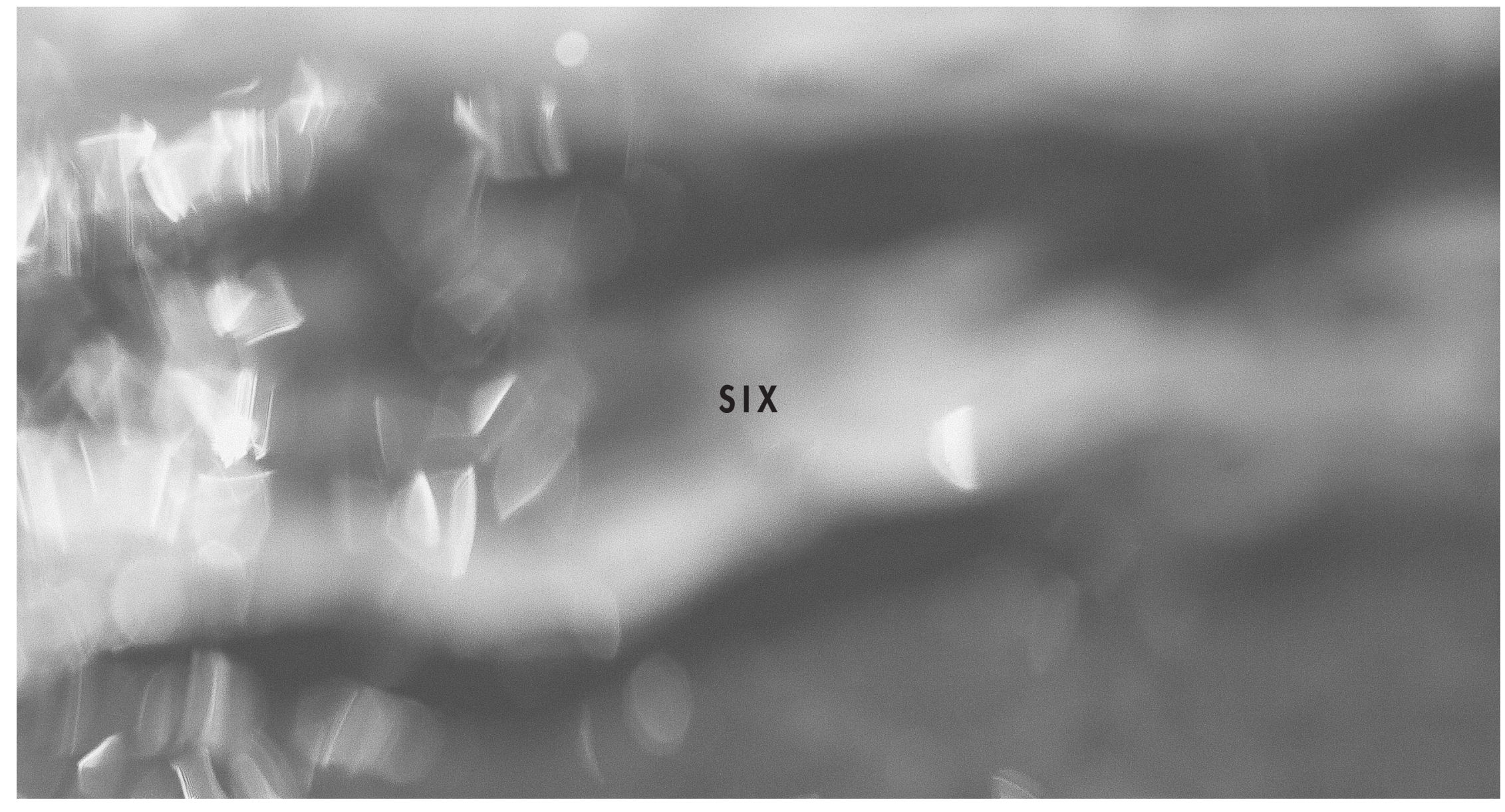

104 


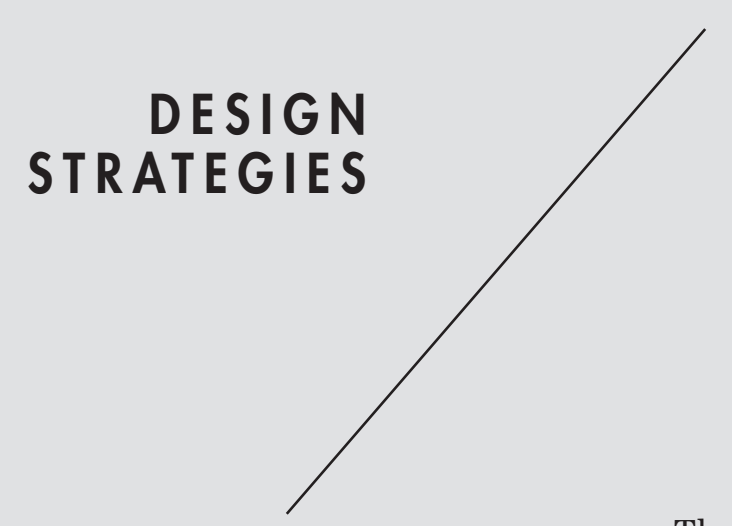

Throughout this research each chapter has ended with a summary and strategies derived from that chapter. This chapter combines all attributes together forming the overarching strategies for the amalgamation of the components of new urbanism, retail experience and ecology. The project strategies are categorized together as planning, organisation of vertical and horizontal spaces and experience. 


\subsection{PLANNING}

\section{DEFINING EDGES}

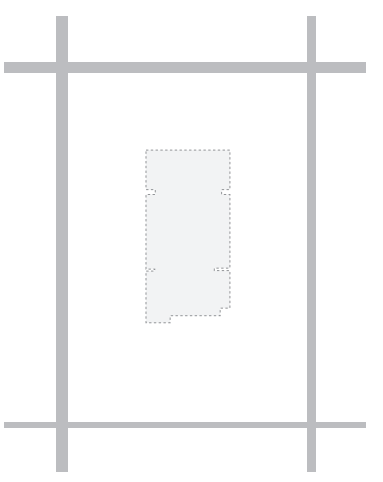

Typical Centre position

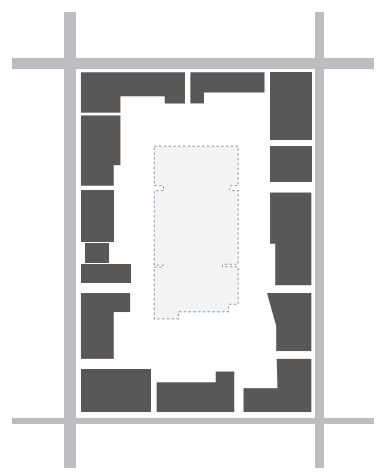

Defining the street edge

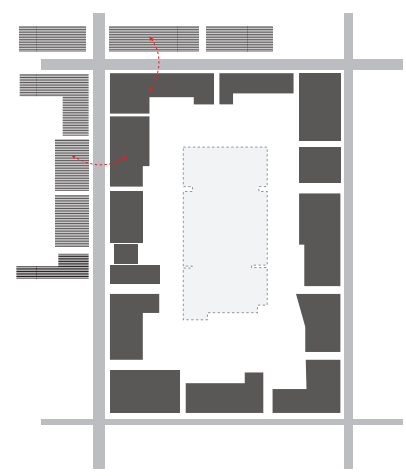

Intensifying at the intersection

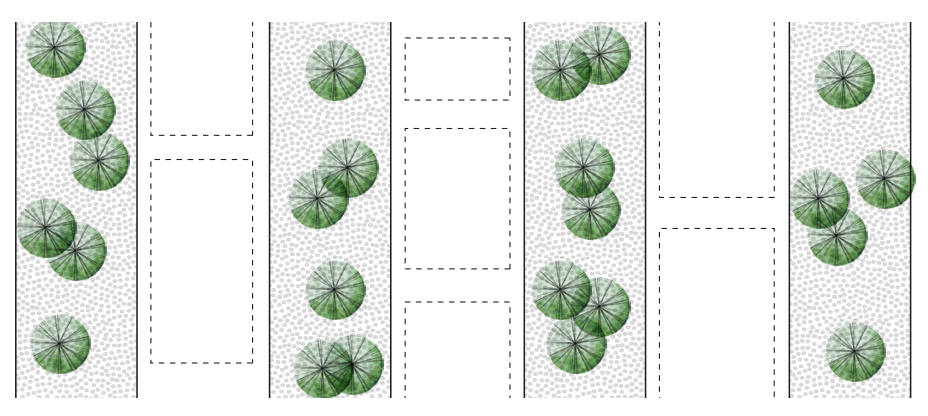

Natural systems define the built form 


\section{DYNAMIC GRID}

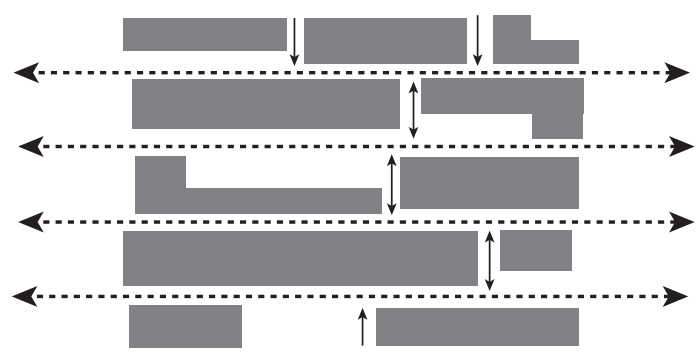

Prominent direction

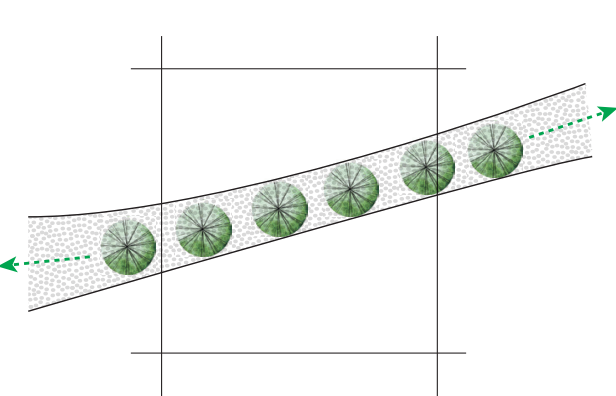

Green corridor connecting site to contexts natural systems

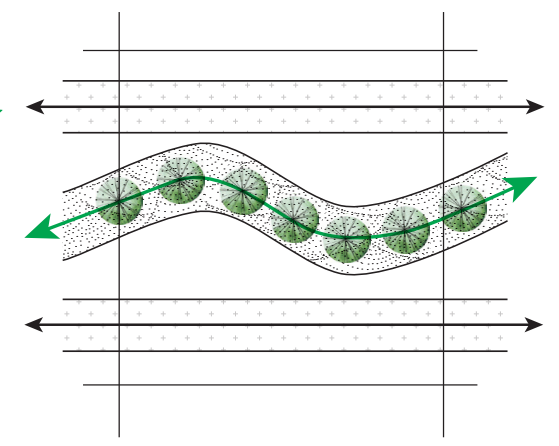

Natural systems organic form contrasting the linearedged built form

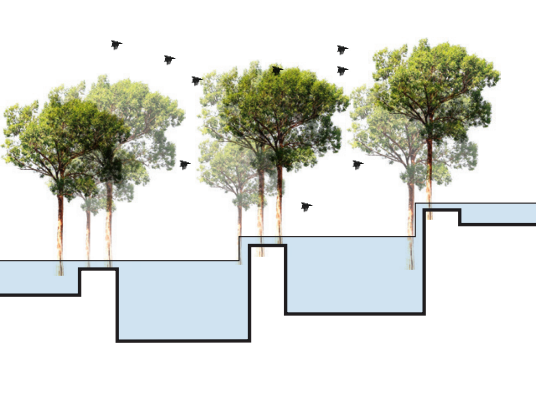

Ponding waterways forming ecosystems 


\section{COMPONENTS PLACEMENT}

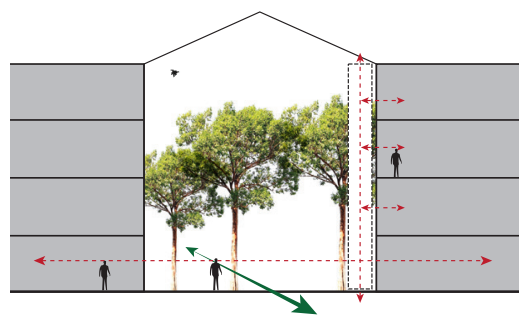

Green-house for vertical circulation
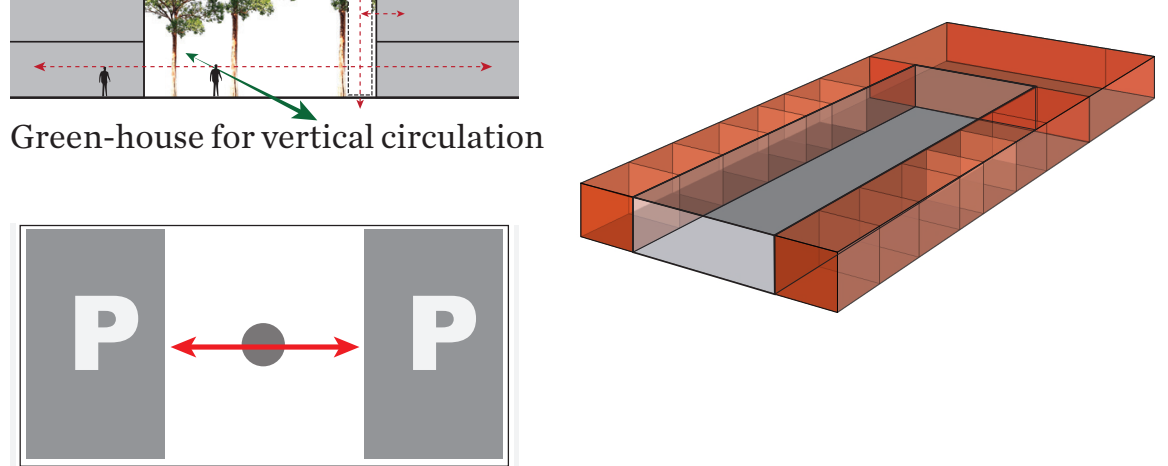

Parking structures placed on sites fringes

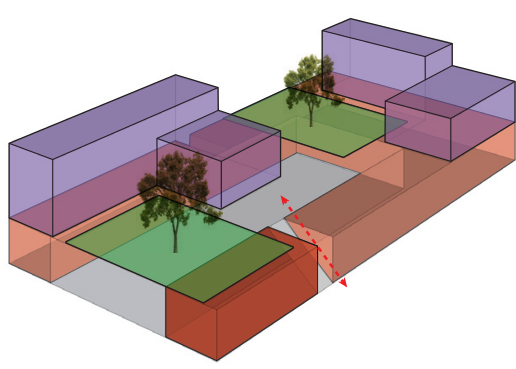

Breaking the mass $\mid$ rooftop terraces and retail above large footprints

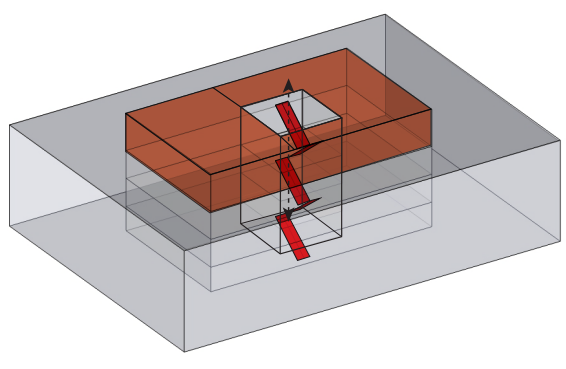

Vertical void opening underground spaces 


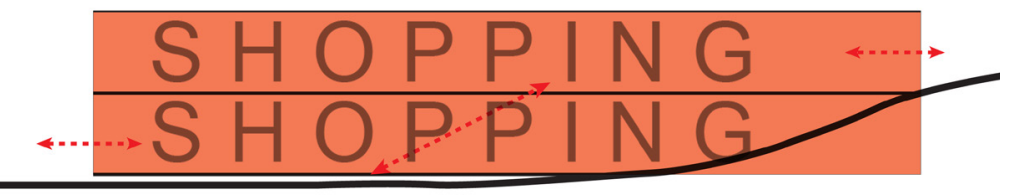

Multiple 'ground' floor retail

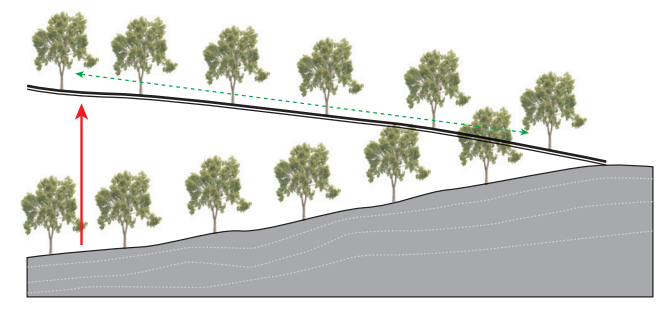

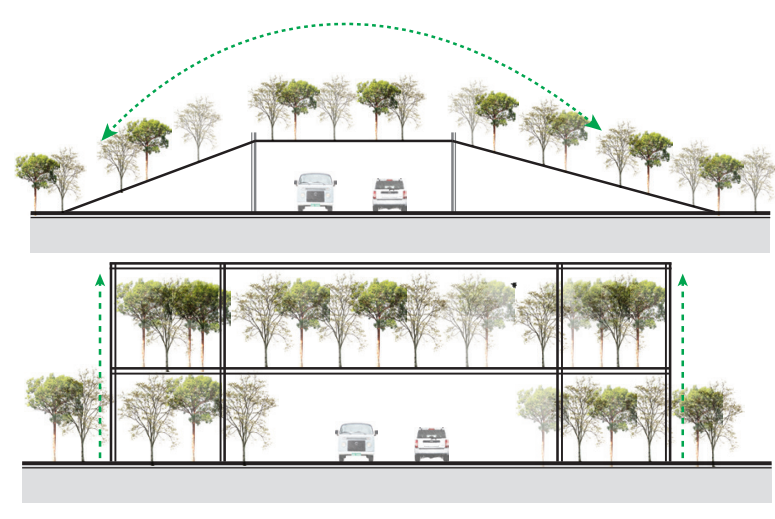

Connecting natural systems over obstructions | Eco-bridge and ramp structures

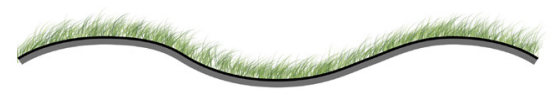

Undulating green roof

Multileveled corridors 


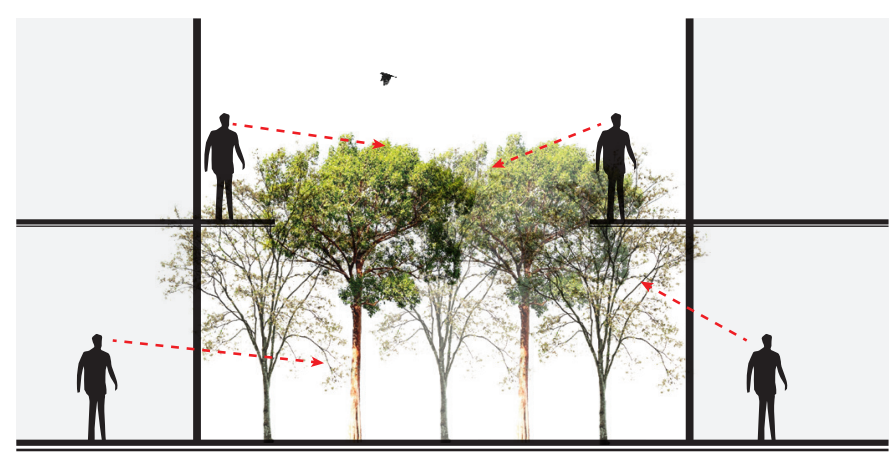

Observing ecology at multiple levels

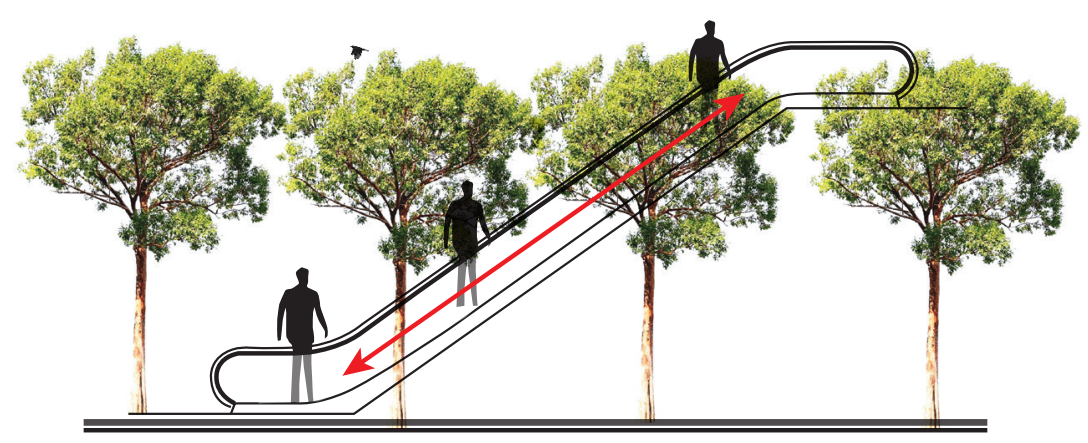

Transitional thresholds: Movement through canopy 


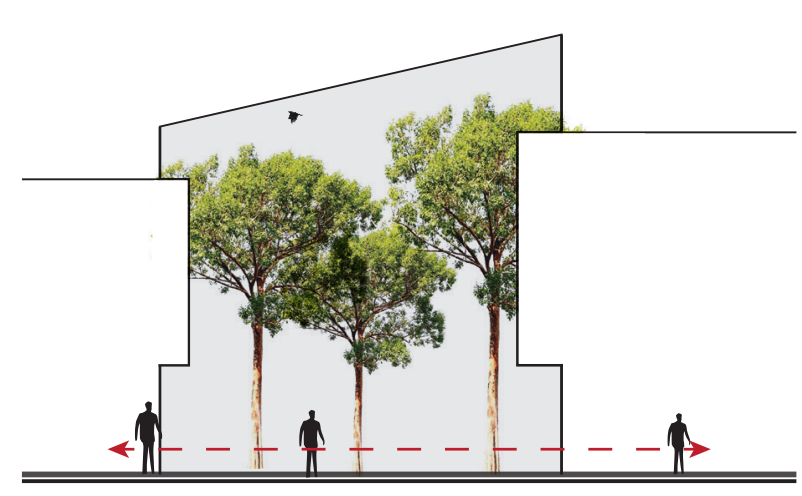

Transitional thresholds: Indoor and outside environment
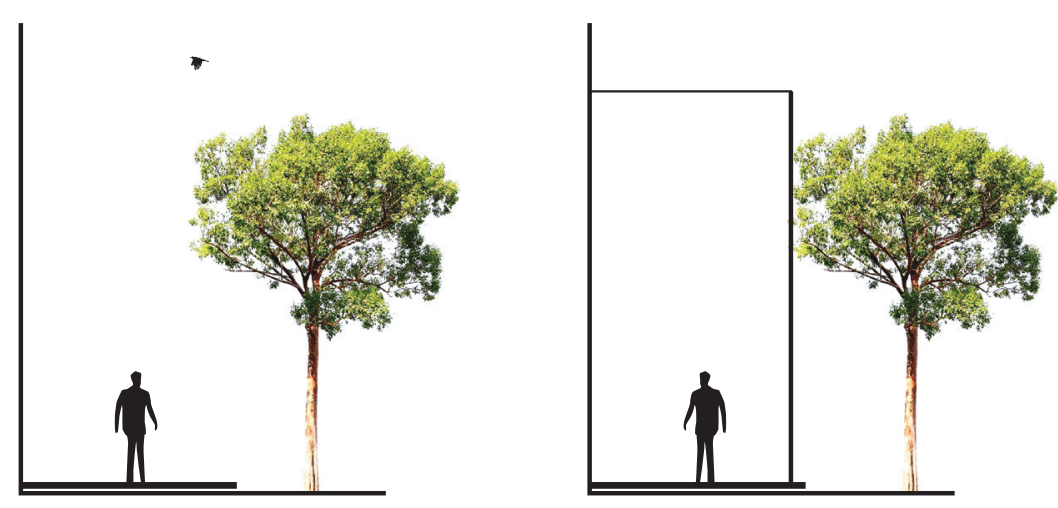

Thresholds with natural elements 
PRELIMINARY DESIGN D

$$
\text { 24te }
$$




\section{BOTANY TOWN CENTRE}

This chapter explores a sketch design for the site at Botany Town Centre, testing the design strategies in plan, section and perspective. The design intention was to retain part of the original town centre and create a retail pedestrian arcade that runs in the north and south direction utilising the shopping centre's original thoroughfare. The natural systems are relinked through the use of eco bridges and arterial underpasses. The buildings on the perimeter are permeable and focus pedestrian activity towards the retail spine. 

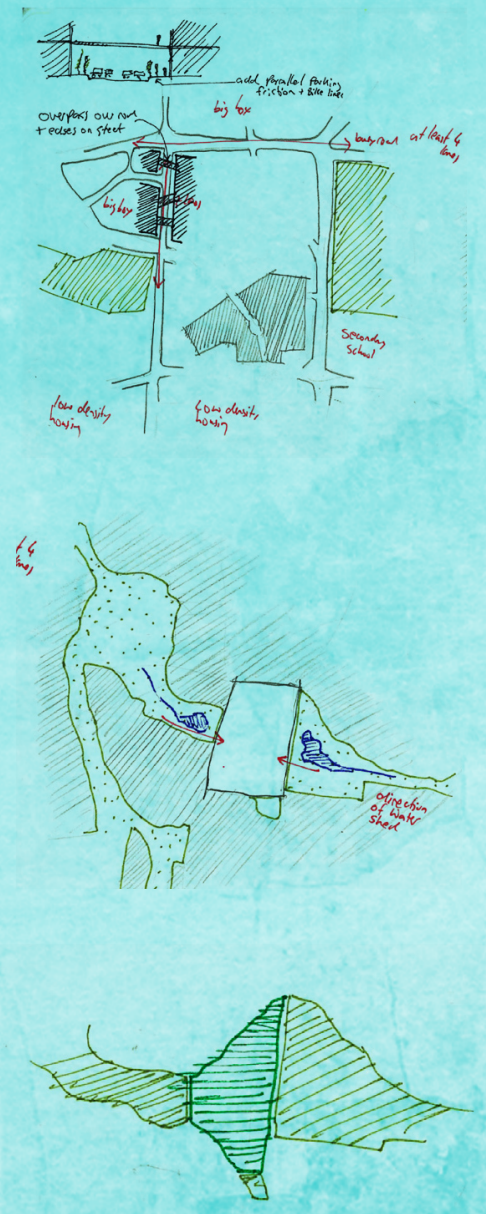

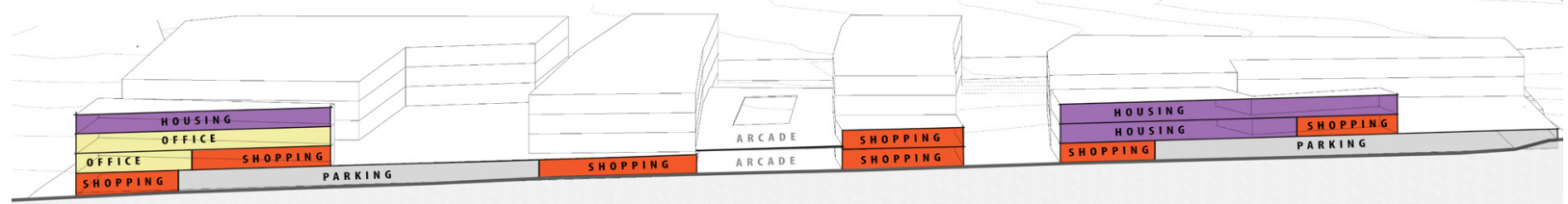

Section AA

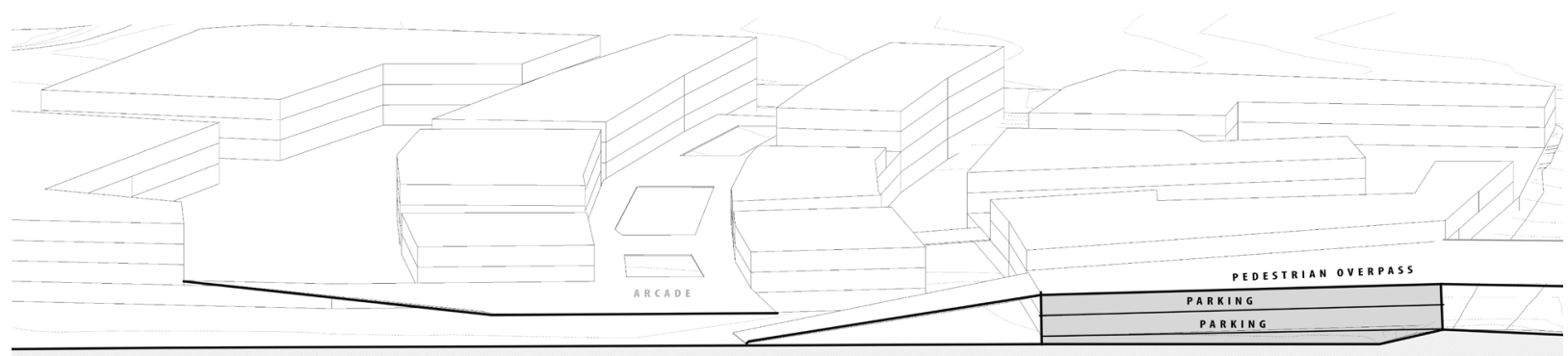

Section BB

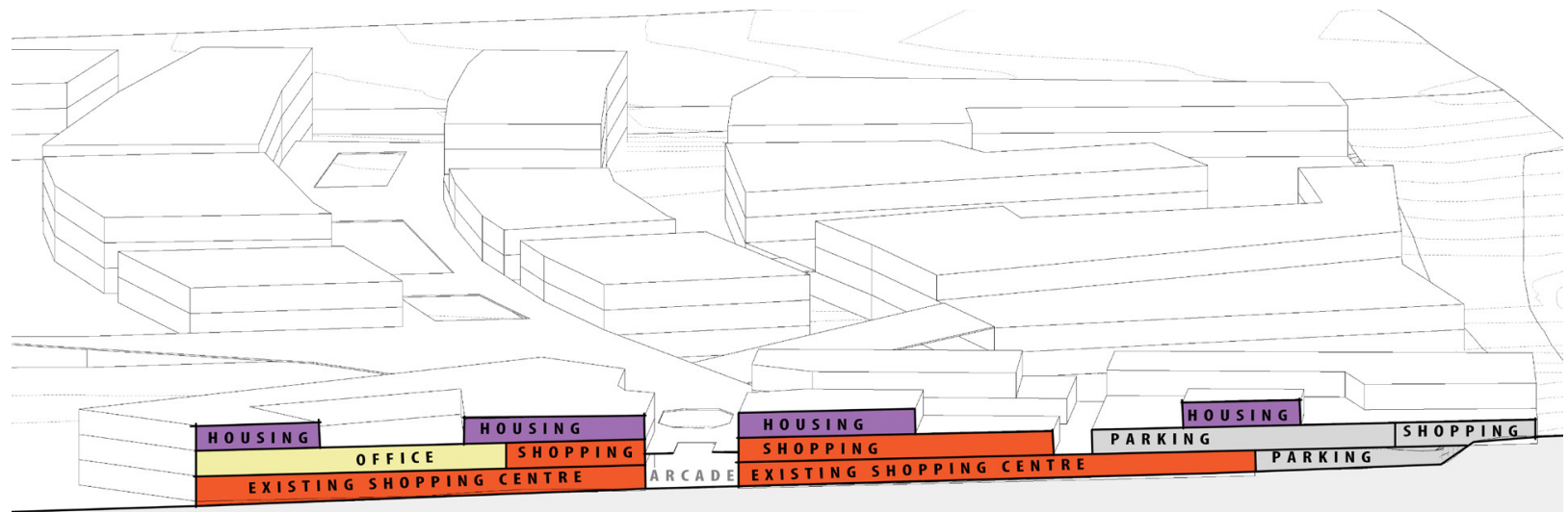

Section CC 


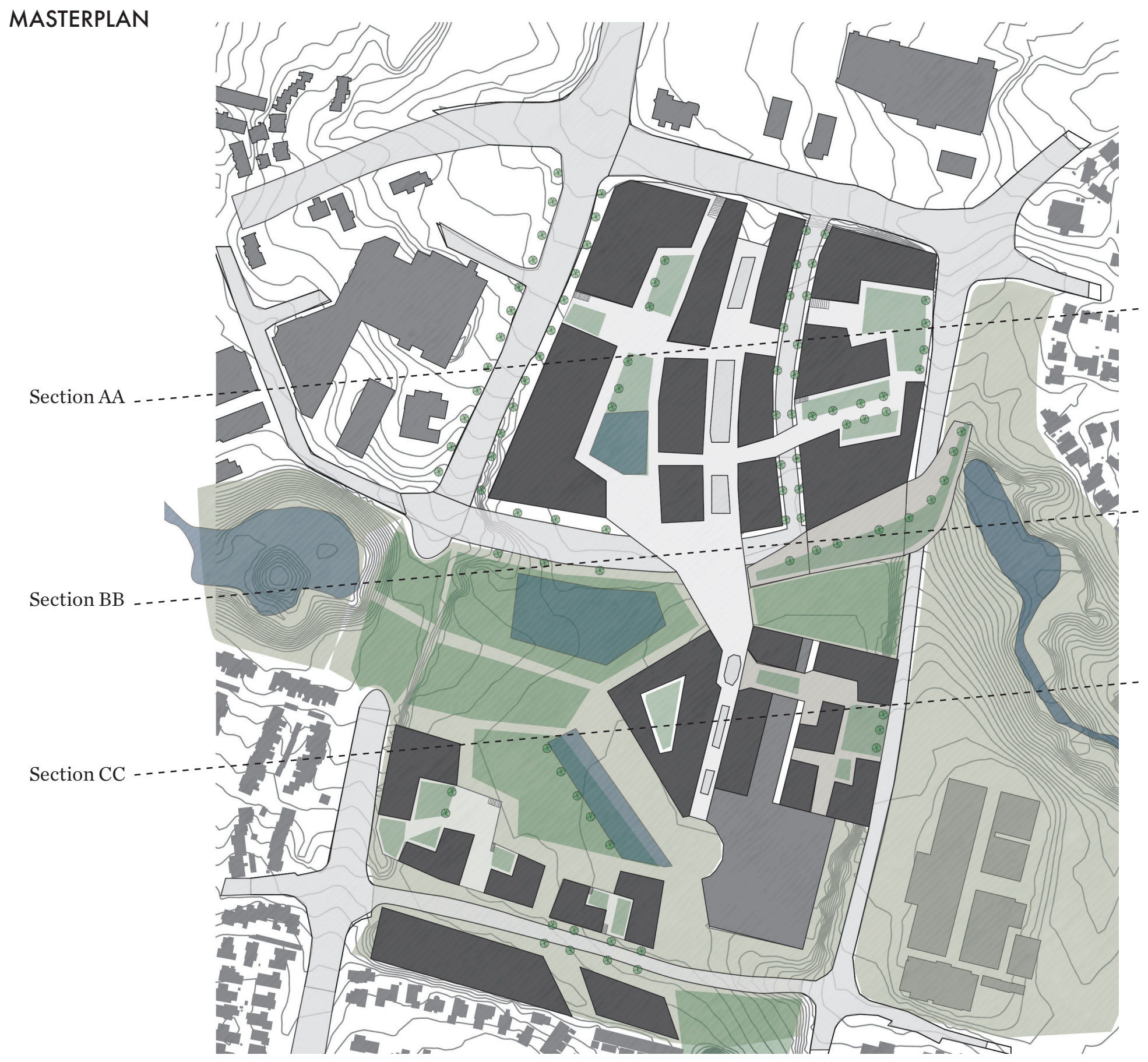


^Ground floor sketch | v First floor sketch |vv Second floor sketch
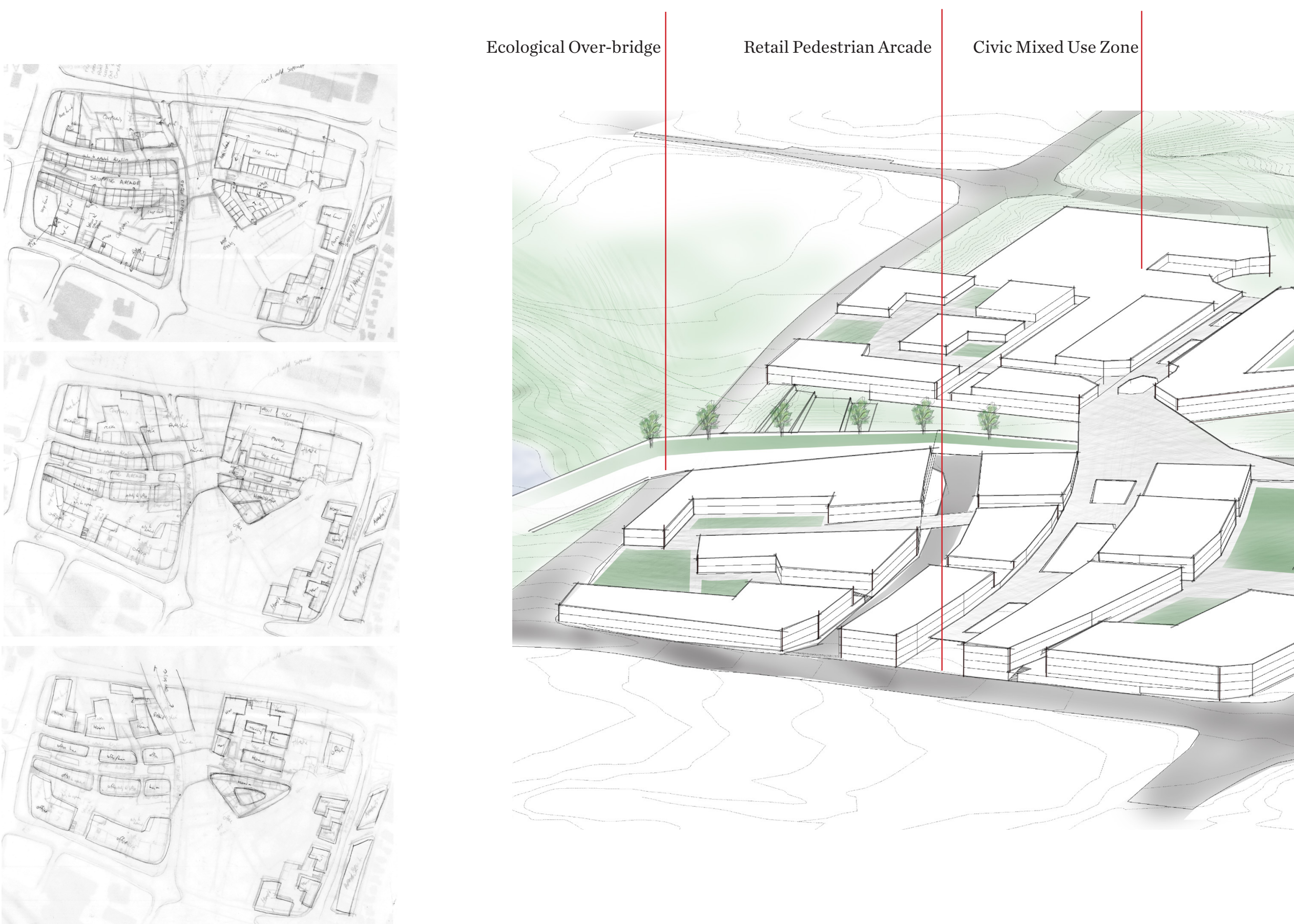


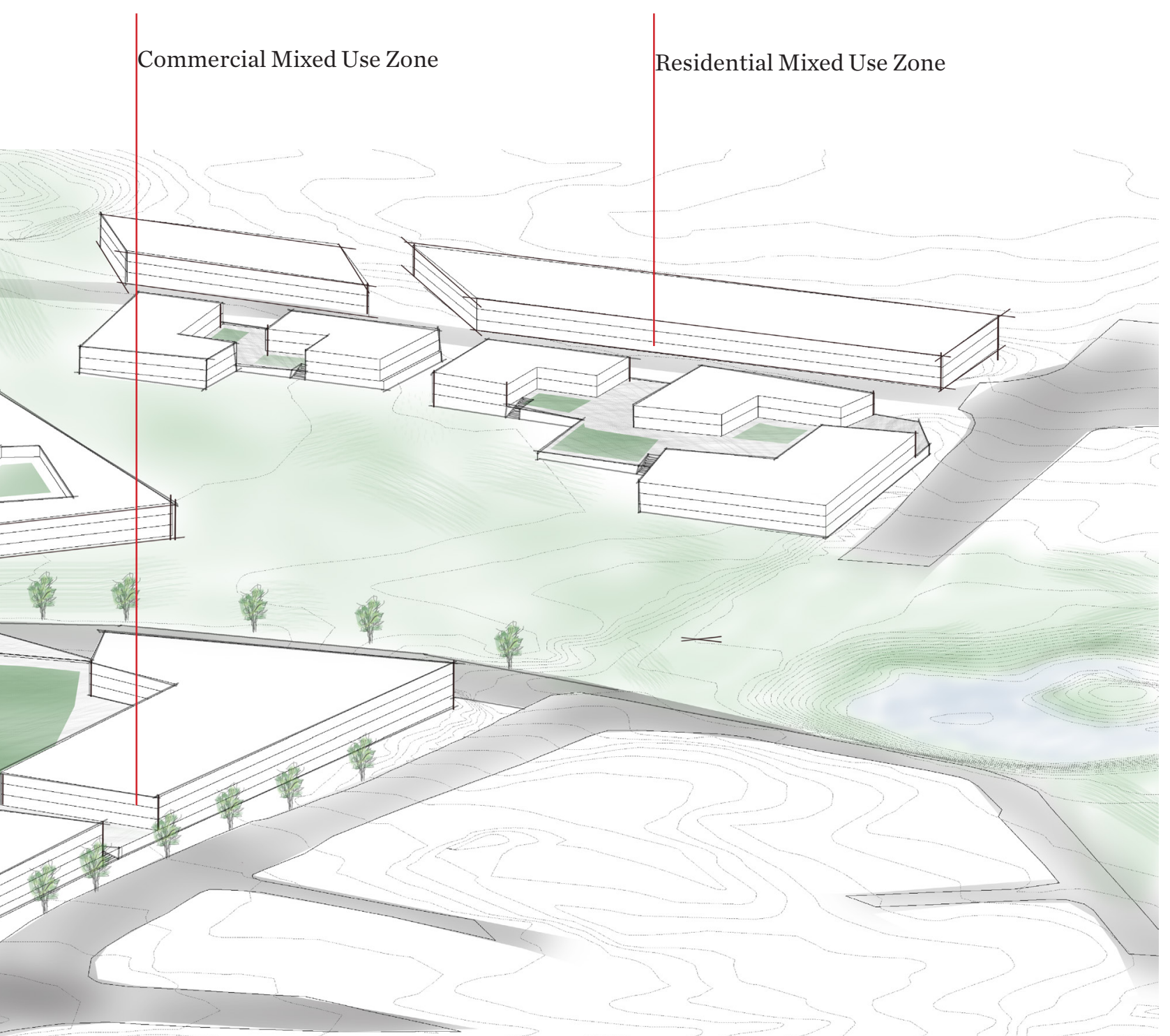

\section{SUMMARY}

There is large potential to increase the ecological linkages intertwining the ecology through the retail spine. The retail/ ecospectacle experience will need further development. The masterplan currently is fragmented into three areas due to the natural systems and roads dissecting the site, it can be improved to become a fluid and coherent urban form.

Botany Town Centre is 60 acres and is the largest site. This vastness will therefore create more complexities in the developed design stage and take longer to resolve. The author has decided that attempting to resolve Botany Town Centre will not be necessary for this research and has chosen Highland Park Shopping Centre to continue the research. 


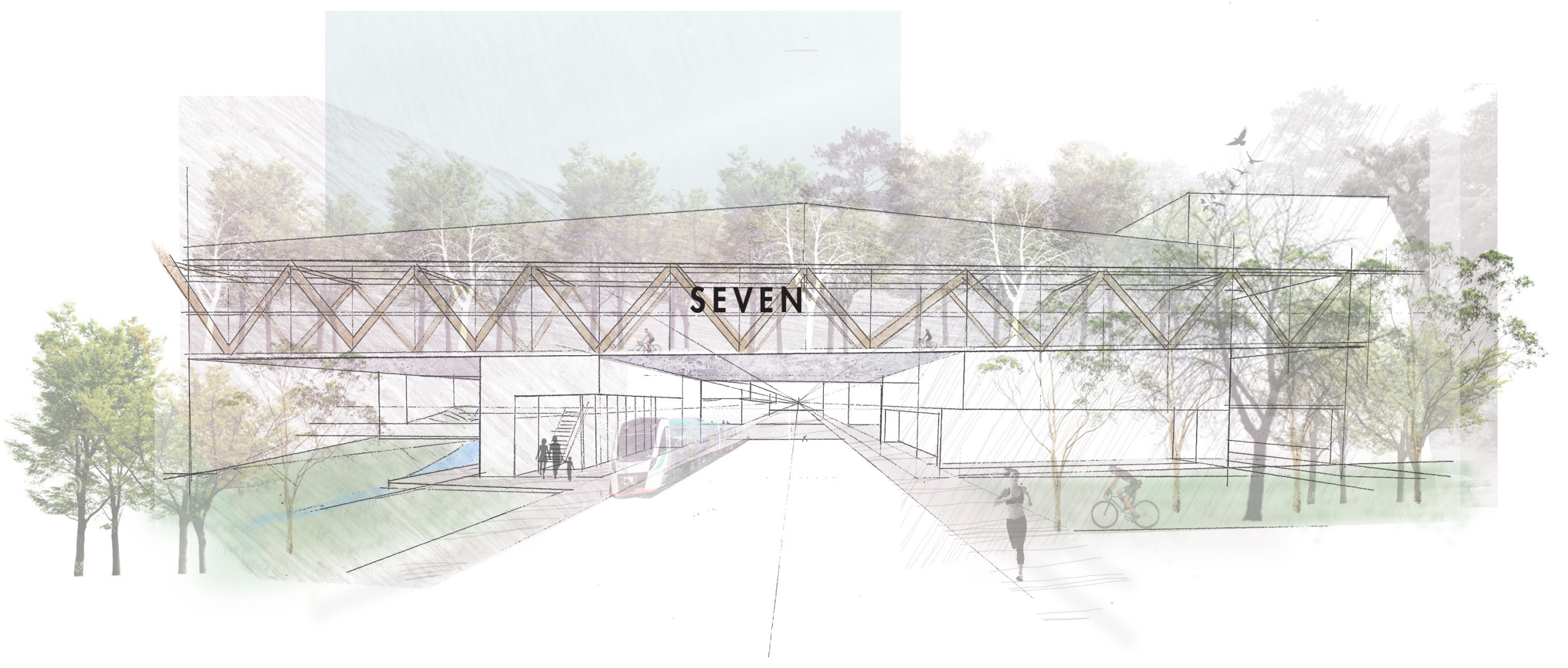




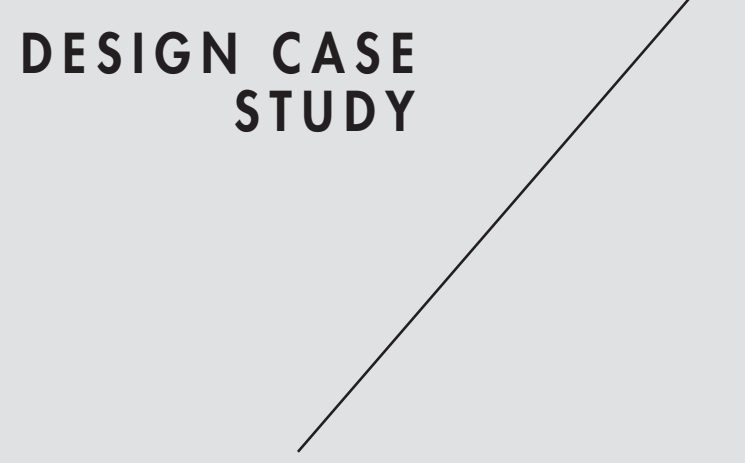




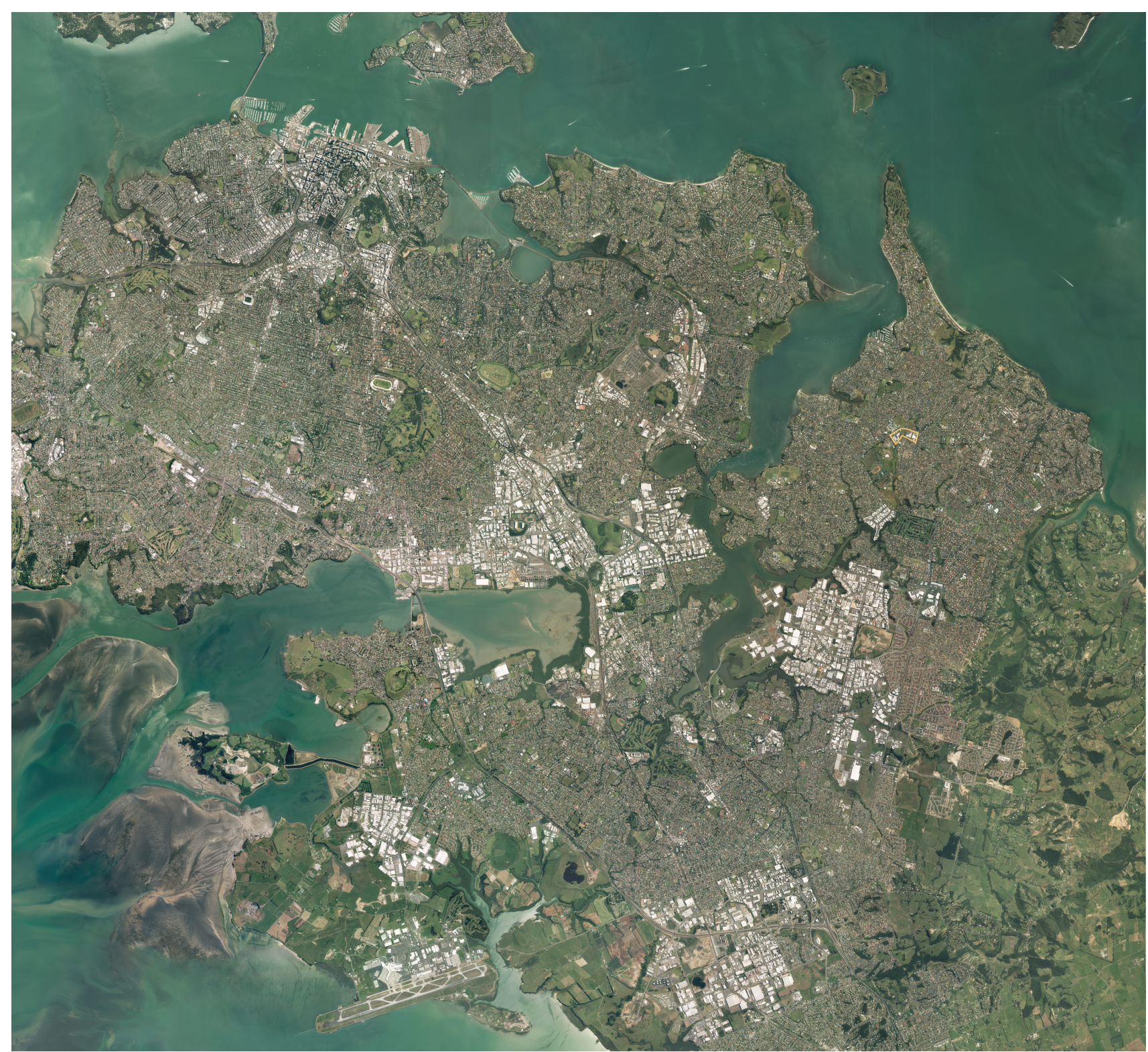

Fig 62.

\subsection{SITE \& CONTEXT}

Highland Park Shopping Centre is situated 25 minutes east of central Auckland. The outer context features the Tamaki Estuary which braids through the region. The amenities within close proximity to the site are Pakuranga College, Lloyd Elsmore Park, William Green football turf and low rise residential housing clustered around part of the centre. The site is divided by Aviemore $\mathrm{Dr}$ and a low quality polluted stream.

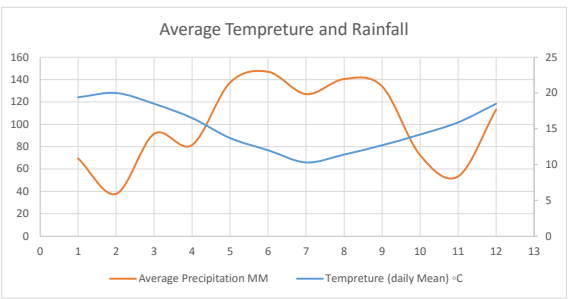




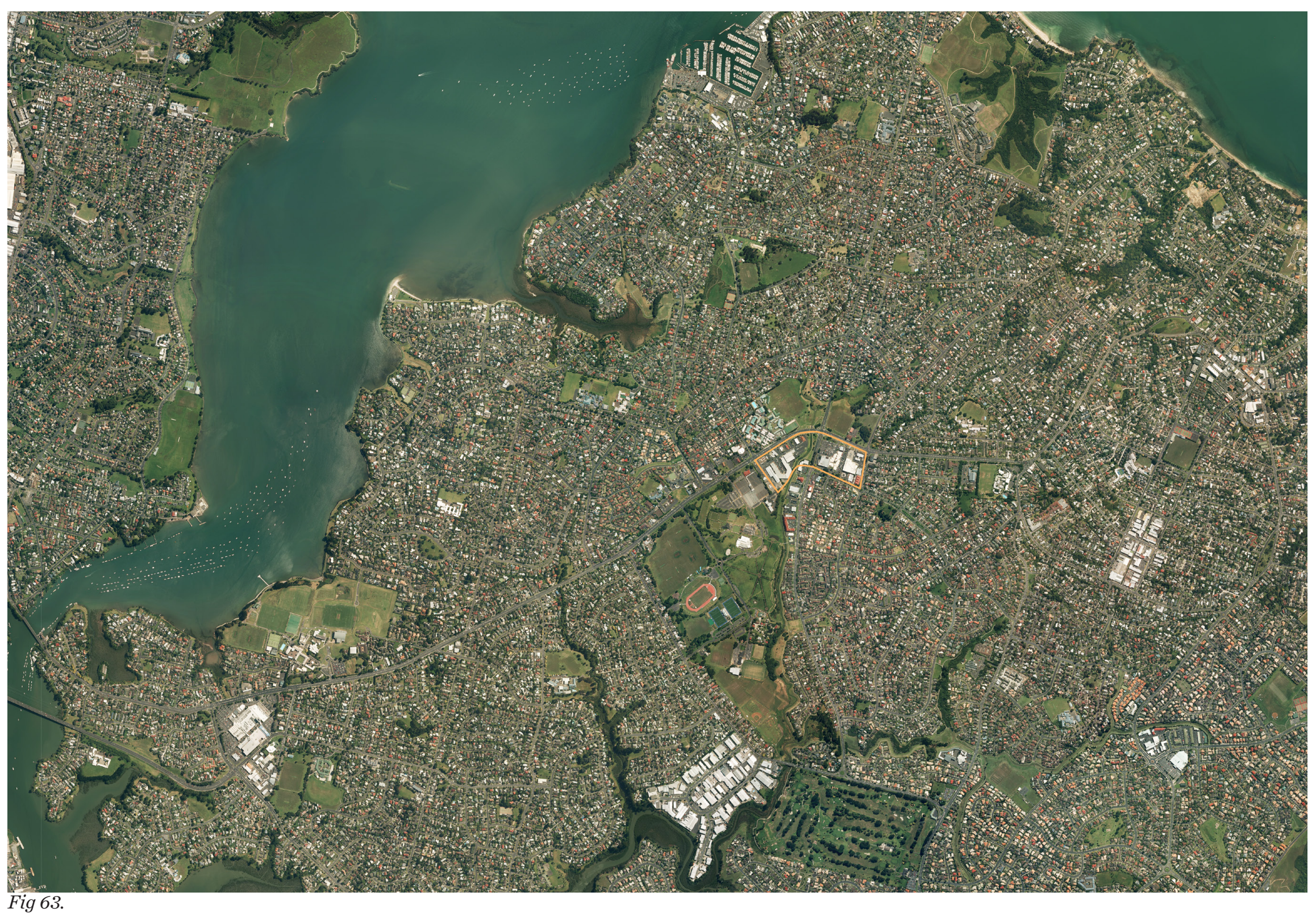


7.2 SITE ANALYSIS

NATURAL FEATURES

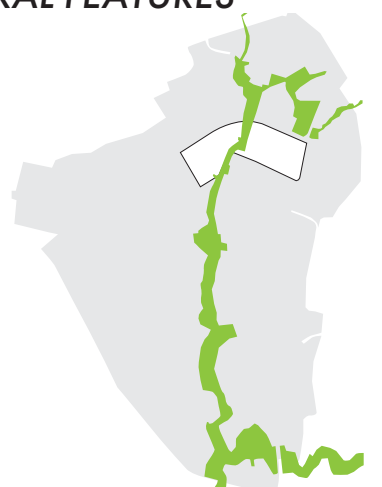

Natural Reserves

\section{INFRASTRUCTURE}

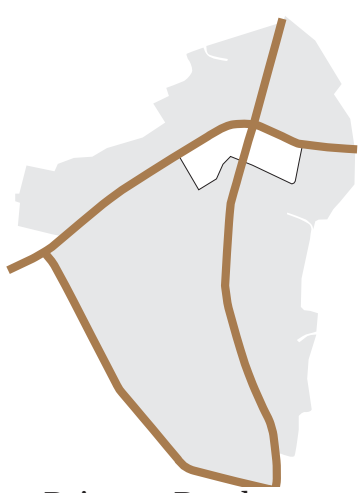

Primary Roads

\section{BUILDING STOCK}

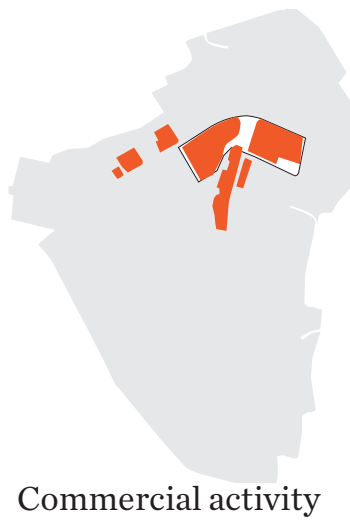

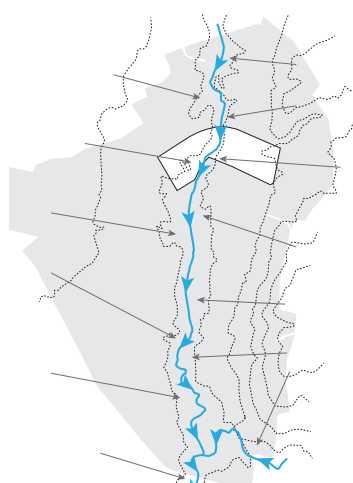

Stream \& Gradient

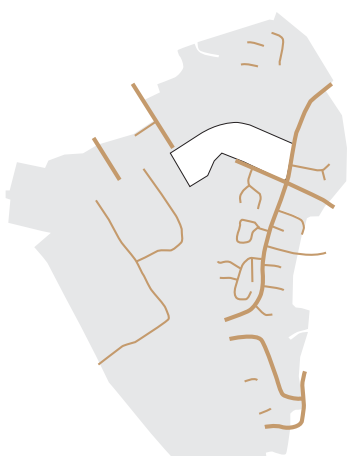

Secondary Roads

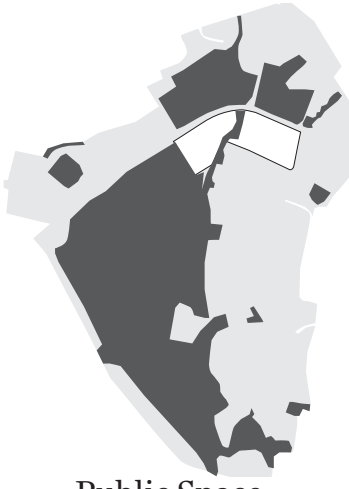

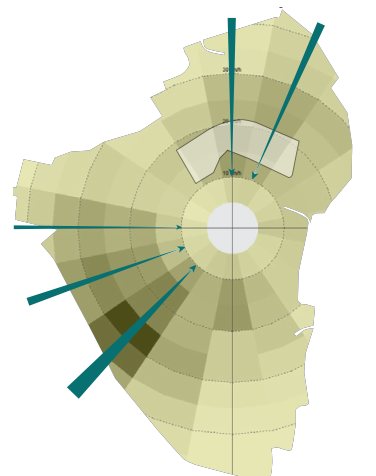

Wind direction

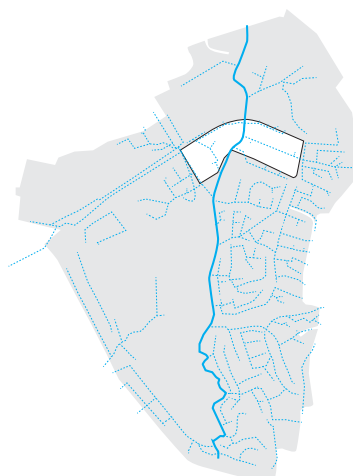

Storm water pipes

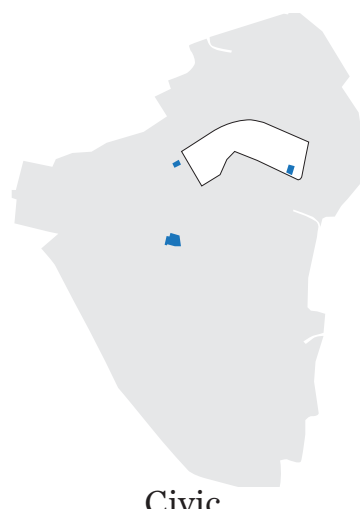

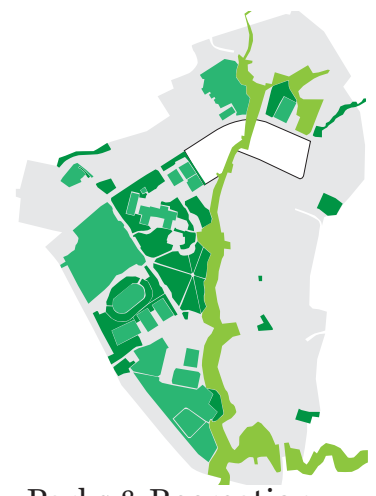

Parks \& Recreation

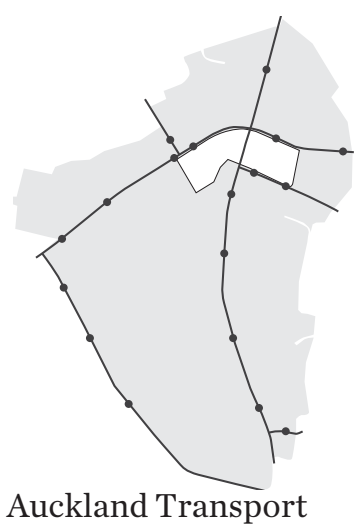

Auckland Transport

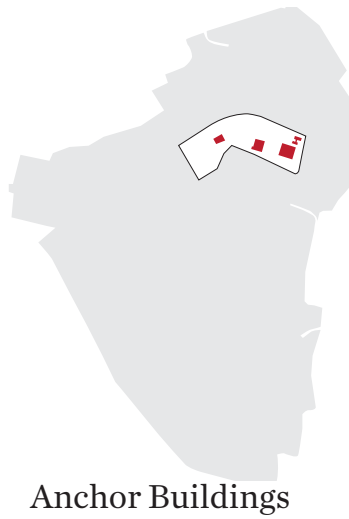


| Highland Park Shopping Centre and Context |

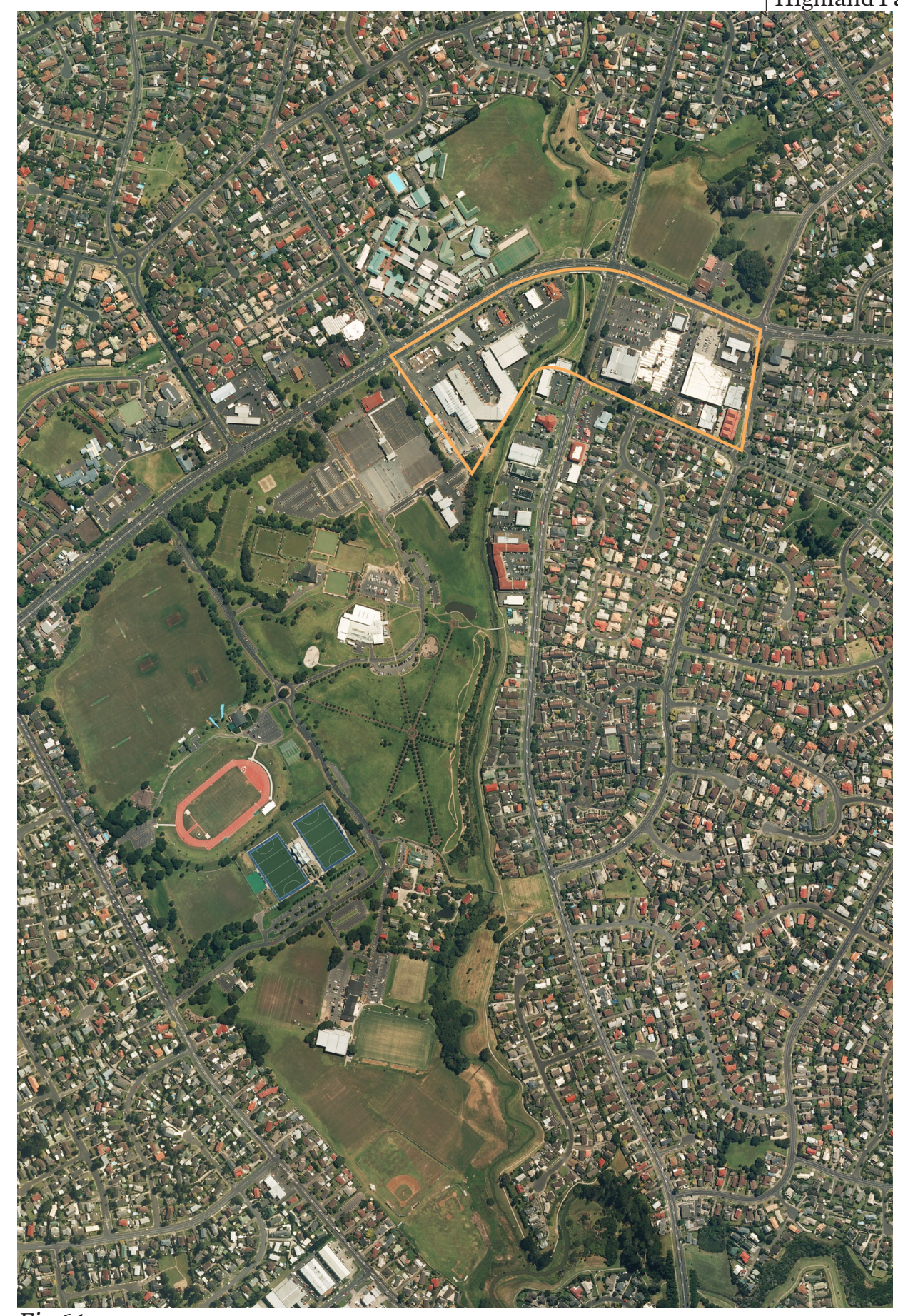




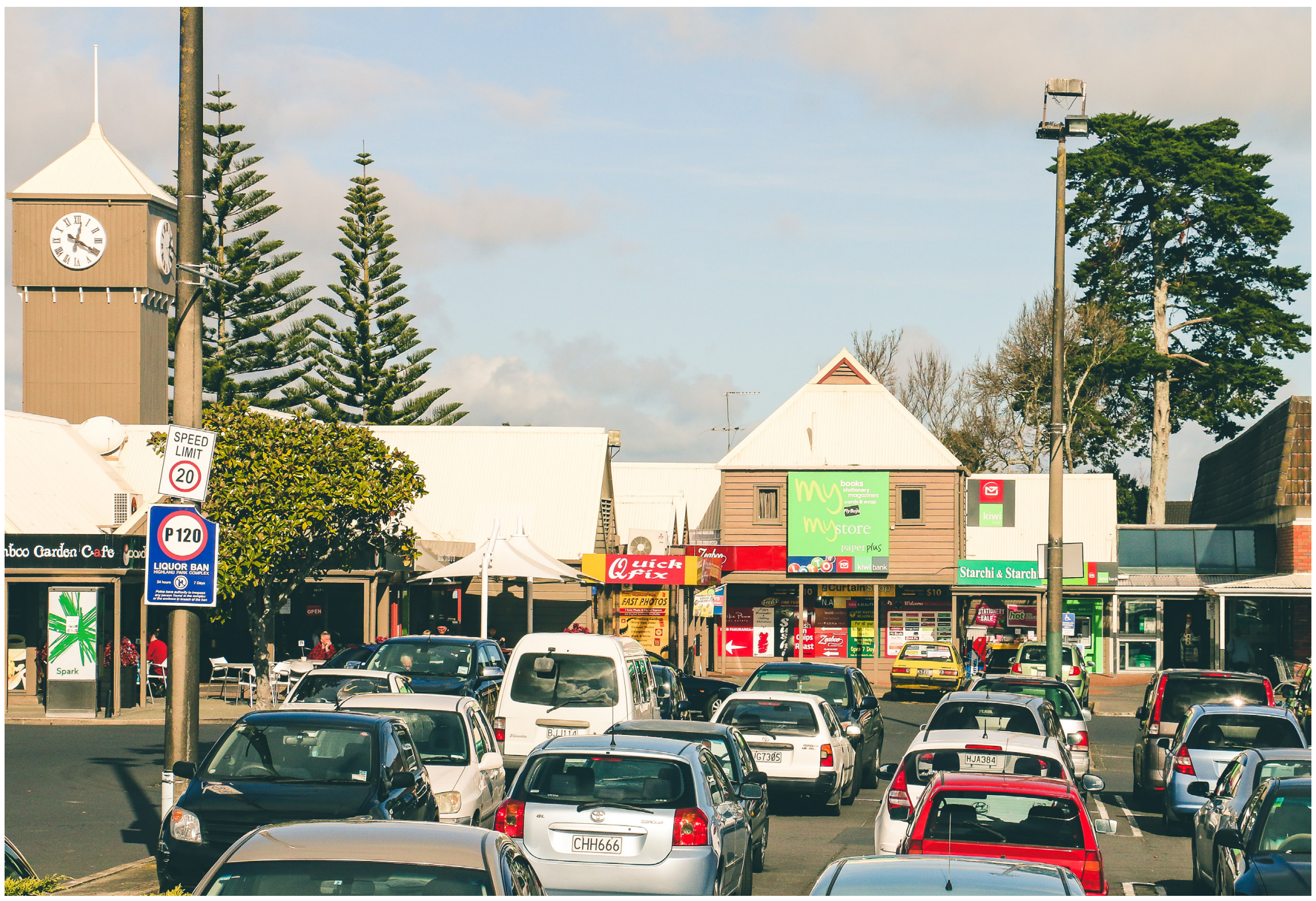




\subsubsection{SITE PHOTOS}
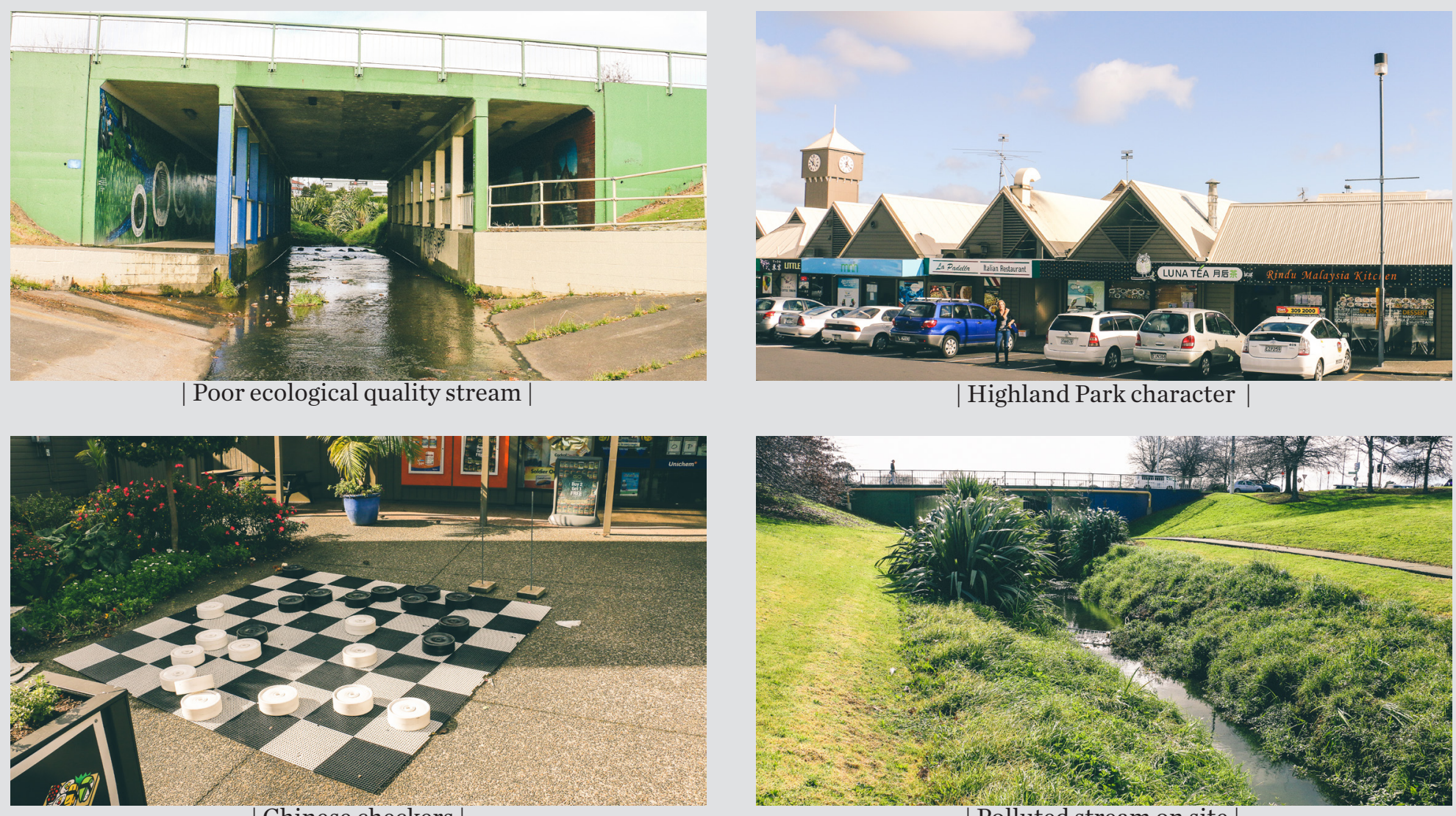

| Chinese checkers

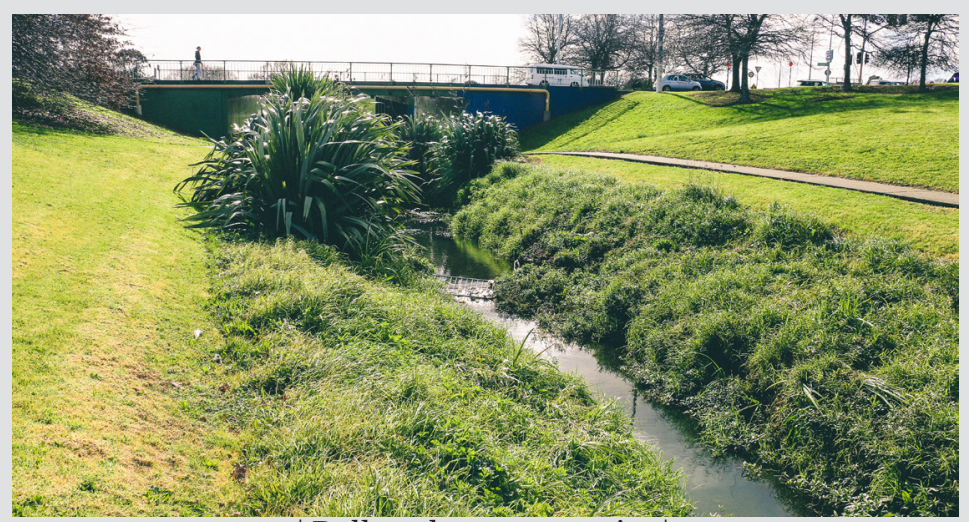

| Polluted stream on site | 


\subsubsection{TAMAKI ECOLOGICAL DISTRICT}

Highland Park is located in the Tamaki Ecological District, which also includes New Zealand's largest urban centre. Highland Park's native vegetation has significantly changed, containing none of the original flora (Fig65). The original ecosystems were assumed to have similar characteristics to Northland's lowland forest with kauri, puriri, taraire and large areas of pohutukawa forests near the coast. The lowland hills supported conifer-dominated stands with kauri and tanekaha. Also there were networks of freshwater wetlands and lakes formed by volcanic activity (Lindsay, Wild \& Byers, 35). An Auckland Council report identifies the Tamaki Estuary, grading the $17 \mathrm{~km}$ stretch a ' $\mathrm{D}$ ' grade, which is well below acceptable as the 1600HA area supports many diverse species.

Vulnerable Fauna

- $\quad$ Grey duck

- $\quad$ Black billed gull

- Wrybill

- Banded dotterel

- $\quad$ Northern NZ dotterel

- $\quad$ Long tailed Bat

- Reef Heron

- Caspian Tern

- $\quad$ North Island Kaka

- Longfin Eel

- Ornate Skink

- $\quad$ Northern Little Blue Penguin

- Giant Kakupu

- $\quad$ Red Billed Gull

- $\quad$ Auckland Green Gecko

- White Fronted tern
Originally Rare Ecosystems

Coastal cliffs on mafic rock

Coastal rock stacks

Debris flow or lahar

Estuary

Gumland

Lake margin

Subterranean basalt fields

Volcanic boulder fields 


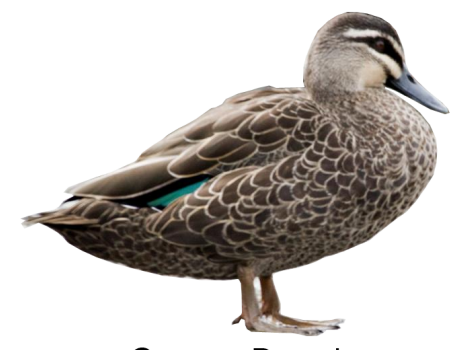

Grey Duck

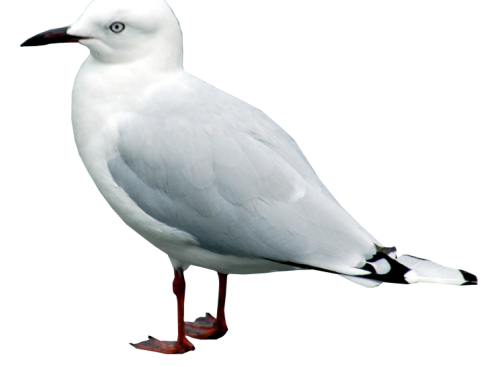

Black Billed Gull

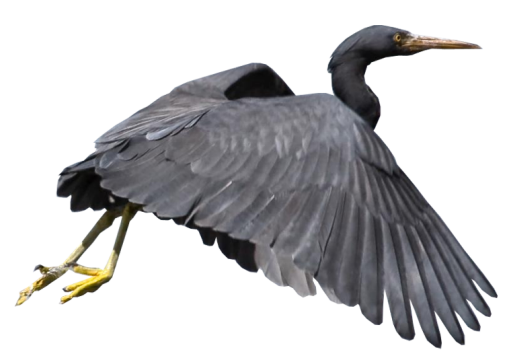

Reef Heron

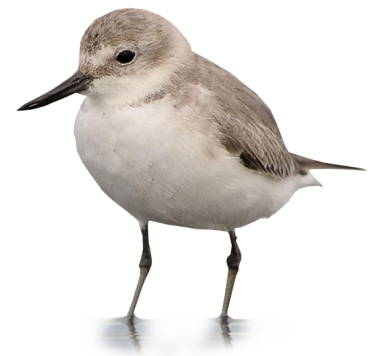

wrybill

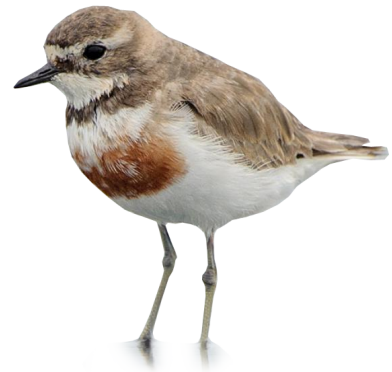

Branded Dotterel
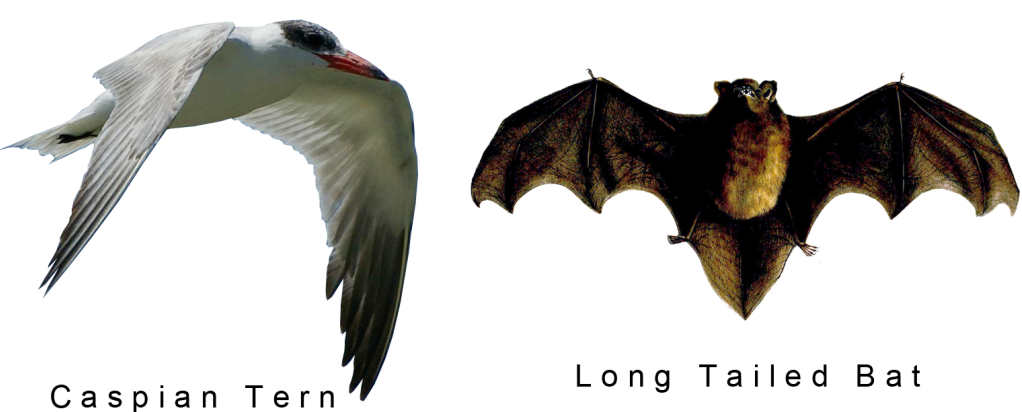

Long Tailed Bat
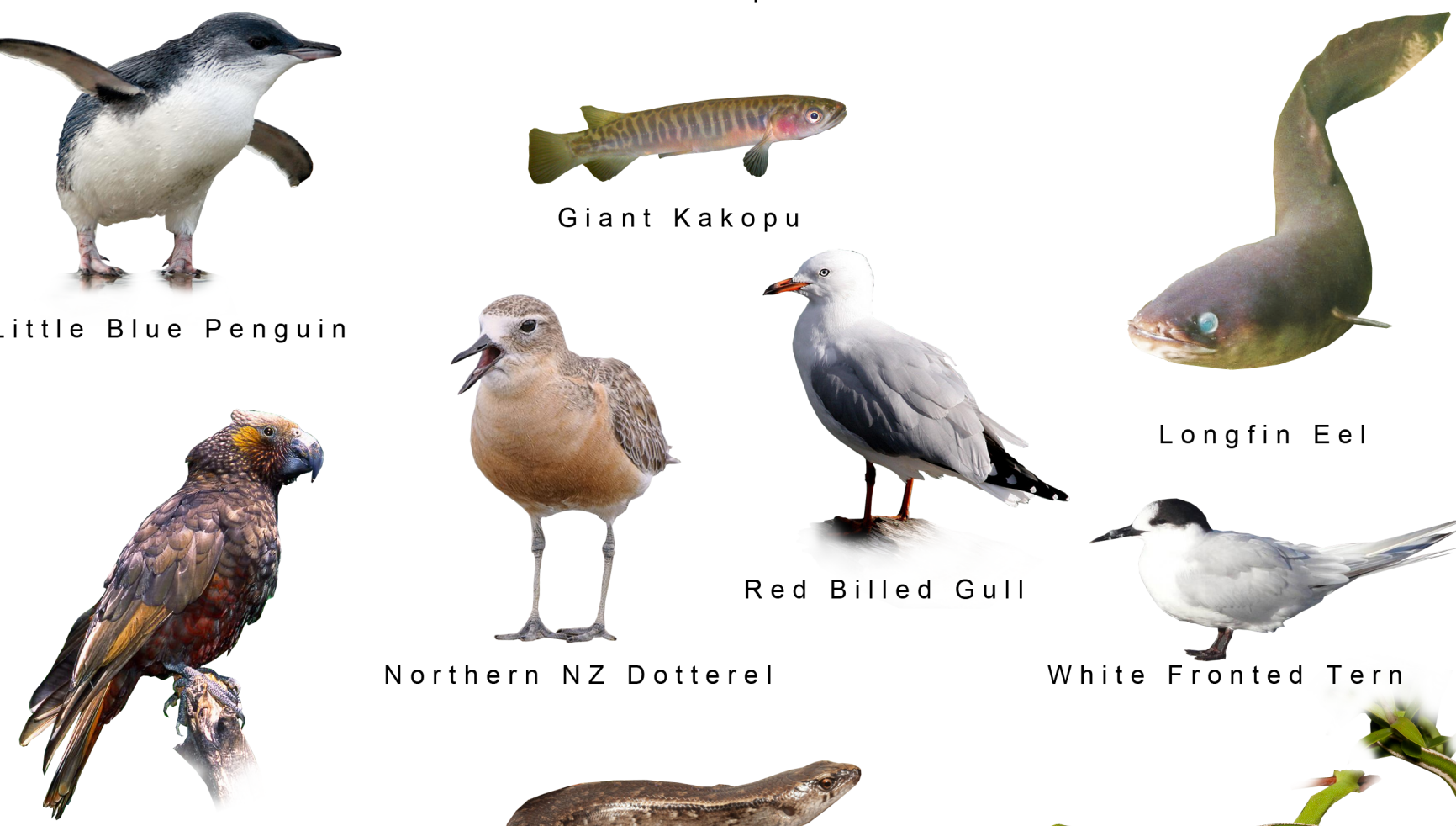

Northern NZ Dotterel

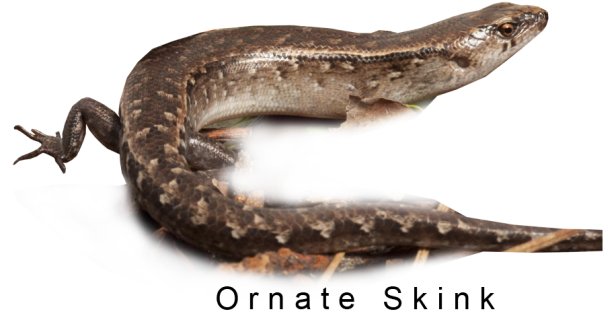

Longfin Eel

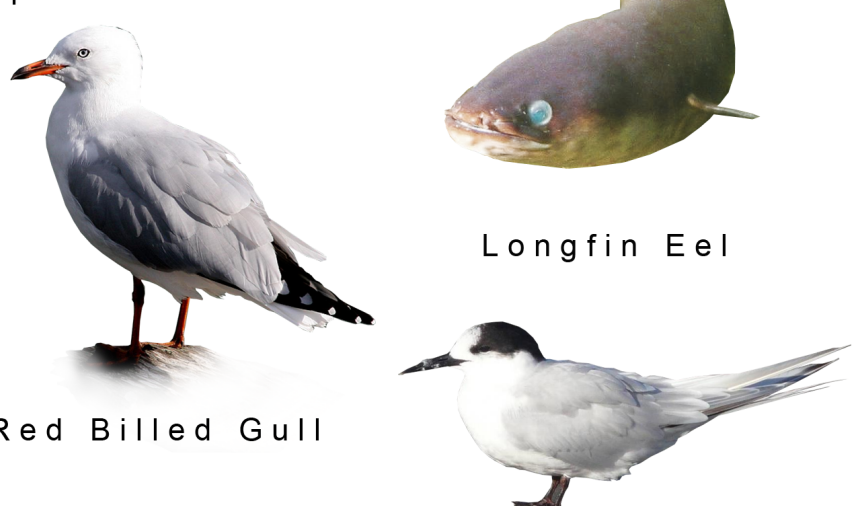

White Fronted Tern

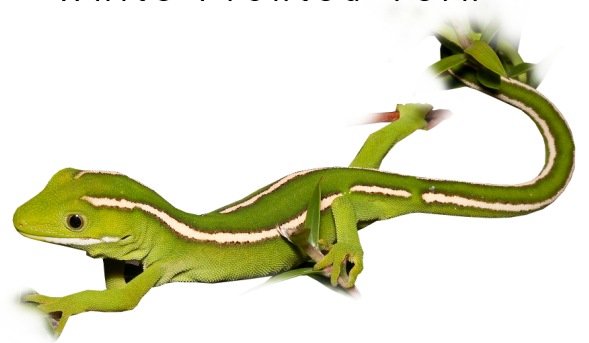

Auckland Green Gecko 


\subsubsection{PUBLIC TRANSPORT}

The Auckland Rapid Transit System (fig66) contains corridors connecting many areas of Auckland, however the eastern region where Highland Park is located is not connected. This disconnection puts this area at a significant disadvantage for efficient public transportation. There are alternative schemes for light rail to connect this area published on the "Transportblog" and the route proposed has been applied to the design case study and reconfigured how it flows through the site.

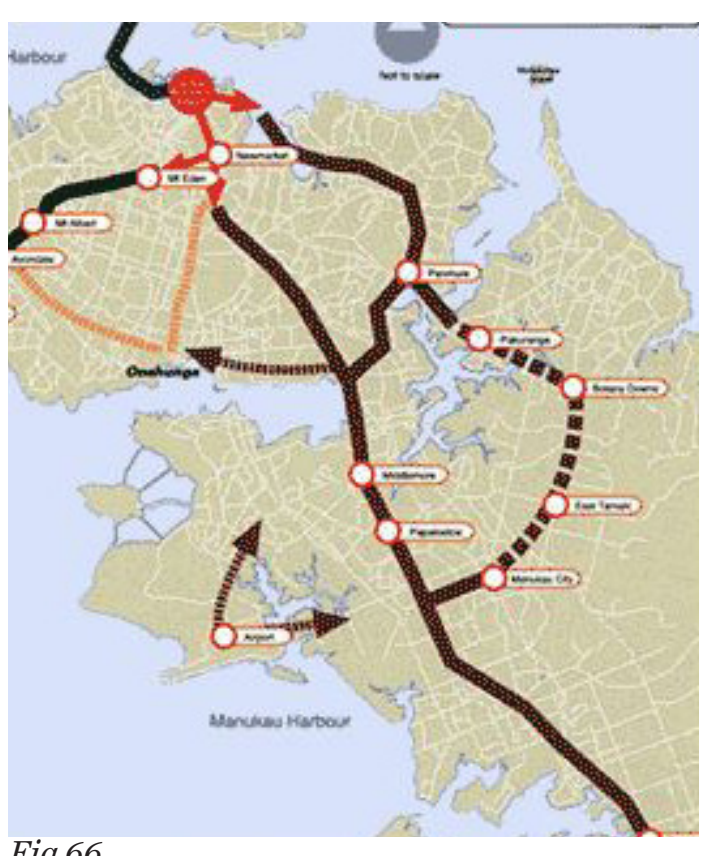

Fig 66. 


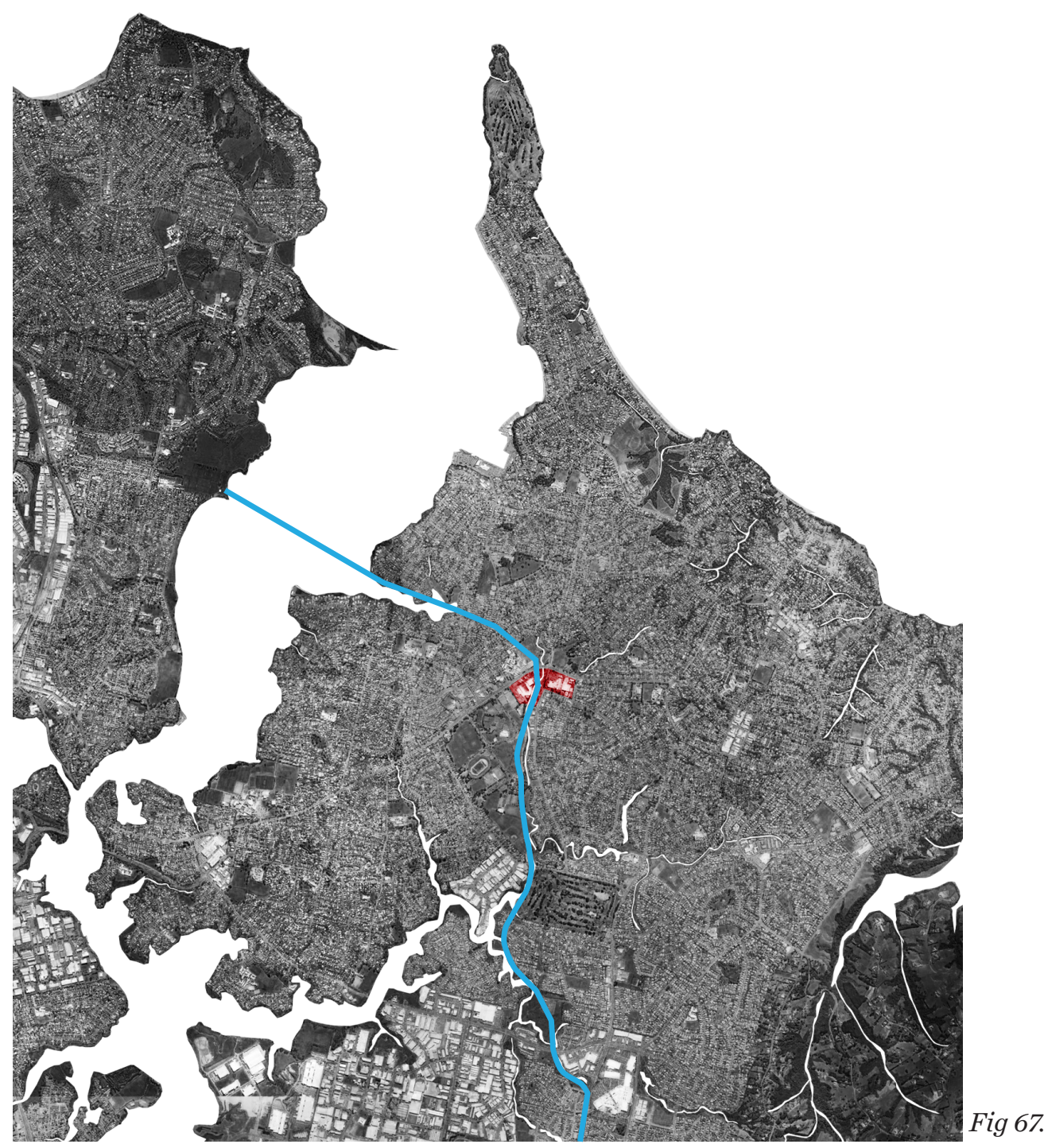

| Proposed Light Rail Route | 


\subsubsection{URBAN FORM DEVELOPMENT}

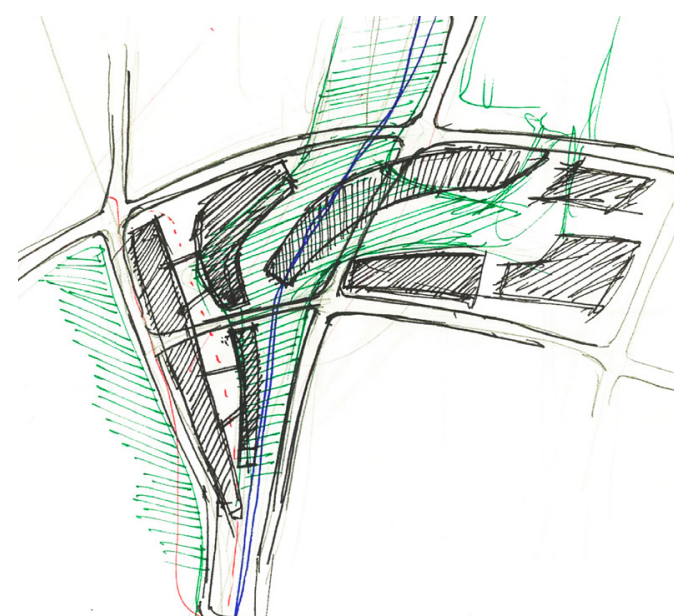

Initial Free-Sketch

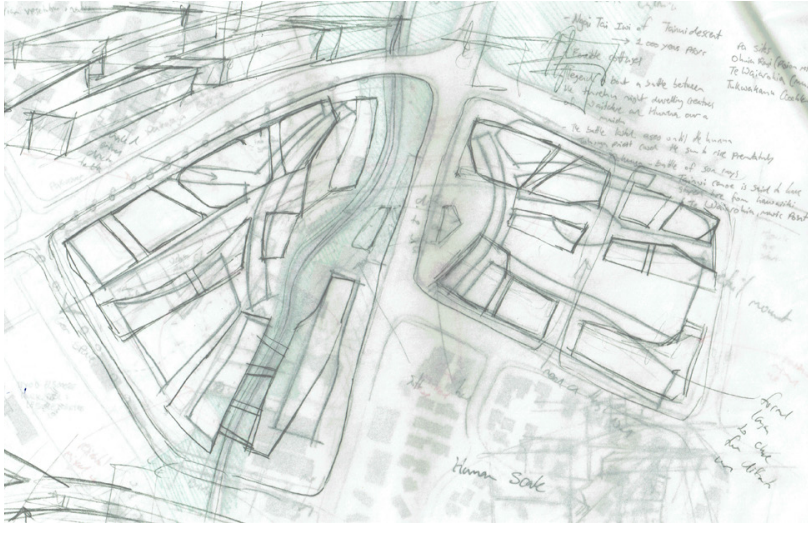

Initial Drawing Stack

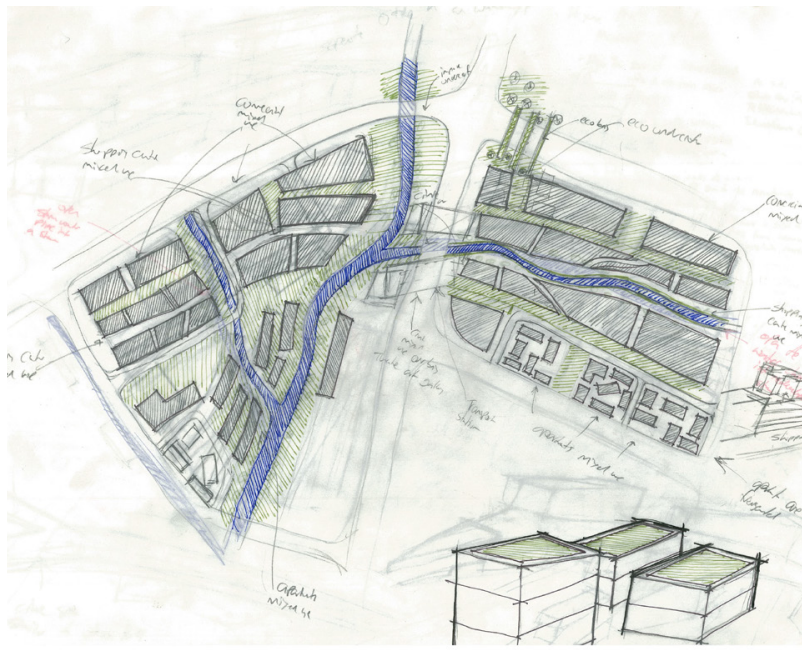

Activating stormwater streams 


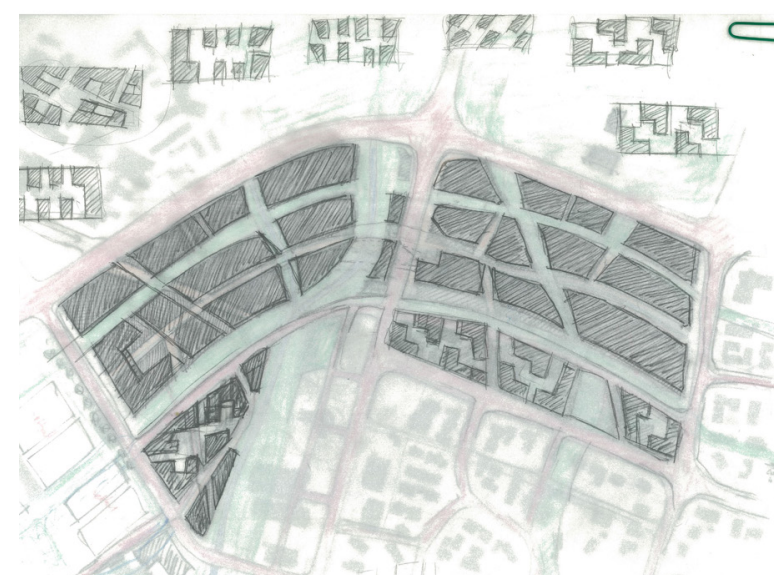

Road Networks \& geometric pattern

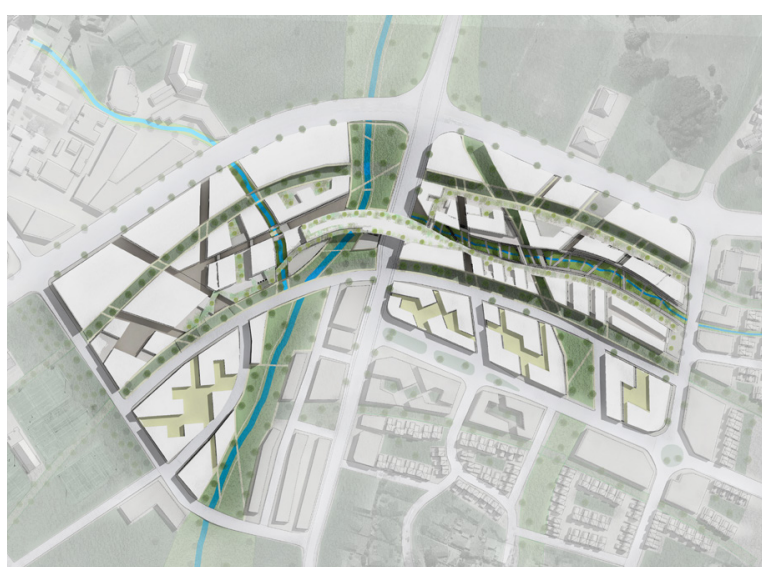

Digital Model Masterplan - October Review

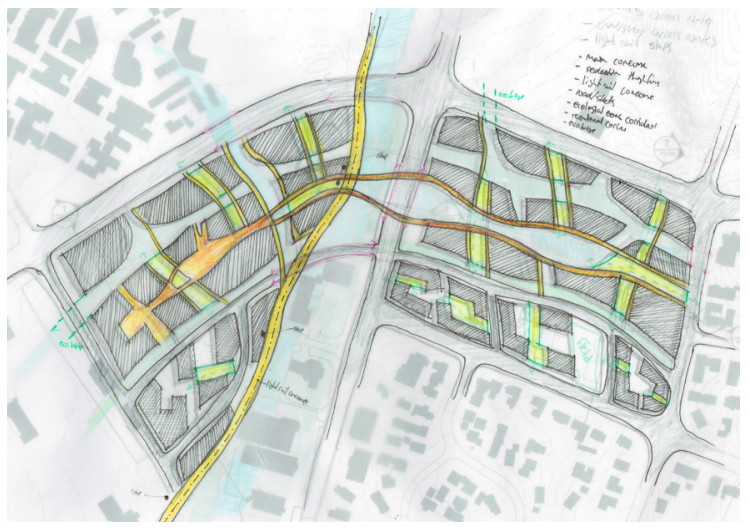

Enhancing Ecology \& Service Connectivity 
| Concept section |

7.3.2 SKETCHES

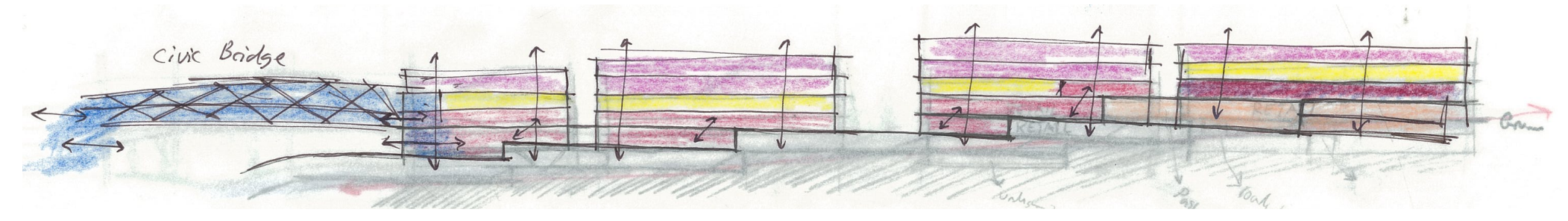



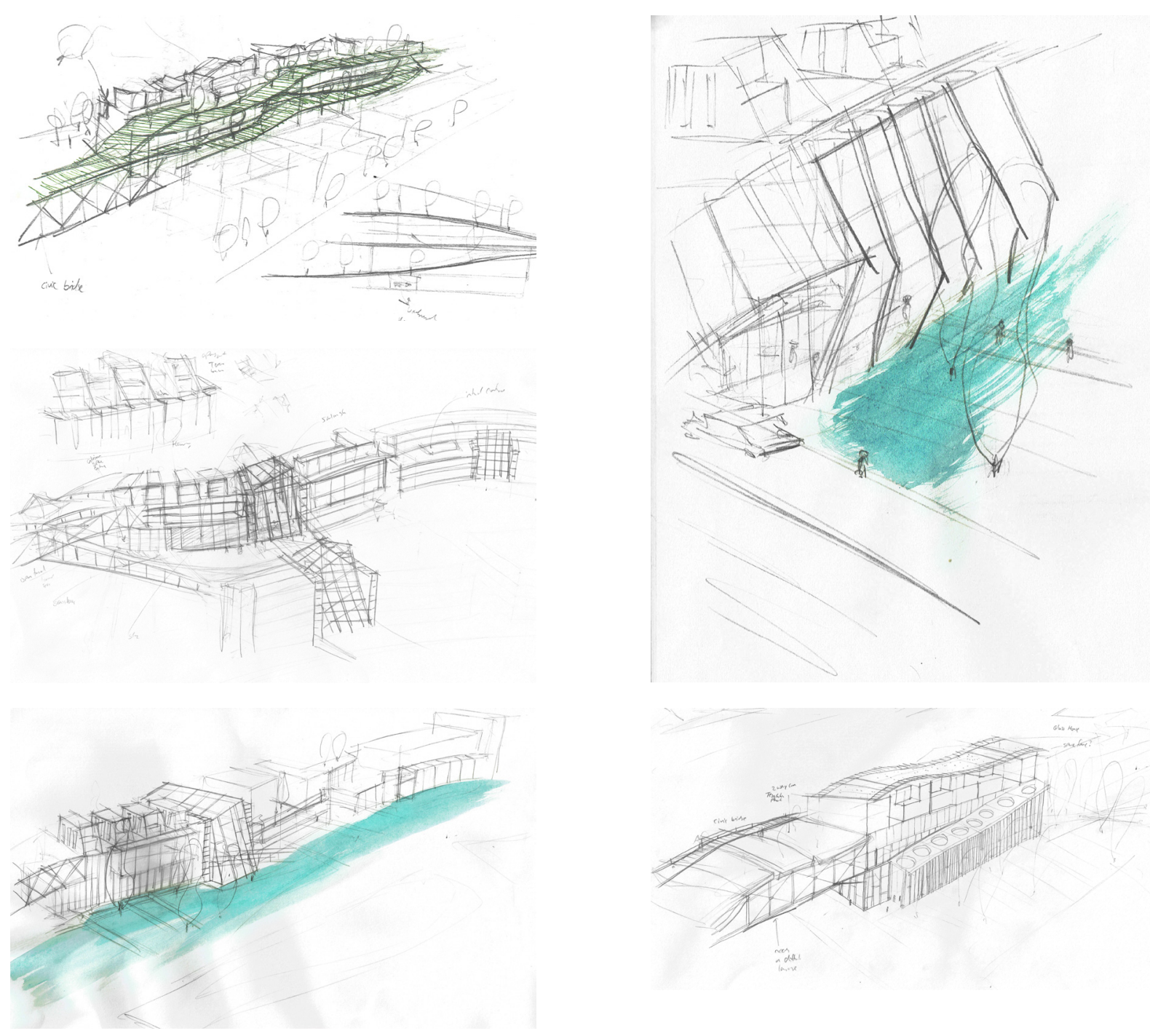


\subsubsection{ECOLOGICAL CORRIDORS}

Exploration of habitation of humans and non-human species along waterways and forest corridors.

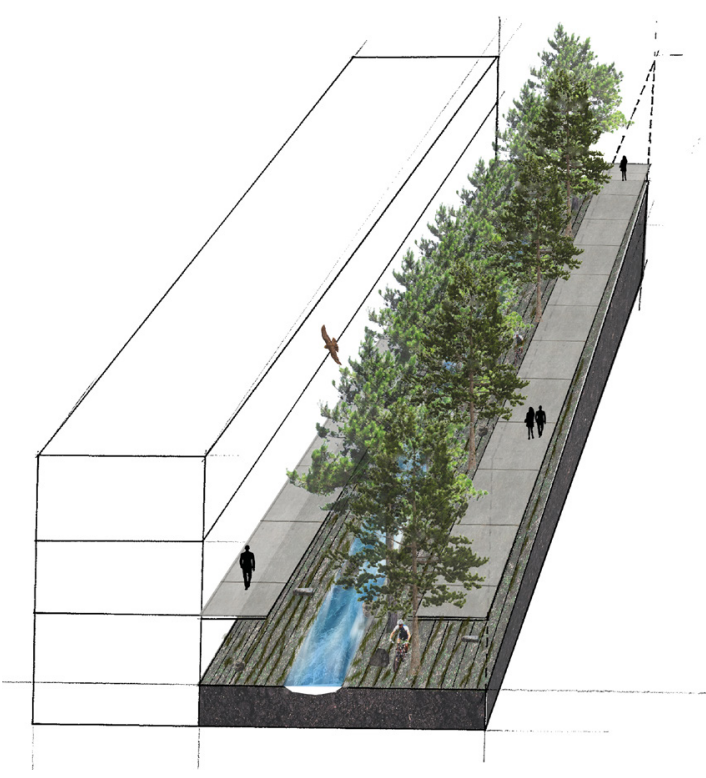

Conifer forest $\&$ stream

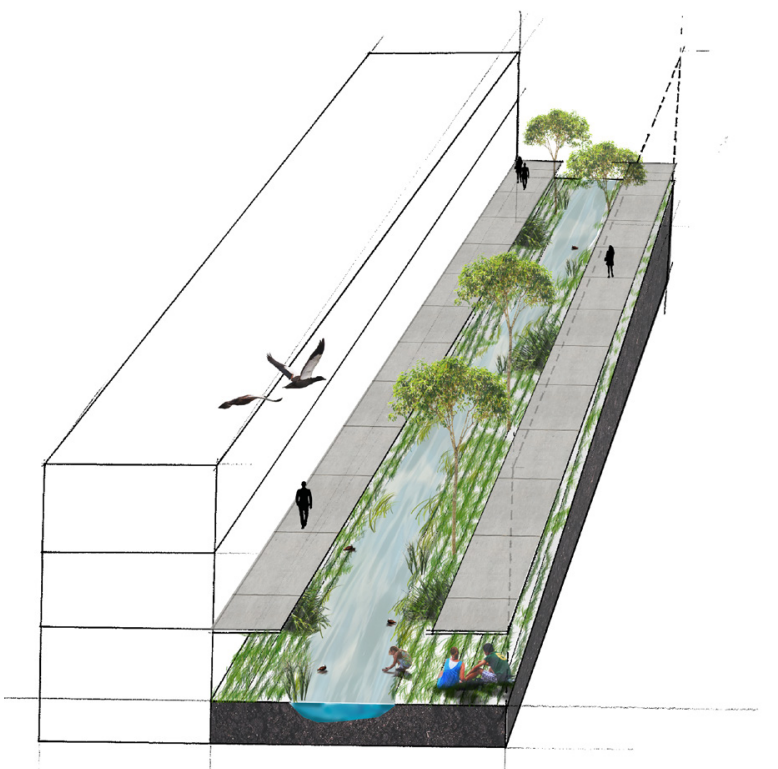

Open stream

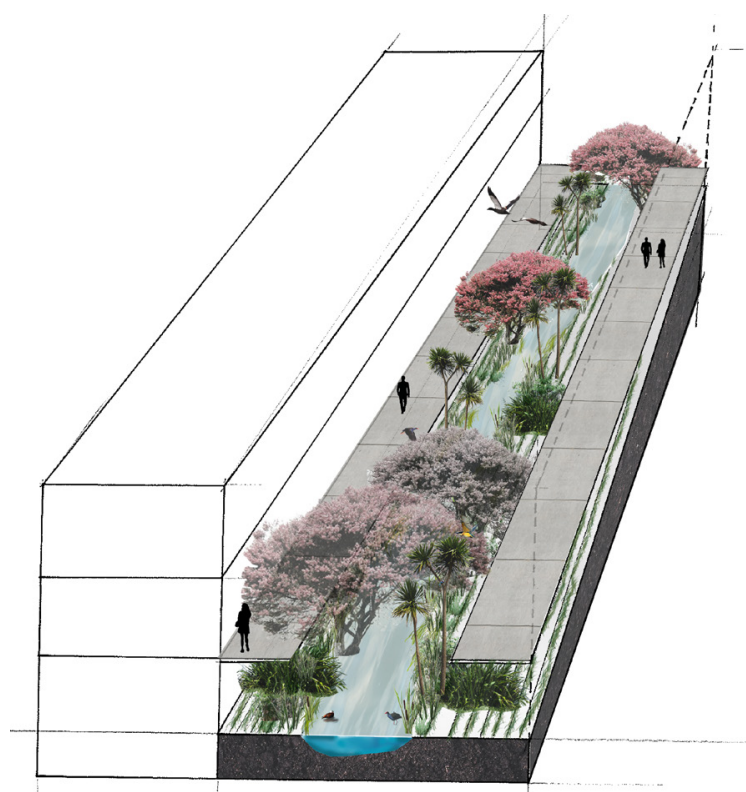

Wetland 


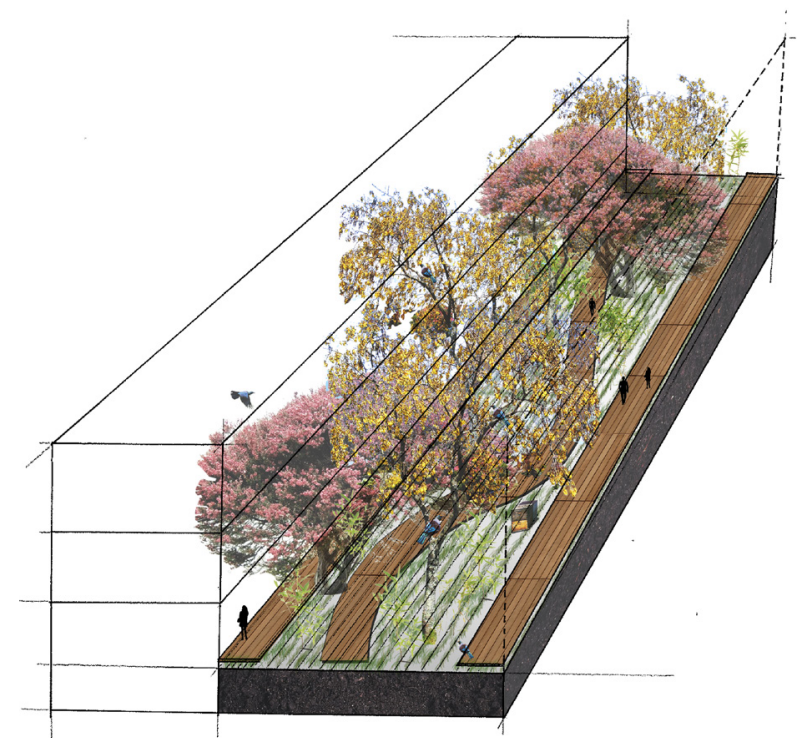

Ecological corridor: Manuka \& Kowhai

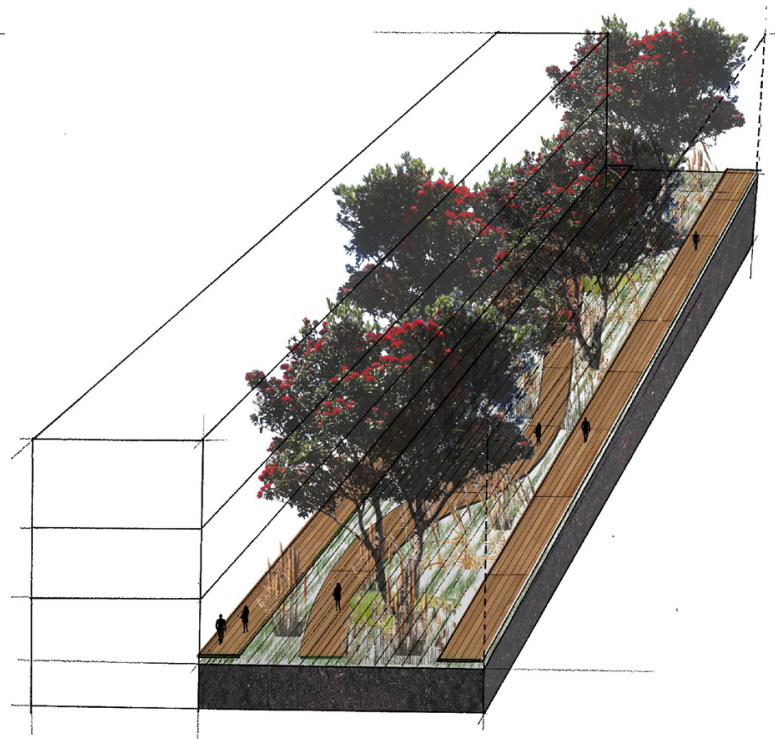

Ecological corridor: Pohutukawa

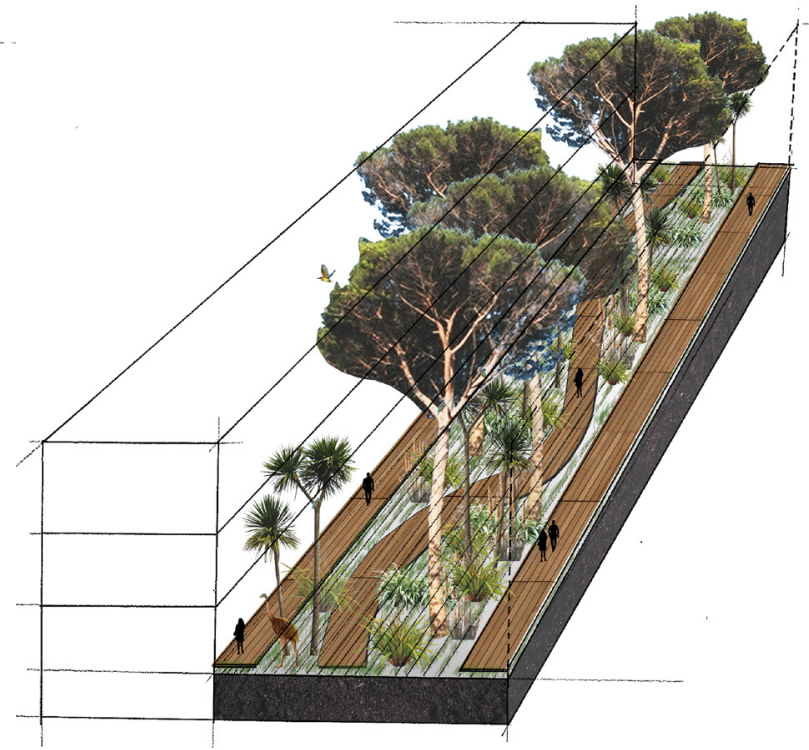

Ecological corridor: Native Hardwoods 


\subsubsection{ECOLOGY \& ARCHITECTURE}

Perspective design exercise exploring the relationship of landscape with architecture, beginning with a conventional approach and finishing with the idea that the ecology is not controlled by the pavement. Instead it is free to change, grow and develop. To create habitats for different species the architecture needs to provide diverse environmental conditions; wet and dry, direct light and shade, open space and closed, steep and flat.
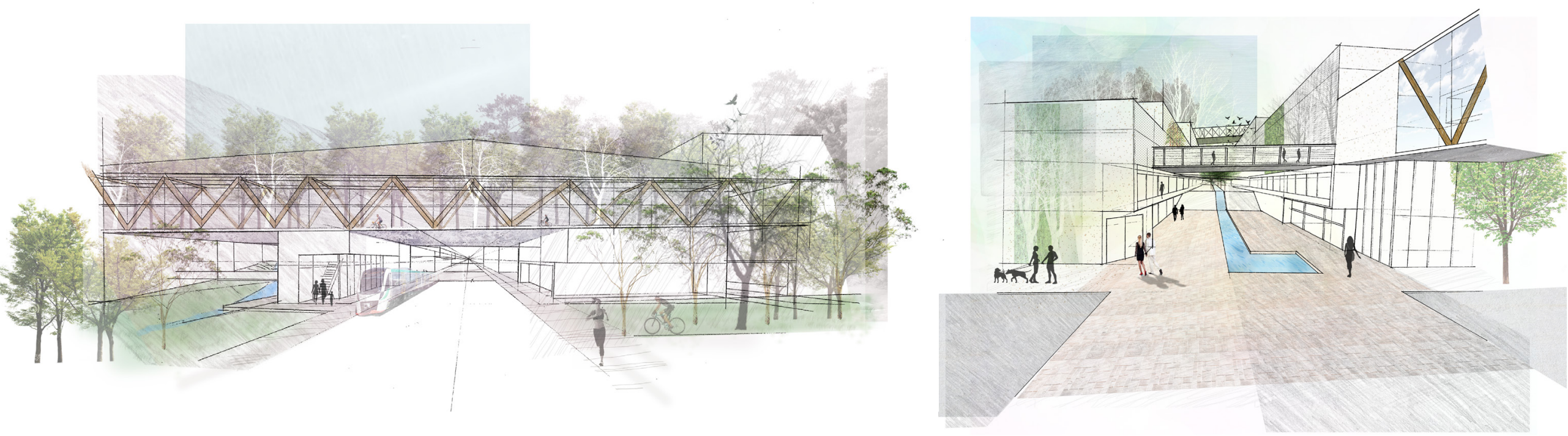

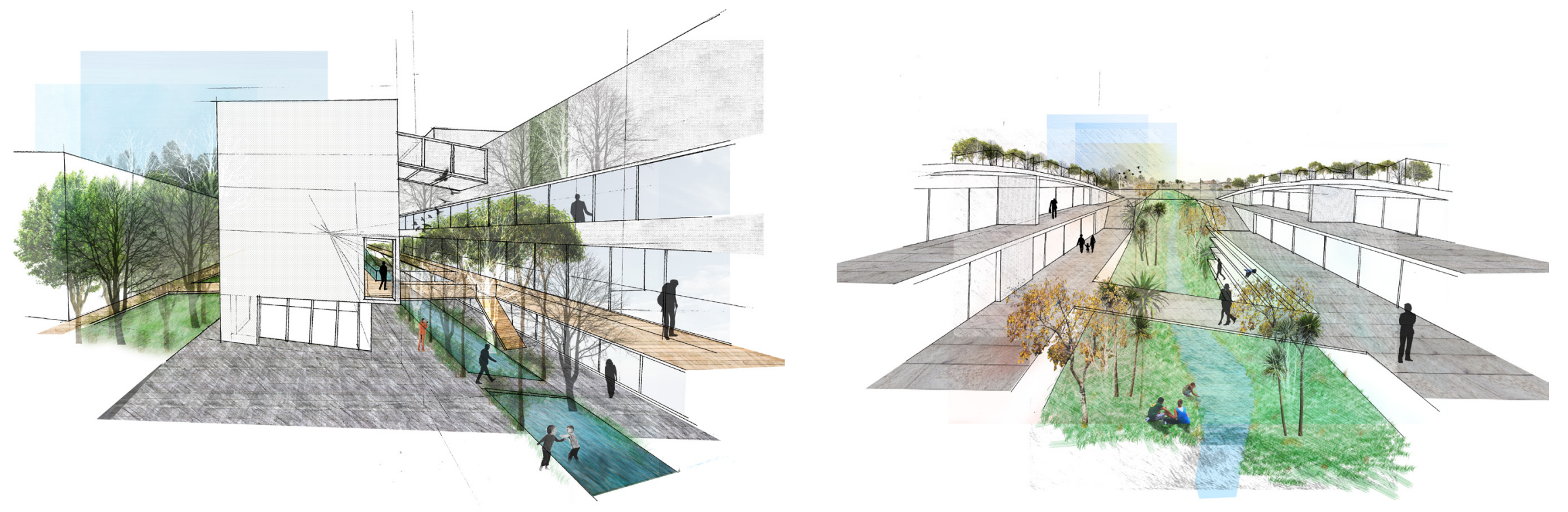


\subsection{URBAN DOCUMENTATION}

\subsubsection{DESIGN INTENTION}

The urban design framework utilises a longitudinal grid structure influenced by the shape of the arterial road which now contains a new ecological corridor, pedestrian concourse, recreational corridor and a new road that run parallel to the arterial road. The original polluted stream has been enhanced through the use of ponding to create new habitats. Furthermore, two storm water pipes have been reinstated as waterways providing more ecological habitats. The area experiences high annual rainfall which will allow these waterways to fluctuate in water levels. The buildings facing Pakuranga road on the northern end consist of commercial mixed use buildings. The pedestrian concourse in the middle of the site consists of retail mixed use buildings, featuring a "civic bridge" with anchor buildings connecting both sites. The civic functions include: a cinema complex; a market space; a library; an exhibition space; a bar, cafes and restaurants; a light rail stop; a gym and a niche supermarket. The civic bridge creates an architectural landmark. The buildings on the southern end of the site consist of residential mixed use. The masterplan includes two underground carparks, one each at the eastern and western ends.

\section{Car Parking: 1,500 Spaces}

\section{Residential Units: 500}

Commercial office space: $30,000 \mathrm{~m} 2$

Retail floor area: 46,00 m2 


\section{URBAN INFRASTRUCTURE}

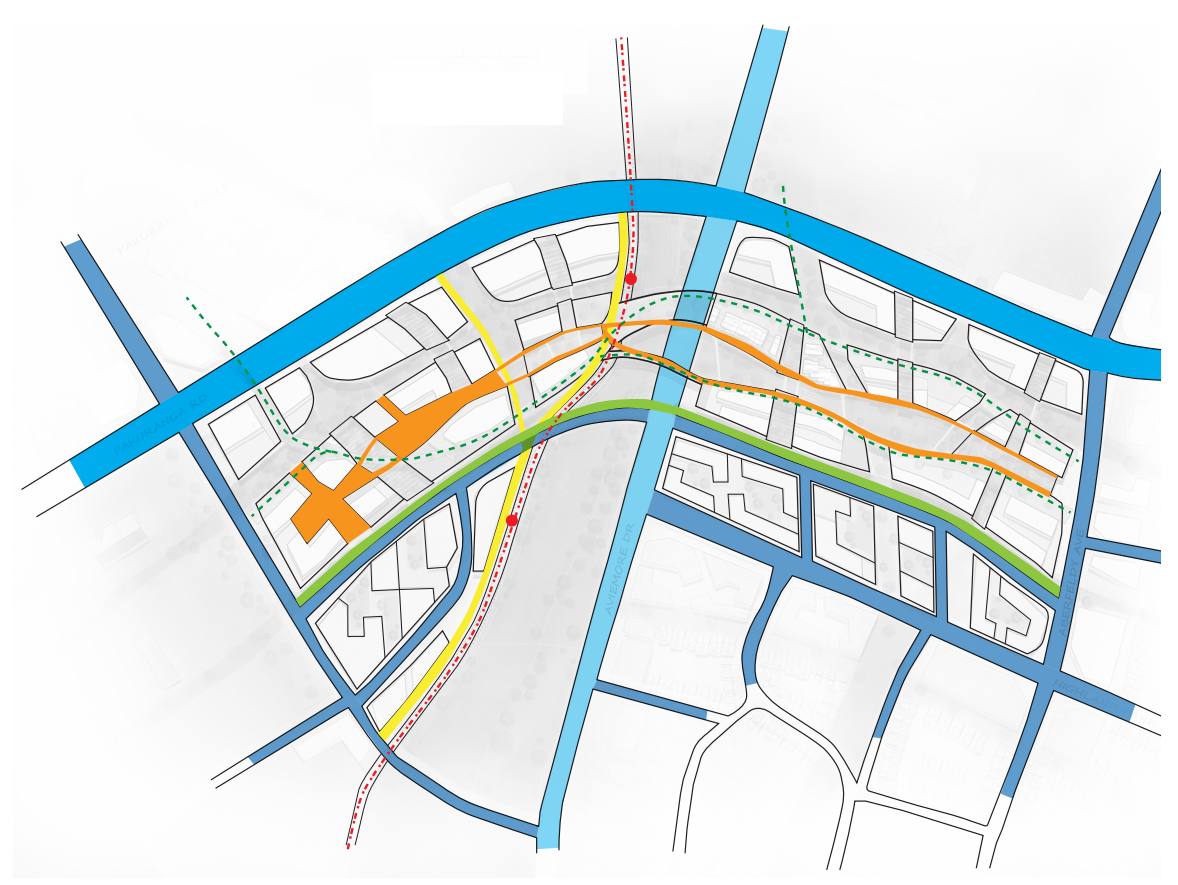

District Arterial Road

Primary Streets

Secondary Streets

Retail Pedestrian Concourse

Secondary Pedestrian Concourse

Recreational Corridor

Light rail Route

Light rail Stop

- - -

Rooftop Terrace
BUILT INFRASTRUCTURE

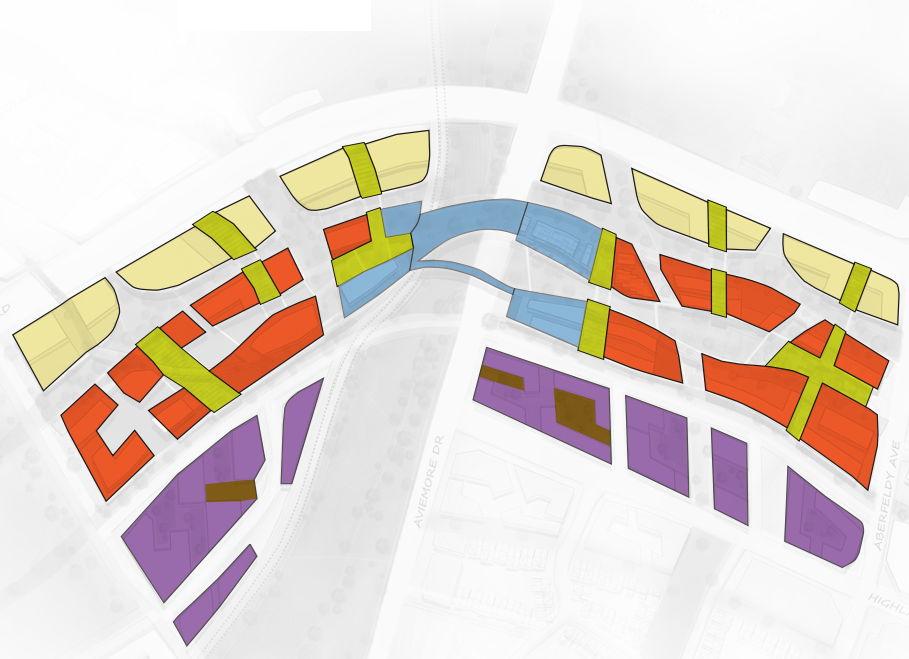

Comercial Mixed Use Zone

Retail Mixed Use Zone

Reseidential Mixed Use Zone

Civic Core

Greenhouse

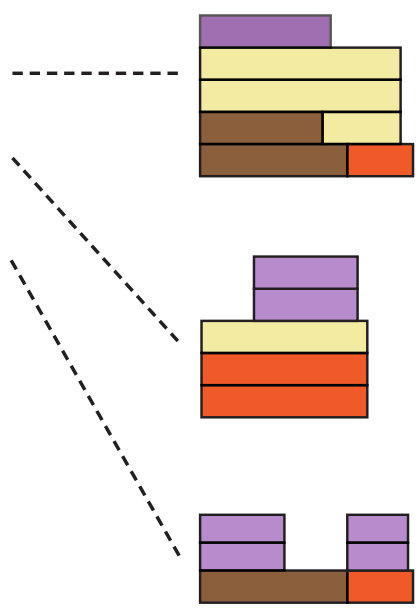


GREEN INFRASTRUCTURE

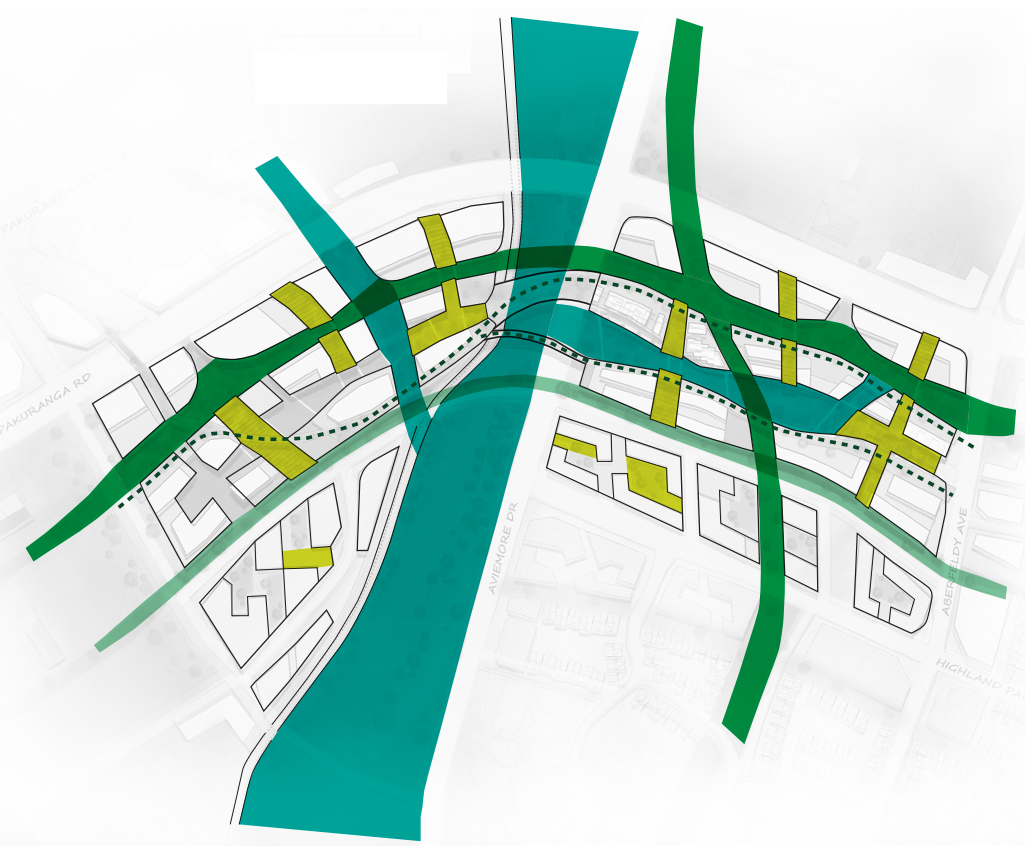

Ecological Corridor

Waterway Ecological Corridor

Ecological Rooftop Corridor

Recreational Corridor

Greenhouse
ROOFTOP TERRACE

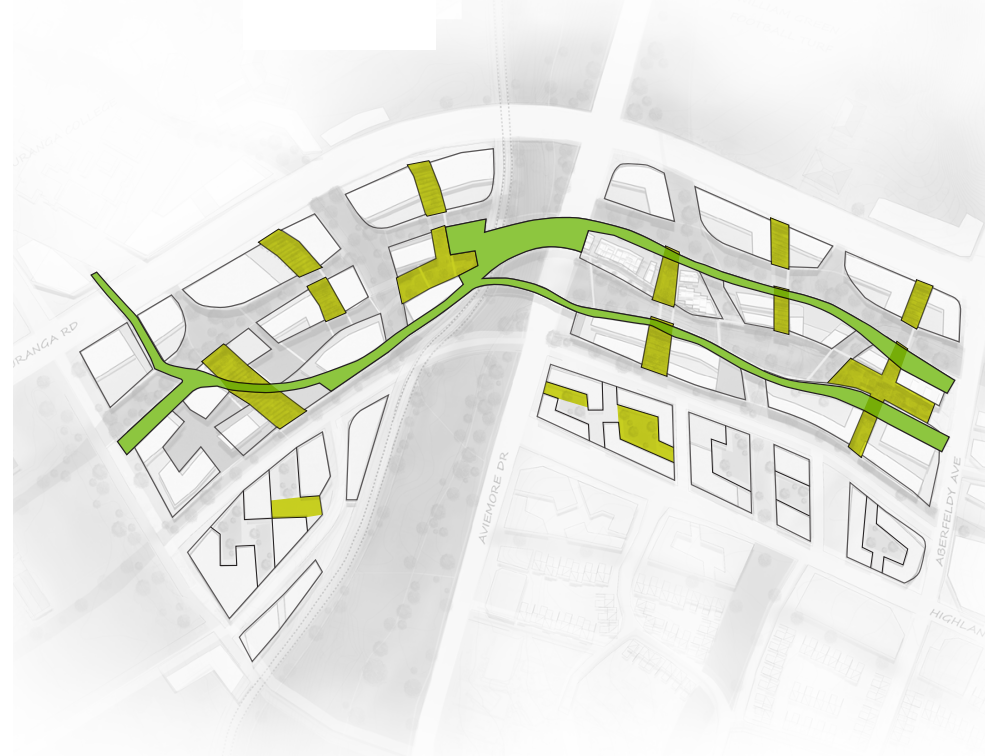

Ecological Rooftop Corridor

Greenhouse 


\section{RETAIL SPACES}

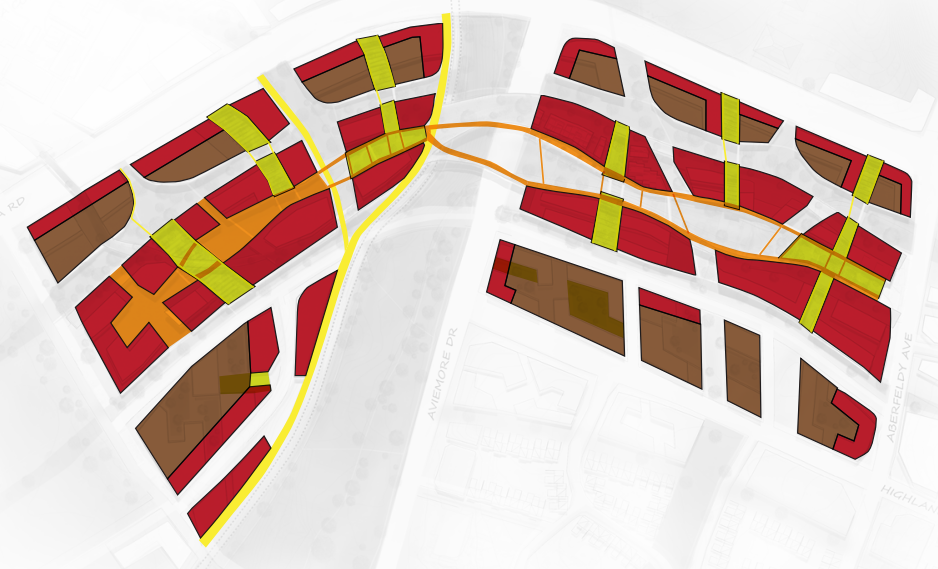

Retail Activity

Greenhouse

Retail Pedestrian Concourse

Secondary Pedestrian Concourse

Parking Structure

\section{PARKING AND SERVICING}

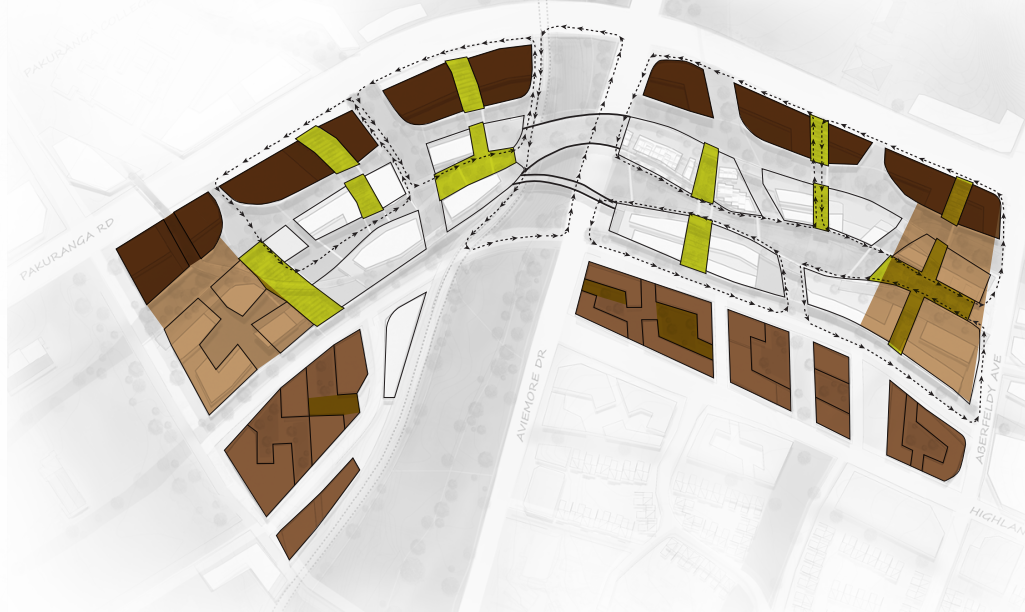

Parking Structure

Greenhouse

Underground Parking

Ground Floor Parking

Servicing Accessibility 


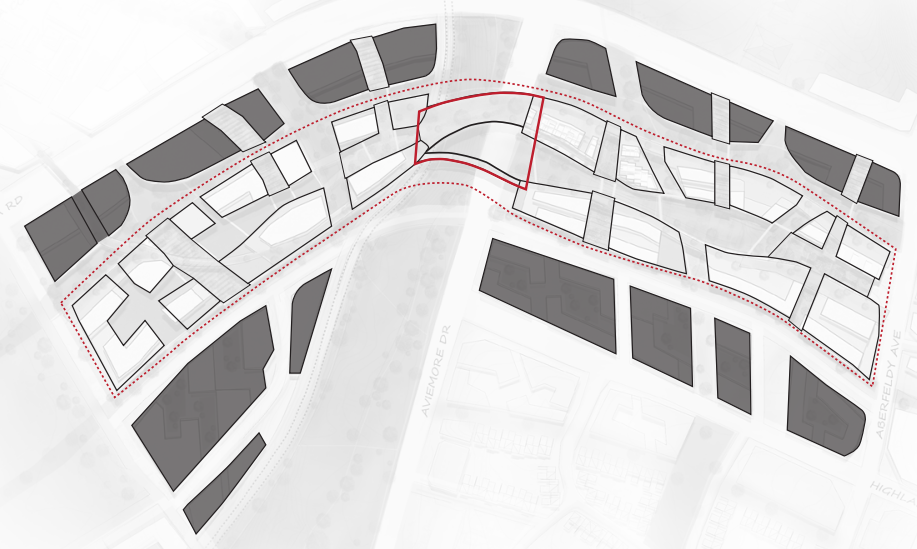

URBAN GRAIN

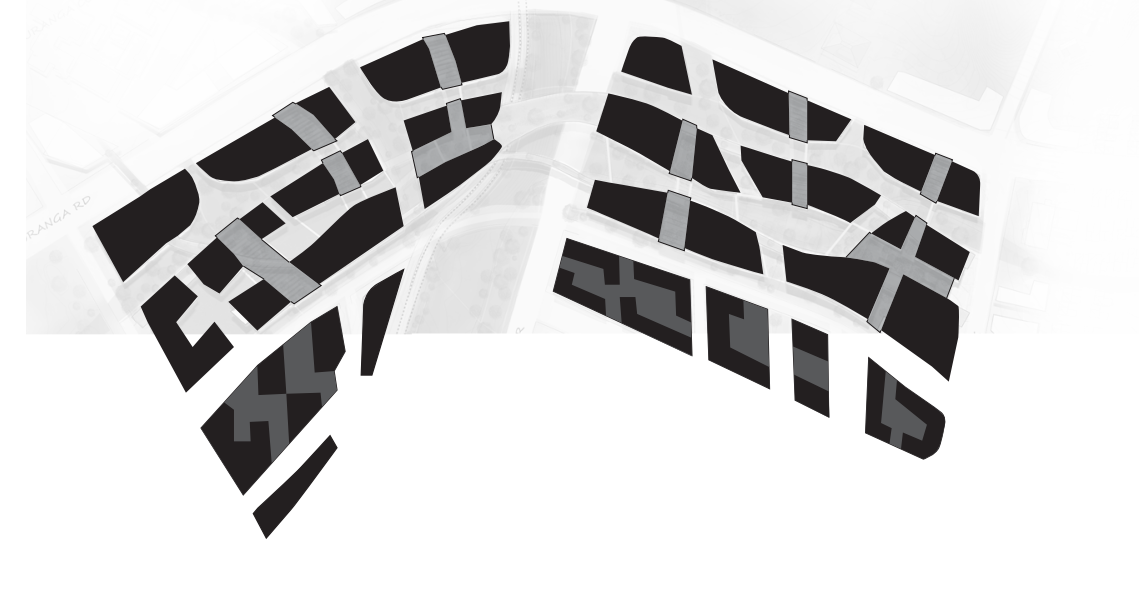

Landmark Civic Bridge

I

Individual Identity 


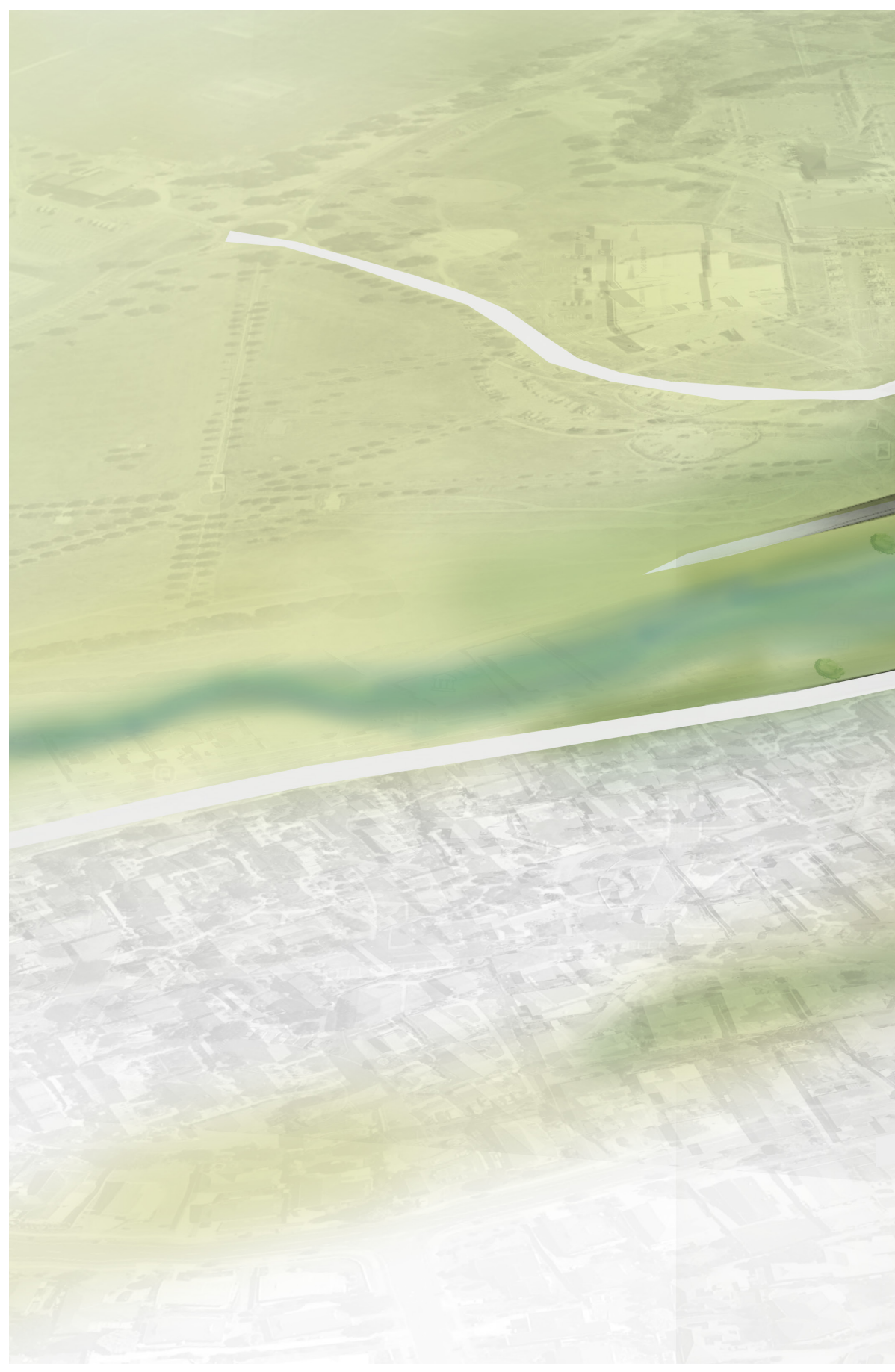




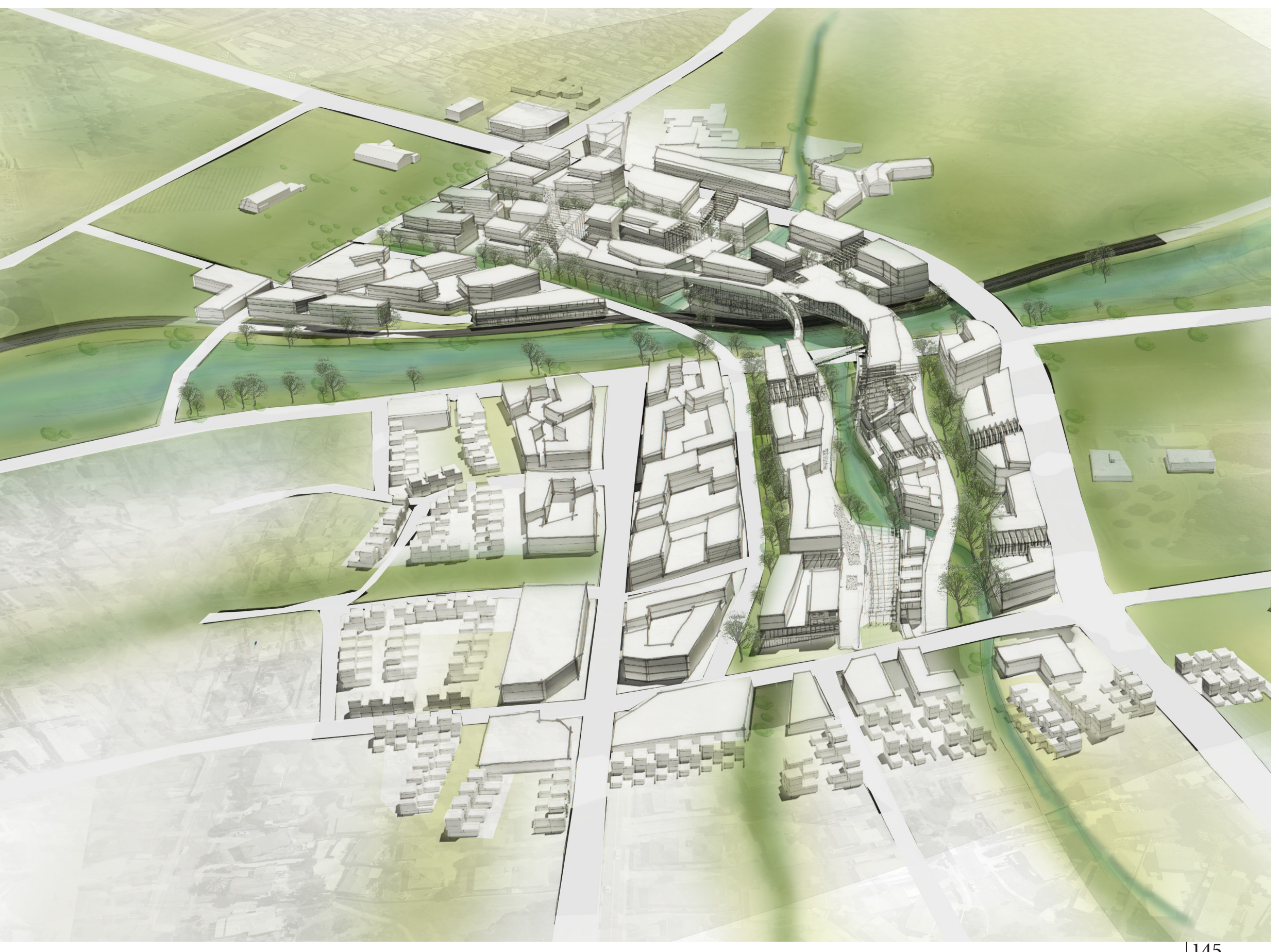


| v Lightrail Pedestrian Pathway Perspective |

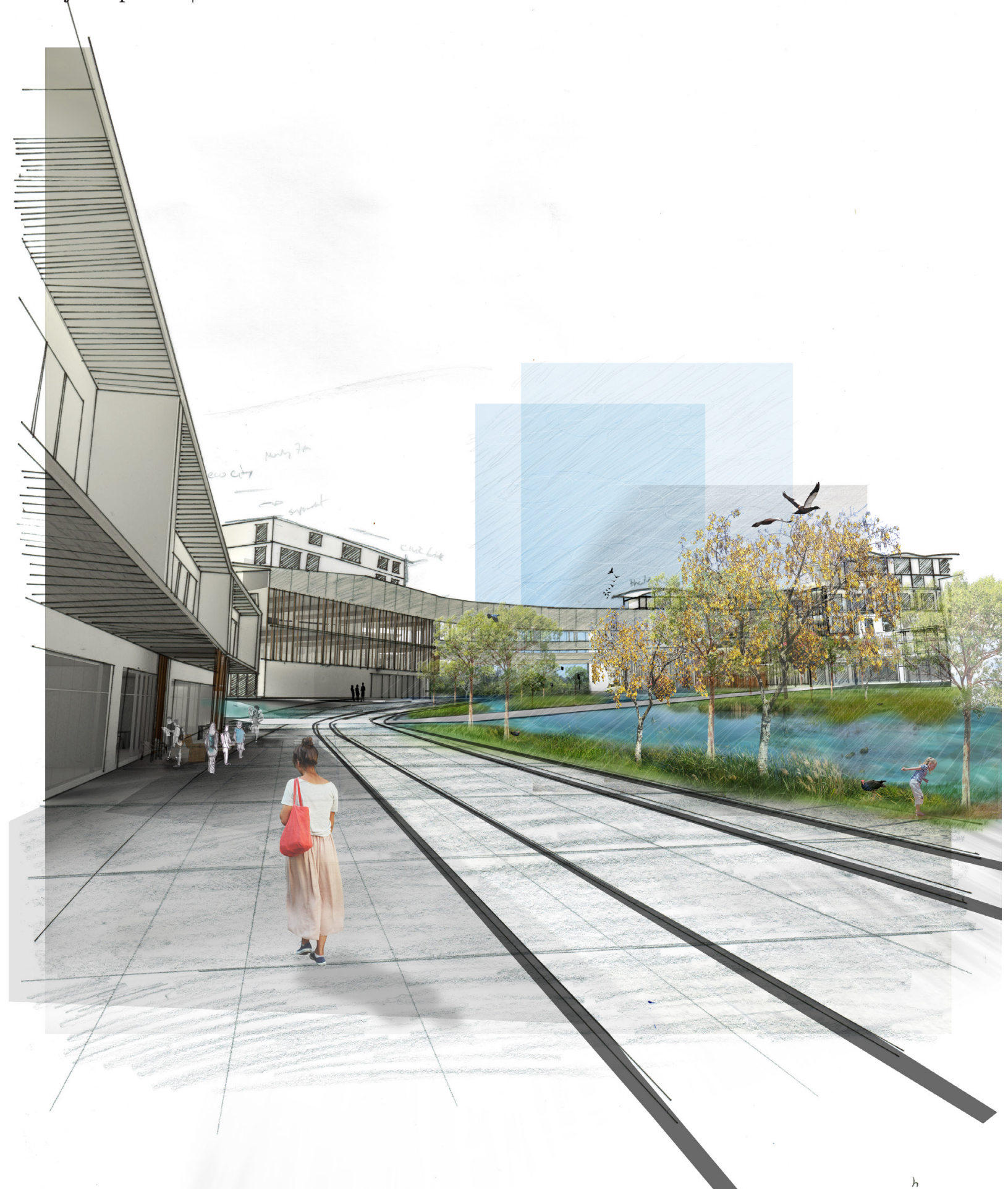




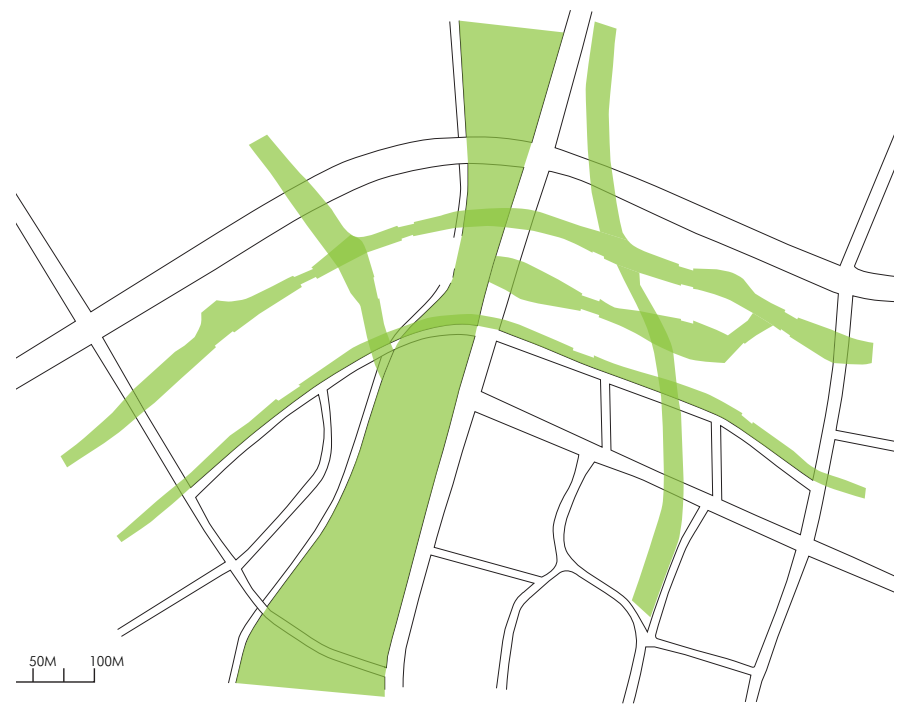

PHASE 3: RETAIL SPINE

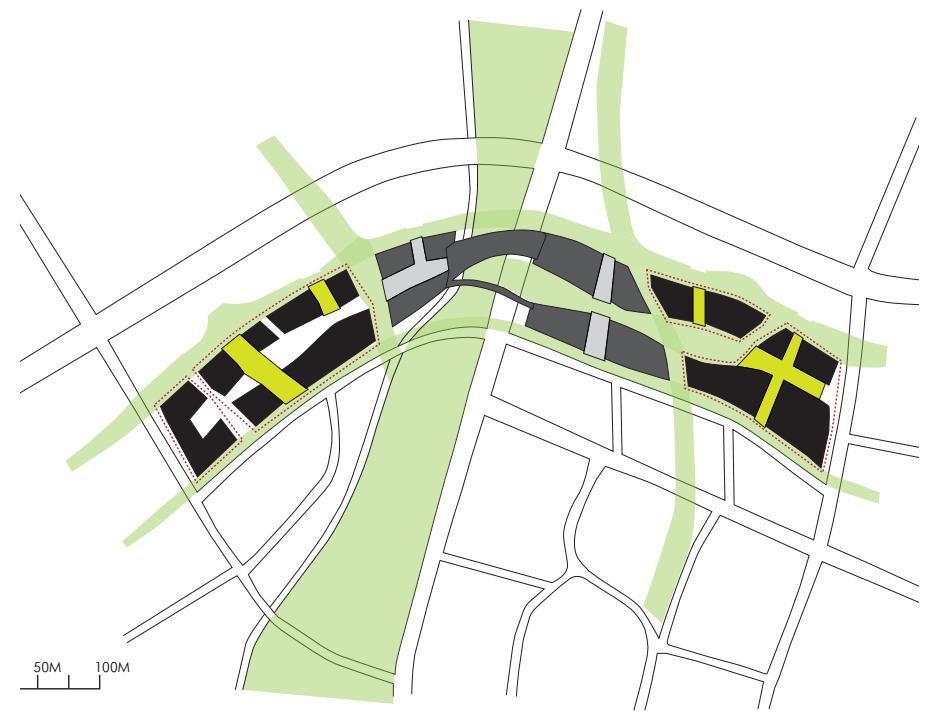

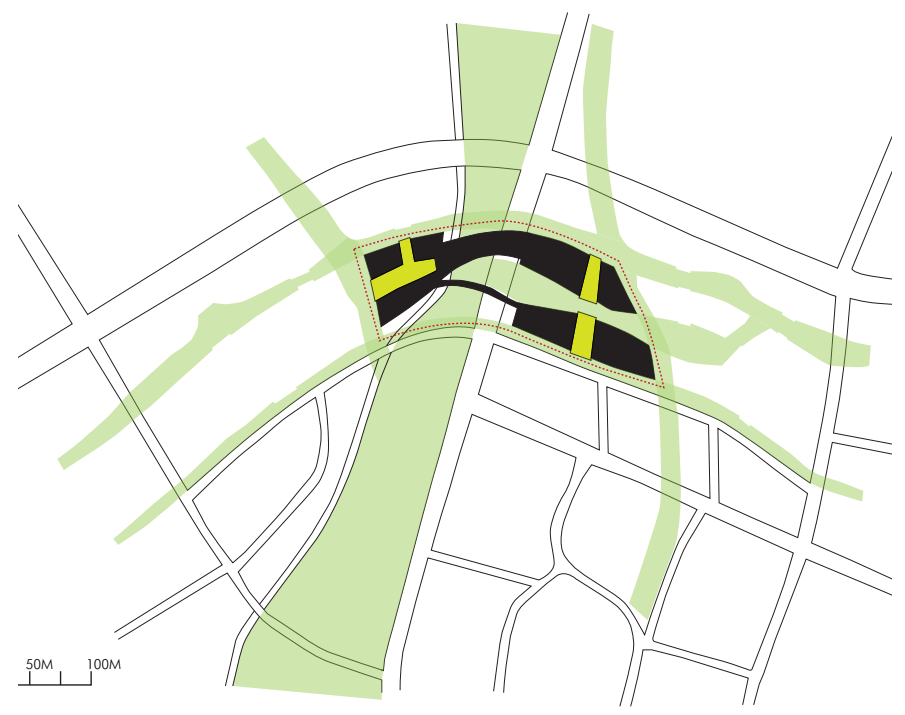

PHASE 4: COMMERCIAL AND RESIDENTIAL ZONES

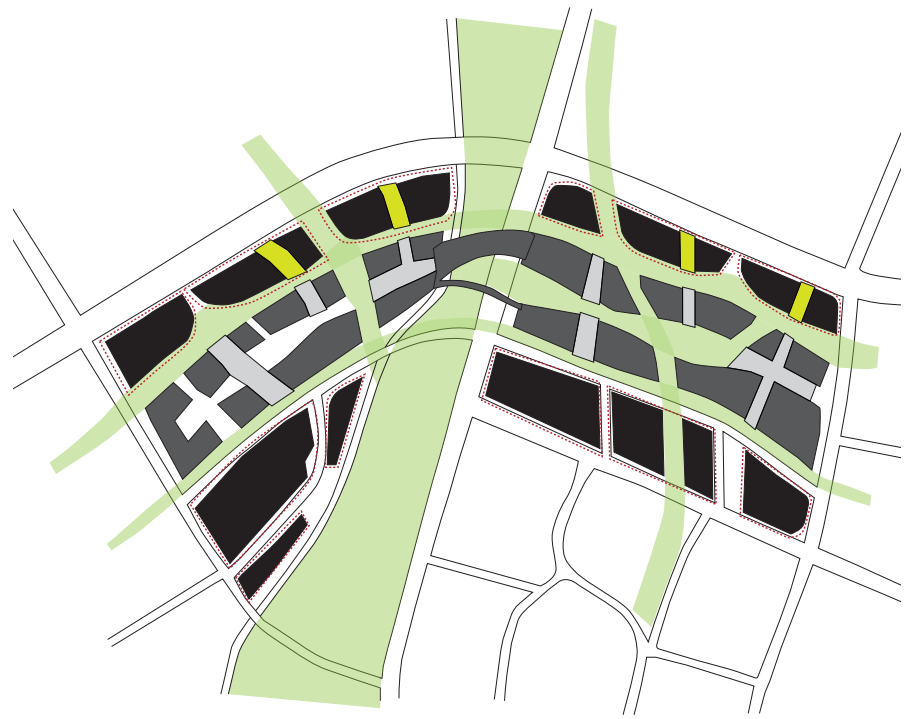

Development Pockets 


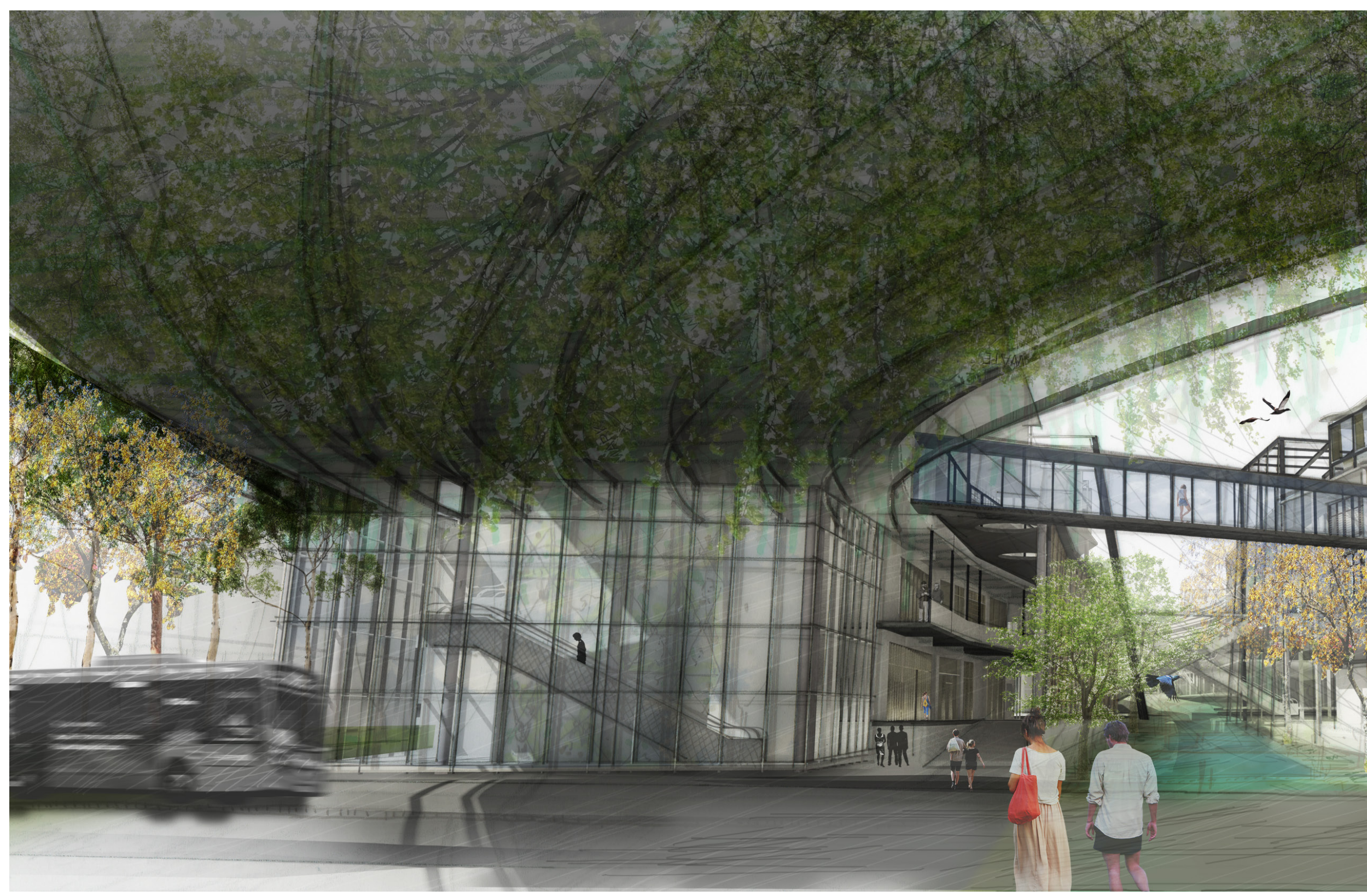




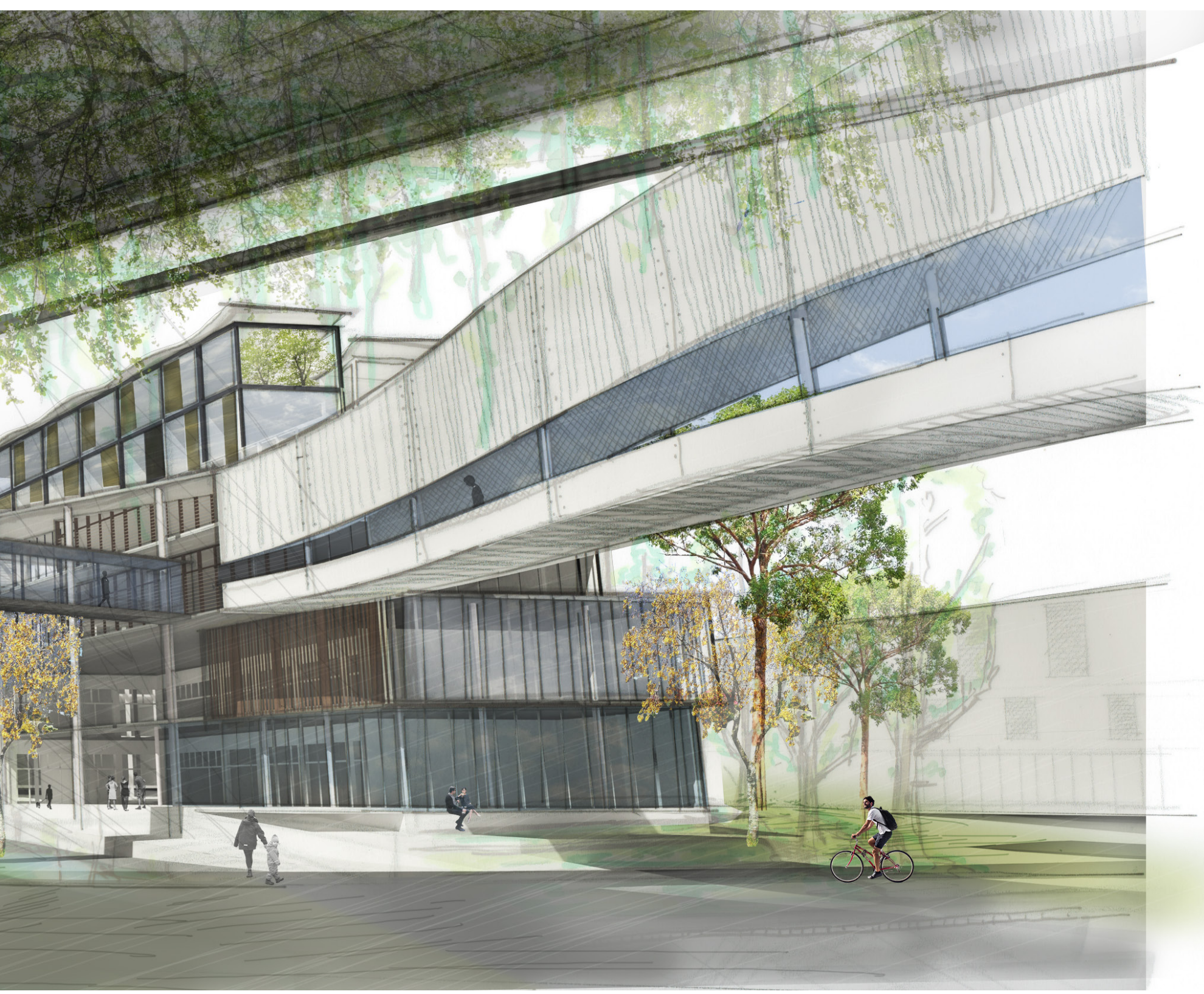


| > Pedestrian Concourse Perspective | 


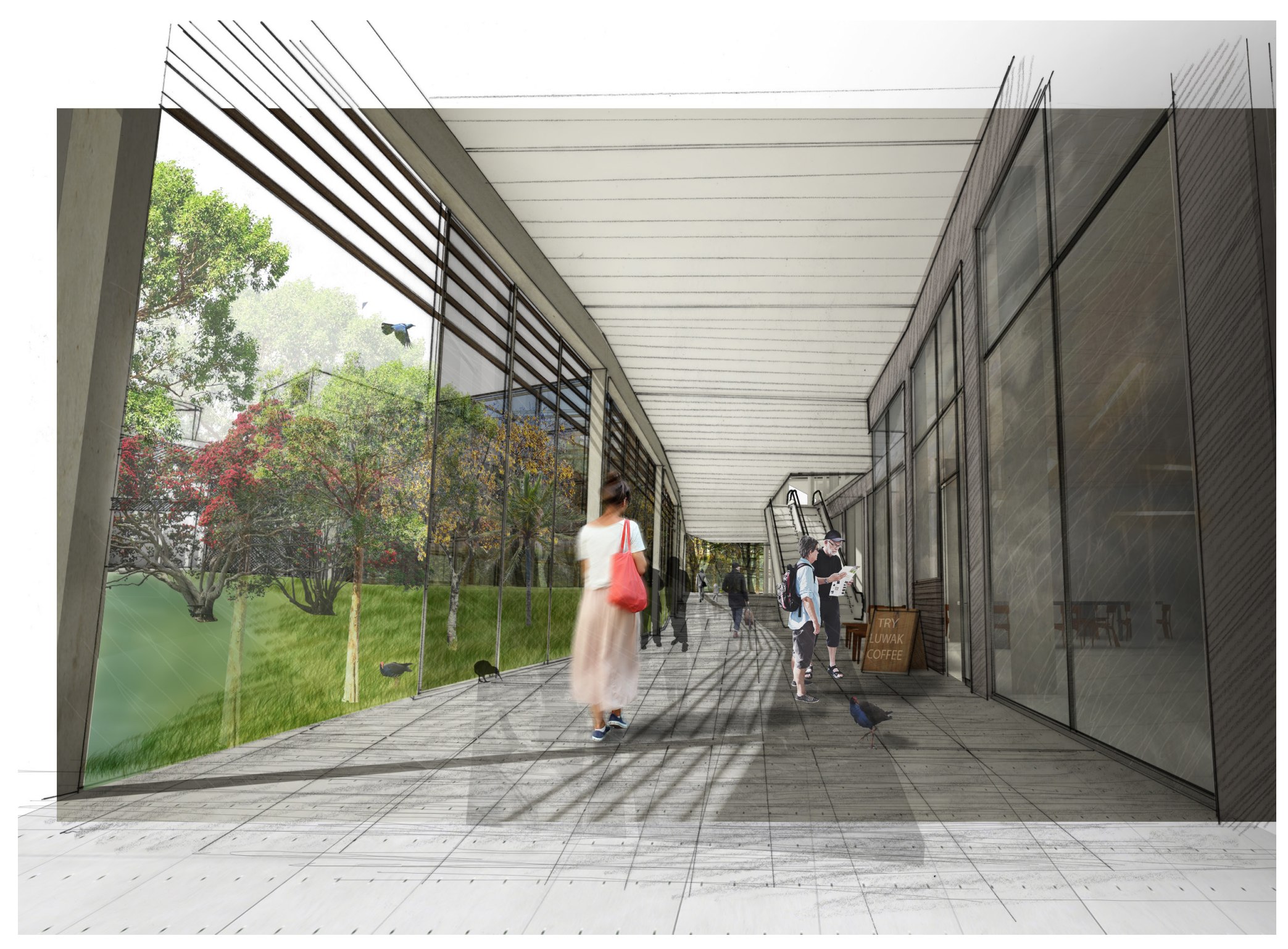


| v Light Rail Section | > Transverse Section |

Scale: 1:500
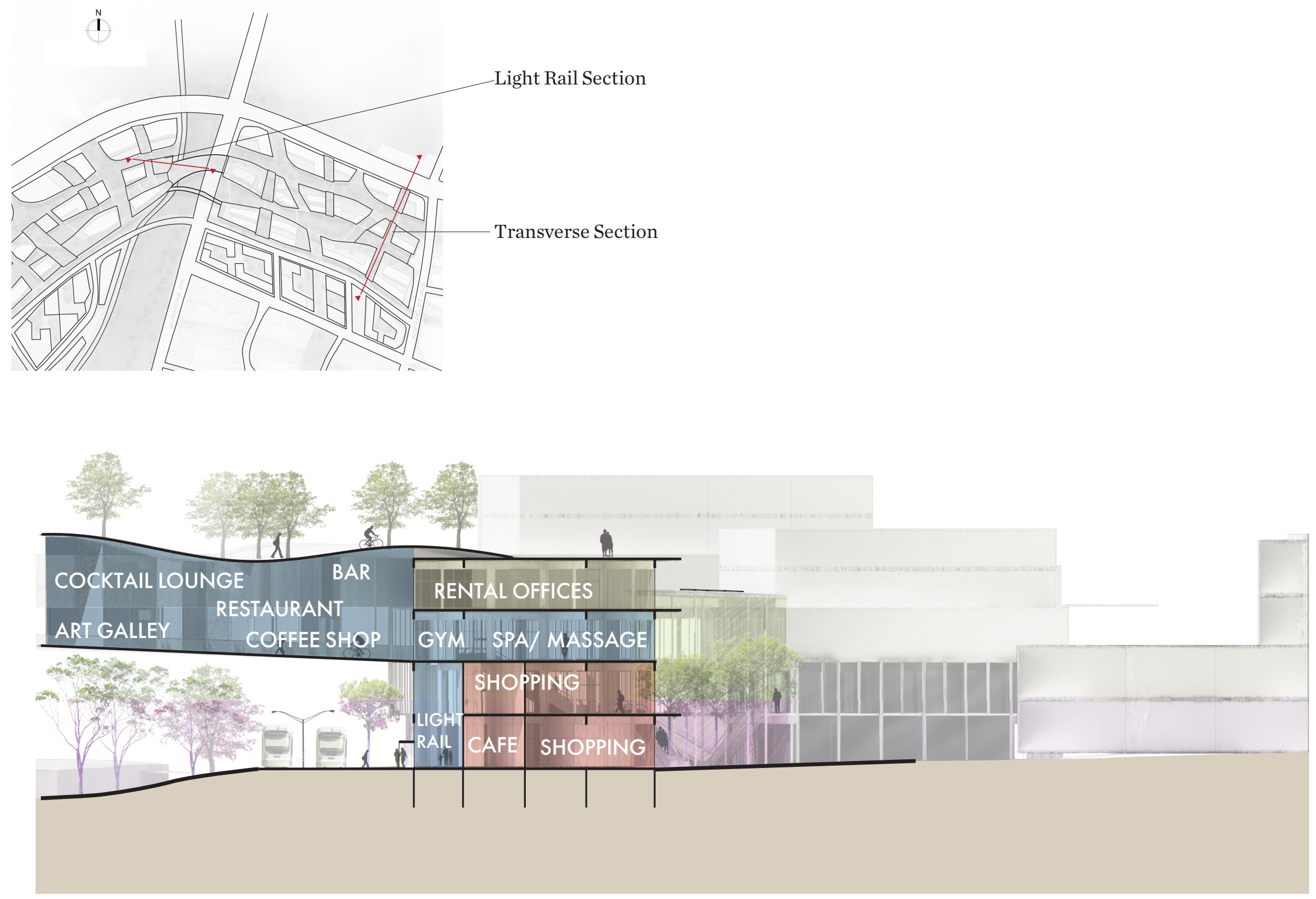


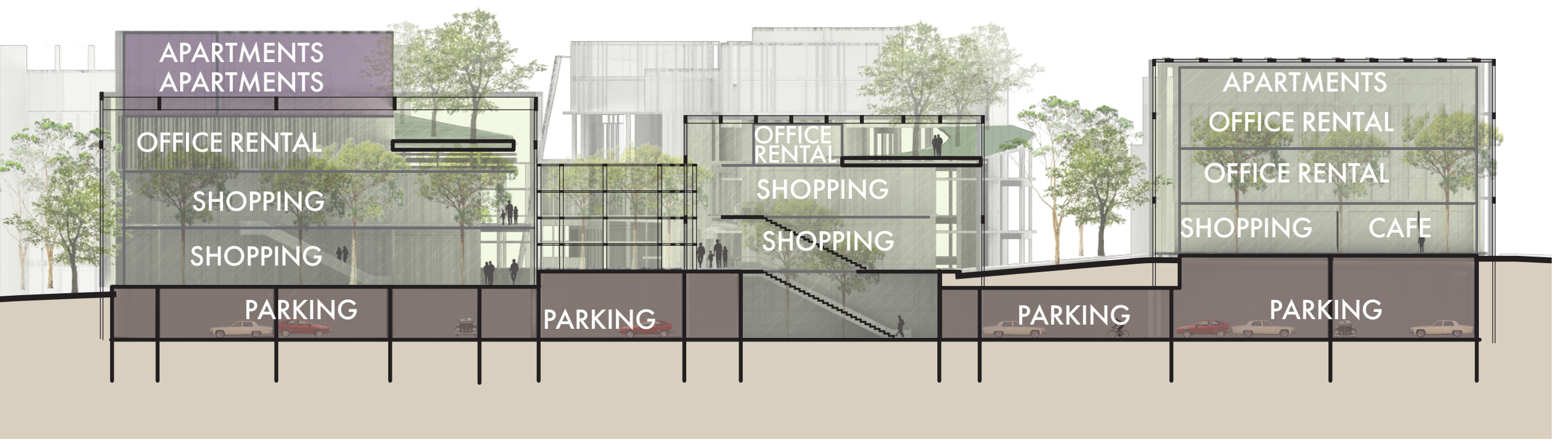




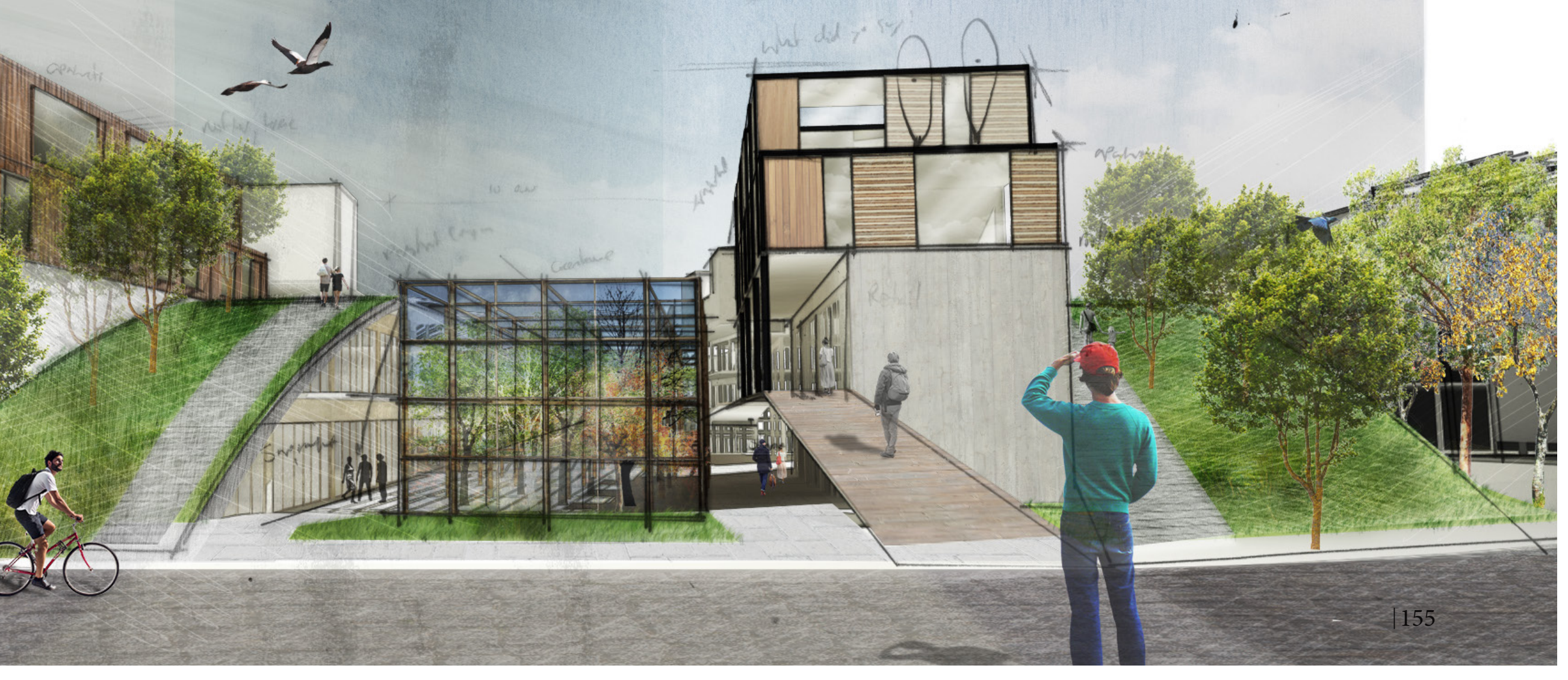




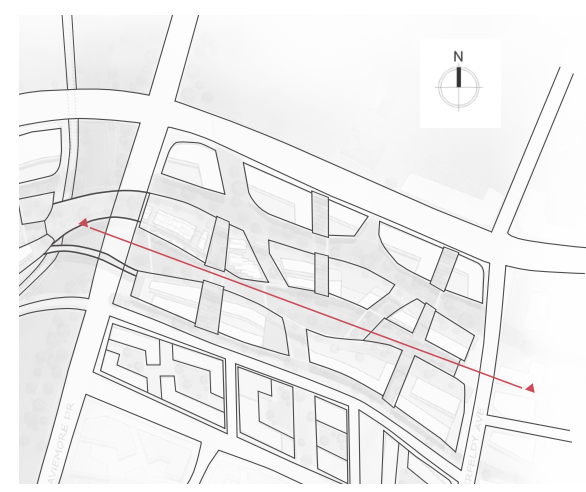

Cinema Civic Building Architectural Case Study

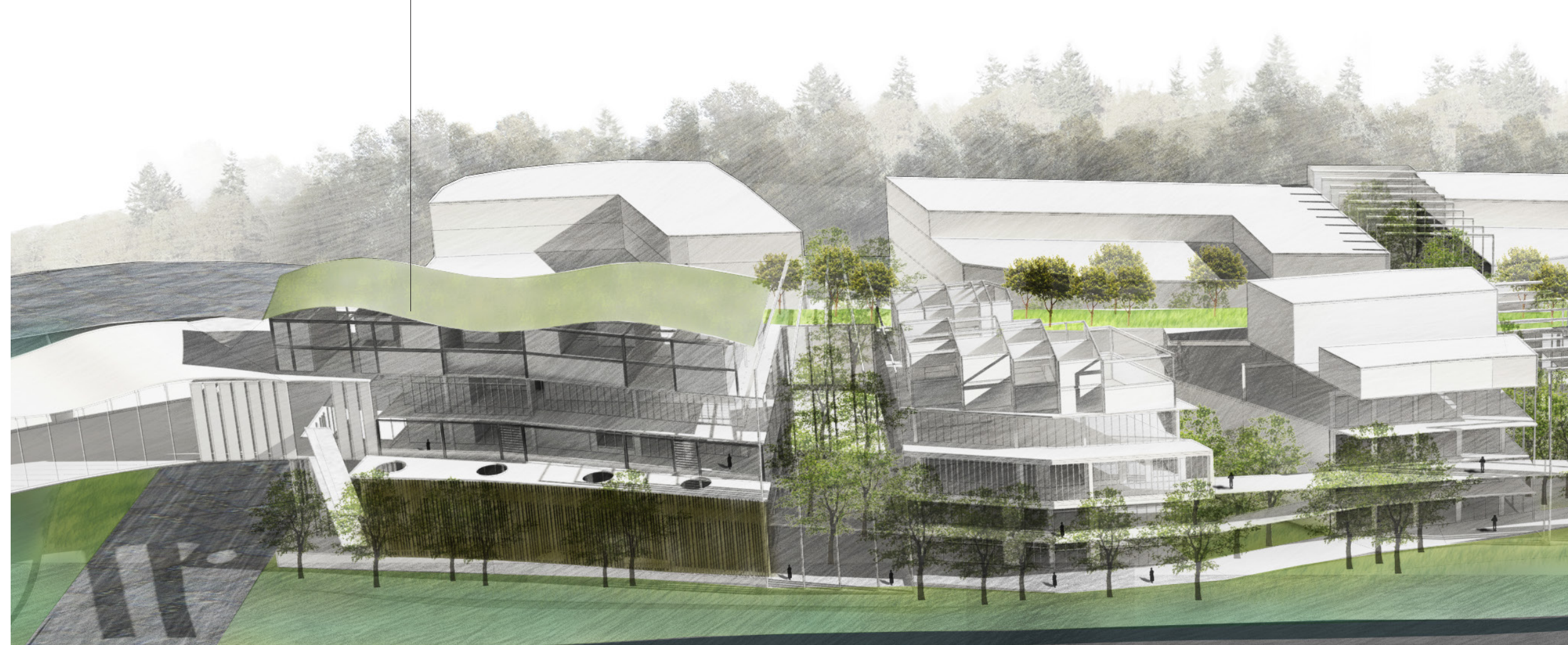




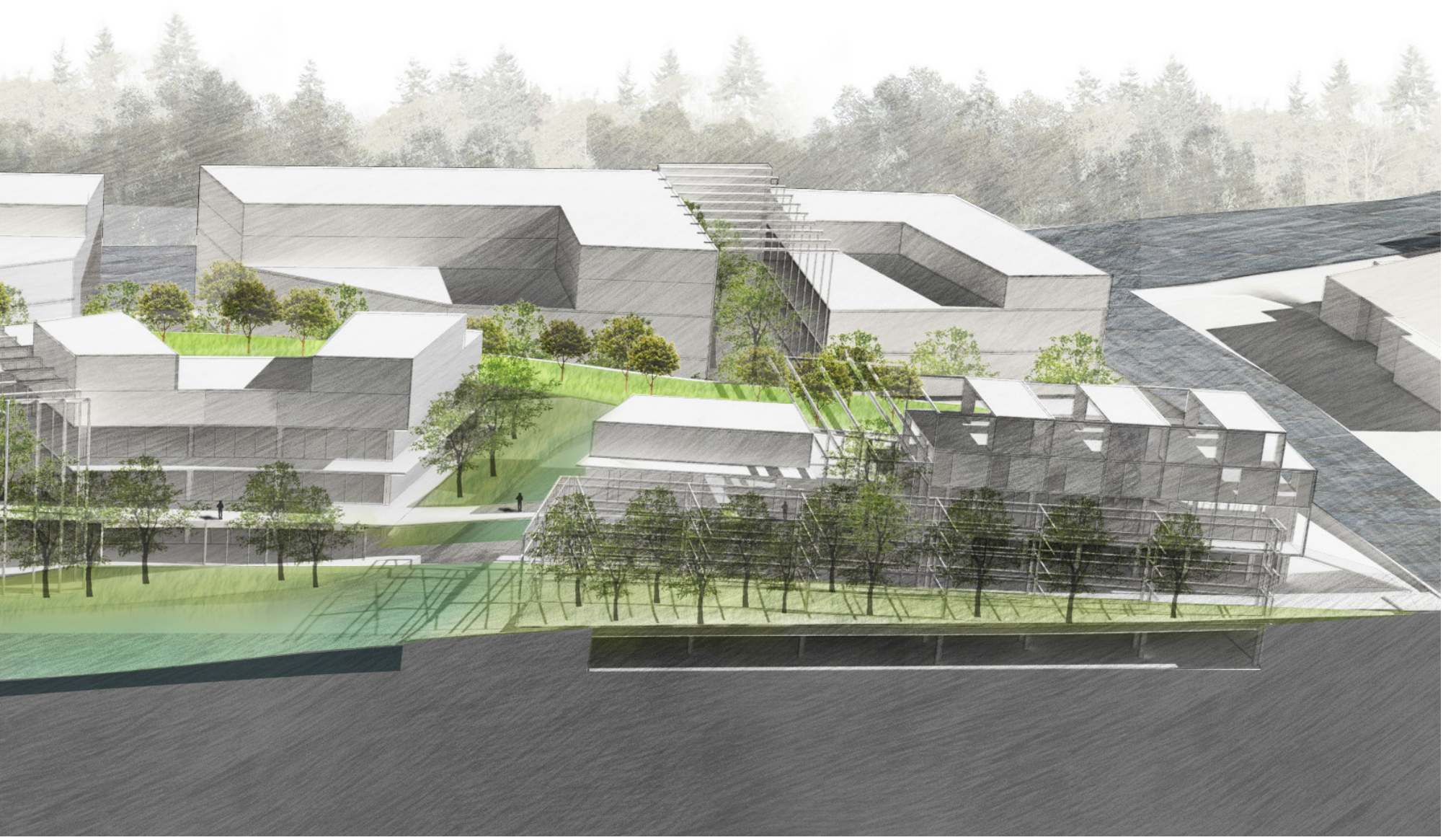


| v Civic Anchor Buildings Site Plan |

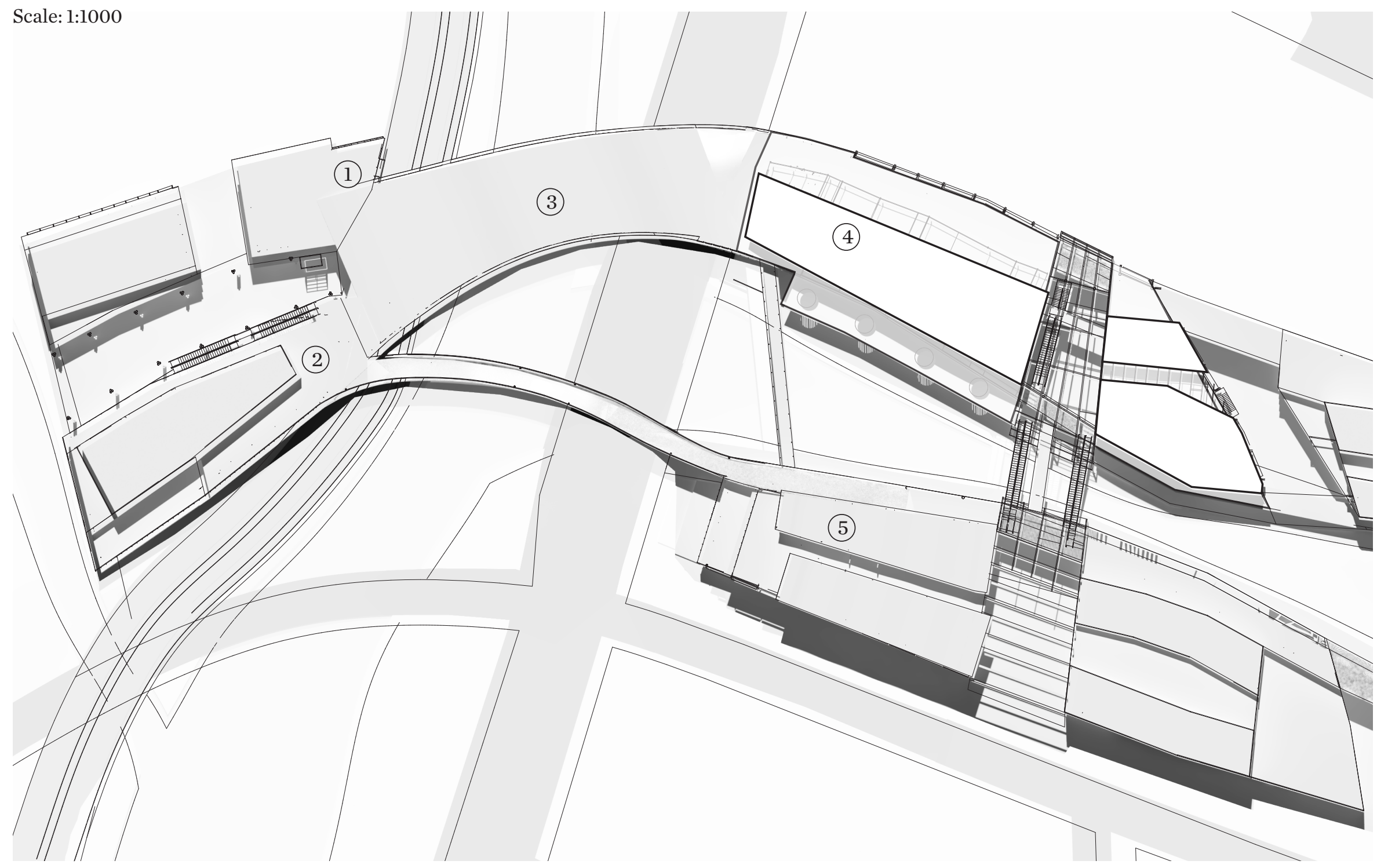

1 Transport Hub

2 Niche Supermarket \& Gym

3 Civic Bridge

\section{Cinema Theatre}

5 Public Markets \& Library 


\subsection{ARCHITECTURAL DOCUMENTATION}

\subsubsection{DESIGN INTENTION}

The cinema complex civic anchor building has been designed in higher detail to explore the configuration of the components at the different levels and how they are linked vertically. Also the atmosphere and 'ecospectacle' of the retail spaces are explored through design. The design addresses the complexity that the hybridisation of the residential, commercial and retail components have created. The design features a 4 cinema complex designed to seat over 500 people; retail shops and interlocking apartments above, connected via the greenhouse. There are two entrances on Aviemore Drive; the civic atrium bridge atrium which provides connection to the "civic bridge" and the light rail hub on the other side of the road and stream, and the pedestrian concourse which is enclosed by double height vertical louvers. The greenhouse provides access across to the other levels of the building and to the rooftop terrace, also the greenhouse features an escalator that connects occupants to level 2 of the public library civic anchor building. 


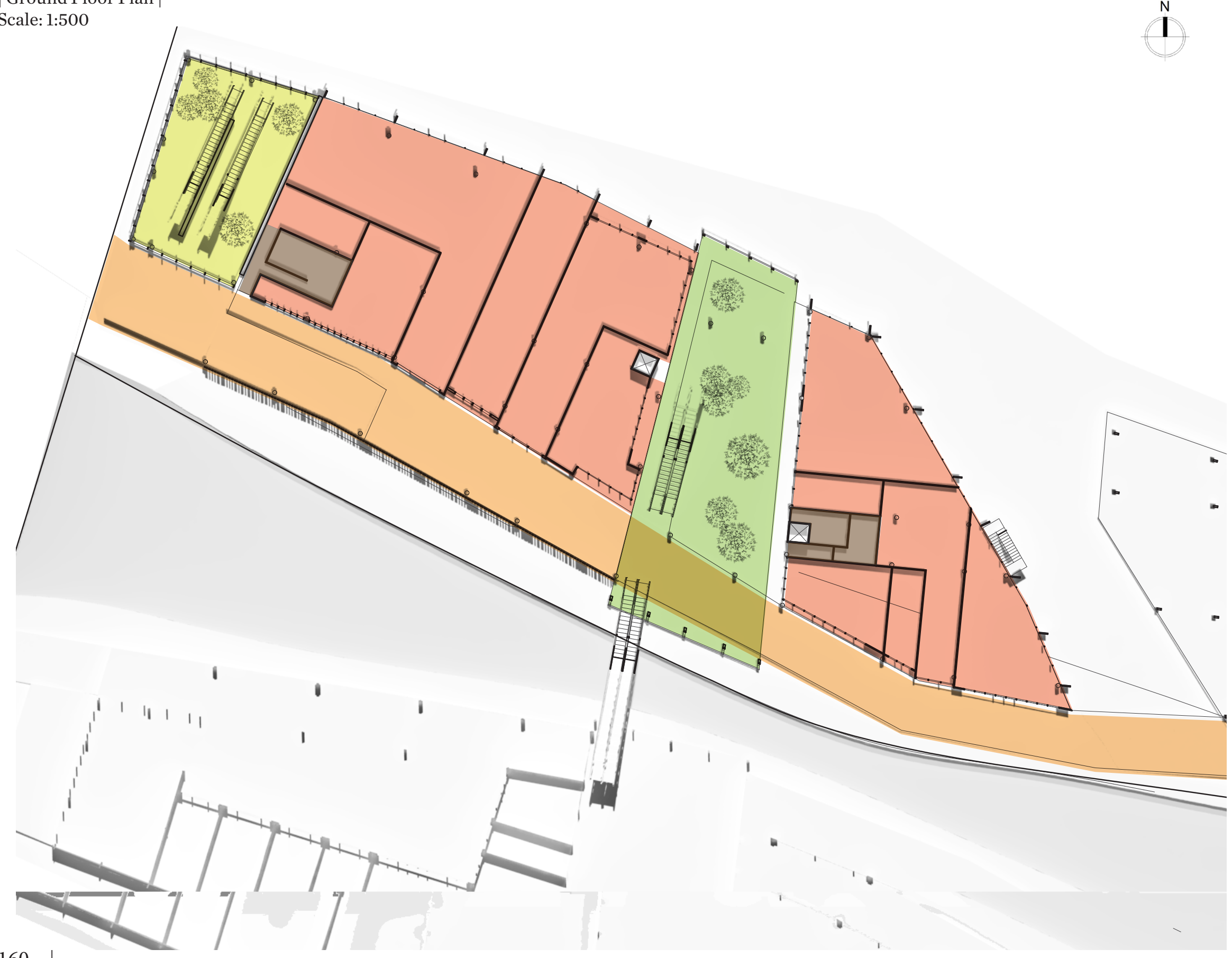




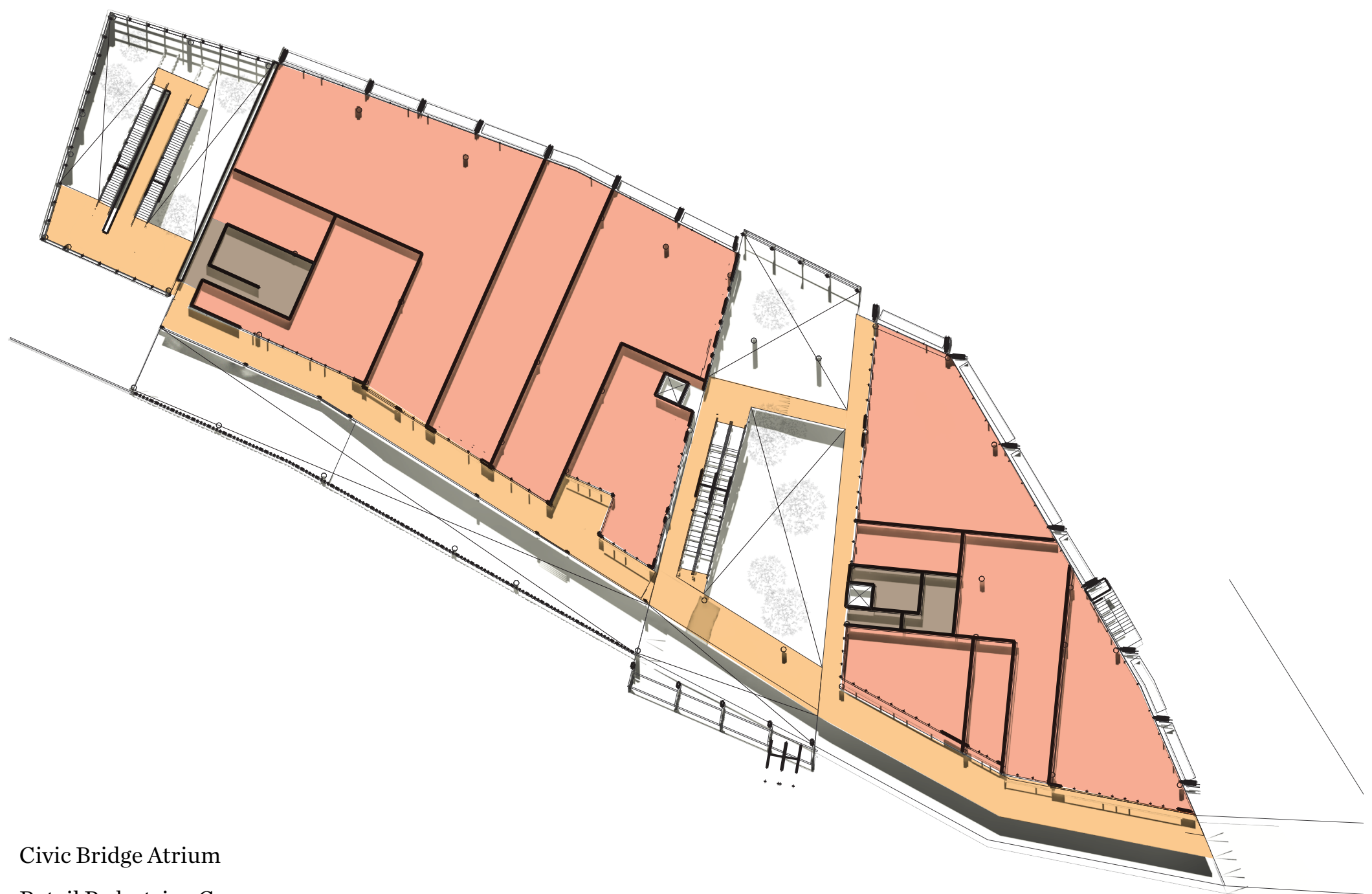

Retail Pedestrian Concourse

Retail

Toilet Core

Greenhouse 


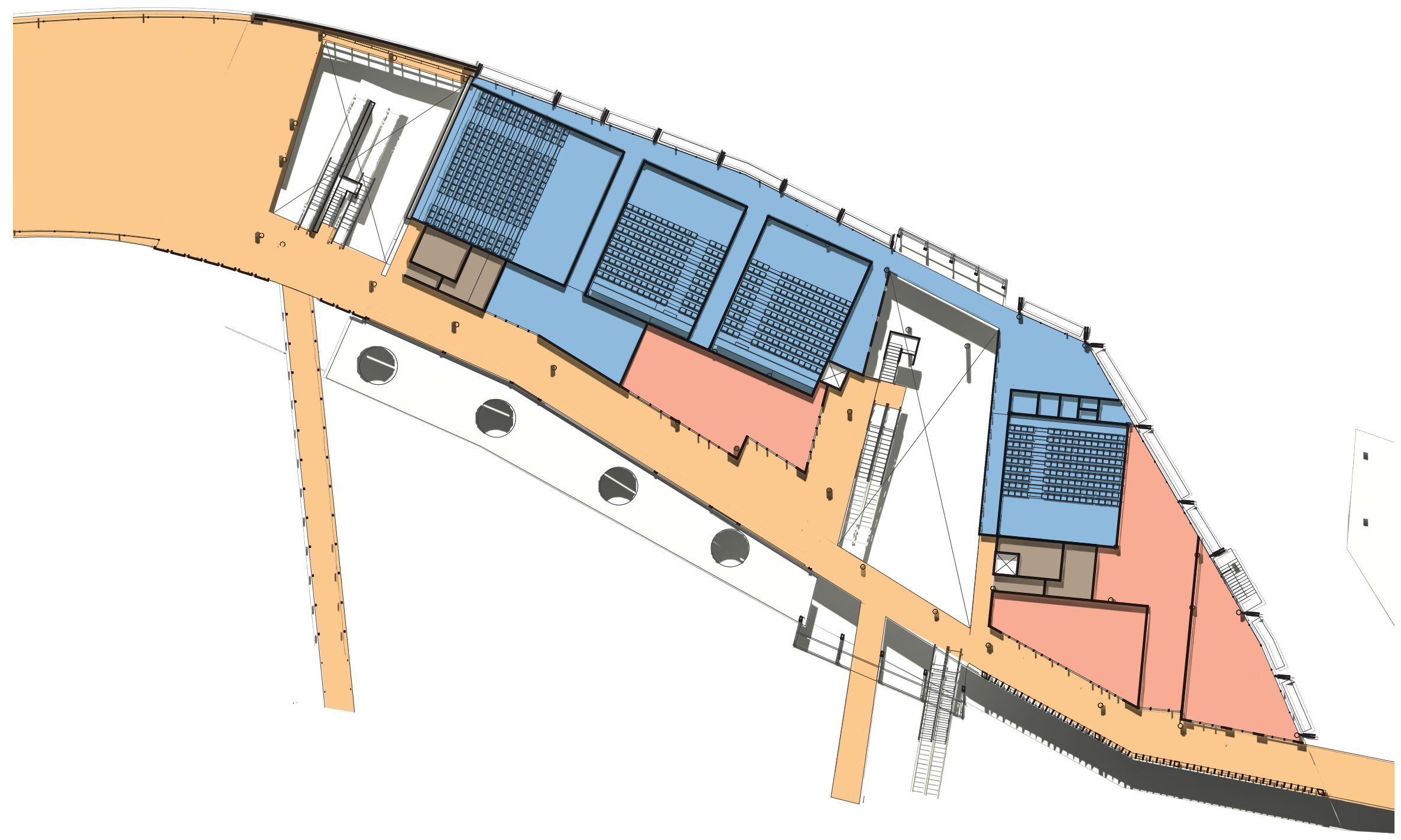




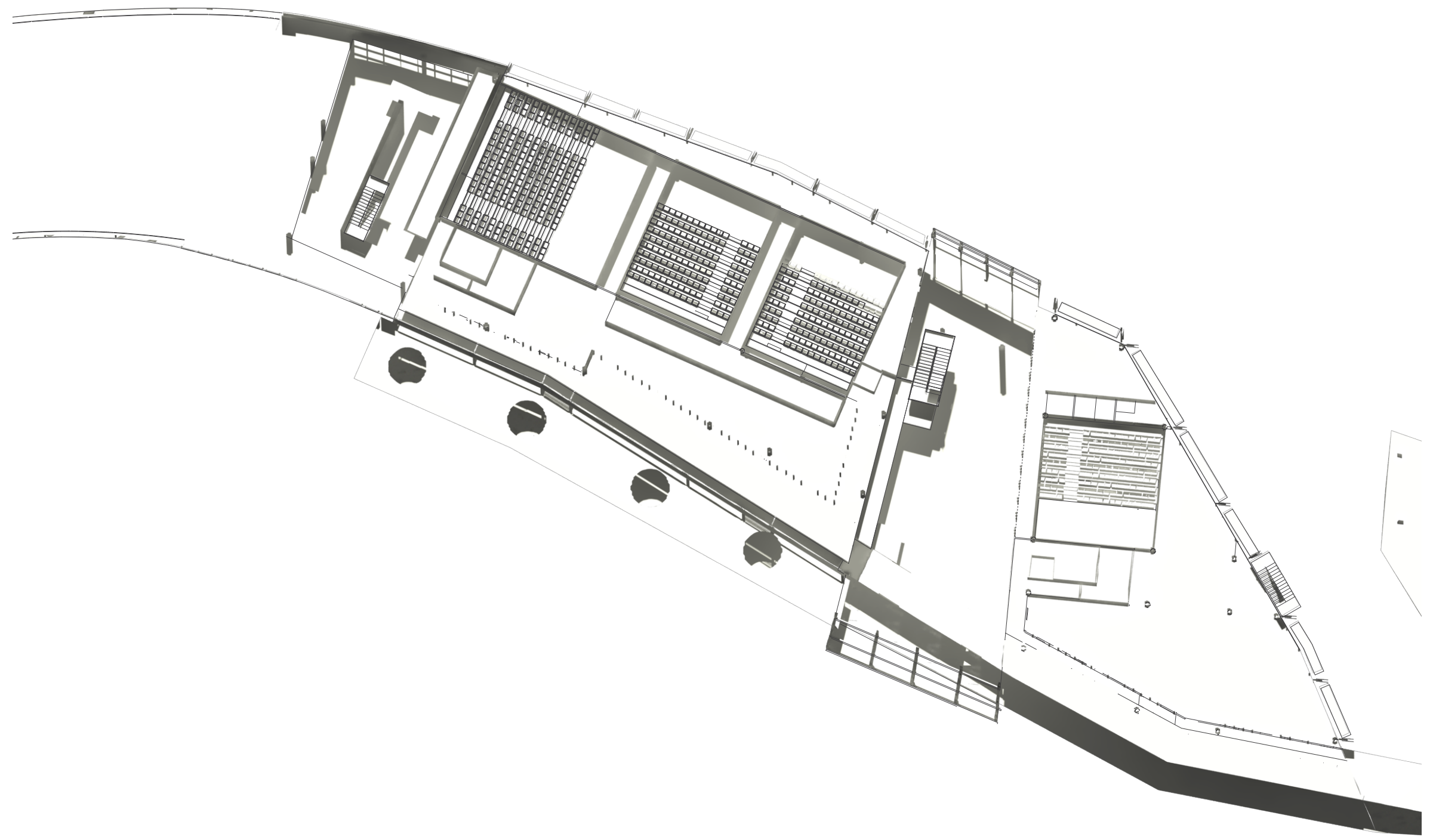




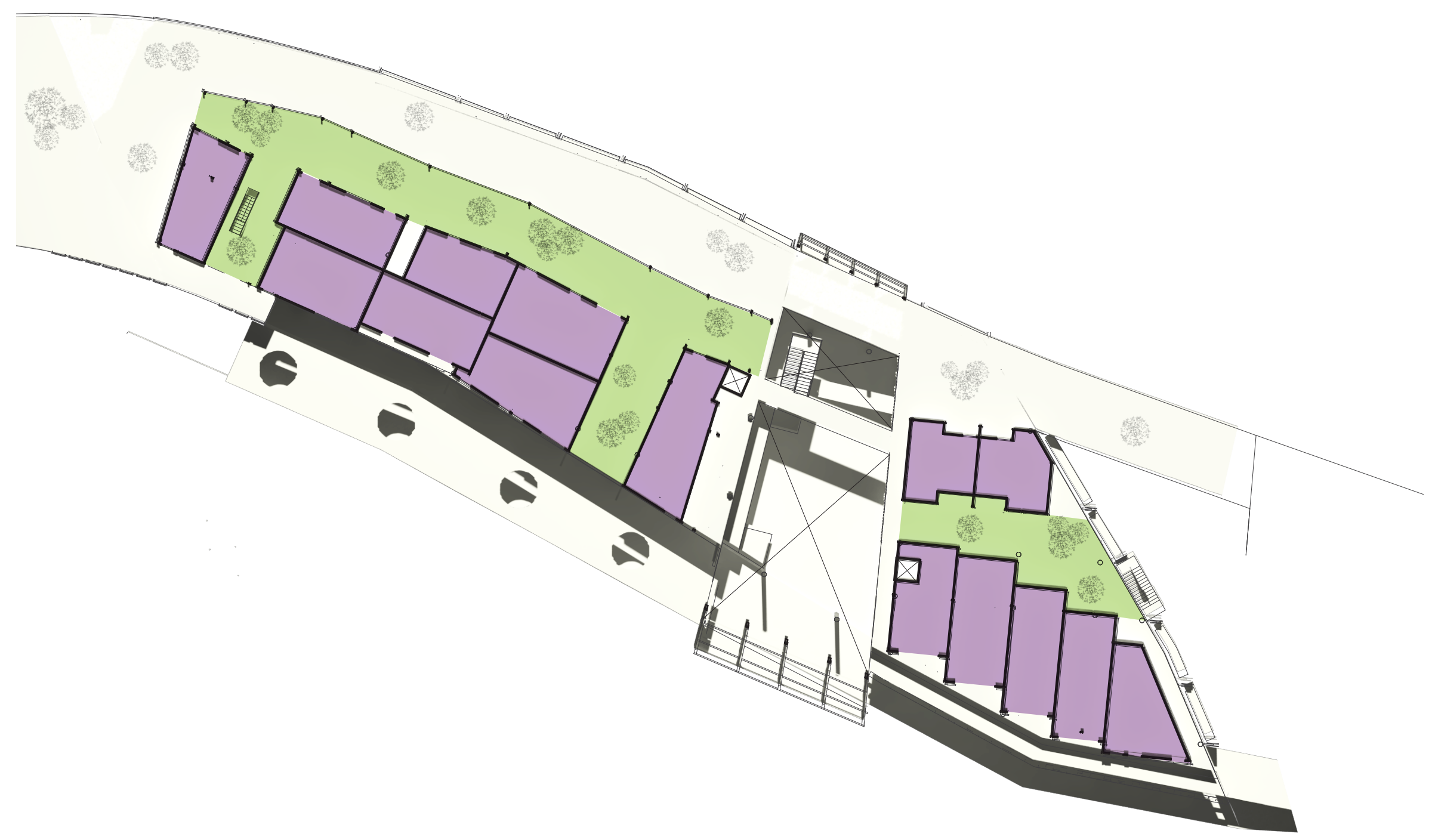




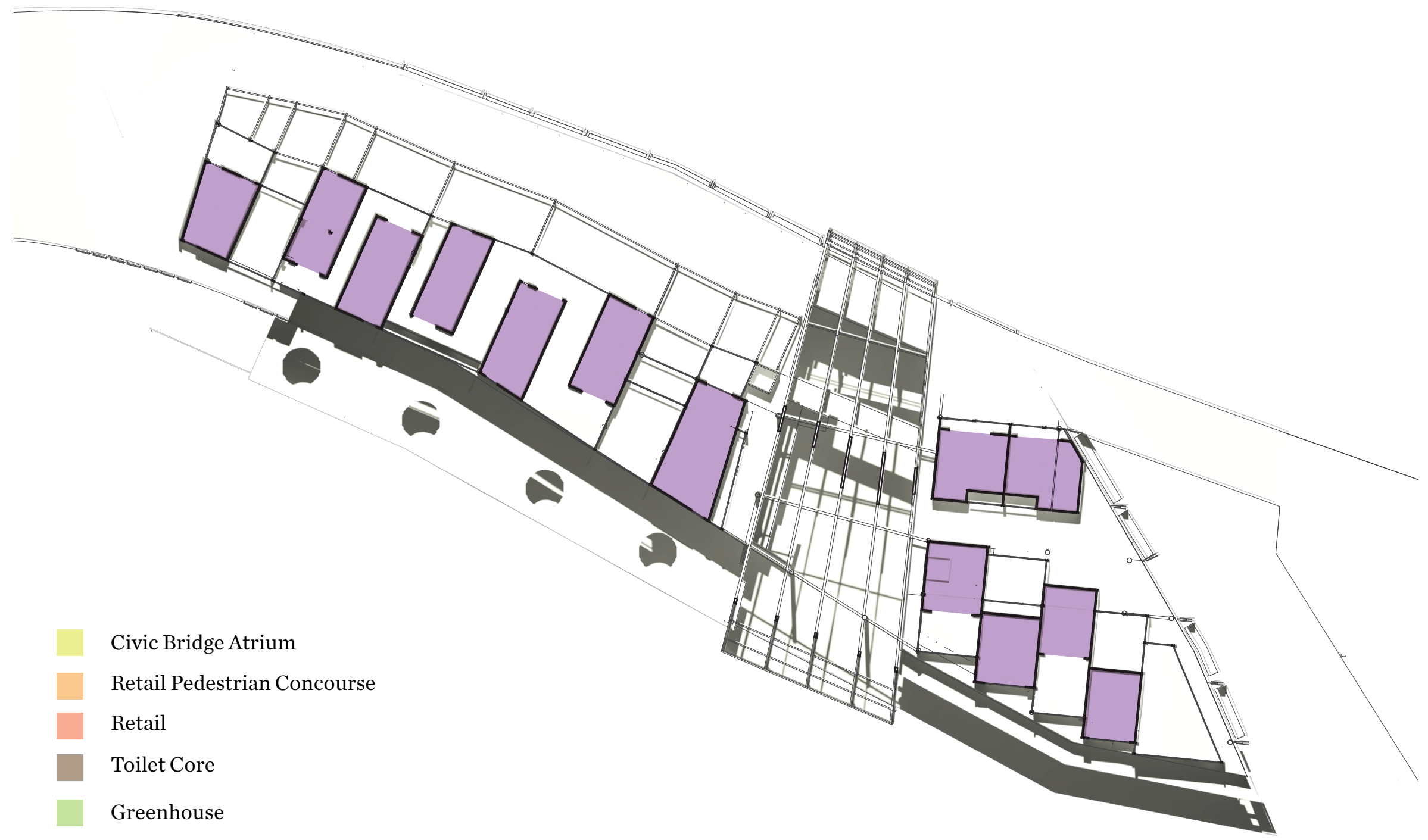

Cinema (600 seat capacity)

\section{Rental Office}

Interlocking Apartments (x13) 


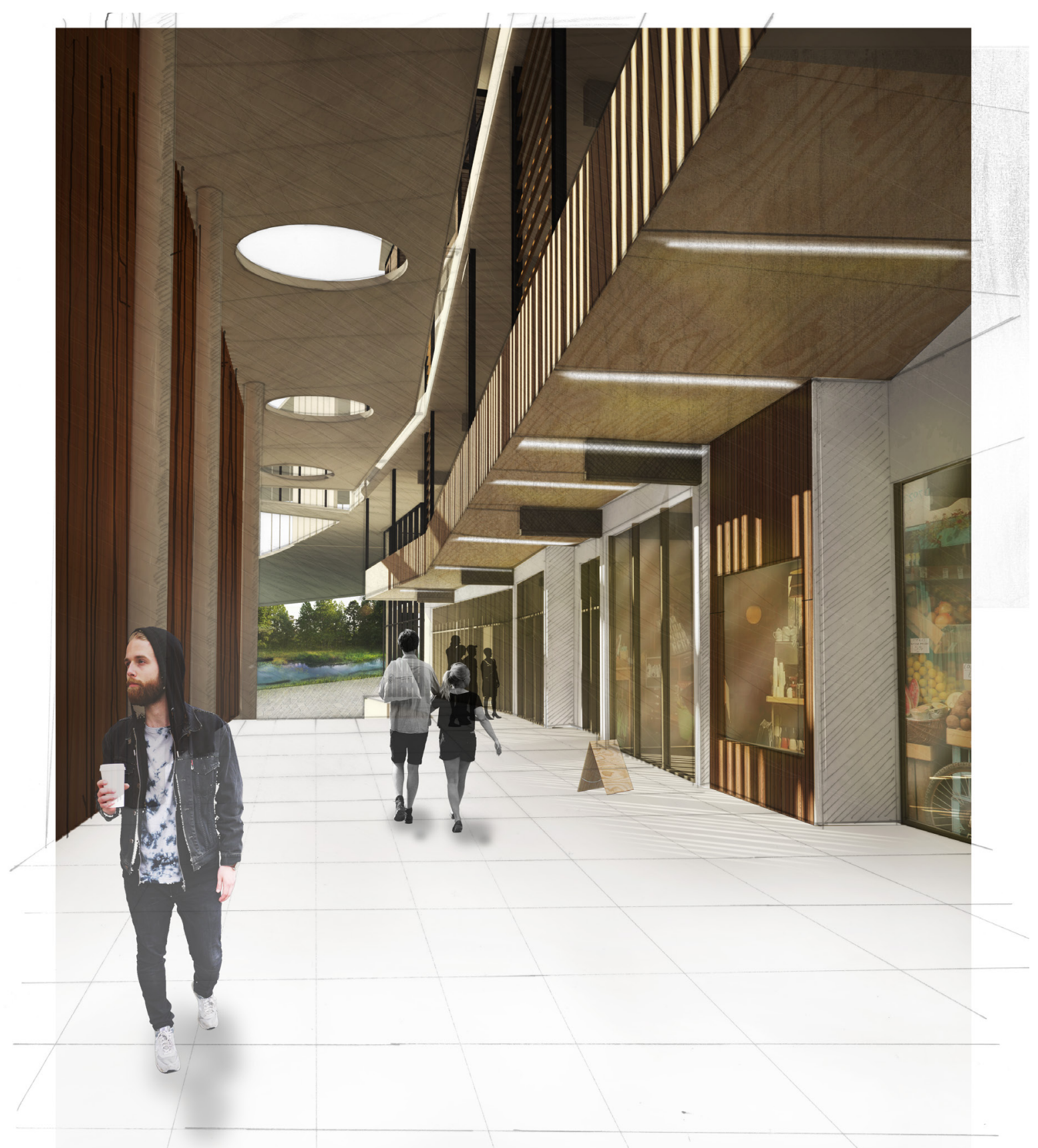


$\mid<$ Retail Pedestrian Concourse Perspective | 


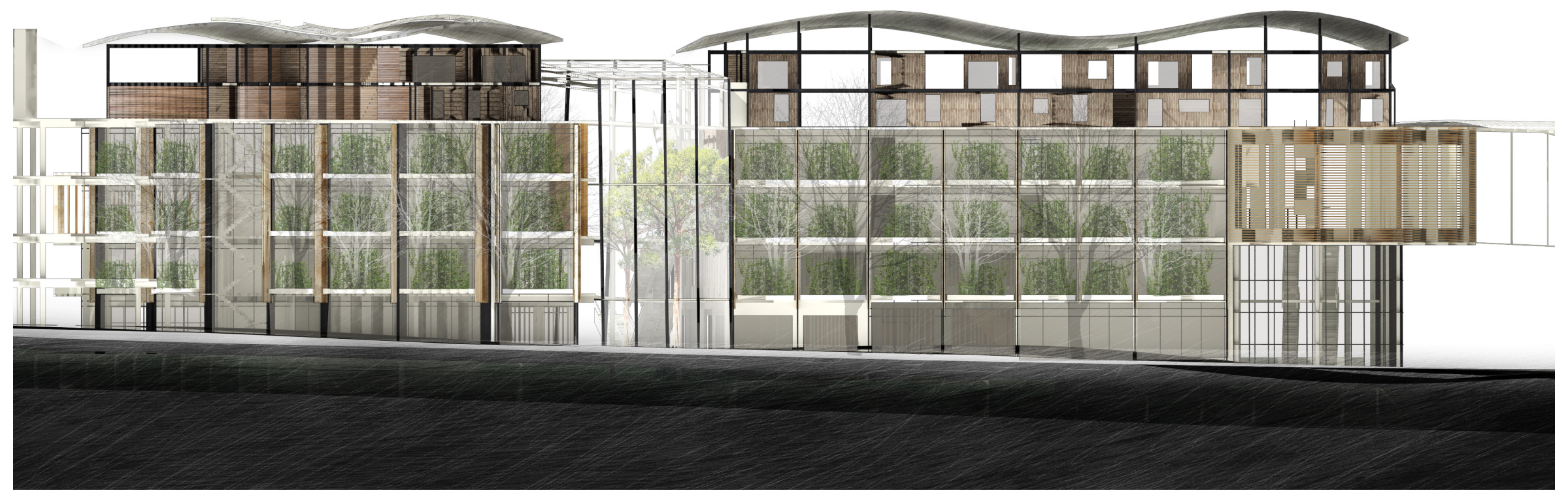




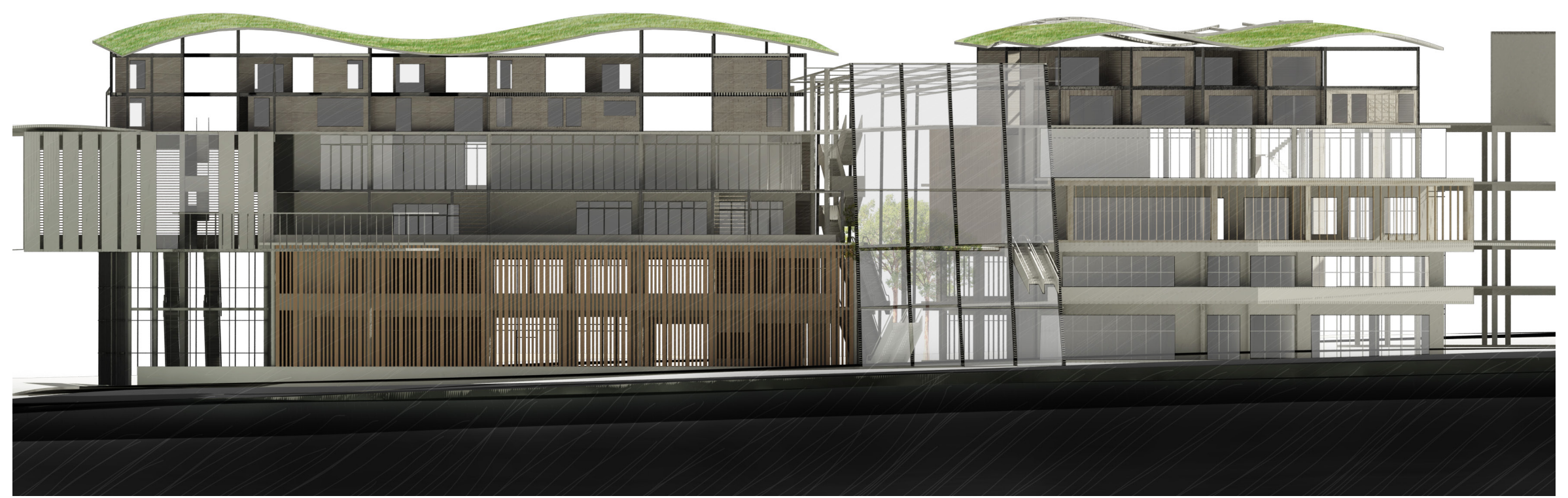




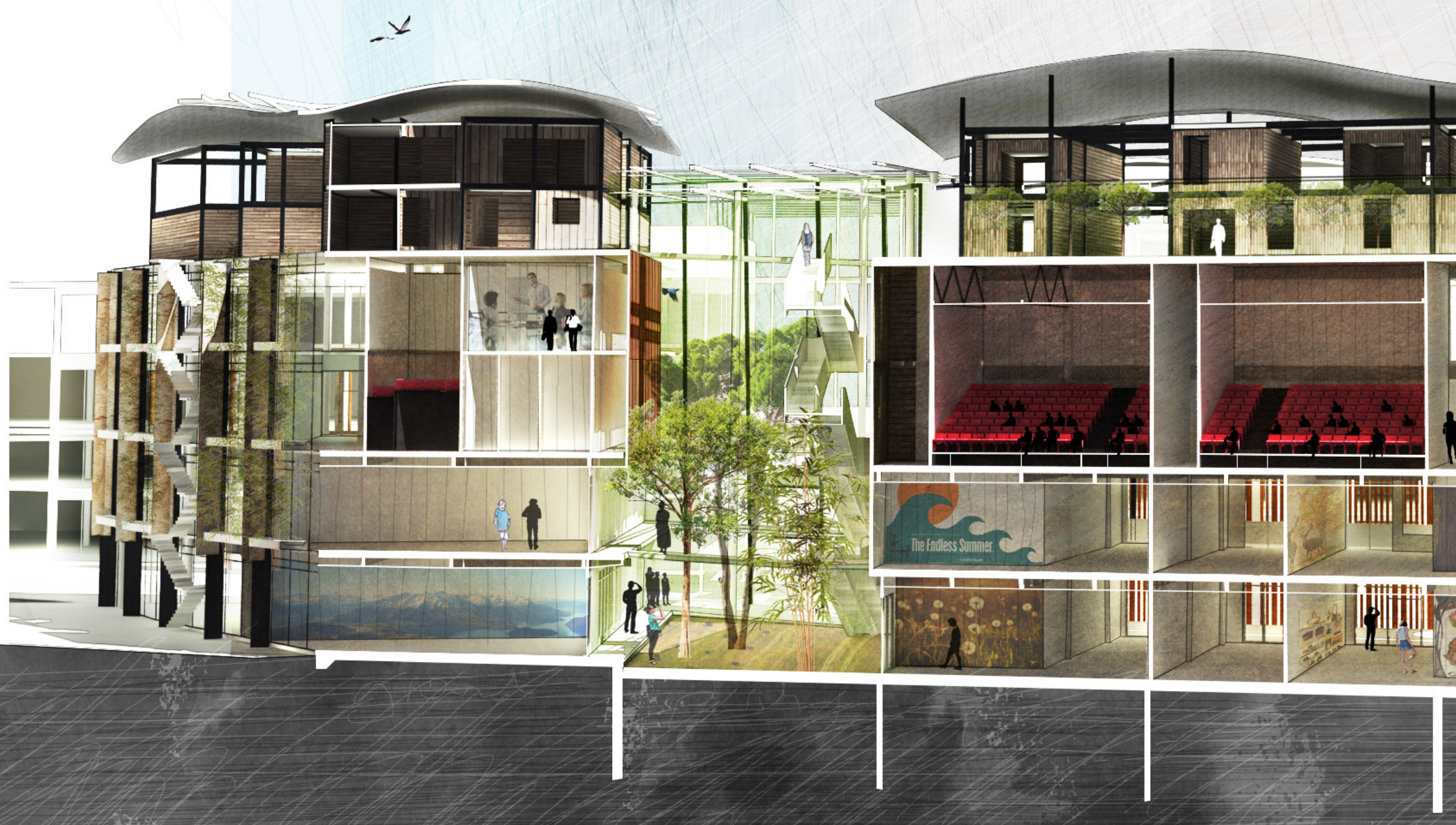




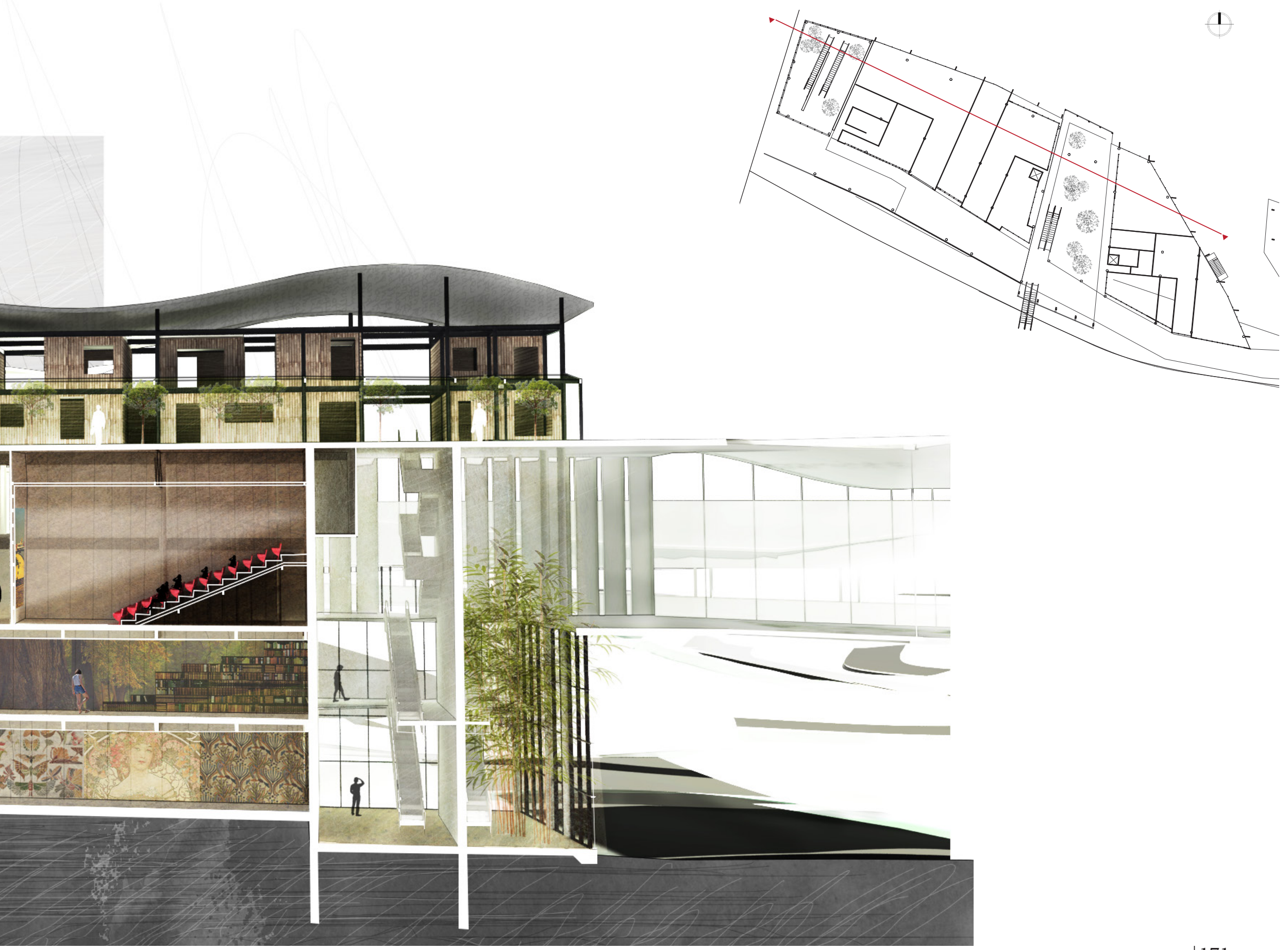




\section{EIGHT}


EXEGESIS + CONCLUSION 
The discussion will break down the design into three components; urbanism, retail-environments, and ecologicalmasterplanning. It will address both the positive and negative attributes that can be conceived from this research, continuing to a discussion on the amalgamation of the three components. Each section begins with the premise for research and then discusses a series of findings associated with the design criteria.

\subsection{URBANISM}

\section{PREMISE}

Shopping Centre sites are large parcels of land that sit awkwardly within their context owing to the infrastructure frameworks disconnecting them from their surroundings. The sites provide ample space for an intensified suburban development for a city facing the problems associated with urban sprawl. The centre provides residential, commercial, retail and recreational uses in one centralised development. (Chpt 1.5, Pg 13)

\section{HUMANISM}

The characteristics of an enjoyable urban environment are associated with the strategies for humanizing space. The project strategies are defining the street edge, breaking up the mass and diversifying public space. The public concourse that runs longitudinally through the development is the main pedestrian thoroughfare and it provides a positive pedestrian experience. The concourse consists of multiple levels; parts of the path are internal while others are external and the pathway changes in size 174 and direction opening up to courtyards and green spaces (fig68). Linkages are provided in the transverse direction which break up the buildings mass and connect pedestrians to the other areas of the development. The civic bridge and green roof terraces further add to this vibrant pedestrian experience, making the complex a positive experience for shoppers, workers, residents and recreational users.

The public spaces consisting of the pedestrian concourse, green corridors, and roof top terraces etc are technically private spaces and could create issues pertaining to the control and manipulation of an occupant's behaviour to conform in a particular way. The private nature of the development could hinder the human aspect of the civic and public spaces and make consumers, workers, residents and other occupants feel uncomfortable. For example, if an occupant was to behave in an unconventional way security could remove them from the premises. Would buskers feel comfortable to perform in these spaces? Buskers can add vibrancy and diversity to an urban space. An answer to this issue is that the public space could be owned and managed by the Auckland City Council; but this could be difficult with the homogeneous integration of the walkways and built structures and could prove to be too expensive and complicated for the council to maintain.

\section{ACCESSIBILITY}

The project uses the strategy of layering transport networks; activating visual interested along street edges and welltravelled routes, and the reduction of

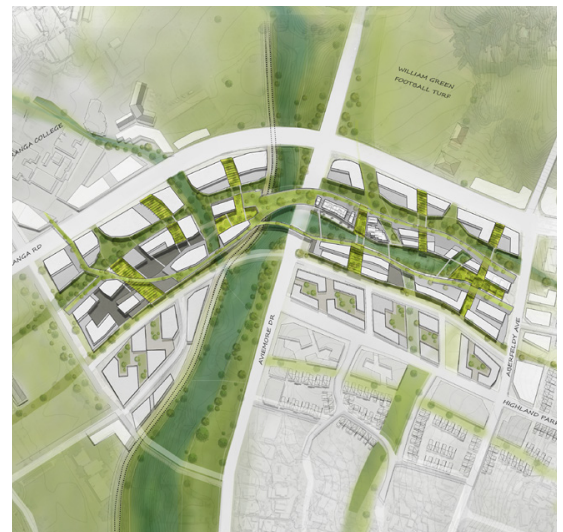

Fig 68. Masterplan

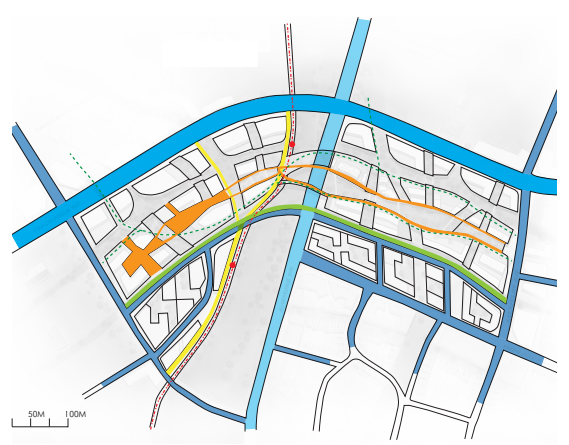

Fig 69. Layered networks

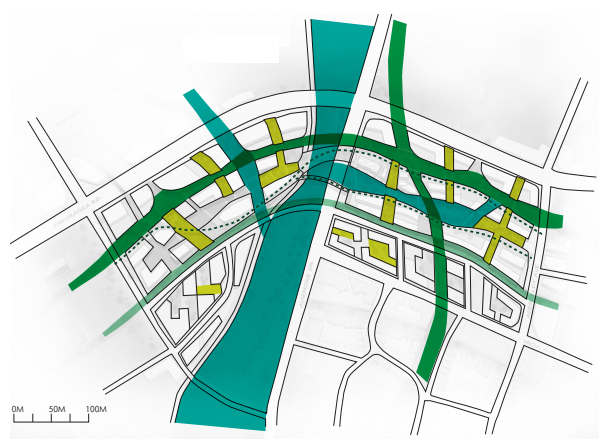

Fig 70. Ecological networks 
surface parking and vehicular traffic in public spaces (fig 69). This will contribute to the accessibility of the development and the greater context. The aim of the design is to contribute to a change of culture away from the reliance on the automobile. This has been successfully achieved by introducing light rail to the suburb, providing uncompromised pedestrian and cycle routes through the development, and reducing car parks by over $50 \%$ when compared to other recent Auckland shopping centres (Sylvia Park). The development forms a microcosm and therefore residents will be less reliant on using their cars as day to day amenities are within walking distance and trips to the city can be conducted through the proposed light rail. The light rail system also connects consumers and workers from other suburbs to the development.

The design of the master plan is unconventional when compared to an urban development with defined streets, footpaths and buildings. Pedestrian paths, cycle and recreational corridors, ecological corridors, light rail tracks, and road networks are both integrated with and separated from one another (fig69 \& 70). These networks are connected at multiple levels and servicing is intertwined between them all. There could be an issue with the complexity of the layers being confusing for public and private use and therefore not fully realised for their accessibility potential. In Auckland City, an example of this occurs in the shared streets around lower Queen Street. The public dislike them because they don't understand how the right-of-way rules operate.

\section{IDENTITY}

The predominant aim for the intensification is to create a sense of place and identity for the people who occupy and live nearby the development. The introduction and enhancing of the ecology has successfully created a sense of place for residents living within the development but also the ecology has re-imaged a shopping centre focused towards environmental consumption. The identity of the development is about nature, sustainability and ecology and will attract residents and consumers who identify with the sense of well-beingfrom the environment or the protection of the environment.

The identity of this intensification is created from the ideals that frame this research and also from the architectural gestures. The design strategy of the public concourse and civic bridge is a large gesture. The architectural massing and form are intentionally similar and coherent allowing the whole complex to read as a united design. This similarity and lack of diversity in the architecture could cause the issue of a 'campus' or 'district' effect as the appearance is large and similar (fig 7l). While it creates its own individual identity this uniformity also hinders its integration within the context and potential future intensification. It could be read that as an "eco shopping centre" and not as Highland Parks centre, any future intensification could consist of large fragmented and interfering masses that might not integrate well with each other.

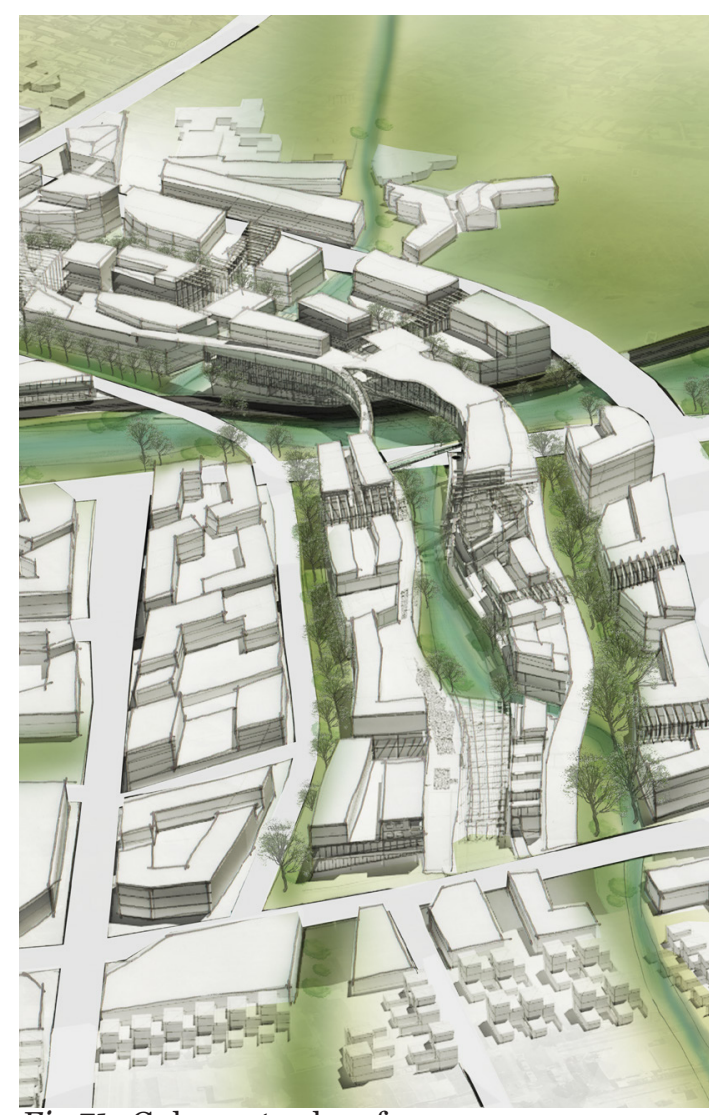

Fig 71. Coherent urban form 


\subsection{RETAIL ENVIRONMENTS}

\section{PREMISE}

That suburban shopping centres have lost the original authenticity of a space that was celebrated for its point of difference as a new retail environment in suburbia. Today, there are many shopping centres that lack variation. The aim of the project was to create a new retail environment for suburbia. (Chpt 1.5, Pg 13)

\section{THEATRICAL EXPERIENCE}

A typical shopping experience is designed for consumption. By introducing a theatrical component, the design creates a more dynamic experience. A sense of thrill will change the shopper's state of consciousness. The project criteria for achieving a theatrical experience is through the creation of thresholds; indoor to outdoor, comfortable to slightly less comfortable, loud to quiet, dense vegetation to open space and bright to dark. This will control the exposure consumers have to the natural environment over multiple levels. The design utilises the ecology as a large attribute to the theatrical experience in the form of 'eco-spectacle'. Thresholds are created by screening and revealing the natural elements in the green houses exposing pedestrians to the different climatic conditions and utilising natural gradient to create multiple thoroughfare levels. The spectacle is further reinforced by pedestrians moving vertically through the forest canopy.

The project is largely grounded by the ecology thus creating a theatrical experience and also providing an environmental friendly image. The 'eco-spectacle' theatrical experience could be misinterpreted as 'eco bling' and could be seen as just a treatment or a sales pitch. Similar to how large corporations build green roofs on their buildings for the image of being sustainable. The architectural intentions could therefore lose its authenticity. Adding ecology to retail creates the potential risk of it being conceived as artificial or fake. This issue could be mitigated by the centre working in partnership with an environmental organisation such as DOC or Forest and Bird. These organisations could manage and monitor the ecological habitats, reinforcing the intentions.

\section{BRANDING}

Branding contributes significantly to the design of a typical shopping centre (fig73) and anchor stores usually have strong negotiating power resulting in their image or colour scheme being applied over their portion of the building. The design case study has no branding on the outside of the buildings and the aesthetics do not represent any single brand (fig72). The store frontages are the onlyplacefor advertising. This creates both positives and negatives for the different parties involved in the complex. Residents don't have to worry about potential eyesores created by branding which could influence their choice to live here. However a lack of obvious branding may cause shoppers not to be aware of the different retailers along the pedestrian concourse. The 'eco-spectacle' discussed earlier is its own brand and image which would attract environmentally conscious consumers. Retailers and shoppers would associate with the ecology image more than with the conventional marketing and branding, encouraging consumption of products that contribute to a cleaner environment. This creates a network where retailers and consumers support each other. Environmental marketing will have a greater effect here than cost competitive branding. 


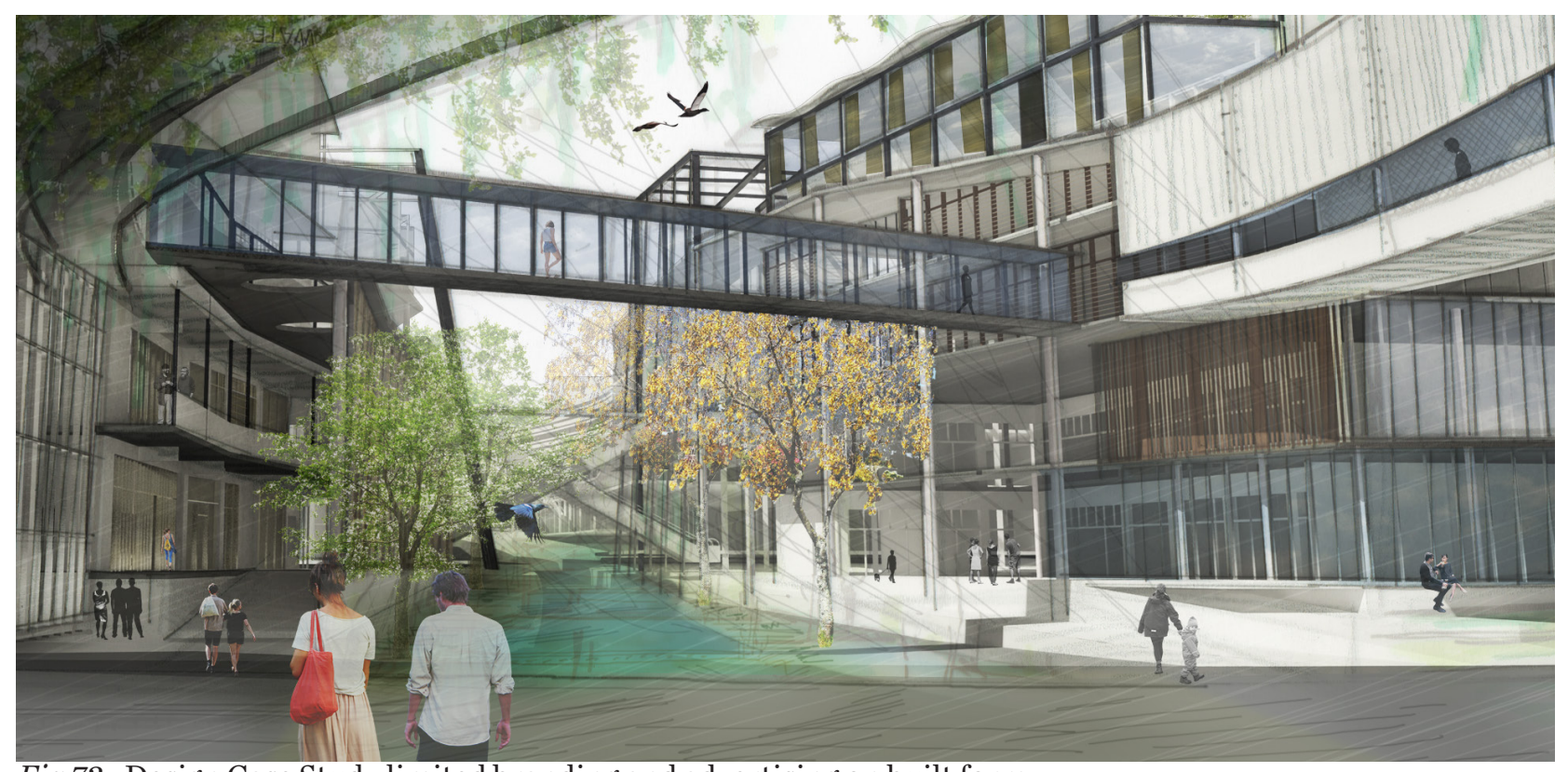

Fig 72. Design Case Study limited branding and advertising on built form

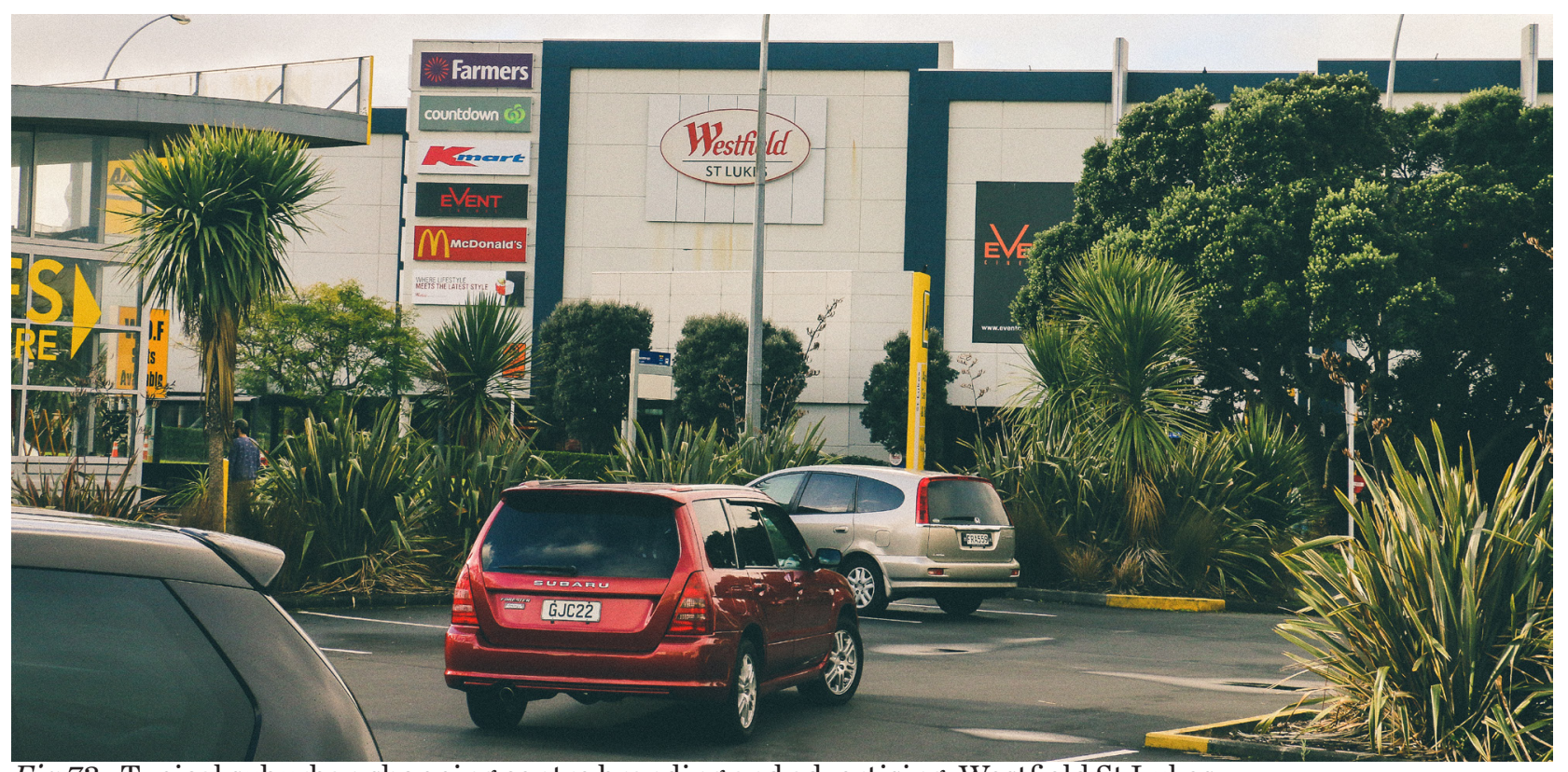

Fig 73. Typical suburban shopping centre branding and advertising, Westfield St Lukes 


\subsection{ECOLOGICAL MASTERPLANNING}

\section{PREMISE}

Auckland regional ecosystems have been diminishing since human settlement. Threatened native vegetation and animal species now remain on the region's fringes and offshore islands. The research utilises ecology to mitigate the issues of combining urban and retail environments. The projects aim is to relink and enhance the existing ecosystems to allow the native species to prosper in an urban environment. (Chpt 1.5, Pg 13)

\section{HETEROGENEOUS ECOSYSTEMS}

The design case study uses the design strategy of stimulating organic growth on and within the built structure in combination with the urban design criteria to form a united ecology where humans and the natural threatened species can live together, i.e. a heterogeneous ecosystem. The project attempts to combine landscape and architecture blurring the distinction between the two, creating an exciting new urban environment to be experienced. The design of the ecological green corridor is deliberately diverse so as to provide different habitat conditions. It utilises curves and organic shapes to create different lighting, water and exposure conditions. Separation from vehicles and control of pedestrian pathways allows multiple flora and fauna to flourish. The human interaction is through observation. Additionally the undulating green roofs provide a diverse habitat with limited human contact where species can move from the corridors to the roof. The design case study utilises passive design solutions to allow the architecture and the occupants to be in tune with the environment.

Our culture is formed by cultivating and conquering the land for economic gain at the expense of the natural environment. Architecture contributes to the altering of landscapes. The business sector is focused towards producing large quantities of goods which are marketed to the public as the latest and best products (electronics, appliances, fashion etc) even if consumers may actually not need them. Most products have a very short lifespan and quickly end up in landfills, rivers or the ocean. The waste is destroying the biodiversity of the natural ecosystems. Therefore combining consumption with a project about preserving ecology in the form of a heterogeneous ecosystem could be seen as a contradiction of the ecological aims. People are always going to consume as it is human nature, but the success of an 'eco-spectacle' and heterogeneous retail environment is that the space does not encourage a consumption frenzy such as found in a typical shopping centre because the spaces encourage loitering, having a connection to nature, therefore occupants will not feel a notion or have the expectation of consumption. The ecology breaks the consumption mentality and focuses it towards having an experience with nature. Consumers should become more aware of the environmental impact and lifespan of a product. The 'eco-spectacle' as discussed earlier creates an environmental image of the complex and will attract retailers who sell products that are directed towards protecting the environment. A project that

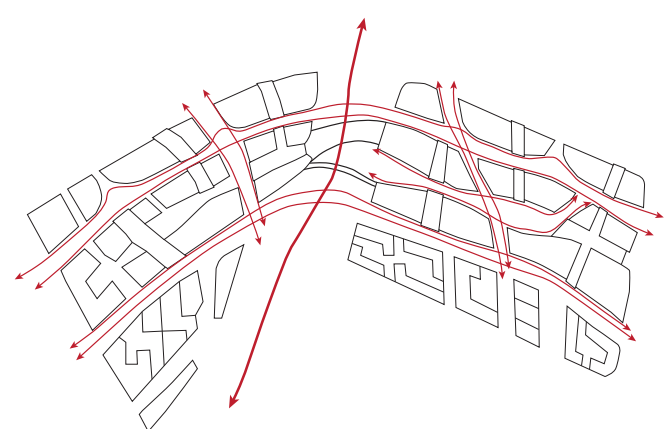

Fig 74. Organic shape of ecological components

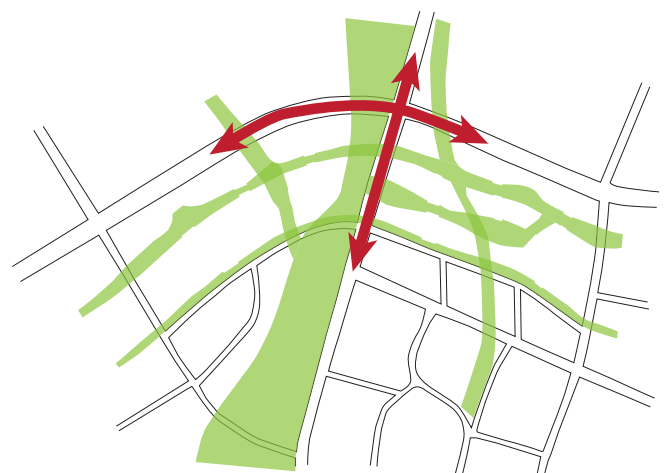

Fig 75. Disconection from road infastructure

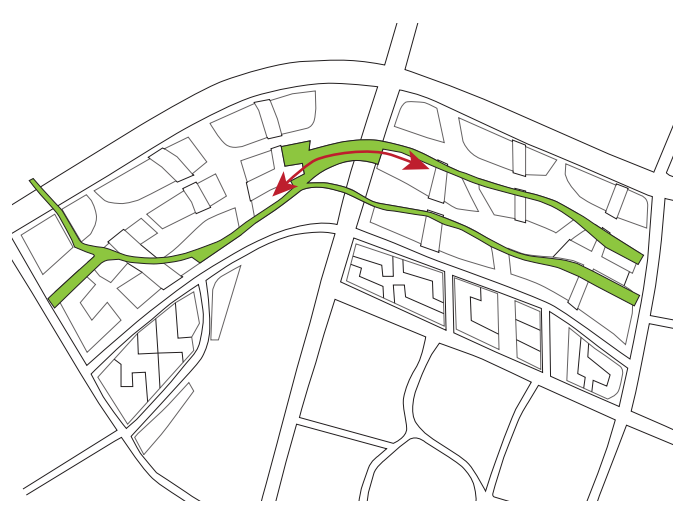

Fig 76. Civic bridge provides above road connection 
utilises ecology to reimage the urban and retail environments is successful because the development will make a positive contribution to the natural ecology and also produce more environmentally aware consumers.

\section{PARTIAL RECONSTRUCTION OF ORIGINAL NATURAL HABITATS}

The investigation into the context's ecosystems and species provided an approach to restore ecological balance on site by partially reconstructing the original natural habitats. The project criteria is to strengthen natural systems on site, sustain diverse native vegetation within and on the architecture and provide habitats for threatened animal and plant species. The reconstruction and terracing of the existing stream and the introduction of two other waterway systems collects and retains storm water to be filtered and cleansed (fig68 \& 74). These waterways provide the ecological tissue to support animal and plant habitats to flourish and support the broader regional natural systems. The ecological green corridor contains lowland and conifer forests similar to the site's original environment and will provide bird and reptile habitats, returning these vulnerable species to the mainland.

The design case study is a large experiment testing design ideas for ecological corridors, green houses and roof-top terraces. It assesses their potential to provide a sustaining habitat for multiple species as well as an effective shopping facility. The ecological habitats are confined and restricted when compared to the natural reserves and islands that these species are used to living on. The dramatic change in environments for some species may be too large to allow them to adjust to the change. The success will be determined by the resilience of each individual species. For further research the border between the ecological corridor and buildings can be explored in terms of creating a gradual change in habitat, or softening the edge of buildings allowing habitation of many species on a porous façade. The monitoring and observing of the progress of the reintroduction of the species will be paramount to the ecological success of this project.

\section{RE-CONNECTION OF FRAGMENTED \\ ECOLOGIES}

Initial planning prioritised the 're-linking' of Auckland's fragmented ecological networks connecting them together in the form of green corridors, rooftop terraces, bridges and tunnels that avoid the fragmentation that road networks create. The research is influenced by Ken Yeang's critique on urbanism stating that planning has dissected and fragmented natural ecosystems and contended to re-link these ecologies by spanning landscapes over and under roads, thus allowing green spaces to continually flow through the urban environment without being affected by the road infrastructure. But a compromise (fig75 \&76) was made due to the interconnecting green spaces causing buildings to be land locked within the development, hindering the functionality of a sub-urban centre. The compromise involved allowing service vehicles into the green corridors and pedestrian paths to gain access to the 'land locked' buildings. This could weaken the ecological integrity of the project. The only alternative was to implement a ramp and bridge infrastructure above and below ground to provide vehicular access to all parts of the project. This approach would have been costly and would have limited future flexibility. 


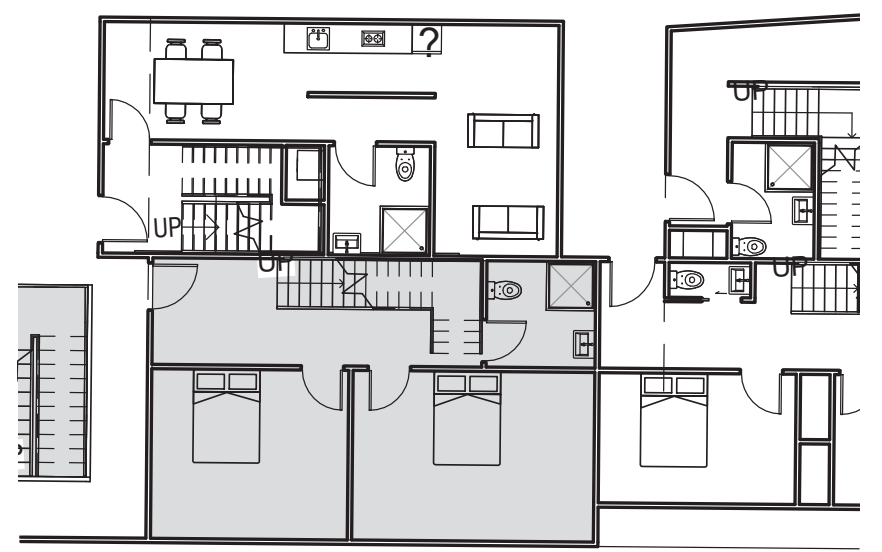

Fig 77. Ground Floor Apartments

Scale 1:200
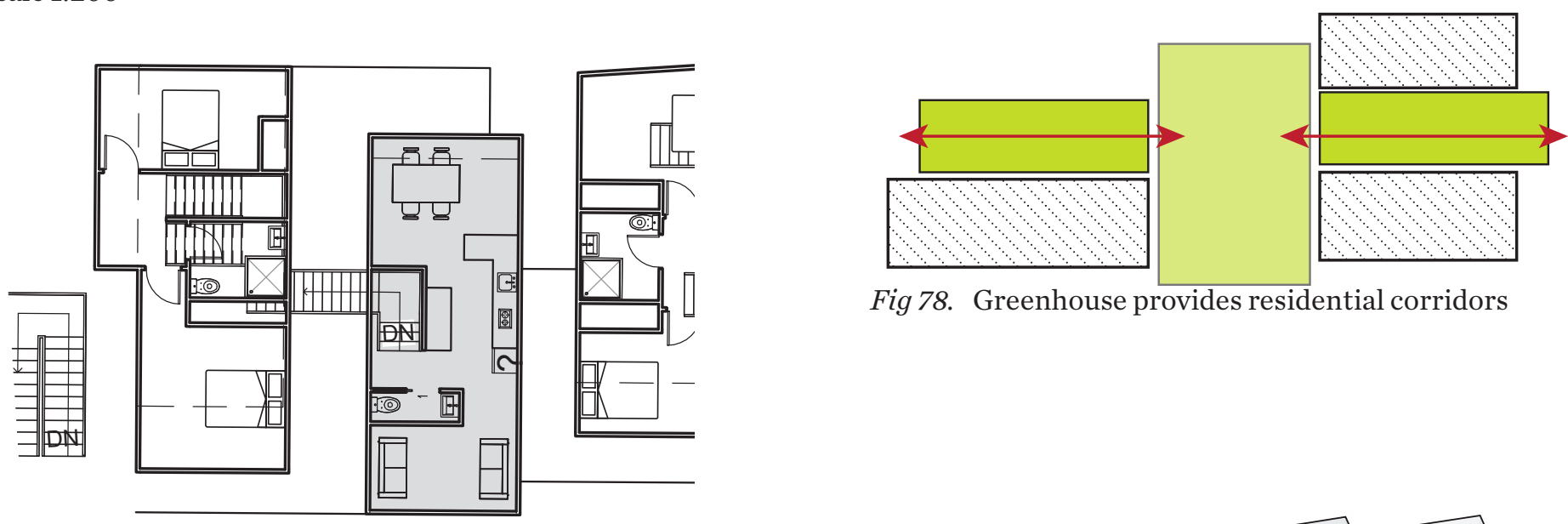

Fig 78. Greenhouse provides residential corridors

Level 1 Apartments

Scale 1:200

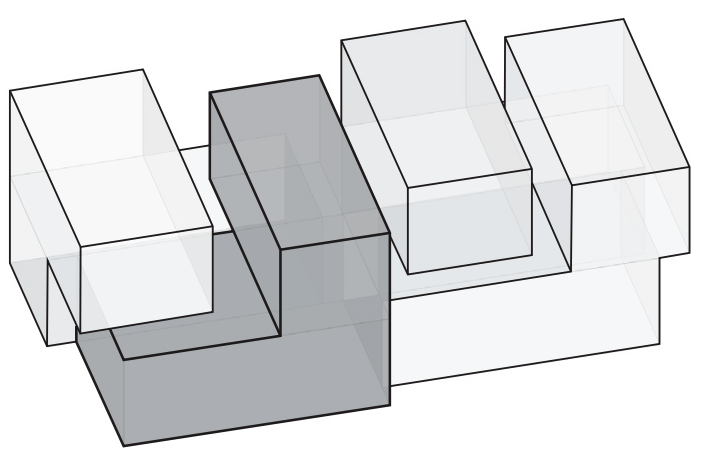

Fig 79. Interlocking Configuration 


\subsection{AMALGAMATION OF URBANISM RETAIL \& ECOLOGY}

\section{PREMISE}

The research conceives that ecology has the ability to facilitate the hybridisation of new urbanism and retail theory by creating identity and sense of place for an intensified suburban centre. The hybridisation has the capacity to form an ecospectacle to reimage the retail environments for environmentally conscious consumption.

The amalgamation of urbanism, retail theory and ecology together form a microcosm where the functions of the suburban centre combine to produce a mutually beneficial effect. The attributes of the individual parts have been discussed above, but as a whole the development is able to provide a unique exciting experience when compared to typical intensification projects.

The main functional issues faced are conflicting footprint sizes and volumes when combining retail, commercial and residential programmes, providing vertical circulation that did not interfere with the function of different spaces and mitigating the poor aspect and orientation of the residential units. The large footprint sizes and scale of structural grid in the retail spaces make it difficult to efficiently support the residential units without compromising their living conditions. Rooftop terraces and smaller greenhouses are utilised above the retail and commercial buildings to provide an open space aspect for the units (fig78). The greenhouses can operate as a communal garden for the residence providing a permaculture component for the residential occupants matching the environmental image of the development. Additionally, the greenhouses create advantages of passive architectural solutions and accessibility routes. The greenhouses act as ecological atriums providing non-destructive vertical circulation within the complex. These ecological atriums fulfil this function requirement but also provide a threshold between the different integrated spaces. The drawback of the designs longitudinal direction is that it creates a large area of south facing facades, mainly effecting the residential units. The design strategy of interlocking volumes is utilised to resolve this issue and create multiple aspects for the apartments and also provide private balconies (fig77 \&79).

The enhancing and improvement of the condition of the natural systems and the creation of habitats for non-human species also improves the functionality of the architecture. The project collects, filters and contains storm water from the ground and off the roofs which creates habitats for species but also allows the use of the water for grey water activities. Utilising sustainable technologies for solar and water throughout the development reduces the strain on the existing environment and council infrastructure.

Through the integration of the three components the design case study provides an example of a unique intensification that is sympathetic to the environment. One that not only repairs the deteriorating natural environment and provides a habitat for the threatened native species, but also a new retail environment focused towards a new era of sustainable consumption. It is an experience that re-connects people to nature in the form of an 'eco-spectacle' and provides higher density living conditions in the inefficient low rise suburbia. By bringing an environmental identity and sense of place to the context that can contribute to the needed change in culture, the project excites the possibilities for a future where humans and nature can thrive together. 


\subsection{CONCLUSION FROM THE RESEARCH}

The research process discovered that intensifying a suburban shopping centre as an amalgamation of three components, urban, retail and ecological masterplanning, provided a new and unique urban and retail environment that repaired the existing fractured ecology and offered an alternative to current intensification methods.

Urban Findings:

- New urbanist principles of connectivity and diversity are a significant aspect to intensifying suburbia to create a pedestrian friendly public domain.

- $\quad$ Shopping Centre sites with their size and large amount of underutilised land can contribute significantly to the intensification in regions that suffer from urban sprawl.

- $\quad$ Public transport is a significant contributor to connectivity of these new urban places as the reduction of car parking will contribute to people utilising other methods of transport in suburbia. Reducing car parking for future intensified mixed use developments will contribute largely to a more pedestrian orientated place.

Retail Findings:

- $\quad$ The redevelopment of shopping centres can create a microcosm for testing ideas to contribute to intensification.
- $\quad$ Retail spaces are currently stagnant but now have the opportunity to transcend the current model of consumption into an urban theatrical experience using the widely accessibile architectural imagery of 'eco-spectacle'. These centres can now use the city's place making principles to provide urbanism in the suburbs. By utilising commercial and residential activities with the existing retail they create a more dynamic place that people can enjoy.

Ecological Masterplanning Findings:

- $\quad$ The current methods of planning and master-planning are contributing to the degradation of the biodiversity in regions. Ecology needs to be considered just as important as the infrastructure that makes urban life possible in cities.

- $\quad$ Enhancing and reconnecting ecological tissues provides the opportunity to create a sense of place and identity for suburban intensification and also has the opportunity to provide a theatrical experience while shopping. This re-creates habitats for non-human species in the urban environment and provides people with a stronger connection to nature.

- The creation of ecological habitats within the architecture, such as providing green roofs and greenhouses, results in passive solutions for thermal mass and cross ventilation. These solutions can provide ventilation to cool and heat the structure, which provides an alternative to the current mechanical solutions for large buildings. At the urban scale, green corridors and waterways provide filtration to the polluted environment and also create new habitats for species in the urban environment.

The project is largely speculative and further collaboration with ecologists, landscape architects and environmentalists would bring more realism to the outcome. Nevertheless, my preliminary research indicates that a collaborative exercise of this kind would be worthwhile.

Retrospectively, further exploration of the architectural scale could offer more depth to this research and could have been conducted earlier in the research process if less time was spent analysing site and context. But this initial research provided a direction for the research and evolved towards the integration of urban, retail and ecology. The urban design sections of the thesis are beneficial because they can be applied and utilised across different sites throughout the suburbs. Such as used on big box retail or industrial sites. If the study would be repeated again further research would be conducted in the sustainability aspect of the buildings, exploring into materials and passive design solutions to provide an architecture that can contribute significantly to the ecology of the site. 


\subsection{FURTHER RESEARCH}

\section{SUBURBAN INTENSIFICATION}

Further research couldbeconducted on other underutilised sites in suburbia. Industrial sites such as factories and warehouses, the large carparks located next to railway stations, primary and secondary schools and office parks. These types of spaces are now in central locations in relation to the sprawling city and could undergo intensification.

\section{ARCHITECTURAL ECO SYSTEMS}

Exploration of the architectural scale that investigates systems and techniques for façade treatment as a habitat for ecology and attempts to soften the edge between the green corridor and buildings on sites where space is limited. Exploration in this direction can bring greater biodiversity to the suburbs and city.

\section{ECO - ATMOSPHERE}

Further research in addressing ecologyatmosphere; architectural projects utilising material, colour, sound and light to create atmospheres within them. Exploring ecology as an element toward atmosphere can provide an interesting insight into using natural systems to create place, identity and experience for both retail and residential projects. 


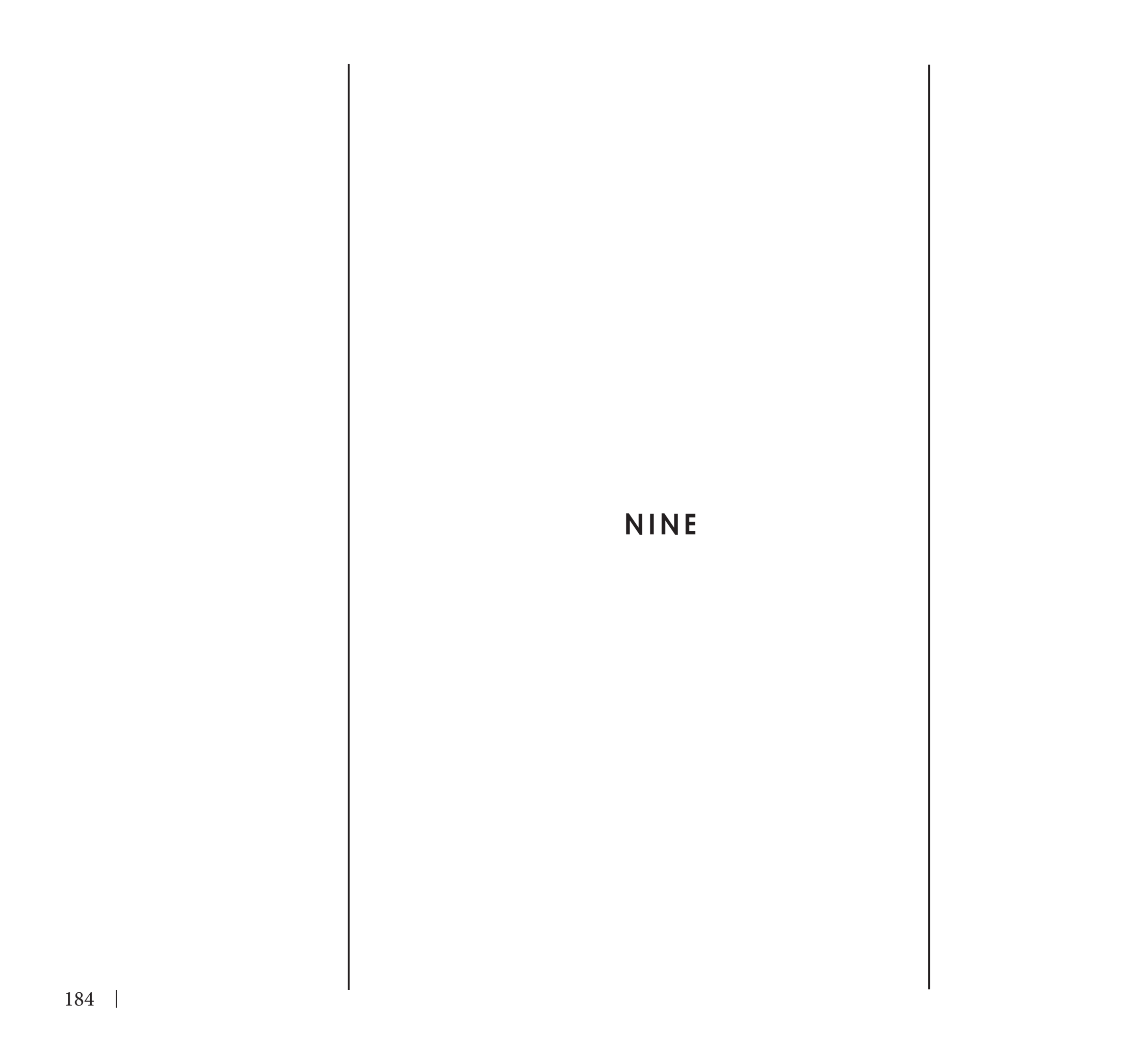


LIST OF FIGURES

\&BIBLIOGRAPHY

| 185 


\section{LIST OF FIGURES}

Note: All figures not attributed are author's own.

Figure 1. The Three Bs, Roselands Shopping Centre. Advertisement. Leader, 6 October 1965. Web < https://pastlivesofthenearfuture. com/tag/shopping/>

Figure 2. Stevens, George. "Auckland, N.Z. 1886”. Map. Sir George Special Collections, Auckland Libraries, NZ Map 374'. <http://www. aucklandcity.govt.nz/dbtwwpd/HeritageImages/images/maps/ maps10f/374.jpg>

Figure 3. Whites Aviation. Aerial view of Otara Town Centre, no. 66784. 5 April 1967. Photograph. Web. < http://thegrid.co.nz/wpcontent/uploads/2015/11/196628sep-700x506.jpg>

Figure 4. Auckland Region \& Shopping Centre Locations [map derived from Google Earth, modified by author]

Figure 5. NZ Herald. Lynmall Shopping Mall, Auckland. 1 June 1965. Photography. Web. < http://media.nzherald.co.nz/webcontent/ infographics/357/080115lynnmall.jpg >

Figure 6. Sharpe, Algred. Golden Evening, New Zealand. 1889. Painting. Web. < http://www.teara.govt.nz/files/large images/14282-aart.jpg>

Figure 7. Byers, Lindsay and Wild. Auckland Protection Strategy: a report to the Nature Heritage Fund Committee, Map (pg16-17). Wellington: Nature Heritage Fund, June 2009. Print

Figure 8. Research Method Diagram [image produced by author] Figure 9. Gehl, Jan. Life Between Buildings: Using Public Space, Diagram (pg110). London: Island Press, 1987, 2011 revisited ed. Print Figure 10. Calthorpe, Peter. The Next American Metropolis: Ecology, Community, and the American Dream, Diagram (pg56). New York: Princeton Architectural Press, 1993. Print

Figure 11. . Calthorpe, Peter. The Next American Metropolis: Ecology, Community, and the American Dream, Map (pg122). New York: Princeton Architectural Press, 1993. Print

Figure 12. Hauser, Michael. Northland Center Mall in Southfield. 1950. Photograph. Web <http://image.mlive.com/home/ mlive-media/width960/img/detroit/photo/2015/01/09/586bf507ef7elle4.png>

Figure 13. Rosset, Steeve. Kanyon, Istanbul. 2011. Photograph. Web <http://reurbanist.com/wp-content/uploads/2011/12/ KanyonIMG_3411.jpg>
Figure 14. March, Sol. JPN Kyoto Town, Kyoto Station. Photograph. Web <http://suggestionofmotion.com/wp-content/uploads/JPN_ Kyoto_Town_025_Kyoto-Station.jpg>

Figure 15. Auckland Council. The Auckland Plan, Auckland's Environment. Map. Chpt 7. Web <http://theplan.theaucklandplan. govt.nz/wp-content/uploads/2012/05/Map-7.4-SignificantEcological-Areas-120501-no-title.jpg>

Figure 16. Yeang, Ken. Eco Master Planning. Map pg20 . UK: 2009. Print

Figure 17. Yeang, Ken. Eco Master Planning. Map pg14 . UK: 2009. Print

Figure 18. Yeang, Ken. Eco Master Planning. Map pg178 . UK: 2009. Print

Figure 19. Yeang, Ken. Eco Master Planning. Map pg136 . UK: 2009. Print

Figure 20. Yeang, Ken. Eco Master Planning. Map pg33 . UK: 2009. Print

Figure 21. Auckland Shopping Centre Locations [map derived from Google Earth, modified by author]

Figure 22. Western Leader. Bold Plans for LynnMall Extension. 1963. Photograph. Web < http://static2.stuff. co.nz/1408316063/999/10394999.jpg>

Figure 23. Riethmaier, Gregory. LynnMall. 1969. Photograph. Web < http://www.teara.govt.nz/files/p-22226-na.jpg>

Figure 24. Auckland Shopping Centre Survey [maps derived from Google Earth, modified by author]

Figure 25. True Surrey. Photograph. Web < http://truesurrey.ca/ wp-content/uploads/2014/04/RS315_3.Noelia-Kostur_SullivanHeights-Secondary_Central-City-lpr.jpg > [modified by author] Figure 26. Lehoux Nic. Surrey Central City. Photograph. Web < http://www.archello.com/en/project/central-city>

Figure 27. Stenberg College. Photography. Web < http://www. stenbergcollege.com/wp-content/uploads/2015/05/Our Campus_large_image_for_Centre-lg.jpg>

Figure 28. Bing Thom Architects. Central City mixed use development. 2009. Photograph. Web < https://upload.wikimedia. org/wikipedia/commons/d/d6/Central_city_development_ 
lehoux.jpg>

Figure 29. Continuum Partners. Belmar Colorado. Photograph. Web < http://3.bp.blogspot.com/_AcUdTl7Aq-s/R4UHE8twMoI/ AAAAAAAADXk/lfuSuIxS_fg/s400/Belmar_Alaska+and+Teller. jpg>

Figure 30. Saunders Building Confidence. Belmar Block 2. Photography. Web < http://www.saundersci.com/files/ portfolio\%20pictures/Belmar\%201.jpg>

Figure 31. Lakewood Colorado. Downtown Lakewood and Belmar. Photography. Web < http:/www.lakewood.org/uploadedImages/ Images/City_Manager/Economic_Development/Bel\%20 Mar\%203.jpg? $\mathrm{n}=5820>$

Figure 32. Duany Plater - Zyberk \& Co. Cottonwood. Illustration. Web < http://www.dpz.com/uploads/Projects/0611-06.jpg>

Figure 33. Duany Plater - Zyberk \& Co. Cottonwood. Illustration. Web <http://www.dpz.com/uploads/Projects/061l-02.jpg>

Figure 34. Duany Plater - Zyberk \& Co. Cottonwood. Illustration. Web < http://www.dpz.com/uploads/Projects/0611-04.jpg>

Figure 35. Ivanhoe Cambridge. New Neighbourhood Street. Illustration. Web < http://vancouver.ca/files/cov/oakridge-openhouse-boards-from-developer-all.pdf $>$

Figure 36. Rethink. Oakridge Centre. Illustration. Web < http:// www.oakridge2025.ca/images/img_facts_oakridge02_lg.jpg>

Figure 37. Theory, Justin. Island City Park - Toyo Ito. 2007. Photography. Web < http://pre10.deviantart.net/8303/th/pre/ f/2007/219/5/f/island_city_park___toyo_ito_by_j_theory.jpg > [modified by author]

Figure 38. Behnisch Architekten. Institute for Forestry and Nature Research. Photograph. Web < http://behnisch.com/content/02. projects/22/22_01.jpg>

Figure 39. Teer Marc. Institute for Forestry and Nature Research. 2010. Photograph. Web < https://www. flickr.com/photos/marcteer/5459158405/in/galleryikbenmooi-72157626888275893/>

Figure 40. California Academy of Sciences. 2015. Photograph. Web < http://www.hbjzds.com/data_images/wallpapers/3/262287- california-academy-of-sciences.jpg>

Figure 41. California Academy of Sciences. Efficient Building Design. Photograph. Web < http:/www.calacademy.org/sites/ default/files/styles/manual_crop_standard_960x540/public/ assets/images/KW_IMAGES_DO_NOT_USE/cas22-155_edit-edit. jpg?itok=gUpT8Bx_\&c=f02clf9a5c6c0le66ec795209c6d6de8>

Figure 42. California Academy of Sciences. Photograph. Web. < http://www.art-days.com/wp-content/ uploads/2013/11/1996009194_20-rainforest-interior.jpg>

Figure 43. Griffith, Tim. California Academy of Sciences. Photograph. Web < https://teecom.com/media/CAS_HeroImage-1.jpg>

Figure 44. Green, Scarlet. Grin Grin. 2007. Photograph. Web < https://c2.staticflickr.com/2/1006/1386188093_b8458a02f4_o. jpg>

Figure 45. Hiraio, Takashi. Grin Grin. 2009. Photograph. Web < https://flic.kr/p/6jY5tS>

Figure 46. Green, Scarlet. Grin Grin. 2009. Photograph. Web < https://c2.staticflickr.com/2/1133/1386191417_ae2d39e258_o.jpg> Figure 47. Green, Scarlet. Grin Grin. 2009. Photograph. Web < https://c2.staticflickr.com/2/1094/1387094018_9cb5565b29_o. jpg>

Figure 48. Linked Hybrid. Photograph. Web $<$ https://aedesign. files.wordpress.com/2009/09/hybel.jpg> [modified by author]

Figure 49. Hybrid Diagram [image produced by author]

Figure 50. Maxwan. Red Hill Rise Proposal. Illustration. Web < http://images.adsttc.com/media/images/521f/cbb3/e8e4/4ea6/ cd00/0018/large_jpg/image283-05.jpg?1377815469>

Figure 51. Maxwan. Red Hill Rise Proposal. Illustration. Web < http://images.adsttc.com/media/images/52lf/cba8/ e8e4/4ea4/2e00/0025/large_jpg/image283-04.jpg?1377815458>

Figure 52. Kullegaard. Kullegaard Take First Place in Hobaek. Illustration. Web < http://images.adsttc.com/media/images/5547/ fb7c/e 58e/ce50/2900/061c/large_jpg/Harbour_square. jpg?1430780770>

Figure 53. Kullegaard. Kullegaard Take First Place in 
Hobaek. Illustration. Web < http://images.adsttc.com/media/ images/5547/fb9d/e58e/ce50/2900/061d/large_jpg/City_centre. jpg?1430780802>

Figure 54. Saieh Nico. Markthat Rotterdam. 2014. Photograph. Web < http://images.adsttc.com/media/images/5431/bl36/ c07a/8054/8fo0/05c3/large_jpg/-\%C2\%AEProvast__MVRDV__ foto_Daria_Scagliola_Stijn_Brakkee_21.jpg?1412542751>

Figure 55. Saieh Nico. Markthat Rotterdam. 2014. Photograph. Web http://images.adsttc.com/media/images/5433/03d2/c07a/80cb/ e800/0036/large_jpg/542bleaec07a809a0e0002d1_first-lookmvrdv-completes-largest-covered-market-in-the-netherlands mrkthl_mvrdv_49.jpg?1412629445>

Figure 56. Baan Iwan. Linked Hybrid. 2009. Photograph. Web < http://images.adsttc.com/media/ images/5011/6129/28ba/0d70/4200/05c3/large_jpg/stringio. jpg?1414471179>

Figure 57. Baan Iwan. Linked Hybrid. 2009. Photograph. Web < http://images.adsttc.com/media/ images/5011/6114/28ba/0d70/4200/05be/large_jpg/stringio. jpg?1414471191?>

Figure 58. West Auckland Map [maps derived from Google Earth, modified by author]

Figure 59. East Auckland Map [maps derived from Google Earth, modified by author]

Figure 60. Natural Water Systems West Auckland [maps derived from Google Earth, modified by author]

Figure 61. Natural Water Systems East Auckland [maps derived from Google Earth, modified by author]

Figure 62. Land Information New Zealand. Auckland 0.5m Rural Aerial Photos. 2010-2012. Orthophotography. Web < https:// data.linz.govt.nz/layer/1769-auckland-05m-rural-aerialphotos-2010-2012/> [modified by author]

Figure 63. Land Information New Zealand. Auckland 0.5m Rural Aerial Photos. 2010-2012. Orthophotography. Web < https:// data.linz.govt.nz/layer/1769-auckland-05m-rural-aerialphotos-2010-2012/> [modified by author]
Figure 64. Land Information New Zealand. Auckland 0.5m Rural Aerial Photos. 2010-2012. Orthophotography. Web < https:// data.linz.govt.nz/layer/1769-auckland-05m-rural-aerialphotos-2010-2012/> [modified by author]

Figure 65. Byers, Lindsay and Wild. Auckland Protection Strategy: a report to the Nature Heritage Fund Committee, Map (pg34). Wellington: Nature Heritage Fund, June 2009. Print

Figure 66. Railway Technology. Regional Rapid Transit Corridors. Map. Web < http://www.railway-technology.com/projects/ auckland_rapid/images/imagel.gif>

Figure 67. Proposed Light Rail Route. [maps derived from Google Earth, modified by author]

Figure 68. Masterplan [image produced by author]

Figure 69. Layered networks [image produced by author] Figure 70. Ecological networks [image produced by author]

Figure 71. Coherent urban form [image produced by author]

Figure 72. Design case study limited branding and advertising on built form [image produced by author]

Figure 73. Typical suburban shopping centre branding and advertising, Westfield St Lukes [image produced by author]

Figure 74. Organic shape of ecological components [image produced by author]

Figure 75. Disconnection from road infrastructure [image produced by author]

Figure 76. Civic bridge provides above road connection [image produced by author]

Figure 77. Apartments floor plans [image produced by author]

Figure 78. Greenhouse provides residential corridors [image produced by author]

Figure 79. Interlocking configuration [image produced by author] 


\section{BIBLIOGRAPHY}

Arbury, Joshua. “The Howick/ Botany Lin II”. Transportblog, July 2009. Web < http://transportblog.co.nz/2009/page/24/>

Calthorpe, Peter. "Urbanism in the Age of Climate Change”. 2 edition. Island Press, 2013. Print.

Dunham-Jones, Ellen, and June Williamson. “Retrofitting Suburbia, Updated Edition: Urban Design Solutions for Redesigning Suburbs”. 1 edition. Wiley, 2011. Print.

Gehl, Jan. “Life Between Buildings: Using Public Space”. Sixth Edition edition. Island Press, 2011. Print.

Herman, Daniel. "High Architecture”. The Harvard Design School Guide to Shopping / Harvard Design School Project on the City 2. Chung, Chuihua Judy et al. Ed. 1St Edition edition. Köln: Taschen, 2002. 391-402. Print

- "High Architecture". The Harvard Design School Guide to Shopping / Harvard Design School Project on the City 2. Chung, Chuihua Judy et al. Ed. 1St Edition edition. Köln: Taschen, 2002. 391-402. Print

- "Jerde Transfer". The Harvard Design School Guide to Shopping / Harvard Design School Project on the City 2. Chung, Chuihua Judy et al. Ed. 1St Edition edition. Köln: Taschen, 2002. 403-407. Print

- "Mall”. The Harvard Design School Guide to Shopping / Harvard Design School Project on the City 2. Chung, Chuihua Judy et al. Ed. 1St Edition edition. Köln: Taschen, 2002. 461-476. Print

Leong, Sze Tsung. "Mobility”. The Harvard Design School Guide to Shopping / Harvard Design School Project on the City 2. Chung, Chuihua Judy et al. Ed. 1St Edition edition. Köln: Taschen, 2002. 477-500. Print

Lindsay, Helen, Wild, Chris and Byers, Stacey. “Auckland Protection Strategy: A Report to the Nature Heritage Fund Committee". Wellington, Nature Heritage Fund. Web < http://www.doc.govt.nz/Documents/getting-involved/landowners/nature-heritage-fund/nhf-akld-protection-strat.pdf>

Matsushita, Kiwa. "Depato”. The Harvard Design School Guide to Shopping / Harvard Design School Project on the City 2. Chung, Chuihua Judy et al. Ed. 1St Edition edition. Köln: Taschen, 2002. 243-270. Print

McMorrough, John. "City of Shopping”. The Harvard Design School Guide to Shopping / Harvard Design School Project on the City 2. Chung, Chuihua Judy et al. Ed. 1St Edition edition. Köln: Taschen, 2002. 193-204. Print 
Muller, Brook. "Ecology and the Architectural Imagination”. New York; London: Routledge, 2014. Print.

RCG Limited. “Retail Examiner New Zealand’s Leading Shopping Centres: August 2012”. Auckland, RCG Ltd, 2012. Web < http://www.rcg.co.nz/sites/ default/files/RE-Leading-Shopping-Centre-Report-2012-Complete-Media-Edition.pdf>

Yeang, Ken. “EcoMasterplanning”. 1 edition. Chichester, West Sussex: Wiley, 2009. Print. 
